\title{
Cancer pain \& how to relieve it : effects of a pain education program in cancer patients with chronic pain
}

Citation for published version (APA):

de Wit, A. (1999). Cancer pain \& how to relieve it : effects of a pain education program in cancer patients with chronic pain. [Doctoral Thesis, Maastricht University]. Universiteit Maastricht. https://doi.org/10.26481/dis.19990616aw

Document status and date:

Published: 01/01/1999

DOI:

10.26481/dis.19990616aw

Document Version:

Publisher's PDF, also known as Version of record

Please check the document version of this publication:

- A submitted manuscript is the version of the article upon submission and before peer-review. There can be important differences between the submitted version and the official published version of record.

People interested in the research are advised to contact the author for the final version of the publication, or visit the DOI to the publisher's website.

- The final author version and the galley proof are versions of the publication after peer review.

- The final published version features the final layout of the paper including the volume, issue and page numbers.

Link to publication

\footnotetext{
General rights rights.

- You may freely distribute the URL identifying the publication in the public portal. please follow below link for the End User Agreement:

www.umlib.nl/taverne-license

Take down policy

If you believe that this document breaches copyright please contact us at:

repository@maastrichtuniversity.nl

providing details and we will investigate your claim.
}

Copyright and moral rights for the publications made accessible in the public portal are retained by the authors and/or other copyright owners and it is a condition of accessing publications that users recognise and abide by the legal requirements associated with these

- Users may download and print one copy of any publication from the public portal for the purpose of private study or research.

- You may not further distribute the material or use it for any profit-making activity or commercial gain

If the publication is distributed under the terms of Article $25 \mathrm{fa}$ of the Dutch Copyright Act, indicated by the "Taverne" license above, 


\section{Cancer pain \\ $\&$ \\ how to relieve it}

Effects of a Pain Education Program in cancer patients with chronic pain 
Cancer pain \& how to relieve it.

Effects of a Pain Education Program in cancer patients with chronic pain

(c) 1999 Rianne de Wit, Leiden, the Netherlands

All rights are reserved. No part of this publication may be reproduced or transmitted in any form or by any means electronic or mechanical including photocopy recording, or any information storage and retrieval systeem without permission in writing from the copyright owner.

ISBN 90-9012-800-X

Cover: C. Kortlang

Layout: H.M. van Kan

Printed by: PrintPartners Ipskamp bv, Enschede 


\section{Cancer pain \\ $\&$ \\ how to relieve it}

\section{Effects of a Pain Education Program in cancer patients with chronic pain}

\section{Proefschrift}

ter verkrijging van de graad van doctor aan de

Universiteit Maastricht

op gezag van de Rector Magnificus,

Prof. Dr. A.C. Nieuwenhuijzen Kruseman,

volgens het besluit van het College van Decanen

in het openbaar te verdedigen

op woensdag 16 juni 1999 om 16.00 uur.

door

Adriana de Wit

(Rianne) 


\section{Promotoren}

Prof. Dr. F.S.A.M van Dam

Universiteit van Amsterdam

Antoni van Leeuwenhoek Huis/

Nederlands Kanker Instituut

Prof. Dr. H. Huijer-Abu-Saad

\section{Beoordelingscommissie}

Prof. Dr. H. Philipsen

Prof. Dr. M. Grypdonck

Prof. Dr. S. Rodenhuis

Prof. Dr. C. Spreeuwenberg

\section{voorzitter}

Universiteit Utrecht

Universiteit van Amsterdam

Antoni van Leeuwenhoek Huis/

Nederlands Kanker Instituut

The research described in this thesis was performed at the Department of Psychosocial Research and Epidemiology of the Antoni van Leeuwenhoek hospitaV Netherlands Cancer Institute, Plesmanlaan 121. 1066 CX Amsterdam.

The research was supported by a grant from the Dutch Cancer Society (Nederlandse Kanker Bestrijding) (Grant nr 92-469). 


\section{Contents}

\section{Chapter 1}

Introduction

\section{Chapter 2}

The treatment of chronic cancer pain

in a cancer hospital in the Netherlands

Journal of Pain and Symptom Management, 1999;17:333-350.

\section{Chapter 3}

A Pain Education Program for chronic cancer pain patients:

Follow-up results from a randomized controlled trial

Pain, 1997:73;55-69.

\section{Chapter 4}

Evaluation of the use of a pain diary in chronic cancer pain patients at home

Pain, 1999; 79:89-99.

\section{Chapter 5}

Empirical comparison of commonly used measures to evaluate pain treatment in cancer patients with chronic pain

Journal of Clinical Oncology, 1999;17:1280-1287.

\section{Chapter 6}

The Amsterdam Pain Management Index compared to eight frequently used outcome measures to evaluate the adequacy of pain treatment in cancer patients with chronic pain

Pain (Accepted)

\section{Chapter 7}

Improving the quality of pain treatment by a tailored

Pain Education Program for cancer patients in chronic pain

European Journal of Pain (Provisionally accepted)

\section{Chapter 8}

Adherence with the pain medication prescription:

effects of a Pain Education Program to assist cancer patients

to follow pain medication prescriptions

Pain (Submitted)

\section{Chapter 9}

The role of district nurses in the care of cancer patients with chronic pain at home Journal of Advanced Nursing (Submitted) 


\section{Chapter 10}

Assessment of pain cognitions in cancer patients with chronic pain

Journal of Pain and Symptom Management (Submitted)

\section{Chapter 11}

Conclusions and general discussion

Summary

Samenvatting

Dankwoord

\section{Curriculum Vitae}


Chapter 1

\section{Introduction}




\section{Introduction}

Patients with advanced cancer experience multiple symptoms. ${ }^{1,2}$ Among these symptoms, pain is the most feared. . $^{3.5}$ The prevalence of pain varies widely from $33 \%$ to $88 \%$, depending on the investigated group, the stage of disease, and the methods employed to measure pain. ${ }^{6}$ In general, about $50 \%$ of patients at all stages of disease experience pain, and over $70 \%$ of patients with advanced cancer report pain. ${ }^{7}$ Pain treatment should allow patients to function at a level they choose, and to live relatively free of pain. ${ }^{3}$ Poor pain control often results in undermining physical functioning, psychological suffering and exhaustion, loss of hope, and diminishing quality of life. ${ }^{8}$

Most pain in cancer patients can be controlled by pharmacological pain treatment either alone, or supplemented with adjuvant drugs (co-analgesia) and nonpharmacological pain treatment. The basic approach to the control of pain consists of the "three-step analgesic ladder" of the World Health Organization. 9,10 Based on the principles of the World Health Organization guidelines, the pain medication needs to be matched to the severity of pain: non-opioids (step I) for mild pain, weak opioids (step II) for patients with moderate pain, and strong opioids (step III) for patients with severe pain. ${ }^{3}$ Because there is great variation in patients' individual pain experience and susceptibility to analgesic drugs, an essential principle in pain treatment is to individualize the regimen to the patient. Although adequate pain treatment for most cancer patients is now available, data from numerous studies have demonstrated that these methods are not used to their fullest, leading to inadequate pain relief in large numbers of patients. ${ }^{11-13}$

Many explanations have been proposed for this failure, e.g. barriers related to health care professionals, the health care system, and patients. ${ }^{14-16}$ Examples of barriers related to health care professionals are that physicians and nurses have inadequate pain knowledge, they do not pay enough attention to pain control, and they are overly concerned about addiction, tolerance, and adverse reactions to analgesics. ${ }^{17}$ The health care system contributes to inadequate pain treatment by giving low priority to pain control, lack of pain policies, lack of protocols or standards of care, and the lack of resources available for pain control. ${ }^{16,18}$ Finally, patient-related barriers include reluctance to report the intensity of pain, reluctance to take pain medication, and the lack of pain knowledge. Patients' reluctance to report pain to caregivers might be caused by patients wishing not to appear "weak," or "frail," because this could divert the physician's attention from treating the tumor. Cancer pain can lead to loss of hope, fear of worsening or progression of disease, rejection of treatment, and loss of quality of life. Because an increase in pain intensity is often interpreted as tumor progression, patients might become hesitant to discuss the pain with the caregiver. Patients also hesitate to use medication, wait too long before asking for pain relief, and have difficulty in reporting and communicating about pain, because they are concerned about addiction, tolerance, and side-effects. ${ }^{17,19}$ Furthermore, patients' lack of pain knowledge is reported as one of the main causes for non-adherence. ${ }^{13,19,20}$

In recent years, efforts to improve pain management in cancer patients have focused mainly on enhancing the expertise of health care providers. ${ }^{10,14,21,22}$ Less attention has been paid to the role of the patients themselves in managing their own pain, despite the fact that cancer pain is increasingly being managed on an outpatient basis. The shift from hospital care to home care for seriously ill cancer 
pain patients requires some degree of adaptation from both the caregivers and patients. This transition to home care requires more emphasis on the self-care approach. This means that patients need to become active and conscious participants in their own pain treatment. For the caregivers, greater emphasis needs to be placed on educating patients and stimulating them to actively participate in their own pain treatment program. ${ }^{23}$

Although the importance of patient education and active involvement of patients in pain treatment is emphasized by several organizations, such as the World Health Organization ${ }^{10}$ and the American Pain Society, ${ }^{21}$ few studies have considered the important role of the patients themselves in the process of relieving pain. For optimal pain management, it is necessary that both hospital and home care remain continuously involved throughout the patients' disease. Maintaining continuity of care with regard to pain management involves communication between the different caregivers and the patient, and coordination of care. Patients should play an active role in this. In the home setting, district nurses play a significant role in the assessment and management of cancer pain. They spend more time with patients than any other health care provider. Because the current advances in therapeutic and palliative technologies affect the duration of the palliative phase, cancer patients live longer with their pain and need pain management for a longer period of time at home. Consequently, (district) nurses are essential for adequate pain control, both in the hospital and at home, and are an important link between the patient, the family, and other health care providers.

In this thesis, the development and effectiveness of a Pain Education Program in cancer patients with chronic pain offered by specially trained nurses was investigated. The Pain Education Program was tailored to the needs of the individual patient and consisted of three elements: 1) educating patients about the basic principles of pain and pain management; 2 ) instructing patients how to report their pain in a pain diary; and 3) instructing patients how to communicate about pain and how to contact health care provi-ders. The Pain Education Program uses a multi-method approach in which verbal instruction, written materials, an audiocassette tape, and a pain diary were combined to inform and instruct patients about pain and pain management.

\section{Outline and research questions}

The main purpose of this thesis was to develop and evaluate the Pain Education Program in advanced cancer patient with chronic pain. The Pain Education Program was evaluated by means of a prospective, randomized longitudinal study utilizing a "pretest-posttest experimental design." Patients with and without district nursing in the home setting were distinguished before randomization as they were expected to differ regarding medical variables and pain experience. Both patient groups were randomized after stratifying for gender (male/female), age ( $<60$ years/ $\geq 60$ years), and metastatic sites (yes/no/unknown). Control patients received regular pain treatment, while the Pain Education Program was implemented in the intervention group patients. Summarizing, four study groups were distinguished: 1) a control group without district nursing; 2 ) an intervention group without district nursing; 3 ) a control group with district nursing; and 4) an intervention group with district nursing. 


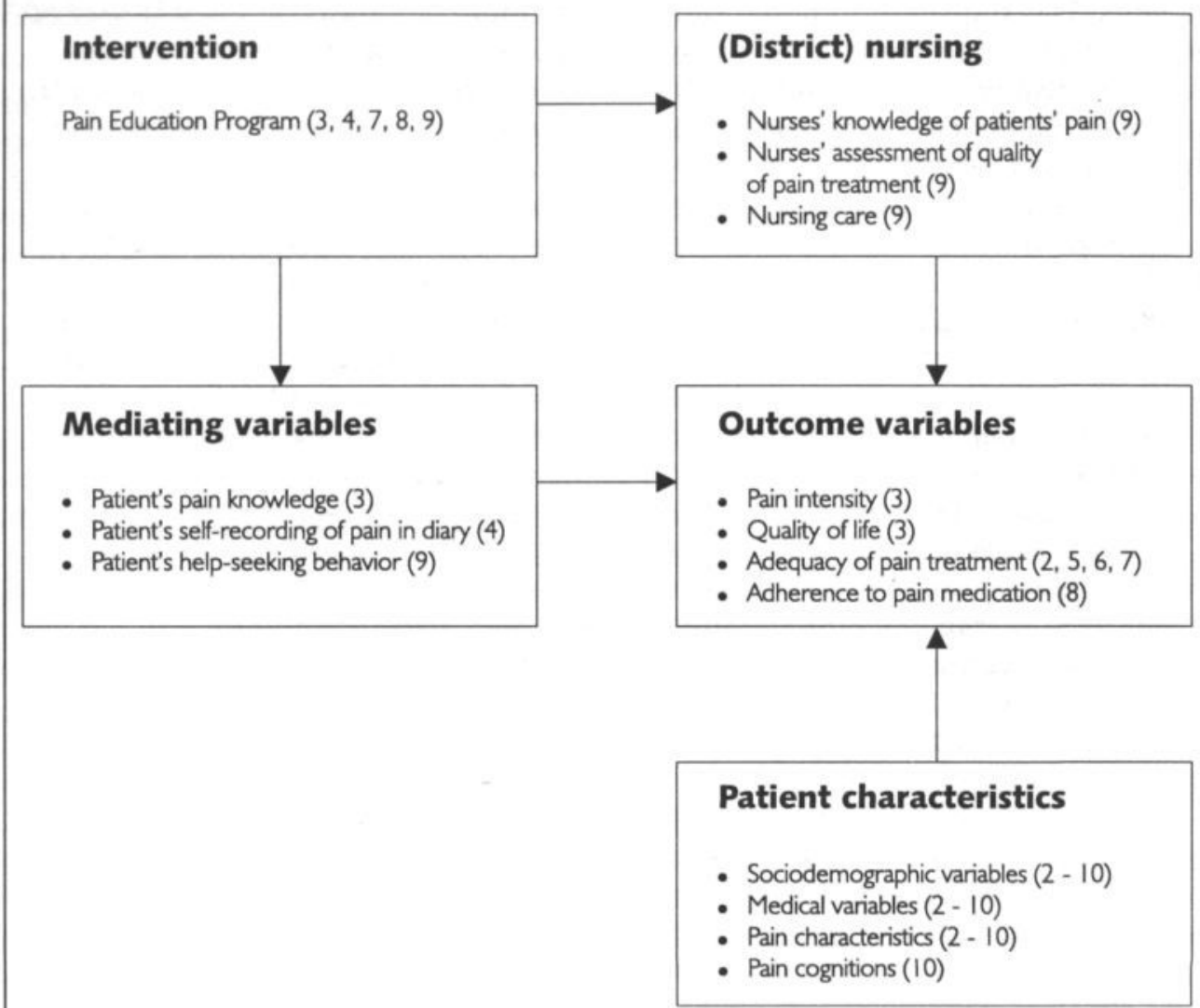

Numbers in parenthesis refer to the chapters in this thesis.

Figure 1. Overview of the Pain Education Program

An overview of the components relevant to study the Pain Education Program is given in Figure 1. A distinction is made between the effects of the Pain Education Program on mediating and outcome variables.

This thesis comprises 11 chapters. In this chapter (chapter 1), the rationale for the study is presented.

Chapter 2 presents a description of the practice of pain treatment in the Antoni van Leeuwenhoek Hospital/Netherlands Cancer Institute.

To give an overview of the practice of pain treatment, Donabedian's structureprocess-outcome framework was used, including: 1) structural resources, describing the setting in which pain treatment is provided; 2 ) process components, which describe the clinical practice; and 3) outcome measures, which refer to patients' pain intensity, patient satisfaction, or composite pain management index scores. The research question addressed in chapter 2 is: 
- What is the current practice in pain treatment of cancer patients with chronic pain?

Chapter 3 discusses the use of the Pain Education Program by patients in the home setting. The effects of the Pain Education Program on patients' pain knowledge are described, as well as effects on patients' pain intensity and quality of life. The research questions addressed in this chapter are:

- How was the Pain Education Program applied in practice?

- What is the effect of the Pain Education Program on pain knowledge?

- What is the effect of the Pain Education Program on pain intensity?

- What is the effect of the Pain Education Program on quality of life?

Part of the Pain Education Program was to register pain in a paper-and-pencil pain diary. Patients were instructed to daily record their pain on a numeric rating scale. Chapter 4 presents an evaluation of the use of a pain diary at home. The following aspects were evaluated: the association between pain intensity scores obtained by means of the pain diary and those obtained by patient interview; the ability to recall past pain intensity; the fluctuation of pain intensity scores over time; and effects of the use of the pain diary. The main research questions addressed in chapter 4 can be summarized as:

- How do cancer pain patients value the use of a pain diary at home?

- What are the effects of the use of a pain diary?

The literature shows that many different outcome measures are being used to evaluate the effect of pain treatment. Because there is no "gold standard" to evaluate the efficacy of pain programs, eight commonly used measures to evaluate the adequacy of cancer pain treatment are described and evaluated. The main research question in chapter 5 is:

- What is the association between the commonly used measures to evaluate pain treatment in cancer patients with chronic pain?

To address some limitations of these commonly used measures, the development and evaluation of a new measure, the Amsterdam Pain Management Index, was developed and discussed in chapter 6 . The Amsterdam Pain Management Index compares patients' Present Pain Intensity, Average Pain Intensity, and Worst Pain Intensity with a composite score of analgesics used, while adjusting for what a patient considers to be a tolerable level of pain. The main research question is:

- What are the psychometric properties of the Amsterdam Pain Management Index in comparison to eight frequently used outcome measures to evaluate the adequacy of pain treatment?

Chapter 7 presents an evaluation of the effects of the Pain Education Program on adequacy of pain treatment by means of the Amsterdam Pain Management Index. Characteristics predicting change in both the short-term and long-term 
adequacy of pain treatment were investigated. The two research questions in thi chapter are:

- What is the effect of the Pain Education Program on the adequacy of pain treatment?

- Which characteristics predict change in the adequacy of pain treatment?

A neglected issue in pain treatment is medication adherence. Poor adherence to pain medication is a substantial problem in the management of cancer pain patients. Chapter 8 addresses the extent of non-adherence to pain medication, and the effects of the Pain Education Program on patients' medication use. Deviation from prescribed pain medication may be caused by patients' lack of awareness and understanding about the prescribed pain medication (noncomprehension), or by lack of adherence even when the prescription is known (non-adherence). The research questions addressed in this chapter are:

- What is the extent of patients' comprehension and adherence to pain medication?

- What is the effect of the Pain Education Program on patients' pain medication prescription, extend of comprehension, and extend of adherence to pain medication?

In the home situation, district nurses play an important role in the treatment 0 pain patients. Chapter 9 presents a description of patients' help-seeking behavio at home. An outline is given of the impact district nurses have on the patients' pain complaints, and the effect of the Pain Education program on district nurses pain knowledge and pain management is evaluated. The research questions addressed in chapter 9 are:

- What is the role of the district nurse on patients' pain complaints at home?

- What is the effect of the Pain Education Program on district nurses' assessment of pain intensity and the quality of pain treatment?

Pain is a multidimensional, subjective, and uniquely personal experience, ${ }^{24,25}$ and has various dimensions, e.g., sensory, physiological, affective, cognitive, and behavioral. ${ }^{26}$ The cognitive dimension refers to how patients think about their pain and what the pain means for them. Patients' pain cognitions are assumed tc have a great impact on patients' pain experience, the degree of disability, and quality of life. Chapter 10 describes the psychometric evaluation of patients' pain cognition as measured bij the Pain Cognition List. In addition, the occurrence of cognitions in cancer patients with chronic pain was assessed, and the association with sociodemographic variables, medical variables, pain experience, and quality of life was investigated. The main research questions are:

- What are the psychometric properties of the Experimental version of the Pain Cognition List? 
- What is the relationship among the scales of the Pain Cognition List for cancer patients and sociodemographic and medical variables, patients' pain experience, and quality of life?

Finally, chapter 11 presents the conclusions and general discussion, in which the main conclusions, methodological and theoretical reflections, and implications for clinical practice are described. A summary in English and Dutch concludes the thesis.

To address the main research questions, a number of measures has been used. An overview of all measures is given in Table 1.

The chapters 2-10 of this thesis have been published or are submitted for publication. There is some repetition of information regarding design, methodology and description of the intervention. However, it has the advantage that all chapters can be read separately. In order to increase readability, minor changes in the layout have been made.

Table 1. Study measures

Measures

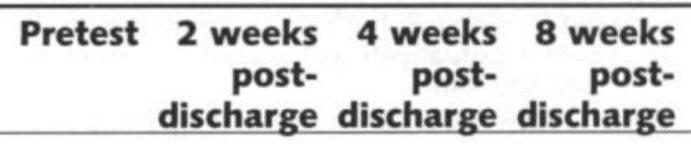

\section{Patient characteristics}

Sociodemographic variables

Medical variables

Pain cognition

\section{Pain Education Program}

Use of pain brochure

Use of audiocassette

Use of pain diary

Use of help-seeking behavior

\section{Outcome variables}

Pain experience

Pain intensity (numeric rating scales)

Quality of Life

Pain Knowledge

Adherence to pain medication

Pain treatment

Quality of pain treatment

\section{(District) nurses}

Nurses' knowledge of patients' pain

Nurses' assessment of quality of pain treatment

Nursing care 


\section{References}

1. Brescia FJ, Adler D, Gray G, Ryan MA. A profile of hospitalized advanced cancer patients. Journal of Pain and Symptom Management, 1990;5:221-227.

2. Coyle N, Adelhardt J, Foley KM, Portenoy RK. Character of terminal illness in the advanced cancer patient: pain and other symptoms during the last four weeks of life. Journal of Pain and Symptom Management, 1990;5:83-93.

3. Foley KM. The treatment of cancer pain. New England Journal of Medicine, 1985;313:84-95.

4. Grond S, Zech D, Diefenbach C, Bischoff A. Prevalence and pattern in patients with cancer pain: a prospective evaluation of 1635 cancer patients referred to a pain clinic. Journal of Pain and Symptom Management, 1994;9:372-382.

5. Portenoy RK. Practical aspects of pain control in the patient with cancer. Cancer, 1988;38:327-352.

6. Higginson IJ, Hearn J. A multicenter evaluation of cancer pain control by palliative care teams. Journal of Pain and Symptom Management, 1997;14:29-35.

7. Portenoy RK. Cancer pain. Epidemiology and syndromes. Cancer, 1989;63:2298-2307.

8. Cherny NI, Coyle N, Foley KM. Suffering in the advanced cancer patient: a definition and taxonomy. Journal of Palliative Care, 1994;10:57-70.

9. World Health Organization. Cancer pain relief. Geneva: World Health Organization, 1986.

10. World Health Organization. Cancer pain relief and palliative care. Technical report series 804 . Geneva, Switzerland; 1990.

11. Bonica JJ. Treatment of cancer pain: current status and future needs. In: Fields HL, Dubner F, Cervero F, eds. Advances in pain research and therapy. New York: Raven Press, Ltd., 1985: 589-616.

12. Cleeland CS, Gonin R, Hatfield AK, Edmonson JH, Blum RH, Stewart JA, Pandya KJ. Pain and its treatment in outpatients with metastatic cancer. New England Journal of Medicine, 1994;330:592-596.

13. Ward S, Gatwood J. Concerns about reporting pain and using analgesics. A comparison of persons with and without cancer. Cancer Nursing, 1994;17:200-206.

14. AHCPR. Management of cancer pain. Clinical Practice Guideline. Rockville, Md. Agency for Health Care Policy and Research, Public Health Service, U.S. Department of Health and Human Services, 1994.

15. Grossman SA. Undertreatment of cancer pain: barriers and remedies. Supportive Care in Cancer, 1993:1:74-78.

16. Max MB. Improving outcomes of analgesic treatment: is education enough. Annals of Internal Medicine, 1990;113:885-889.

17. Von Roenn JH, Cleeland CS, Gonin R, Hatfield AK, Pandya KJ. Physician attitudes and practice in cancer pain management. A survey from the eastern cooperative oncology group. Annals of Internal Medicine, 1993;119:121-126.

18. Cleeland CS. Documenting barriers to cancer pain management. In: Chapman CR, Foley KM, eds. Current and Emerging Issues in Cancer Pain. New York: Raven Press, Ltd., 1993: 321-330.

19. Ward SE, Goldberg N, Miller-McCauley V, Mueller C, Nolan A, Pawlik-Plank D, Robbins A, Stormoen D, Weissman DE. Patient-related barriers to management of cancer pain. Pain, 1993;52:319-324.

20. Ferrell BR, McCaffery M, Rhiner M. Pain and addiction: an urgent need for change in nursing education. Journal of Pain and Symptom Management, 1992;7:117-124.

21. American Pain Society. Principles of analgesic use in the treatment of acute pain and chronic cancer pain: a concise guide to medical practice. Skokie, II. American Pain Society, 1992.

22. Nederlandse Vereniging ter Bestudering van Pijn. Pijn en pijnbehandeling bij de patient met kanker. In: Schulkes-vd Pol JA, red. Groningen, 1990.

23. Stratton Hill C. When will adequate pain treatment be the norm? JAMA, 1995;274:1881-1882.

24. Melzack R. The perception of pain. Science, 1961;204:41-49.

25. Melzack R, Wall PD. The challenge of pain: New York Basic Books, 1982.

26. Ahles TA, Blanchard EB, Ruckdeschel JC. Multidimensional nature of cancer pain. Pain, 1983;17:277-288. 


\section{Chapter 2}

\section{The treatment of chronic cancer pain in a cancer hospital in the Netherlands}

De Wit, R., Van Dam, F., Huijer Abu-Saad, H., Vielvoye-Kerkmeer, A., Mattern, C. The treatment of chronic cancer pain in a cancer hospital in the Netherlands. Journal of Pain and Symptom Management, 1999;17:333-350. 


\section{Introduction}

Pain treatment in chronic cancer patients is a complex matter because of the many divergent components which play a role, such as the nature of the pain, the medical condition of the patient, the pain treatment, patients' reaction to analgesics, the extent to which pain treatment is multidisciplinary, and the expertise of the health care providers with cancer pain and its treatment. Several organizations, including the Dutch chapter of the International Association for the Study of Pain (IASP), have published guidelines that should be followed to optimize analgesic outcomes..$^{1-5}$ These various pain guidelines are fairly similar and widely used, and one might conclude that consensus has been reached on what is good clinical pain practice. Despite these guidelines, various studies report that $38-74 \%$ of cancer patients do not receive adequate pain relief. $6-11$

In most studies evaluating reasons for inadequate pain treatment, only one or a few of the components relevant for optimal pain treatment are taken into consideration, which gives an incomplete picture of all interrelated aspects relevant in pain treatment. In this article, we describe the practice of pain treatment in a more comprehensive way in cancer patients with chronic pain. To clarify the many components that play a role in the treatment of pain and determine the quality of its outcomes, Donabedian's structure-process-outcome framework was used (Table 1). ${ }^{12}$ Donabedian's framework is a useful tool for organizing the divergent components which play a role in quality of health care in general, and can be easily adapted to the practice of pain treatment. In Donabedian's structure-process-outcome framework, "structure" is defined as the resources used in the provision of care and the more stable arrangements under which care is produced. ${ }^{12}$ The setting in which pain treatment is provided can be considered as a structure component. One resource is, for instance, the availability of opioids, such as morphine, needed for adequate pain treatment. "Process" refers to the actions and behaviors undertaken by health care providers to accomplish a certain goal. How analgesics are used and the extent to which pain assessment tools are used in clinical practice is related to process components with regard to pain treatment. Finally, the "outcome" component refers to the result. In the light of this study, it describes what is achieved by treating patients' pain. An example of a commonly used outcome measure is pain intensity.

\section{The structure-process-outcome pain framework}

\section{Structure}

First, resources which should be available for good clinical pain practice were considered. Structure may include facilities, resources (manpower, skill mix), management structure, building structures, financial allocations, legislation and so on. ${ }^{13} \mathrm{Koch}^{14}$ used structure to describe the physical, organizational and other characteristics of the system that provides care. This may include peer review mechanisms, continuing education programs, procedure manuals, patient classification systems, and delivery of nursing methods. Based on the available pain guidelines, ${ }^{1-5}$ one can infer that the following structural resources should be 


\section{Table 1. Framework to evaluate the practice of pain treatment}

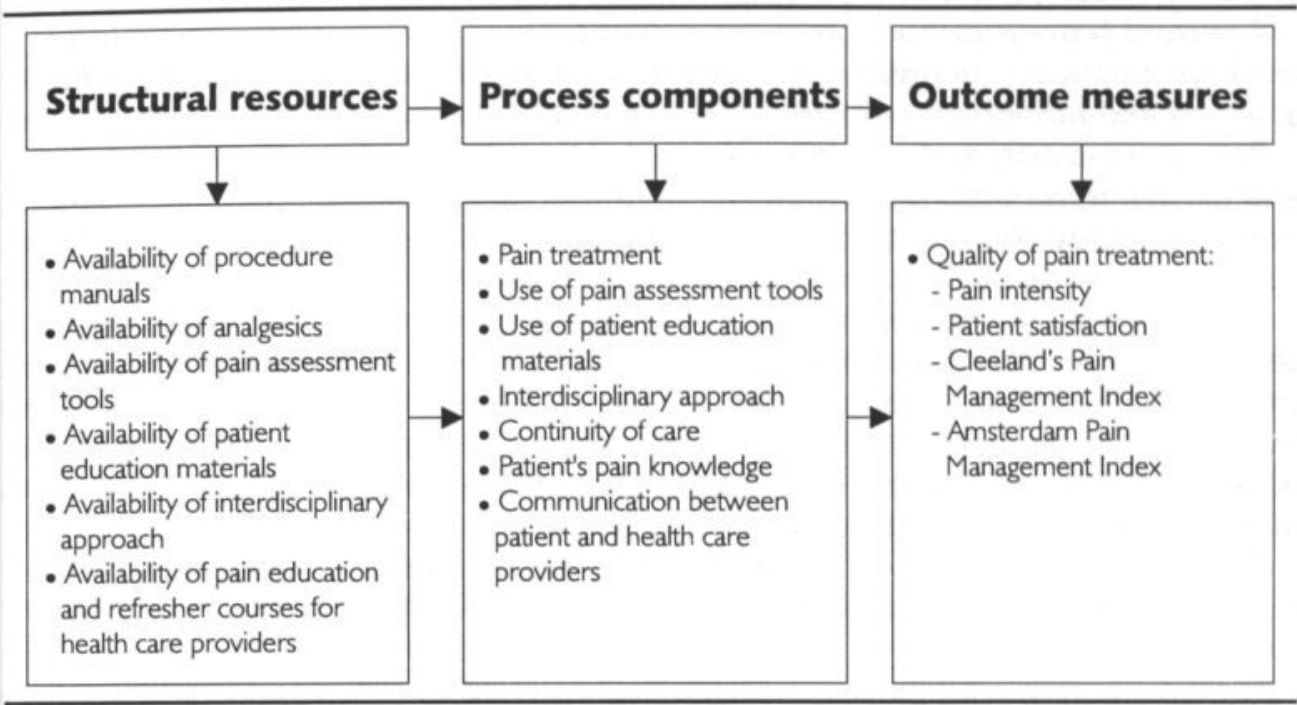

available: 1) procedure manuals in which an overview is given of how to treat pain in cancer patients; 2) analgesics, including opioids such as morphine; 3) pain assessment tools to monitor pain; 4) pain education materials for patients; 5) interdisciplinary pain treatment by means of pain teams consisting of, e.g., oncologists, anesthesiologists, psychologists, nurses, social workers, physical therapists, who can be called in for patients with uncontrolled pain or complex pain complaints; and 6) health care providers who are well versed in treating patients' pain, e.g., pain education and refresher courses.

\section{Process}

A component which refers to process variables is the pain treatment itself. Consensus has been reached on what comprises good pain treatment and how analgesics should be handled..$^{1-5}$ The use of analgesics is considered as the first option in the management of cancer pain. ${ }^{1,15-17}$ According to the "analgesic ladder" of the World Health Organization (WHO), stronger opioids are prescribed when pain increases in severity. Because there is great variation in patients' individual pain experience and susceptibility to analgesic drugs, an essential principle in pain treatment is to individualize the regimen to the patient. ${ }^{15}$ The oral route is the preferred route of administration. For patients with severe pain who require rapid incremental doses of analgesics, who experience severe side effects, or who have swallowing difficulty, there are effective alternative routes, e.g., intravenous, subcutaneous, intraspinal, or intrathecal. The use of analgesic drug administration is recommended on a regular basis (around the clock) rather than as needed. ${ }^{1,3}$ Besides the administration of analgesics on a regular basis, "rescue" medication can be prescribed. If the use of opioids in combination with nonopioids and adjuvant drugs does not relieve pain or causes intolerable side effects, invasive methods (e.g., nerve blocks) can be considered. 
Finally, non-pharmacological pain techniques, e.g., massage, relaxation, the use of heat and cold, are described as an integral part of pain treatment.

A second process component is the extent to which pain assessment tools are used systematically. In order to be alert to insufficient pain relief, pain should be assessed and monitored regularly in each patient. ${ }^{1,18}$

Patient educating and informing them and their families by means of verbal and written information, constitutes a third process component. Patient education with regard to pain control and the correction of myths about the use of opioids should be part of any proper pain program. . $^{5} 19-21$

A fourth process component is the interdisciplinary approach to treat pain by consulting other disciplines, and a fifth process component is the extent to whict continuity of care has been provided. Continuity of care refers to the link between hospital and home care in the form of communication, e.g., between the general practitioner at home and the physician in the hospital, and between the hospital nurse and the district nurse.

A sixth process component is patients' pain knowledge. The rationale for adequate pain knowledge in patients is that better pain knowledge enhances pain control.

The final process component refers to communication between the patient an the health care provider(s). Faulty communication may cause patients to under report their pain, to wait too long to ask for pain relief, or may cause difficulties in reporting and communicating about pain. 22

\section{Outcome}

Outcome indicators relating to practice of pain treatment remain a difficult issue because of their complexity and the lack of a gold standard. Given the lack 0 systematic use of well-established outcome measures to evaluate the adequacy of cancer pain treatment, four measures have been selected. Although not all four measures show sufficient levels of reliability and validity, these measures were assessed in the present study to increase comparability with results obtained by other studies. Outcome measures can be defined by patients only, or combined with the judgment of health care providers. Of all outcome measures, pain intensity is most commonly used. High pain intensity scores are considered as interfering with daily functioning, ${ }^{22}$ meaning that these patients are treated less adequately for their pain than patients with low pain intensity scores.

The second outcome measure, which is suggested by the American Pain Society, ${ }^{3,18}$ and the Agency for Health Care Policy and Research' ${ }^{1}$ is patients' evaluation of health services or health providers (patient satisfaction).

Besides patients' judgment about pain and pain treatment, professionallyoriented outcomes can also be used to evaluate pain treatment. Based on the principles of the WHO cancer pain guidelines, the extent of pain medication needs to be matched to the severity of pain: nonopioids for mild pain, so-called "weak" opioids for patients with moderate pain, and so-called "strong" opioids for patients with severe pain (Cleeland's Pain Management Index ${ }^{7}$ ).

Although the "Pain Management Index" as developed by Cleeland et al.7 has been used in different research settings, ${ }^{6,8-11,23}$ research has shown a need for a more sophisticated index in adequacy of pain management. Based on this index, de Wit et al. ${ }^{24}$ developed a revised "Amsterdam Pain Management Index." 
This index compares patients' pain intensity with a composite score of analgesics used, while correcting for the level of acceptable pain.

It can be concluded that pain relief is the endpoint of a complicated process, in which many factors are related. Quality of care studies, primarily based on Donabedian's structure-process-outcome framework and conducted in the field of pain treatment, are scarce because mostly one or only a few of the various components relevant for optimal pain treatment are taken into consideration. Bookbinder et al..$^{25}$ described a model for improving the quality of pain management by using the standards as developed by the American Pain Society. ${ }^{3}$ These standards provide a structure to address the key components of a pain management program, including the use of standardized measures to self-report pain intensity; professional and patient education; polices and procedures related to new technologies and more efficient systems of medication delivery (equipment, skills, and resources such as patient controlled analgesia, and epidural analgesia); availability of clinical experts to respond to patient, family and staff needs; and a mechanism for ensuring professional and administrative accountability to meet the standards. Kitson et al. ${ }^{26}$ investigated criteria for postoperative pain management according to Donabedian's framework. Regular updating on pain management, knowledge of pain assessment techniques, the need for a pain assessment tool on the ward, the need to provide information to staff, and resources and equipment were identified as structure criteria. Elements of process were pain assessment, patient involvement, giving information, observations, and evaluations and action

Physiological status, pain intensity, and patient satisfaction were identified as outcome variables.

In the present study, we describe current practice in treatment of cancer pain. Donabedian's framework was used to evaluate different measures to describe quality of pain treatment simultaneously in cancer patients with chronic pain in a cancer hospital.

\section{Methods}

\section{Patients and procedure}

The study was conducted at the Netherlands Cancer Hospital/Antoni van Leeuwenhoek Hospital, a 180-bed cancer hospital in Amsterdam, in the Netherlands. It is part of a randomized longitudinal study in which the effect of a "Patient Education Program" (intervention) was evaluated. A more detailed description of the intervention is reported elsewhere. ${ }^{27}$ Patient accrual was carried out over a twenty-month period. Patients were eligible to participate if they met the following criteria: 1) pain related to cancer, cancer therapy, or illness; 2) a pain duration of at least 1 month; 3 ) a life expectancy of at least 3 months (assessed by physicians); 4) able to read and speak Dutch; 5) accessible by telephone; and 6) not residing in a nursing home or retirement home. After informed consent was obtained, patients were interviewed in the hospital and at home. In addition, district nurses who provided care for the patients at home were interviewed by telephone about patients' pain complaints and pain treatment. 


\section{Measures}

Measures related to patient characteristics were obtained by means of patient interviews, medical and nursing records, and included sociodemographic variables, and medical variables. Symptoms other than pain were measured by means of the European Organization for Research and Treatment of Cancer Core Quality of Life Questionnaire (EORTC-QLQ-C $30+3$ ). ${ }^{28}$ Data related to the practice of pain treatment were described in terms of structural resources, process components, and outcome measures.

A description of the structural resources is given in the results section. Information on structural resources was based on the literature or was provided by pain experts.

Of the process components, patients' pain treatment was deduced from the medical records and consisted of: 1) the use of causal pain treatment from chemotherapy, hormonal therapy, radiation or supportive surgery; 2 ) the use of symptomatic pain treatment by means of analgesics (name, dose, frequency of nonopioids and opioids, route and schedule of administration; 3 ) the use of symptomatic pain treatment by means of invasive therapies (e.g., nerve blocks) 0 physical modalities (e.g., transcutaneous electrical nerve stimulation (TENS)); 4) total daily opioid consumption, which was measured by converting the amount of opioids to oral morphine equivalent $\mathrm{mg}$, and total nonopioid consumption which was converted to acetaminophen equivalents by considering the daily dosage of one nonopioid as equianalgesic to the daily dosage of another nonopioid; ${ }^{29,30} 5$ ) the use of adjuvant analgesics, which can potentiate the effect of analgesic drugs, neutralize side effects such as constipation, sedation, drowsiness, confusion, dizziness, nausea, and vomiting, or function as analgesic drugs themselves, such as antidepressants, hypnotics, psychotropic drugs, and corticos. teroids; and 6) the use of non-pharmacological pain techniques (e.g., use of heat and cold, massage, relaxation, distraction), which was assessed by interviewing patients about which techniques they used themselves to relieve pain.

The second process component, the use of pain assessment tools, was measured by extracting patients' pain intensity scores from the nurses' records. In the Netherlands Cancer Institute/Antoni van Leeuwenhoek Hospital, all patients are routinely asked to indicate their actual pain twice a day. It was recorded when and how often nurses graphically registered the pain score on the temperature chart.

The third component, the use of patient education materials, was assessed by recording whether patients had received written pain information and by patients' self-report on how they were informed about pain and pain treatment. Pa. tients who reported to be well informed about pain and pain treatment were considered as patients who received satisfactory patient education materials.

The fourth process component, the use of an interdisciplinary approach to treat pain, was measured by the extent to which a pain physician or pain team was consulted for pain patients.

Continuity of care, the fifth process component, was assessed by verifying the extent to which hospital nurses provided information about patients' pain complaints and pain treatment to district nurses. Therefore, we contacted district nurses to evaluate whether they were informed by hospital nurses about the patient's pain complaints and pain treatment. 
Furthermore, patients' pain knowledge was measured by means of the Dutch Language Version of the Pain Knowledge Questionnaire (PKQ-DLV). ${ }^{31,32}$ The PKQ-DLV has been translated backward-forward and pretested in a group of 49 patients and has demonstrated acceptable levels of validity and reliability. The PKQ-DLV included eight items, such as "patients are often given too much pain medicine," "most cancer patients receiving pain medicines will become addicted to the medicines over time," and "it is better to give pain medications around the clock (on a schedule) rather than only when needed." For ease of interpretation, all item scores were linearly transformed to a 0-100 scale and a total score was computed for overall pain knowledge.

The final process component, communication between patient and health care providers, was assessed by interviewing the patient about the frequency and content of pain communication with the physician or general practitioner. Health care provided by general practitioners is covered by the Dutch universal health insurance system.

Finally, four outcome measures were assessed to evaluate the practice of pain treatment. First, patients' pain intensity was assessed. Patients were asked about their actual pain intensity on a scale from " 0 " to " 10 ", with " 0 " representing "no pain", and "10" representing "pain as bad as you can imagine". Using the same scale, their "Average Pain Intensity in the past week" was assessed. The validity, reliability and feasibility of these scales are well established. . $^{33-36}$

Second, patient satisfaction with the pain treatment was evaluated by means of a 5-point Likert self-report scale ranging from "very satisfied" to "very dissatisfied." $1,3,37,38$ Although patient satisfaction is considered an important aspect reflecting patients' evaluations of the satisfaction with pain relief, it is subject to distortion, as many patients are satisfied with the pain treatment despite high levels of pain intensity. ${ }^{37-40}$ In a study, evaluating the psychometric properties of measures to evaluate quality of pain treatment, patient satisfaction was not considered as a valid outcome measure for pain and should be interpreted with caution. ${ }^{24}$ Patients who were not satisfied with the pain treatment were asked to give their reasons for this by means of an open question.

Third, the "Pain Management Index," developed by Cleeland et al. ${ }^{7}$ was used to measure the quality of pain treatment. "Cleelands's Pain Management Index" compares the most potent analgesic for a patient with the patient's reported level of pain. Therefore, patient's level of "Worst Pain Intensity" was determined and categorized into: 0 (no pain), 1 (1-3: mild pain), 2 (4-7: moderate pain), and 3 (8-10: severe pain). The pain level was then subtracted from the most potent level of analgesic drug therapies prescribed: 0 (no analgesic drug), 1 (a nonopioid), 2 (a "weak" opioid), and 3 (a "strong" opioid). Thus, the "Pain Management Index" consists of scores ranging from -3 (a patient with severe pain receiving no analgesic drugs) to +3 (a patient without pain receiving "strong" opioids). Negative scores indicate inadequate analgesic prescriptions, whereas scores of " 0 " or higher are considered to be a conservative estimate of acceptable pain treatment. Evidence of the validity of this index has been demonstrated by Ward et al. ${ }^{23}$

Taking into consideration some of the limitations of "Cleeland's Pain Management Index," a revised index to describe the adequacy of pain treatment was developed. The revised index, the "Amsterdam Pain Management Index," was based on an average of patient's "Present Pain Intensity," "Average Pain Intensity," and 
"Worst Pain Intensity." Because pain is a subjective experience, the pain score is corrected for patient's "Tolerable Pain Intensity," meaning that patients were asked to provide an anchor point for what they consider an acceptable level of pain. When patient's "Present Pain intensity" is above the level of patient's "Tolerable Pain Intensity," the index score was subtracted with one point. Because pain medication prescribed is not always used by patients (non-adherence), pain medication used, as described by patients, instead of medication prescribed was included. Because of the variety of opioids and nonopioids, analyses of total anal gesic use requires conversion of each drug to give a precise picture of the medication. Therefore, all nonopioids and opioids used within a $24-\mathrm{h}$ period were con verted to oral morphine equivalents using information gathered from an extensive review of the literature. 15,41,42 Although there is some controversy about the conversion from nonopioids to opioids, the one-day dose of one nonopioid was considered equianalgesic to the daily dose of another nonopioid, and $650 \mathrm{mg}$ of acetaminophen was considered as equianalgesic to $6 \mathrm{mg}$ of oral morphine (Table 2). Based on guidelines regarding starting dose, ${ }^{1,2}$ the patient's total dose of nonopioids and opioids per 24 hours was categorized into: 0 (no analgesic drug) 1 (1-60 mg equianalgesic dose oral morphine, 2 (61-120 mg equianalgesic dose oral morphine), 3 (121-240 mg equianalgesic dose oral morphine), and 4 ( 240 mg equianalgesic dose oral morphine). The "Amsterdam Pain Management Index" ranges from -4 (patient with severe pain receiving no analgesics) to +4 (patient receiving high doses of opioids with complete pain relief).

In a recent study, ${ }^{24}$ it was found that the "Amsterdam Pain Management Index" showed acceptable levels of validity.

Table 2. Comparative equianalgesic dose opioids and nonopioids

\section{Oral (mg) Parenteral (mg)}

\section{Opioids ${ }^{\mathrm{a}}$}

Morphine

Codeine

Tramadol

Pethidine

Pentazocine

Dextroproxypophene

Nicomorphine

Piritramide

\section{Nonopioids ${ }^{b}$}

Acetaminophen

Ibuprofen

Diclofenac

Naproxen
200

200

300

180

\section{5}

60

300

45

15

a: The amount of opioids was converted to oral morphine.

b: The I-day dose of a nonopioid was considered equivalent to the I-day dose of acetaminophen $2000 \mathrm{mg}$. 


\section{Results}

\section{Patient characteristics}

In total, 383 patients were eligible for participation. Seventy patients (18.3\%) declined to participate for the following reasons: 48 patients $(68.6 \%)$ found the study too burdensome, 15 patients $(21.4 \%)$ were not motivated, and 7 patients $(10 \%)$ were too ill. Patients who declined to participate were significantly older than those who participated $\left(\chi^{2}=6.0, p=0.01\right)$, and females refused to participate more frequently than males $\left(\chi^{2}=4.1, p<0.05\right)$.

Of the 313 participants, $62.6 \%$ were female $(\mathrm{N}=196)$ and the mean age of the total group was 55.5 years $(\mathrm{s} d=12.4)$. In total, $40.9 \%(\mathrm{~N}=128)$ had low education, $33.2 \%(\mathrm{~N}=104)$ were middle-high educated, and $25.9 \%(\mathrm{~N}=81)$ had high education. Only $12.1 \%(\mathrm{~N}=38)$ was employed. For $33.2 \%(\mathrm{~N}=104)$ of the patients, district nursing was planned postdischarge.

Of the 104 patients for whom district nursing was planned, 81 (77.9\%) district

Table 3. Medical characteristics of the study population

$\mathbf{N}^{\mathbf{a}}$

$\%$

Type of cancer $(>100 \%)$

Lip, oral cavity, and pharynx

Digestive organs and peritoneum

18

5.8

Respiratory and intrathoracic organs

12.1

Breast

10.9

Bone, connective tissue, and skin

30.0

Genitourinary organs

13.7

Other (e.g., non-Hodgkin's lymphoma)

\section{Extent of disease}

Local

Regional

Metastatic

182

Unknown

Not applicable

\section{Cancer treatment (>100\%)}

No

Surgery

Chemotherapy

Radiotherapy

Other and unknown

21


nurses were interviewed postdischarge. Reasons for not interviewing district nurses were: patients died before discharge or a few days postdischarge $(\mathrm{N}=13)$ no permission was given by the patient to interview the district nurse after the patient dropped out $(\mathrm{N}=2)$, patients were readmitted to the hospital or admitte to a nursing home postdischarge $(\mathrm{N}=6)$, or for other reasons $(\mathrm{N}=2)$. The mean stay in the hospital was 14.5 days $(s d=12.3$, range $=2-88$ ).

Patients suffered from cancer of different sites (Table 3 ). As could be expected with hospitalized cancer patients in chronic pain, most patients $(58.1 \%)$ were in an advanced stage of their disease. Of the patients, $37.7 \%$ received chemotherapy, $18.5 \%$ received radiotherapy, and $17.9 \%$ had surgery. In $22.4 \%$ of the patients, no anticancer treatment was provided. Approximately $40 \%$ of the patient experienced pain in the abdominal region and in the lower back region (Table 4) and a mean of 1.8 pain locations was reported. Pain was associated with direct tumor involvement in $77.3 \%(\mathrm{~N}=242)$ of the patients. The mean pain duration was 14.2 months ( $s d=33.4$, range $=1-324$ months). Constant pain was reported by $7.4 \%(\mathrm{~N}=23), 73.3 \%(\mathrm{~N}=228)$ reported that pain occurred intermittently with out pain-free periods, $19.0 \%(\mathrm{~N}=59)$ reported that pain was intermittent with pain-free periods, and in $0.3 \%$ of the patients $(\mathrm{N}=1)$ the pattern of pain was unknown.

Pain was not the only symptom experienced. There was also a particularly higt prevalence of fatigue, loss of appetite, sleep disturbance, constipation, and nausea and vomiting (data not shown). Overall, $41.3 \%$ of the patients experienced three or more symptoms other than pain.

Table 4. Pain characteristics of the study population.

$\mathbf{N a}^{\mathbf{a}}$

Pain location (>100\%)

Head, face, mouth

Breast, thoracic region

Upper shoulder and upper limbs

Abdominal region

Lower back, lumbar spine, sacrum, coccyx

Lower limbs

Anal, perianal, and genital region

Everywhere

$\begin{array}{rr}66 & (21.1 \%) \\ 64 & (20.4 \%) \\ 91 & (29.1 \%) \\ 124 & (39.6 \%) \\ 122 & (39.0 \%) \\ 85 & (6.5 \%) \\ 17 & (5.4 \%) \\ 2 & (0.1 \%)\end{array}$

\section{Source of cancer pain ( $>100 \%$ )}

Direct tumor involvement

Cancer therapy

Associated with cancer disease

Unknown

$\begin{array}{rr}242 & (77.3 \%) \\ 75 & (24.0 \%) \\ 21 & (6.7 \%) \\ 14 & (4.5 \%)\end{array}$

a: Number of patients 


\section{Structure}

Almost all resources necessary for good clinical practice are available in the hospital. The guidelines of the Dutch chapter of the International Association for the Study of Pain (IASP) ${ }^{2}$ are well-known nationally and widely available in the hospital. These guidelines include procedure manuals in which an overview is given of how to treat pain in cancer patients by means of the WHO "analgesic ladder." In the Netherlands, analgesics are available to all patients, including opioids such as morphine. For the systematic assessment of pain, a nursing pain measurement was developed and implemented in the hospital. ${ }^{43} \mathrm{~A}$ fourth structural resource is the availability of pain education materials for patients. The Dutch Cancer Society has published a pain brochure which contains extensive information about pain and pain relief for cancer patients; this material is readily available to patients. Another resource is the availability of an interdisciplinary approach to control pain. In the Netherlands Cancer Institute/Antoni van Leeuwenhoek Hospital, one anesthesiologist and one physician, both specialized in pain control, can be consulted in case of complex pain problems. Furthermore, complex pain problems can also be discussed in a multidisciplinary pain team consisting of an oncologist, an anesthesiologist, a pain physician, a psychologist, a neurologist, a pharmacist, a nurse, a psychiatrist, and a physical therapist. A final

aspect of the structural resources concerns education and training of health care workers in managing pain. In the Netherlands Cancer Institute/Antoni van Leeuwenhoek Hospital, all registered nurses receive a special oncology nursing training including pain education for at least 4 hours. However, there is no formal training for residents in the Netherlands Cancer Institute/Antoni van Leeuwenhoek Hospital.

It can be concluded that almost all resources which are considered necessary for good clinical pain practice are met in the Netherlands Cancer Institute/Antoni van Leeuwenhoek Hospital. However, formal training in pain and pain treatment for both physicians and nurses is not optimal.

\section{Process}

In total, seven process components were assessed. Causal pain treatment was given only to a small group of patients: $15.0 \%(\mathrm{~N}=47)$ received radiation therapy, $12.1 \%(\mathrm{~N}=38)$ chemotherapy, $2.6 \%(\mathrm{~N}=8)$ surgery, and $1.6 \%(\mathrm{~N}=5)$ hormonal therapy. Nerve blocks, TENS, etc. were utilized in only $3.6 \%(\mathrm{~N}=11)$ of the patients. The mainstay of pain treatment consisted of the use of analgesics: $88.2 \%$ of the patients received a variety of nonopioids and/or opioids. Acetaminophen was prescribed most frequently as a nonopioid, codeine as a "weak" opioid, and morphine, immediate or slow-release morphine, as "strong" opioids. No analgesics were prescribed in $11.5 \%(\mathrm{~N}=36)$ of patients. Nonopioids were given to $71.6 \%(\mathrm{~N}=224)$ of the patients, either alone $(27.2 \%$; WHO step I) or in combination with opioids (72.8\%; WHO Step II, WHO step III, and WHO Step IV). Of all patients, $69.0 \%(\mathrm{~N}=216)$ received "weak" or "strong" opioids, either alone (24.5\%) or in combination with nonopioids $(75.5 \%)$. "weak" opioids were combined with nonopioids in $94.1 \%(\mathrm{~N}=111)$, while "strong" opioids were combined 
with nonopioids in $57.9 \%(\mathrm{~N}=66)$. Of all patients, $36.4 \%(\mathrm{~N}=114)$ received "strong" opioids (WHO step III and IV). Parenteral medication (WHO step IV) was given to 34 patients $(10.9 \%)$. An overview of the percentage of patients being

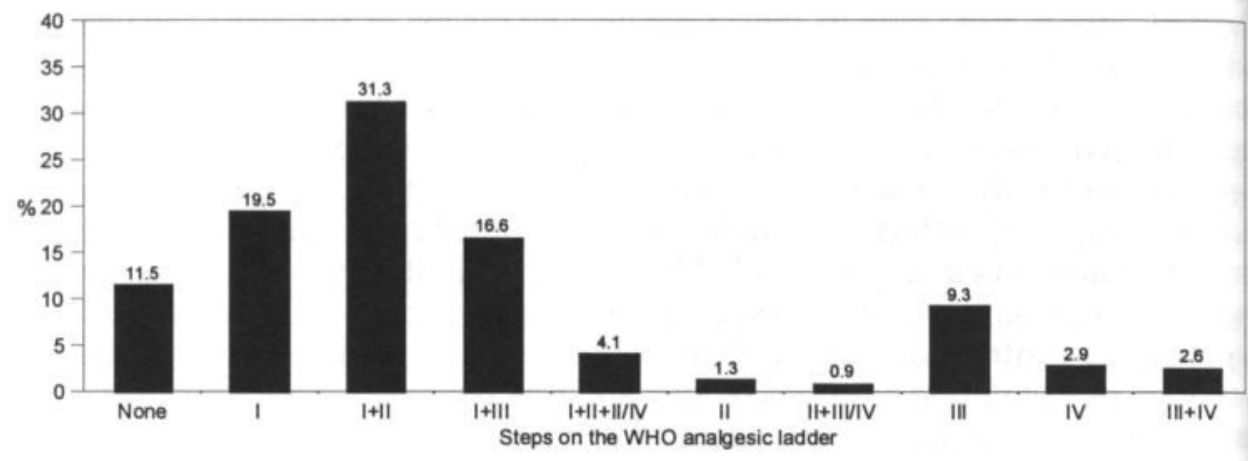

Figure 1. Percentages of patients being treated on different steps of the WHO analgesic ladder at baseline

treated on the different steps of the WHO analgesic ladder is given in Figure 1.

Each dose of opioids and nonopioids was determined for a 24-hour period and converted to $\mathrm{mg}$ equianalgesic to oral morphine. The daily prescription of opioids ranged from 6-2700 mg equianalgesic dose to oral morphine. If the most potent analgesic prescribed was a "weak" opioid (WHO step II), patients were prescribed on average 31 morphine equivalent $\mathrm{mg}$ per day (range $=6-135 \mathrm{mg}, \mathrm{sd}=27$ ). If "strong" opioids (WHO step III) were part of the pain treatment, patients were prescribed, on average, 89 morphine equivalent $\mathrm{mg}$ per day for enteral prescription (range $=12-360 \mathrm{mg}, \mathrm{sd}=64$ ), and parenteral prescription, on average 272 morphine equivalent $\mathrm{mg}$ per day (range $=12-2700 \mathrm{mg}, \mathrm{sd}=517$ ). Only 18 patients $(5.8 \%)$ were prescribed an opioid dose of more than $200 \mathrm{mg}$ morphine equivalent $\mathrm{mg}$ per day. The prescription of daily nonopioids ranged from $500-9000 \mathrm{mg}$ equianalgesic to oral acetaminophen. When patients were prescribed nonopioids, either alone or in combination with an opioid, they received on average 3662 acetaminophen equivalent $\mathrm{mg}$ per day (range $=250-9000 \mathrm{mg}, \mathbf{s d}=1679$ ).

Analgesics were prescribed on a regular basis in $49.1 \%(\mathrm{~N}=136)$ of the patients; $26.7 \%(\mathrm{~N}=74)$ received analgesics on a regular basis, combined with analgesics as needed; $23.1 \%(\mathrm{~N}=64)$ of the patients were prescribed analgesics as needed; and in $1.1 \%(\mathrm{~N}=1)$ the prescription was unknown. Patients who were prescribed analgesics on demand did not differ with regard to pain intensity scores from patients who were prescribed analgesics on a regular basis.

All patients who were prescribed pain medication were asked about any side effects they experienced as a result of the analgesics. Of the 277 patients who were prescribed pain medications, 132 patients $(47.7 \%)$ reported side effects due to analgesics. Constipation was reported by 59 patients $(21.3 \%)$, drowsiness by 44 patients (15.9\%), nausea and vomiting by 19 patients $(6.9 \%)$, dry mouth by 
15 patients (5.4\%), gastritis by 9 patients (3.2\%), dizziness by 6 patients $(2.2 \%)$, and other symptoms, e.g., itching, loss of appetite, confusion, and decreased memory, by 41 patients (14.8\%). Patients who were only prescribed nonopioids reported significantly fewer side effects $(18.0 \%)(F$-value $=25.6, p<0.001)$ than patients who were prescribed "weak" or "strong" opioids $(45.1 \%$ and $65.8 \%$, respectively). Patients who were prescribed a dose of "weak" or "strong" opioids of more than 30 morphine equivalent $\mathrm{mg}$ per day reported more side effects than patients who were prescribed less than 30 morphine equivalent $\mathrm{mg}$ per day ( $\mathrm{F}$ value $=7.9, \mathrm{p}<0.01$ ).

In addition to analgesics, the use of adjuvant medication was registered. Results showed that hypnotics were prescribed in $43 \%(\mathrm{~N}=135)$ of the patients, anxiolytics in $19.2 \%(\mathrm{~N}=60)$, antidepressants in $6.4 \%(\mathrm{~N}=20)$, neuroleptics in $3.2 \%(\mathrm{~N}=10)$, anticonvulsants in $2.6 \%(\mathrm{~N}=8)$, and corticosteroids in $1.6 \%(\mathrm{~N}=5)$. In total, $56.5 \%(\mathrm{~N}=177)$ of the patients were prescribed one or more medications which may be considered as adjuvant analgesic drugs.

A last aspect of pain treatment is the use of non-pharmacological pain treatment. In total, $89.8 \%$ stated that they applied non-pharmacological methods. The use of specific positions or movements while sitting, laying or moving was reported in $81 \%$, distraction in $45.7 \%$, the use of heat and cold in $34.6 \%$, relaxation in $22.8 \%$, massage in $15.8 \%$, and $11.9 \%$ mentioned other non-

pharmacological pain-relieving methods. Patients reported a mean of 2.0 nonpharmacological pain techniques $(s d=1.2$, range $=0-6)$ to alleviate their pain.

With regard to the second process component, the use of a pain assessment tool, it was found that the nurses registered patient's "Present Pain Intensity" in $89.9 \%$ of the cases at least once a day.

With regard to the third process component, patient education, patients were asked about the extent to which they were informed about pain and pain treatment. Of the 265 patients completing this item at two weeks postdischarge, $65.7 \%(\mathrm{~N}=174)$ stated that they were (very) well informed about pain and pain treatment; 34 patients $(12.8 \%)$ were moderately informed; 54 patients $(20.4 \%)$ were (very) poorly or not informed, and 3 patients $(1.1 \%)$ were unable to answer. Reasons given by patients for not being satisfied with the pain information provided by health care providers were: having received insufficient or no pain information $(66.6 \%)$; being treated in different ways for their pain by different health care providers $(9.3 \%)$; not enough attention given to the pain problem $(14.7 \%)$; having received information only when it was explicitly asked for $(8 \%)$; or other reasons $(1.3 \%)$. Of all patients, only $15.8 \%(\mathrm{~N}=46)$ had received a pain brochure. Patients who had received written pain information showed better pain knowledge compared to patients who did not receive written materials ( $F$ value $=10.1, \mathrm{p}<0.01$ ).

Results regarding the use of an interdisciplinary approach showed that a pain physician was consulted in $31.9 \%(\mathrm{~N}=100)$ of the patients. The higher the patient's pain intensity, the more frequently a pain physician was consulted $\left(\chi^{2}=20.9, p<0.001\right)$. Furthermore, a pain physician was consulted more frequently by patients who received district nursing postdischarge than by those who did not receive district nursing $\left(\chi^{2}=7.7, p<0.01\right)$.

Results regarding continuity of care, measured by means of information about patients' pain complaints that was provided by hospital nurses to district nurses, 
Table 5. Patient's pain knowledge measured by the Pain Knowledge Questionnaire-Dutch Language Version

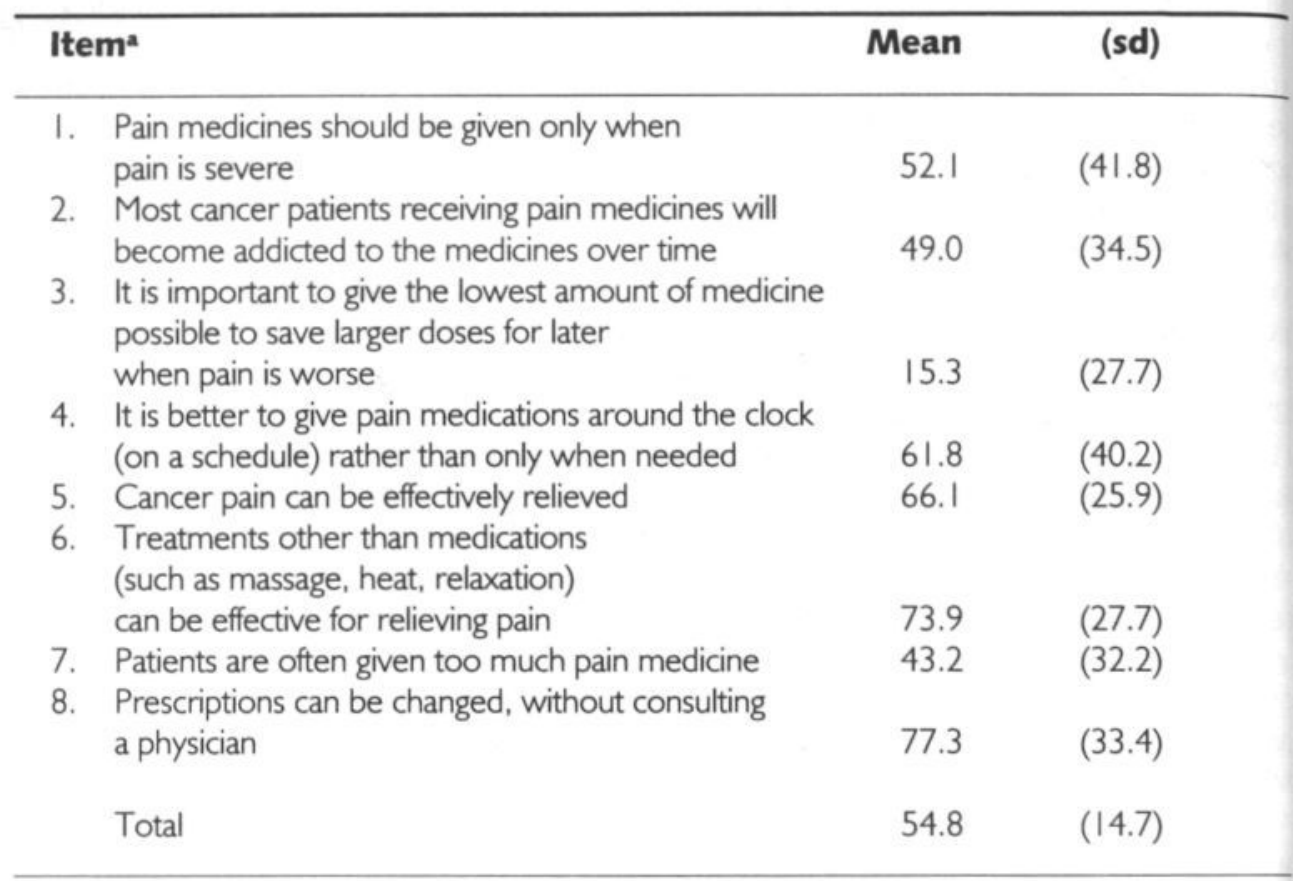

a: Range $0-100$ with higher scores indicating better knowledge.

showed that only $35.8 \%$ of the district nurses $(\mathrm{N}=29)$ were informed about any aspect of patients' pain.

Patients' mean score on the sixth process component, pain knowledge, was 54.8 on a scale from $0-100$, with higher scores representing better knowledge (Table 5). Patients were best informed about "the effective use of nonpharmacological pain treatments (such as massage, heat and cold, relaxation, etc.)" and "the belief that health care providers need to be consulted when changing prescriptions." Many patients were wrongly informed about the item "it is important to give the lowest amount of medicine possible to save larger doses for later when pain is worse." There were no differences between the patient groups with and without district nursing, except that patients with district nursing showed better knowledge with regard to "the use of medication around the clock instead of on demand" as compared to patients without district nursing $(\mathrm{F}$-value $=5.7, \mathrm{p}<0.05)$. No differences were found between male and female patients. Older patients ( 60 years) showed significantly less pain knowledge than younger patients $(<60$ years) $(\mathrm{F}$-value $=19.9, \mathrm{p}<0.001)$. Higher-educated patients showed significantly more pain knowledge than lower educated patients ( $F$ value $=8.1, p<0.001$ ), especially on two of the eight items, namely on the item "pain medication should be given only when pain is severe" ( $F$-value $=5.3$, $p<0.01)$, and the item of "becoming addicted" (F-value $=13.9, p<0.001)$. Finally, patients who reported to be well or very well informed, as measured by means of 
patients' self-report, showed better results regarding pain knowledge than patients who reported to be (very) badly or not informed ( $F$-value $=3.9, p=0.05$ ).

Patients reported that they had communicated with their general practitioner on average 5.8 weeks previously $(s d=13.6)$. Their relationship with the general practitioner was assessed as good or very good in $79.8 \%(\mathrm{~N}=241)$. A majority of patients $(83.1 \%)$ reported that their general practitioner was aware of their pain problems, but only $29.0 \%(\mathrm{~N}=91)$ thought that their general practitioner was able to treat their pain; $55.6 \%(\mathrm{~N}=174)$ of patients did not have any experience with the general practitioner treating their pain, and according to $15.3 \%(\mathrm{~N}=48)$ the general practitioner was not competent to treat their pain. In the case of increased pain, 117 patients (37.6\%) stated that they would wait and see, 74 patients $(23.8 \%)$ responded they would contact their general practitioner, 66 patients $(21.2 \%)$ would contact the physician in the hospital, 23 patients $(7.4 \%)$ would take more pain medication without contacting a health care provider, and 31 patients $(10.0 \%)$ would use a combination of the approaches mentioned above.

\section{Outcome}

The mean pain intensity scores for patients' "Present Pain Intensity," and "Average Pain Intensity during the previous week" were $3.3($ s.e. $=0.24)$ and 4.9 (s.e. $=0.22)$. A score of " 5 " or more, which is defined as substantial pain, was reported by $32.6 \%(\mathrm{~N}=101)$ for "Present Pain Intensity," and by $59.1 \%(\mathrm{~N}=179)$ for "Average Pain Intensity." It is striking that, based on these outcome measures, high percentages of patients were experiencing substantial pain. "Present Pain Intensity" correlated $r=0.50(p<0.001)$ with "Average Pain Intensity." No differences in pain intensity were found between patients who needed district nursing and those who did not need district nursing. Additionally, no differences were found between male and female patients, and patients' pain intensity was not affected by age and pain duration.

The second outcome component, patient satisfaction, showed that $65.7 \%$ $(\mathrm{N}=203)$ of the total of 309 patients were somewhat or very satisfied with the pain treatment, $11.3 \%(\mathrm{~N}=35)$ were neither satisfied nor dissatisfied, $12.3 \%$ were somewhat or very dissatisfied $(\mathrm{N}=38), 9$ patients $(2.9 \%)$ did not know, and 24 patients $(7.8 \%)$ were not able to answer the question because no pain treatment was provided. Surprisingly, $67.9 \%$ of the patients $(\mathrm{N}=203)$ who reported moderate to severe pain were somewhat or very satisfied with the pain treatment. Pain intensity and patient satisfaction with their pain treatment were weekly correlated $(r<0.21)$. However, patients who were dissatisfied with their pain treatment were significantly more likely to report higher levels of "Present Pain Intensity" (4.2 versus $2.9, \mathrm{p}<0.001)$.

Results of the third outcome measure, "Cleeland's Pain Management Index," showed that of the 305 patients, $51.1 \%(\mathrm{~N}=156)$ received less than optimal analgesics at baseline: $28.2 \%(\mathrm{~N}=86)$ were prescribed somewhat inadequate pain treatment (score of -1$), 17.0 \%(\mathrm{~N}=52)$ were more seriously undertreated (score of -2$)$, and $5.9 \%(\mathrm{~N}=18)$ were very seriously undertreated (score of -3 ) (Figure 2 ). There were no differences between patients with and without district nursing. However, female patients scored significantly lower on this index than male 


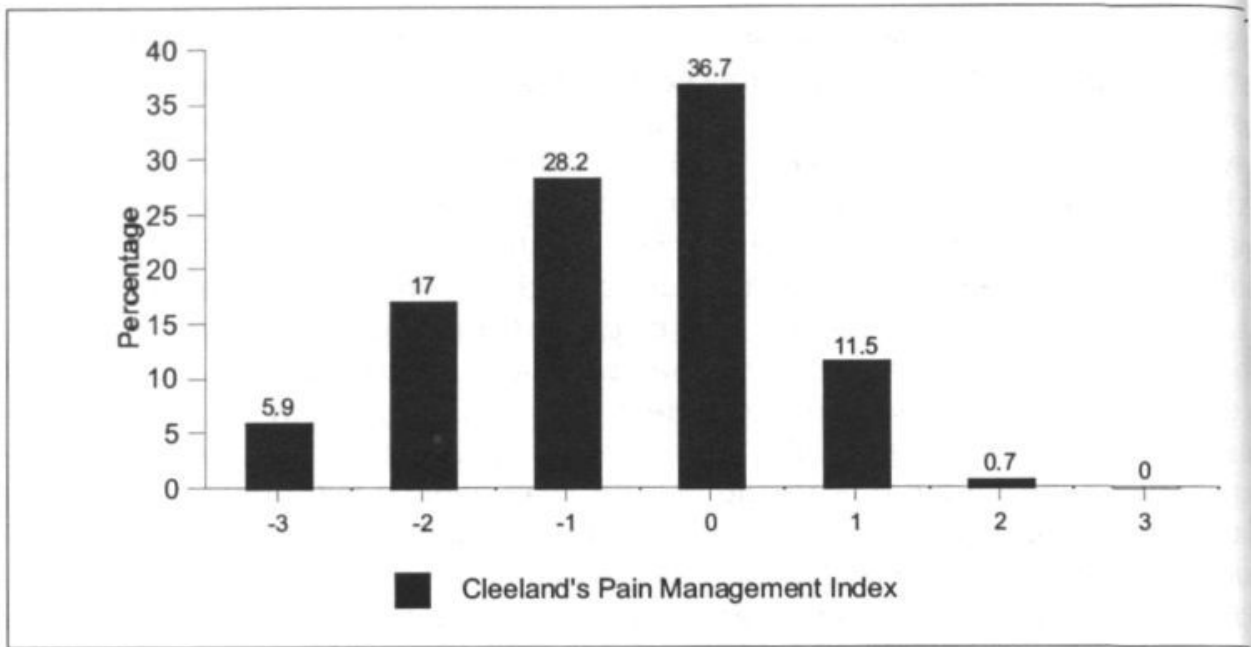

Figure 2. Percentage of inadequate treated patients measured by Cleeland's Pain Management Index $(N=305)$

patients $(56 \%$ versus $43 \%, \mathrm{p}<0.05)$. "Cleeland's Pain Management Index" scor were not associated significantly with patient education and pain duration.

Finally, the "Amsterdam Pain Management Index" was assessed in 291 patie (93\%). In all, $59.8 \%(\mathrm{~N}=174)$ received less than optimal analgesic treatment, in cluding $27.5 \%(\mathrm{~N}=80)$ who were prescribed somewhat inadequate pain treatment (score of -1$), 24.7 \%(\mathrm{~N}=72)$ who were more seriously undertreated (score of -2$)$, and $7.6 \%(\mathrm{~N}=22)$ who were very seriously undertreated (score of and -4 ) (Figure 3). There were no differences between patients with and witho district nursing. There was a trend toward female patients receiving less than 0 timal potency analgesics more frequently than male patients (55\% versus $44 \%$, $\mathrm{p}=0.06$ ). This index was not associated significantly with patient education or pain duration.

The "Amsterdam Pain Management Index" correlated $r=0.51(p<0.001)$ with "Cleeland's Pain Management Index." The percentage of agreement between "Cleeland's Pain Management Index" and the "Amsterdam Pain Management dex," assessed by dichotomizing the measures and uncorrected for change, wa. $66.0 \%$. Cohen's kappa, a measure correcting for change was 0.32 , which can b considered as fair agreement. It can be concluded that there is a substantial dif ference between the measures.

Overall, four different types of outcome measures were assessed to describe the outcome of pain treatment. Depending on which measure is chosen to describe the practice of pain treatment, $31.4-59.8 \%$ of the patients were classifie as being treated inadequately. Consequently, when evaluating the adequacy of pain treatment, one cannot substitute one measure for another. All measures seem to describe different aspects. Whatever outcome measure was used, the level of pain treatment was suboptimal for many patients. 


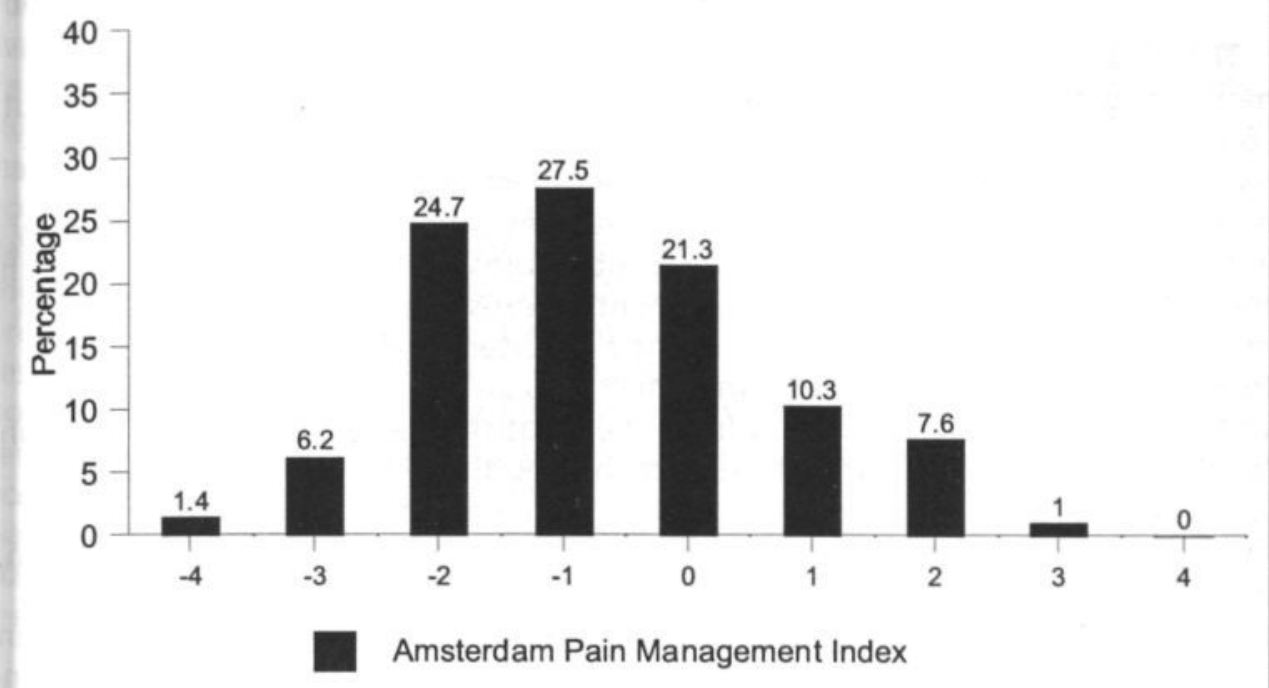

igure 3. Percentage of inadequate treated patients measured by the Amsterdam Pain Management Index $(N=291)$

\section{Jiscussion}

The management of pain in cancer patients is a complex process. Many factors fluence the practice of pain treatment. Most studies focus on only one or a few actors which play a role in pain treatment in cancer patients. The aim of the resent study was to examine in a comprehensive way the current practice in reating chronic cancer pain patients in a cancer hospital in the Netherlands. To jive an overview of the practice of pain treatment, a comprehensive picture of he factors involved in pain treatment needs to be described. In this study, we lescribe the practice of pain treatment by taking into account the divergent facors responsible for adequate pain treatment that are described in the literature. o evaluate these factors, Donabedian's structure-process-outcome framework in quality of care was used and transformed to pain treatment. In this structurerocess-outcome pain framework, divergent components related to pain were lefined. Structural resources refer to all conditions and facilities that should be Ivailable in the setting in which the pain treatment is provided. Process compoients refer to the interaction between the patient and the health care provider, and relate to actions and the manner in which the pain treatment is delivered. Filally, outcome measures refer to the outcome of treatment. The newly develsped pain framework is intended to be utilized to monitor the practice and quality of pain treatment as well as to re-evaluate changes over time. 


\section{Outcome}

The most essential component to evaluate the practice of pain treatment is monitoring the effect of pain treatment. Therefore, one should first focus on out. come measures. However, there is no consensus about the most appropriate measure to assess the adequacy of pain treatment in cancer patients. Consequently, four frequently used outcome measures were evaluated simultaneously in this study. Besides patients' pain intensity scores, and patient satisfaction with the pain treatment, two pain management indexes were used in which the pain medication is compared with the patient's reported level of pain. Although all four outcome measures describe the effect of pain treatment, these measures showed different results. When using patient satisfaction as an outcome measure for the quality of pain treatment, results showed that $31.4 \%$ were not satisfied with the pain treatment. Results regarding pain intensity showed that of all patients, 32.6\% rated their "Present Pain Intensity," and 59.1\% their "Average Pain Intensity" as " 5 " or more, which is considered as inadequate pain treatment. Although pain intensity ratings are used worldwide to evaluate the practice of pain treatment, ${ }^{44-48}$ it is not clear whether these studies can be compared with one another, especially when different time frames are used. Our results, relating to the high percentage of patient satisfaction with the pain treatment, are in accordance with other studies showing satisfaction with the pain treatment in $68-92 \%$ of the cases. ${ }^{37-39}$ However, these results should be interpreted with caution, as patients are sometimes satisfied even when they are in severe pain. In several studies, the correlation between patient satisfaction and pain intensity was very low to low. ${ }^{37-39,49} \mathrm{In}$ a study evaluating measures to assess the adequacy of pain treatment, the patient satisfaction scale showed low levels of reliability and validity..$^{50}$

In addition to patient-oriented outcome measures, two professionally-oriented outcome measures were used, in which both drug choice and patients' pain intensity were included. According to "Cleeland's Pain Management Index" and the "Amsterdam Pain management Index," $51.1 \%$ and $59.8 \%$ of the patients received less than optimal analgesics, respectively. Studies using the same type of index showed that patients receiving inadequate pain treatment ranged between $38-80 \% .^{6-11,50}$ In our study, results of the four outcome measures assessing inadequacy of pain treatment ranged from $31.4-59.8 \%$. Although research has shown that these measures evaluate different aspects of pain treatment, whatever outcome measure we used, the level of pain treatment was suboptimal for many patients. Consequently, it can be concluded that the practice of pain treatment needs to be further improved.

\section{Structure}

The question is: what structural resources are responsible for this suboptimal pain treatment? Results regarding structural resources have shown that almost all conditions as outlined by pain guidelines are partly or fully met in the Netherlands Cancer Institute/Antoni van Leeuwenhoek Hospital. Pain guidelines and protocols are available and used in daily practice. Opioids are available and the use of morphine has increased during the last years in the Netherlands. ${ }^{51}$ Tools to 
assess pain are available and receive attention nationwide. Furthermore, pain education materials are freely available. In the hospital, there is a pain team available consisting of various disciplines. The only structural resource that may be suboptimal is the limited training in pain treatment for physicians and nurses. Nurses are all registered nurses who completed an oncology training, including at least four hours of pain education. The level of pain education for physicians, however, is unknown. Deficits in pain education have been described as a major barrier to effective cancer pain treatment, 52,53 as many research studies have shown inadequacies in the education of health care professionals. ${ }^{54-58}$ In the present study, however, nurses' and physicians' pain knowledge was not assessed. It can be concluded that the structural resources evaluated in this study do not give a complete picture of all relevant aspects, and should be further extended. In a future study, more attention should be paid to aspects such as polices and procedures related to new technologies and medication delivery (e.g., patient controlled analgesia, epidural analgesia). However, with the exception of staff education, it is unlikely that structural resources are the major cause of the less than optimal level of pain treatment in this study.

\section{Process}

A second group of components that might cause a suboptimal level of pain treatment relates to process components. Not only the extent to which analgesics are prescribed is important, but also the amount of analgesics. In this study, it was found that $88.2 \%$ of the patients received analgesics, $36.4 \%$ of the patients received "strong" opioids, and $10.9 \%$ of patients received parenteral "strong" opioids. Considering the high percentage of patients with substantial pain, one might wonder why "strong" opioids were not prescribed to a higher percentage of patients. The literature is not clear on this point, as there is no consensus about the percentage of advanced cancer patients that should be treated with opioids for their pain. Although several studies have shown a large variance in the use of "strong" opioids, the majority of these studies showed higher percentages of patients using these opioids than our study. ${ }^{44-48,59,60}$ Besides the use of opioids, it is advised to use nonopioids concomitant with opioids. The present study showed that nonopioids were not used concomitantly with opioids in $17 \%$ of the prescriptions.

In addition to the percentage of patients being prescribed analgesics, the dosing of analgesics was studied. Each dose of opioids and nonopioids was converted to mg equianalgesic to oral morphine. Comparisons of opioid doses across studies must be interpreted with caution, because of the difference in patient selection and dose reporting methods. In the literature, results showed a surprising variation in mean daily dose of opioids to control cancer pain; ${ }^{61}$ compared to those results, the mean daily dose of oral morphine in our study seems to be low. Due to a lack of studies comparing opioids in different settings, more studies are required to provide guidelines for the use of opioids in cancer pain populations. Furthermore, a lack of comparable studies regarding the equianalgesic efficacy of nonopioids in cancer pain results in rough approximations. These results should be interpreted with caution and more research in this field is necessary. 
Because there are very limited indications for "as needed" dosing, the use of analgesics on a regular schedule is usually recommended. $5,15,62,63$ In this study, we found that $23.1 \%$ of the patients received analgesics only as needed. It can be concluded that the group of patients receiving pain medication only as needed seems to be high and needs further scrutiny. Side effects are often a problem for cancer pain patients, with constipation (21.3\%), drowsiness (15.9\%), and nause and vomiting $(6.9 \%)$ being the most prevalent. In addition to analgesics, adjuvant drugs are suggested for consideration at each step of the analgesic ladder." It should be noted that, in the medical records, it is almost never stated whether this type of medication is prescribed as an adjuvant analgesic drug or for other reasons, e.g., anxiety, depression, sleeping problems. In the present study, hypnotics and anxiolytics were prescribed most frequently in $43 \%$ and $19.2 \%$, respectively. In total $56.5 \%$ of the patients received one or more adjuvant analge sic drugs.

Failure to use a pain assessment tool is often reported as one of the most important barriers to adequate pain treatment. ${ }^{1,18,64}$ Studies have shown that pain assessment by nurses and physicians is often lacking or inadequate, ${ }^{65-67}$ or that a significant difference exists between nurses' or physician's observations and patients' self-reports of pain. ${ }^{68}$ Although research has indicated that nurses often do not use a systematic approach to assess patients' pain, systematic assessment of the patients' pain is the foundation upon which all pain-related interventions should be built. ${ }^{1,3,69}$ In our study, pain was assessed in $89.9 \%$ on a daily basis.

Because patients may have difficulty in understanding and remembering the details of the pain treatment, they need to be given pain education by means of verbal and written information. Although the importance of patient education is often stated, results regarding the use of written pain education for patients are hardly available. ${ }^{70}$ In this study, it was found that only a small group of patients $(15.8 \%)$ had received written pain information. Despite the fact that pain brochures are freely available, health care providers do not distribute them to their patients; two-thirds of the patients reported to be well or very well informed, even though they did not receive written pain information. This indicates that many patients do not expect to receive written pain information.

With regard to patients' overall pain knowledge, results show that patients are lacking knowledge in some ways. The results of this study concur with other studies using the same or a comparable pain knowledge questionnaire. ${ }^{23,31,71}$ Mis conceptions and concerns have an impact on the extent to which patients discus: their pain complaints with their health care providers, and the extent to which patients are compliant with their pain treatment. ${ }^{23,31}$ In the literature, it is often stated that lack of pain knowledge is one of the most important barriers to achieving improved pain management. Only by reducing patient's fear of addiction, drug tolerance, taking too much medicines, etc., will pain management be improved. Our finding that patients lack sufficient pain knowledge, especially with regard to "tolerance," "being overmedicated," and "addiction," suggests the need for more extensive verbal and written pain information. In order to improve patients' pain knowledge, health care providers need to be trained to provide pain information to patients. Tailored pain information should be given to each patient and their pain knowledge should be evaluated regularly. Pain educa tion of the public, especially to patients' relatives, is also needed. At the same time, patients should be instructed to ask for more extensive pain information 
Table 6. Summary of the results in this study by using the pain framework to evaluate the practice of pain treatment

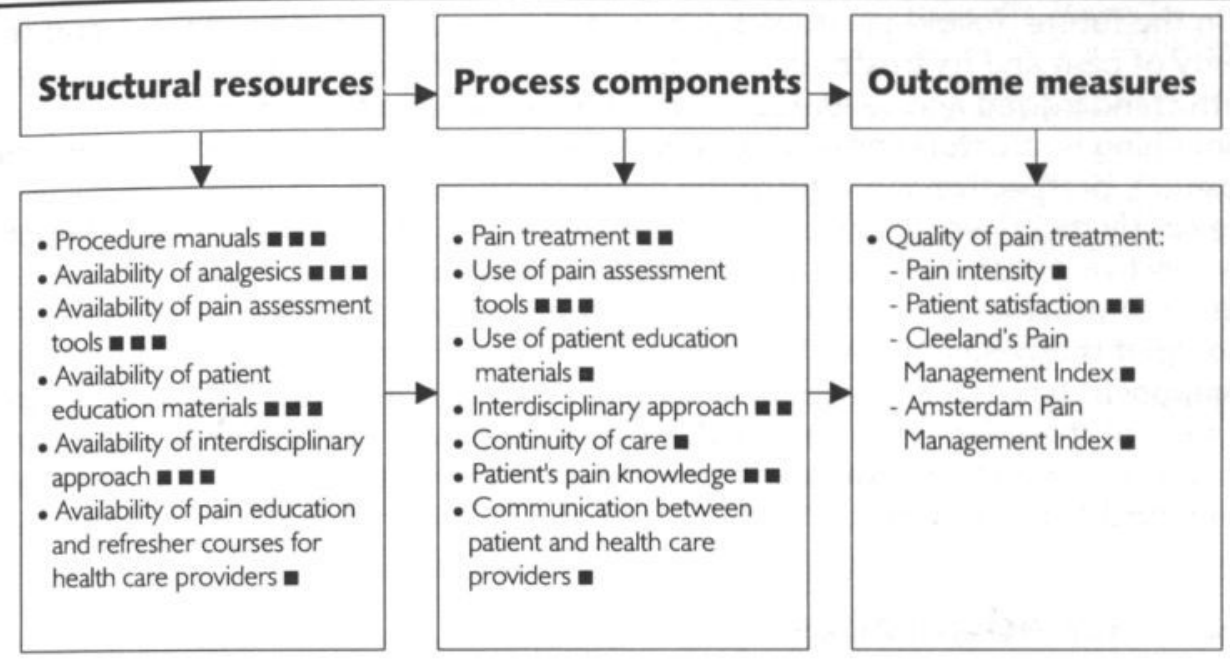

- Poor quality

- Reasonable quality

-1. Good quality

themselves. Empowering the patients will enable them be better manage their own pain.

For patients with complex pain problems, an interdisciplinary approach is strongly recommended. Results showed that a pain physician was consulted in $31 \%$ of the cases. However, in the hospital there is no protocol describing when a pain physician should be consulted. Furthermore, although there are regular clinical conferences in which different disciplines discuss patients' pain problems, pain physicians do not participate on a regular basis.

Discharge from the hospital necessitates effective continuity of care. Although both the relationship between the physician, the patient, and the general practitioner as well as the relationship between the nurse, the patient, and the district nurse are involved in continuity of care, in this study continuity of care was only viewed from a nursing perspective. Results showed that approximately one-third of the district nurses in the community had received information about patients' pain complaints and pain treatment. Consequently, district nurses are often not prepared to care for the patient in pain. It can be concluded that continuity of care with regard to pain needs to be further improved.

Table 6 presents an overview of the various factors relevant to the practice of pain treatment which are given ratings consisting of poor, reasonable, and good quality. Based of this subjective summary, it can be concluded that the current treatment of pain provides only partial relief and is not adequate for a substantial group of pain patients. Improvement in pain treatment requires a commitment by the entire organization. To improve the practice of pain treatment, health care providers need to further address the issue of how to choose appropriate pain treatment, applying it in the right dose and frequency, communicating with the 
patients about their pain, educating patients about the use of analgesics to over come misconceptions, communicating with other health care providers in order to achieve continuity of care, and being educated themselves.

In the future, follow-up studies are needed to document the incidence and se verity of pain and its treatment throughout the course of the disease trajectory with standardized and validated measurement tools. Furthermore, whether something is structure, process, or outcome is not static, but may depend on the position, perspective and time of the person evaluating the criteria. What was previously described as structure items may become process items in a different perspective. Future research is also needed to evaluate the usefulness of the structure-process-outcome pain framework as described in the present study. Al. though it is obvious that each factor describing a structural resource or process component has its own impact on the quality of pain treatment, the importance of each of these factors on the quality of pain treatment is unknown. The extent to which structural resources and process components are interrelated also need to be further investigated.

\section{Acknowledgments}

This study was supported by a grant from the Dutch Cancer Society (Grant 92-469). The authors thank all patients for their cooperation and Anneke van Buuren, Karin van der Heijden, Gerleen Leenhouts, Marie-Jose Litjens, Simone Loonstra, and Linda Zandbelt for recruiting and interviewing the patients. Further, we extend special thanks to the nursing departments of the Netherlands Cancer Institute/Antoni van Leeuwenhoek Hospital, and the district nurses who participated in the study for their invaluable contribution. 


\section{References}

1. AHCPR. Management of cancer pain. Clinical Practice Guideline. Rockville, MD: Agency for Health Care Policy and Research, Public Health Service, U.S. Department of Health and Human Services, 1994.

2. Nederlanse Vereniging ter Bestudering van Pijn. Pijn en pijnbehandeling bij de patient met kanker. Groningen: Nederlandse Vereniging ter Bestudering van Pijn, 1990.

3. American Pain Society. Principles of analgesic use in the treatment of acute pain and chronic cancer pain: a concise guide to medical practice. Skokie, IL: American Pain Society, 1992.

4. Spross JA, McGuire DB, Schmitt RM. Oncology Nursing Society Position Paper on Cancer Pain. Part I. Oncology Nursing Forum, 1990;17:595-614.

5. World Health Organization. Cancer pain relief. Geneva: World Health Organization, 1986.

6. Zelman DC, Cleeland CS, Howland EW. Factors in appropriate pharmacological management of cancer pain: a cross-institutional investigation. Pain (supplement), 1987; S136

7. Cleeland CS, Gonin R, Hatfield AK, et al. Pain and its treatment in outpatients with metastatic cancer. New England Journal of Medicine, 1994;330:592-596.

8. Dorrepaal KL. Pijn bij patienten met kanker [In Dutch]. Amsterdam: Vrije Universiteit, 1989.

9. Ward SE, Hernandez L. Patient-related barriers to management of cancer pain in Puerto Rico. Pain, 1994;58:233-238.

10. Lin CC, Ward SE. Patient-related barriers to cancer pain management in Taiwan. Cancer Nursing, 1995; 18:16-22.

11. Larue F, Colleau SM, Brasseur L, et al. Multicentre study of cancer pain and its treatment in France. British Medical Journal, 1995;310:1034-1037.

12. Donabedian A. Institutional and professional responsibilities in quality assurance. Quality Assurance in Health Care, 1989;1:3-11.

13. Goldstone, L. A very pe'qa'liar practice. Nursing Times, 1991;87:41-43.

14. Koch T. A review of nursing quality assurance. Journal of Advanced Nursing, 1992;17:785-794.

15. Foley KM. The treatment of cancer pain. New England Journal of Medicine, 1985;313:84-95.

16. Portenoy RK, Foley KM. Management of cancer pain. In: Holland JC, Rowland JH, eds. Handbook of Psychooncology. Psychological care of the patient with cancer. New York: Oxford, 1989:

17. Ashburn MA, Lipman AG. Management of pain in the cancer patient. Anesthesia \& Analgesia, 1993;76:402-416.

18. American Pain Society Quality of Care Committee. Quality improvement guidelines for the treatment of acute pain and cancer pain. JAMA, 1995;274:1874-1880.

19. Ferrell BR, Rhiner M, Ferrell BA. Development and implementation of a pain education program. Cancer, 1993;72:3426-3432.

20. Max M. American Pain Society quality assurance standards for relief of acute pain and cancer pain. In: Bond M, Charlton J, Woolf C, eds. Amsterdam: Elsevier, 1991:186-189.

21. Ferrell BR, Rivera LM. Cancer pain education for patients. Seminars in Oncology Nursing, 1997;13:42-48.

22. Bookbinder M, Kiss M, Coyle N, Brown MH, Gianella A, Thaler H. Improving pain management practices. In: McGuire DB, Yarbro CH, Ferrell BR, eds. Cancer pain management. 2nd ed. ed. London: Jones and Bartlett Publishers International, 1995: 321-361.

23. Ward SE, Goldberg N, Miller-McCauley V, et al. Patient-related barriers to management of cancer pain. Pain, 1993;52:319-324.

24. De Wit R, Van Dam F, Loonstra S, et al. The Amsterdam Pain Management Index compared to eight frequently used outcome measures to evaluate the adequacy of pain treatment in cancer patients in chronic pain. European Journal of Pain (provisionally accepted).

25. Serlin RC, Mendoza TR, Nakamura Y, et al. When is cancer pain mild, moderate or severe? grading pain severity by its interference with function. Pain, 1995;61:277-284.

26. Kitson A., Harvey G, Hyndman S, Yerrell P. A comparison of expert- and practitioner-derived criteria for post-operative pain management, Journal of Advanced Nursing, 1993;18:218-232.

27. De Wit R, Van Dam F, Zandbelt L, et al. A Pain Education Program for chronic cancer patients: follow-up results from a randomized controlled trial. Pain, 1997;73:55-69.

28. Aaronson NK, Ahmedzai S, Bergman B, et al. The European organization for research and treatment of cancer QLQ-C30: a quality-of-life instrument for use in international clinical trials in oncology. Journal of the National Cancer Institute, 1993;85:365-376.

29. Van der Kuy Ae. Farmacotherapeutisch kompas 1995: medisch farmaceutische voorlichting. Amstelveen: Centrale Medisch Pharmaceutische Commissie van de Ziekenfondsraad, 1995. 
30. Overweg-van Kints J. Pijnbestrijding bij kankerpatienten. In: Post Academisch Onderwijs Geneeskunde, eds. De behandeling en begeleiding van de patient met kanker. Amsterdam: Pos Academisch Onderwijs Geneeskunde, 1987.

31. Ferrell BR, Ferrell BA, Ahn C, et al. Pain management for elderly patients with cancer at home. Cancer, 1994;74:2139-2146.

32. Ferrell BR, Rhiner MR, Rivera LM. Development and evaluation of the family pain questionnaire Journal of Psychosocial Oncology, 1993;10:21-35.

33. Kremer $\mathrm{E}$, Atkinson JH, Jr. Pain measurement: construct validity of the affective dimension of th McGill Pain Questionnaire with chronic benign pain patients. Pain, 1981;11:93-100.

34. Jensen MP, Karoly P, Braver S. The measurement of clinical pain intensity: a comparison of six methods. Pain, 1986;27:117-126.

35. McGuire DB. Measuring pain. In: Frank-Stromborg M, eds. Instruments for clinical nursing. Norwalk, СT: Appleton and Lange, 1988:333-356.

36. Syrjala KL. The measurement of pain. In: McGuire DB, Yarbro CH, eds. Cancer pain management Philadelphia: Saunders, 1987:133-150.

37. Ward SE, Gordon D. Application of the American Pain Society quality assurance standards. Pain 1994;56:299-306.

38. Miaskowski C, Nichols R, Brody R, et al. Assessment of patient satisfaction utilizing the America Pain Society's quality assurance standards on acute and cancer-related pain. Journal of Pain ant Symptom Management, 1994;9:5-11.

39. Zhukovsky DS, Gorowski E, Hausdorff J, et al. Unmet analgesic needs in cancer patients. Journd of Pain and Symptom Management, 1995;10:113-119.

40. Dietrick-Gallagher $M$, Polomano $R$, Carrick L. Pain as a quality management initiative. Journal of Nursing Care Quality, 1994;9:30-42.

41. Haviley C, Gagnon J, MacLean R, et al. Pharmacological management of cancer pain. A guide fo the health care professional. Cancer Nursing, 1992;15:331-346.

42. Foley KM. Pharmacologic approaches to cancer pain management. In: Fields HL, Dubner F, Cervero F, eds. Advances in pain research and therapy. New York: Raven Press, Ltd. 1985:629-651.

43. De Wit R, van Dam FSAM. Verpleegkundige pijnmeting bij kankerpatienten: een interventiestudie. Verpleegkunde, 1991/92;2:68-75.

44. Grond S, Zech D, Schug SA, et al. Validation of World Health Organization guidelines for cance pain relief during the last days and hours of life. Journal of Pain and Symptom Management, 1991;6:411-422.

45. Grond S, Zech D, Lynch J, et al. Validation of World Health Organization guidelines for pain relief in head and neck cancer. A prospective study. Annals of Otology, Rhinology \& Laryngology, 1993;102:342-348.

46. Ventafridda V, Tamburini M, Caraceni A, et al. A validation study of the WHO method for cance pain relief. Cancer, 1987;59:850-856.

47. Walker VA, Hoskin PJ, Hanks GW, et al. Evaluation of WHO analgesic guidelines for cancer pain in a hospital-based palliative care unit. Journal of Pain and Symptom Management, 1988;3:145-149.

48. Zech DF, Grond S, Lynch J, et al. Validation of World Health Organization guidelines for cancer pain relief: a 10-year prospective study. Pain, 1995;63:65-76.

49. McCracken LM, Klock PA, Mingay DJ, Asbury JK, Sinclair DM. Assessment of satisfaction with treatment for chronic pain. Journal of Pain and Symptom Management, 1997;14:292-299.

50. De Wit R, Van Dam F, Huijer Abu-Saad H, et al. Adequacy of pain treatment: an empirical comparison of common measures to evaluate cancer pain treatment. Journal of Clinical Oncology, 1999;17:1280-1287.

51. Joranson DE. Availability of opioids for cancer pain: recent trends, assessment of system barrier new world health organization guidelines, and the risk of diversion. Journal of Pain and Symptom Management, 1993;8:353-360.

52. Bonica JJ. Treatment of cancer pain: current status and future needs. In: Fields HL, Dubner F, Cervero F, eds. Advances in pain research and therapy. New York: Raven Press, Ltd. 1985:589-616.

53. Max MB. Improving outcomes of analgesic treatment: is education enough? Annals of Internal Medicine, 1990;113:885-889.

54. McCaffery M, Ferrell B, O'Neil Page E, et al. Nurses' knowledge of opioid analgesic drugs and psychological dependence. Cancer Nursing, 1990;13:21-27.

55. Hamilton J, Edgar L. A survey examining nurses' knowledge of pain control. Journal of Pain and Symptom Management, 1992;7:18-26. 
56. McCaffery M, Ferrell B. How would you respond to these patients in pain? Nursing, 1991;21:34-37.

57. Von Roenn JH, Cleeland CS, Gonin R, et al. Physician attitudes and practice in cancer pain management. a survey from the eastern cooperative oncology group. Annals of Internal Medicine, 1993;119:121-126.

58. Vortherms R, Ryan P, Ward S. Knowledge of, attitudes toward, and barriers to pharmacologic management of cancer pain in a statewide random sample of nurses. Research in Nursing and Health, 1992;15:459-466.

59. Coyle N, Adelhardt J, Foley KM, et al. Character of terminal illness in the advanced cancer patient: pain and other symptoms during the last four weeks of life. Journal of Pain and Symptom Management, 1990;5:83-93.

60. Takeda F. Results of field-testing in Japan of the WHO draft interim guidelines on relief of cancer pain. The Pain Clinic, 1986;1:83-89.

61. Boisvert M, Cohen SR. Opioid use in advanced malignant disease: why do different centers use vastly different doses? A plea for standardized reporting. Journal of Pain and Symptom Management, 1995;10:632-638.

62. McGuire DB, Barbour L, Boxler J, et al. Fixed-interval versus as-needed analgesics in cancer outpatients. Journal of Pain and Symptom Management, 1987;2:199-205.

63. Portenoy RK, Coyle N. Controversies in the long-term management of analgesic therapy in patients with advanced cancer. Journal of Pain and Symptom Management, 1990;5:307-319.

64. Francke, AL. Continuing pain education: the impact on nursing. Maastricht: University of Maastrcht (Thesis), 1996.

65. Camp LD, O'Sullivan PS. Comparison of medical, surgical and oncology patients' descriptions of pain and nurses' documentation of pain assessments. Journal of Advanced Nursing, 1987; 12:593-598.

66. Donovan MI, Dillon P. Incidence and characteristics of pain in a sample of hospitalized cancer patients. Cancer Nursing, 1987;10:85-92.

67. McMillan SC, Tittle M. A descriptive study of the management of pain and pain-related side effects in a cancer center and a hospice. Hospice Journal, 1995;10:89-107.

68. Teske K, Daut RL, Cleeland CS. Relationships between nurses' observations and patients' self-reports of pain. Pain, 1983;16:289-296.

69. Miaskowski C, Jacox A, Hester NO, et al. Interdisciplinary guidelines for the management of acute pain: implications for quality improvement. Journal of Nursing Care Quality, 1992;7:1-6.

70. Arthur VA. Written patient information: a review of the literature. Journal of Advanced Nursing, 1995;21:1081-1086.

71. Dalton JA. Education for pain management: a pilot study. Patient Education and Counseling, 1987:9:155-165. 


\section{Chapter 3}

\section{A Pain Education Program for chronic cancer pain patients: Follow-up results from a randomized controlled trial}

De Wit, R., Van Dam, F., Zandbelt, L., Van Buuren, A., Van der Heijden, K., Leenhouts, G. and Loonstra, S.

A Pain Education Program for chronic cancer patients: follow-up results from a randomized controlled trial.

Pain, 1997:73;55-69. 


\section{Introduction}

Although adequate methods of pain relief for most cancer patients are now available, a number of studies demonstrate that these methods are not used to their fullest, leading to inadequate pain relief in large numbers of patients..$^{1-5} \mathrm{Ef}$ forts to improve pain management in cancer patients have focused mainly on enhancing the expertise of health care providers. ${ }^{6-9}$ Less attention has been paid to the role of the patients themselves in managing their own pain, despite the fact that cancer pain is increasingly being managed on an outpatient basis. Patients often hesitate to use medication, wait too long before asking for pain relief, and have difficulty in reporting and communicating about pain..$^{10-12}$ Furthermore, lack of knowledge, fear of drug tolerance, concerns about side effects, and fear of drug addiction are reported as causes for this lack of compliance. ${ }^{10,12-14}$ To address these problems, greater emphasis needs to be placed on educating patients and stimulating them to participate actively in their own pain treatment program. ${ }^{15}$

Although the importance of patient education and active involvement of patients in pain treatment is emphasized by organizations such as the World Health Organization ${ }^{9}$ and the American Pain Society, ${ }^{7}$ few studies have considered the important role of the patients themselves in the process of relieving pain. Rimer and associates" studied the effect of a patient education intervention consisting of nurse counseling and printed materials. Results showed improved levels of compliance, a decrease in patients' concerns about addiction and tolerance, and a trend in pain relief." A nursing study in 30 cancer patients who were given instruction on pain perception and pain management methods such as distraction, relaxation, and massage, showed increased knowledge and use of distraction but did not lead to greater relief of pain. ${ }^{16}$ Finally, a structured pain nursing education program in elderly patients with cancer was conducted, consisting of verbal instruction, a written patient education booklet, and an audio cassette. This program included the basic principles of pain relief, pharmacologic interventions, and non-drug interventions to relieve pain. ${ }^{14,17}$ Results showed an improvement in knowledge and attitudes regarding pain. The use of drugs as well as the use of non-pharmacological pain treatments increased.

From these studies, it can be concluded that educational interventions conducted by nurses can be effective. The educational interventions provided in these studies were the same for all patients, regardless of the cause of pain, pain treatment, and the patient's personal situation. A problem in using a structured and standardized education program is that, possibly, parts of the intervention are not relevant for each patient. Although all of the above-mentioned studies showed some effectiveness, a tailored pain education program aimed at relieving pain in cancer patients should be more efficient. ${ }^{18}$

In this study, a Pain Education Program, tailored to the needs of the individual patient, was developed and evaluated in chronic pain patients. The Pain Education Program consists of enhancing patients' knowledge about pain and pain treatment, instructing patients in how to register their pain intensity in the home setting, and stimulating patients' help-seeking behavior. Nurses were chosen as patient educators as they spend most time with the patient, and play an important role in assessing pain, observing symptoms and reactions, carrying out pain relief methods, and educating patients. ${ }^{19}$ In this paper, we give a description of 
the Pain Education Program, explain how the Pain Education Program was carried out in practice, discuss the role of the nurse as pain counselor, and describe the use of the Pain Education Program by patients and its effect on patient's pain knowledge and pain itself. It was hypothesized that patients who had received the Pain Education Program would have more knowledge about their pain and pain treatment, resulting in better application of pain relief methods, and consequently experience less pain than patients who were not enrolled in the Pain Education Program.

\section{Methods}

\section{Patients}

The study was carried out during a twenty-month period in the Antoni van Leeuwenhoek Hospital, a specialized cancer hospital in Amsterdam, the Netherlands. The following inclusion and exclusion criteria were used: 1) pain related to cancer, cancer therapy, or illness; 2) a pain duration of at least one month; 3) a life expectancy of at least three months (assessed by physicians); 4) able to read and speak Dutch; 5) accessible by telephone; and 6) not residing in nursing home or retirement home.

\section{Study design}

The Pain Education Program was evaluated by means of a prospective, randomized longitudinal study utilizing a 'pretest-posttest experimental design' (Figure 1). After admission to the hospital, patients were approached to participate in the study. At baseline, data were collected to describe demographic, medical and pain characteristics, as well as to determine what parts of the Pain Education Program should be provided. Depending on the patients' ability to perform daily activities, as well as on housing and living conditions, district nursing is offered almost at nominal cost for patients in the Netherlands. Because of differences in health status, patients with district nursing may experience more complex pain complaints compared with patients who do not receive district nursing. Therefore, patients who would receive district nursing at home and patients who would not receive district nursing were studied separately. Both patient groups were randomly assigned to a control or an intervention group, after stratifying for three variables: gender (male/female), age ( $<60$ years $/ \geq 60$ years), and metastatic sites (yes/no/unknown).

Summarizing, four study groups were distinguished: 1) a control group without district nursing; 2) an intervention group without district nursing; 3) a control group with district nursing; and 4) an intervention group with district nursing. All patients were followed up by telephone at 2 weeks postdischarge, 4 weeks postdischarge, and 8 weeks postdischarge. 


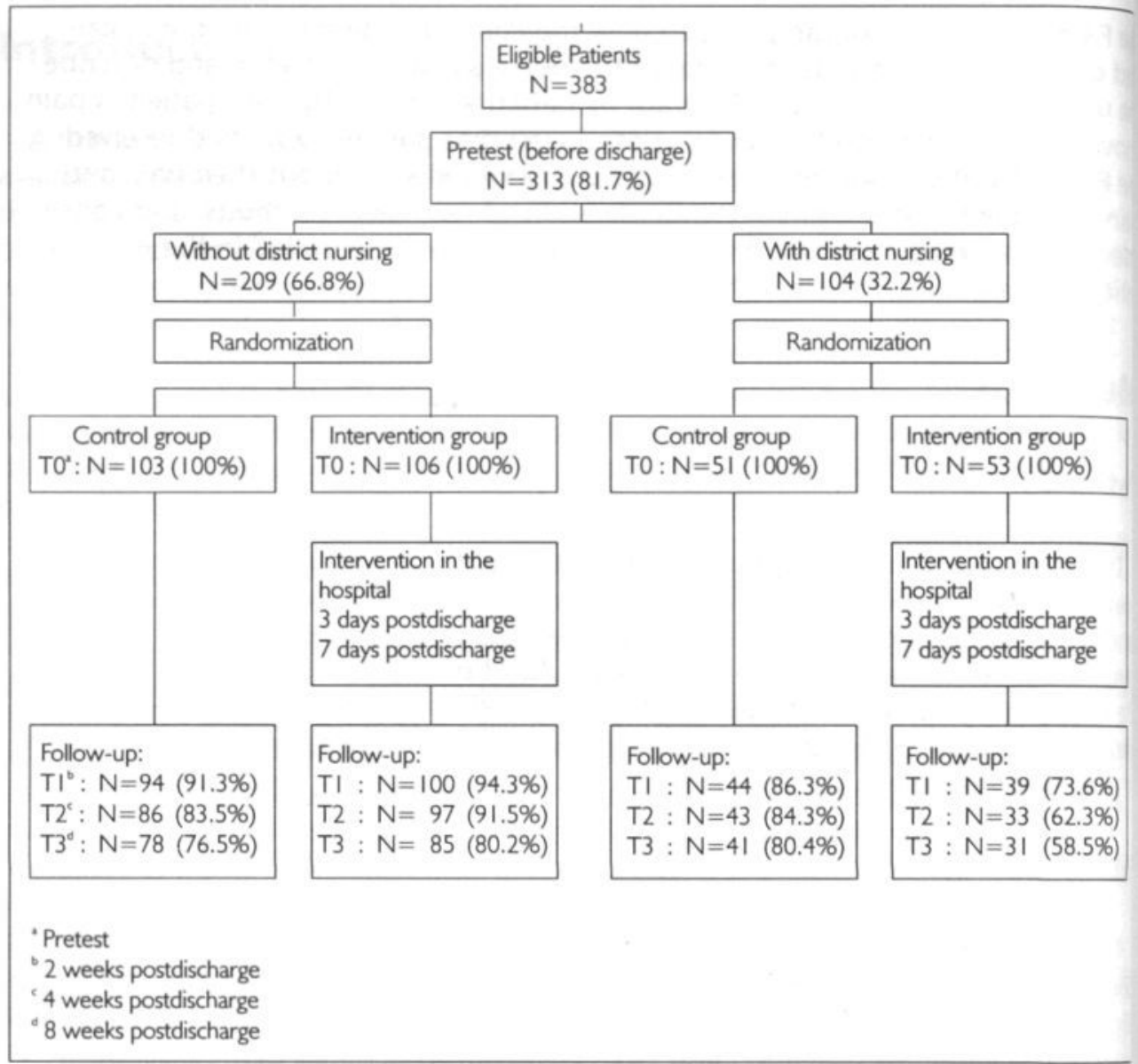

Figure 1. Design summary

\section{The Pain Education Program}

The Pain Education Program was developed on the basis of the literature, exist ing materials, and input of pain experts..$^{7-9,20,21}$ Three nurses were specially trained as pain counselors to educate and instruct patients about pain and pain treatment. A summary of the topics covered by the Pain Education Program is given it Table 1. The Pain Education Program consists of three components:

1) Enhancing patients' knowledge about pain and pain treatment. Twentyone pain topics were identified which are considered to be part of the patients' basic pain knowledge. Prior to the intervention, the pain topics in which patients were not adequately informed were determined by a nurse by means of a checklist. A patient was instructed about a specific pain topic only when that topic was assessed as applicable to the patient, and only when the patient's knowledge about pain and pain treatment was as. sessed as insufficient. Patients were educated about all pain topics that were assessed by the nurse as insufficient. This tailored information was 
I Information and instruction about pain and pain management

Definition of pain

Causes of pain

Pharmacological pain treatment:

- name, doses, schedule, and mechanism of the analgesics

- purpose, procedure, and duration of the analgesics

Purpose, procedure, and duration of other pain management techniques used

(e.g. TENS, nerve block)

Name, doses, schedule, and mechanism of the co-analgesia prescribed

Experienced side-effects related to pain management (e.g. sedation,

constipation, tolerance, sleepiness, nausea and vomiting) and how to deal

with this

Myths and misconceptions related to pain (e.g. addiction, drug dependence, tolerance, and the use of medication around the clock)

Effect of non-adherence

Interference of pain aspects with e.g. mobility, sleep, appetite, interpersonal relationships, and how to deal with this

Use of non-pharmacological pain management techniques (e.g. cold, heat, massage, relaxation)

\section{Self-recording of pain in pain diary}

\section{Help-seeking behavior with regard to pain and pain management}

What actions to undertake if pain is not relieved adequately at home

Communication with health care providers with regard to pain

provided in a one-to-one setting lasting between 30 and 60 minutes. For instance, when a patient was prescribed morphine and was afraid of becoming addicted, information was given concerning addiction in relation to pain treatment. Because patients are often unable to retain all information provided, the oral instruction was audio taped on a cassette which could be listened to at home, alone or with family. Further, the verbal instruction was accompanied by a pain brochure which was especially designed and pretested for this study. ${ }^{22}$ The pain brochure consisted of two parts: 1) a section with general information aimed at all cancer pain patients with chronic pain, describing possible causes of pain, pain control, non-adherence, misconceptions; and 2) a loose-leaf part, including nine supplementary sheets with targeted information about different cancer pain treatments. Patients only received those sheets that were applicable to them.

2) Instructing patients how to register their pain intensity. Patients were instructed how to register their Present Pain Intensity twice daily on a numeric rating scale from 0-10 in a pain diary for a period of two months. Because their Present Pain Intensity was also assessed in the hospital twice daily by nurses, patients were already used to describing their pain inten- 
sity by using a score from $0-10 .{ }^{23}$ In addition to reporting Present Pain Intensity, patients were instructed to document changes in type of pain and use of (non-)pharmacological pain treatment.

3) Stimulating patients' help-seeking behavior. Patients received information about what actions should be undertaken at home when pain relief was in sufficient. They were encouraged to contact health care providers if neces. sary, to talk about their pain experience, and to discuss what bothers them. Patients were instructed how to use simple non-pharmacological pain management techniques, such as cold, heat, relaxation, and massage

Besides the instruction provided in the hospital, patients were called at home at three and seven days postdischarge by the same nurse to determine whether the pain information and instruction provided in the hospital was fully understood by the patient, and to offer the opportunity to ask questions. These phone calls took approximately 5-15 minutes each.

Table 2. Study measures at the four different points

Measures

pretest 2 weeks 4 weeks 8 weeks postpostpostdischarge discharge discharge

Patient characteristics:

- Sociodemographic variables

- Medical variables

\section{Process variables}

(only intervention groups):

- Use of pain brochure

- Use of audiocassette

- Use of pain diary

\section{Outcome variables:}

- Pain experience (MPQ-DLV)

- Pain intensity (numeric rating scales)

- Quality of Life (EORTC QLQ-C30+3)

- Pain Knowledge Questionnaire (PKQ-DLV)
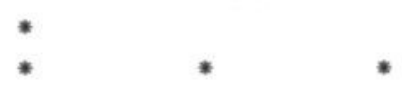

a For abbreviations: see text. 


\section{Study measures}

\section{Patient characteristics}

Sociodemographic variables including gender, age, marital status, religion, and education were collected by means of patient interviews. Medical variables including diagnosis, time since diagnosis, metastatic sites, and treatment were obtained from the medical records. Side-effects were collected through patient interviews. An overview of all measures is given in Table 2 .

\section{Process measures: application and use of the Pain Education Program}

Based on a checklist, the specially trained nurses recorded the information and instruction they had given to the experimental group patients in the hospital, and at three and seven days postdischarge. Postdischarge, patients were asked to what extent they and their family or friends had read the pain brochure, whether they had listened to the audio cassette, and whether they had read "new" information. Finally, it was checked to what extent patients filled in their pain diaries by asking them to send back the pain diary after all three follow-ups. By means of an interview, patients were asked how useful the information provided by the nurses, the pain brochure, the audio cassette, and a pain diary had been to them.

\section{Outcome measures}

Pain experience was measured by means of the Dutch Language Version of the McGill Pain Questionnaire (MPQ-DLV). The McGill Pain Questionnaire is a selfreport instrument with sensory, affective, and evaluative categories describing the multidimensional components of pain. Reliability, consistency and validity of the questionnaire have been well established and tested across many groups, including cancer patients. ${ }^{24,25}$ The reliability and validity of the Dutch version had proven to be satisfactory. ${ }^{26-29}$

Patients' Present Pain Intensity and Average Pain Intensity during the previous week were assessed by an 11-point numeric rating scale ranging from 0-10 in which 0 represents "no pain" and 10 "pain as bad as you can imagine." Numeric ratings of pain have been found easy to administer and clinically useful. The validity and reliability of these scales are well established. ${ }^{30-33}$

Pain is a component of overall quality of life, however, it has a major impact on different dimensions of quality of life. By measuring quality of life, it enables to evaluate an intervention regarding not only its effect on pain intensity but also its impact on patient's overall quality of life. Quality of life was measured by the European Organization for Research and Treatment of Cancer Core Quality of Life Questionnaire (EORTC QLQ-C30(+3)) was used. The EORTC QLQ-C30(+3) contains five functioning scales (physical functioning, role functioning, emotional functioning, cognitive functioning, and social functioning), three physical symptom scales (fatigue and malaise, nausea and vomiting, pain), several single-item symptom measures (constipation, dyspnea, difficulty with sleeping, appetite loss, 
groups, except that patients in the control group with district nursing were pre scribed less analgesics than patients in the intervention group with district nurs. ing $(\mathrm{p}<0.001)$.

Table 4. Pain characteristics at baseline

\begin{tabular}{|c|c|c|c|c|c|c|c|}
\hline & $\begin{array}{r}\text { Control } \\
\text { group } \\
\text { without } \\
\text { district } \\
\text { nursing }\end{array}$ & $\begin{array}{r}\text { Intervention } \\
\text { group } \\
\text { without } \\
\text { district } \\
\text { nursing }\end{array}$ & $\begin{array}{c}\mathrm{p}- \\
\text { value }\end{array}$ & $\begin{array}{r}\text { Control } \\
\text { group } \\
\text { with } \\
\text { district } \\
\text { nursing }\end{array}$ & $\begin{array}{r}\text { Intervention } \\
\text { group } \\
\text { with } \\
\text { district } \\
\text { nursing }\end{array}$ & $\begin{array}{c}\text { p- } \\
\text { value }\end{array}$ & Total \\
\hline Pain location $(\mathbf{N}, \boldsymbol{\%})^{*}$ & & & ns & & & ns & \\
\hline Head, face, mouth, cervical region & $24(23.3 \%)$ & $22(20.8 \%)$ & & $08(15.7 \%)$ & $12(22.6 \%)$ & & $066(21.18)$ \\
\hline Breast, thoracic region & $21(20.496)$ & $22(20.896)$ & & $12(39.29)$ & $09(17.0 \%)$ & & $064(20.480)$ \\
\hline Upper shoulder and upper limbs & $35(34.0 \%)$ & $30(28.3 \%)$ & & $10(19.6 \%)$ & $16(30.2 \%)$ & & $091(29.1 \%)$ \\
\hline Abdominal region & $38(36.99)$ & $43(40.6 \%)$ & & $21(41.2 \%)$ & $22(41.5 \%)$ & & $124(39.6 \%)$ \\
\hline Lower back, lumbar spine, sacrum & 40 (38.996) & $38(35.8 \%)$ & & $23(45.196)$ & $21(39.6 \%)$ & & $122(39.086)$ \\
\hline Lower limbs & $24(23.396)$ & $30(28.3 \%)$ & & $18(35.3 \%)$ & $13(24.5 \%)$ & & $085(06.5 \%)$ \\
\hline Anal, perineal and genital region & $04(03.996)$ & $06(05.796)$ & & $05(09.8 \%)$ & 02 (03.8\%) & & $017(05.48)$ \\
\hline Everywhere & $01(01.0 \%)$ & $01(00.9 \%)$ & & ( & - & & $002(00.196)$ \\
\hline Pain Locations per patient & 1.8 & 1.8 & ns & 1.9 & 1.8 & ns & 1.8 \\
\hline Pain duration (months) & & & ns & & & ns & \\
\hline Mean (s.d.) & $21.0(48.9)$ & $12.6(27.0)$ & & $9.9(13.5)$ & $8.2(13.6)$ & & $14.2(33.4$ \\
\hline Min-Max & 1.324 & $1-180$ & & 1.60 & 1.74 & & 1.324 \\
\hline Pain cause $(\mathrm{N}, \boldsymbol{\%})$ & & & ns & & & ns & \\
\hline Tumor involvement & $63(61.296)$ & $68(64.29)$ & & $36(70.6 \%)$ & $36(67.996)$ & & $203(64.996)$ \\
\hline Cancer therapy & $15(14.6 \%)$ & $14(13.2 \%)$ & & $04(07.896)$ & $03(05.7 \%)$ & & $036(11.5 x)$ \\
\hline Tumor involvement and cancer therapy & $06(05.8 \%)$ & 05 (04.7\%) & & $05(09.8 \%)$ & $05(09.4 \%)$ & & $021(06.786)$ \\
\hline Related to disease or debility & $13(12.7 \%)$ & $15(14.1 \%)$ & & $04(07.8 \%)$ & $07(13.2 \%)$ & & $039(12.59)$ \\
\hline Unknown & $06(05.8 \%)$ & $04(03.8 \%)$ & & $02(03.996)$ & $02(03.8 \%)$ & & $014(05.5 \%)$ \\
\hline \multicolumn{8}{|l|}{ Symptomatic pain treatment $(\mathrm{N}, \%)$} \\
\hline Analgesics & $88(85.49)$ & $94(88.7 \%)$ & ns & $42(82.4 \%)$ & $52(98.1 \%)$ & $<0.01$ & $276(88.28)$ \\
\hline Coanalgesics & $53(51.5 \%)$ & $61(57.5 \%)$ & ns & 29 (56.9\%) & $31(58.5 \%)$ & ns & $174(55.680)$ \\
\hline TENS & & $:$ & ns & 01 (02.0\%) & $01(01.996)$ & ns & $\infty 01(00.36)$ \\
\hline Other & $02(02.096)$ & $04(03.796)$ & ns & 01 (02.096) & $02(03.6 \%)$ & ns & $010(03.36)$ \\
\hline
\end{tabular}

- Percentage > 100\%;

' not significant.

The results of the McGill Pain Questionnaire at baseline are summarized in Table 5. The score on the sensory, affective, and evaluative dimensions, as well a the total score and the total number of words chosen did not differ at baseline between the groups.

The mean score for patients' Present Pain Intensity was $3.3(s d=2.3)$. Patients Average Pain Intensity during the previous week was $4.9(s d=2.1)$. No baseline differences were found among the groups for either Present Pain Intensity or Average Pain Intensity.

Results of the baseline EORTC QLQ-C30(+3) are given in Table 6. At baseline, number of differences on quality of life indicators were found between patients who needed district nursing and those who did not. Patients with district nursin were more impaired on most of the functioning scales (physical functioning $(p<0.001)$, role functioning $(p<0.001)$, social functioning $(p<0.05)$, and global quality of life $(p<0.01)$ ). Furthermore, patients with district nursing were more fatigued $(p<0.001)$, more bothered by nausea and vomiting $(p<0.01)$, experienced more pain $(p<0.01)$, more appetite loss $(p<0.001)$, and more constipatiol 


\section{Table 5. Results of the McGill Pain Questionnaire at baseline}

\begin{tabular}{|c|c|c|c|c|c|c|c|}
\hline & $\begin{array}{r}\text { Control } \\
\text { group } \\
\text { without } \\
\text { district } \\
\text { nursing }\end{array}$ & $\begin{array}{r}\text { Intervention } \\
\text { group } \\
\text { without } \\
\text { district } \\
\text { nursing }\end{array}$ & $\underset{\text { value }}{\mathrm{p}-}$ & $\begin{array}{r}\text { Control } \\
\text { group } \\
\text { with } \\
\text { district } \\
\text { nursing }\end{array}$ & $\begin{array}{r}\text { Intervention } \\
\text { group } \\
\text { with } \\
\text { district } \\
\text { nursing }\end{array}$ & $\begin{array}{c}\mathrm{p}- \\
\text { value }\end{array}$ & Total \\
\hline \multicolumn{8}{|c|}{ Pain Rating Index-Sensory* } \\
\hline Mean (range) $($ Max. $=36)$ & $8.3(0-22)$ & $9.3(0-22)$ & $\mathrm{ns}^{\prime}$ & $9.6(0.25)$ & $9.3(0-28)$ & ns & $9.0(0-28)$ \\
\hline \multicolumn{8}{|c|}{ Pain Rating Index-Affective' } \\
\hline Mean (range) $($ Max $=15)$ & $3.8(0-13)$ & $4.3(0-15)$ & ns & $4.3(0-13)$ & $5.0(0.14)$ & ns & $4.3(0-15)$ \\
\hline \multicolumn{8}{|c|}{ Pain Rating Index-Evaluative } \\
\hline Mean (range) $($ Max $=12)$ & $4.6(0-12)$ & $5.1(0-11)$ & ns & $5.2(0-12)$ & $5.0(0-12)$ & ns & $4.9(0-12)$ \\
\hline \multicolumn{8}{|c|}{ Pain Rating Index-Total' } \\
\hline Mean (range) $($ Max $=63)$ & $16.8(0-39)$ & $18.5(0.42)$ & ns & $19.1(0-48)$ & $19.3(0.48)$ & ns & $18.2(0.48)$ \\
\hline \multicolumn{8}{|c|}{ Number Words Chosen-Total } \\
\hline Mean (range) $($ Max $=20)$ & $10.0(0-20)$ & $10.5(0-20)$ & ns & $10.2(0.18)$ & $10.1(0-20)$ & ns & $10.2(0-20)$ \\
\hline
\end{tabular}

- Range = 0-36;

Range $=0.15$;

Range $=0.12$

Range $=0.63$

- Range = 0-20;

'not significant

$(p<0.05)$ than patients without district nursing. These differences could be expected as district nursing is offered to patients with impaired activities of daily living. However, despite randomization, patients in the intervention group with district nursing scored significantly lower on physical functioning $(p=0.05)$ and cognitive functioning $(p<0.05)$ than control group patients with district nursing.

\section{Process measures: application and use of the intervention}

Because the intervention was tailored to the needs of the individual patient, the results with regard to the implementation of the Pain Education Program itself will be discussed first. Pain topics were discussed by the specially trained nurses with 149 patients $(93.7 \%)$ in the hospital. Ten patients $(6.3 \%)$ did not receive any part of the Pain Education Program: 4 patients had died before discharge, 3 patients were too ill, for 2 patients the application and use of the Pain Education Program was too burdensome, and 1 patient refused participation after randomization. In addition to the Pain Education Program in the hospital, 126 patients $(79.2 \%)$ received additional information as part of the Pain Education Program by telephone at both 3 and 7 days postdischarge.

Of all 21 pain topics that could be discussed with the patient, a mean of 13.8 topics $(65.7 \%)$ was identified by the nurses as relevant for their patients. Of these relevant topics, $73.2 \%$ (10.1) were discussed with the patient because of a lack of knowledge (Table 7). Adherence to medication, misconceptions about tolerance, the use of non-pharmacological pain techniques, and the interference of pain, e.g. with mobility, sleep, appetite were topics in which most of the patients lacked knowledge. Three days postdischarge, a mean of 4.0 topics, and seven days postdischarge a mean of 3.1 topics were again discussed with the patient. Because patients with district nursing experienced more complex pain problems, significantly more topics were applicable to patients with district nursing than to 
Table 6. Results of the Quality of life Questionnaire at baseline and four week postdischarge

\begin{tabular}{|c|c|c|c|c|c|c|c|}
\hline & $\begin{array}{r}\begin{array}{c}\text { Control } \\
\text { group } \\
\text { without } \\
\text { district } \\
\text { nursing }\end{array} \\
\end{array}$ & $\begin{array}{r}\text { Intervention } \\
\text { group } \\
\text { without } \\
\text { district } \\
\text { nursing }\end{array}$ & $\begin{array}{c}\text { P- } \\
\text { value }\end{array}$ & $\begin{array}{r}\text { Control } \\
\text { group } \\
\text { with } \\
\text { district } \\
\text { nursing }\end{array}$ & $\begin{array}{r}\text { Intervention } \\
\text { group } \\
\text { with } \\
\text { district } \\
\text { nursing }\end{array}$ & $\begin{array}{c}\text { P- } \\
\text { value }\end{array}$ & Total \\
\hline & $\operatorname{Mean}($ s.d.) & Mean (s.d.) & & $\operatorname{Mean}(s . d)$. & Mean (s.d.) & & $\operatorname{Mean}(s, d)$ \\
\hline \multirow{2}{*}{\multicolumn{8}{|c|}{$\begin{array}{l}\text { Functioning scales" } \\
\text { Physicd funcioning }\end{array}$}} \\
\hline & $48.3(27.1)$ & $46.7(28.0)$ & ns. & $29.8(29.8)$ & $19.2(24.8)$ & 0.05 & 39.8096 \\
\hline 4 weeks postdischarged & $42.4(2.5)$ & $45.5(27.8)$ & ns & $26.1(25.2)$ & $27.7(30.4)$ & ns & $39.1(27.9)$ \\
\hline \multicolumn{8}{|l|}{ Role funcioning } \\
\hline Pretest & $26.1(27.5)$ & $31.1(30.4)$ & ns & $17.6(29.1)$ & $13.5(21.9)$ & ns & $24.3(28.6)$ \\
\hline 4 weeks postdischarge & $33.3(29.4)$ & $34.9(33.4)$ & ns & $19.5(25.5)$ & $25.3(28.8)$ & ns & $30.7(307)$ \\
\hline \multicolumn{8}{|l|}{ Cognitive functioning } \\
\hline $\begin{array}{l}\text { Pretest } \\
4 \text { weeks postdischarge }\end{array}$ & $71.026 .5)$ & $\begin{array}{l}68.3(27.0) \\
71.2(28.8)\end{array}$ & $\mathrm{ns}^{\mathrm{ns}}$ & $\begin{array}{l}71.2(25.4) \\
825036\end{array}$ & $58.8(27.1)$ & $<0.05$ & $68.0(262)$ \\
\hline \multicolumn{7}{|l|}{ Emotiond functioning } & $73.2(27.9)$ \\
\hline Pretest & $61.7(26.0)$ & $59.9(26.3)$ & ns & $56.2(23.6)$ & $55.0(27.3)$ & ns & $59.1(25.9)$ \\
\hline $\begin{array}{l}4 \text { weeks postdischarge } \\
\text { Socid functioning }\end{array}$ & $67.1(26.2)$ & $67.6(29.1)$ & ns & $69.1(27.3)$ & $67.4(24.8)$ & ns & $67.6(272)$ \\
\hline \multicolumn{8}{|l|}{ Socid functioning } \\
\hline 4 weeks postdischarge & $59.6(32.4)$ & $66.5(32.8)$ & ns & $62.1(32.2)$ & $65.1(33.4)$ & in & $\begin{array}{l}62.0(319.9) \\
63.3(32.6\end{array}$ \\
\hline \multicolumn{8}{|c|}{ ns $\quad 44.103 .5)$} \\
\hline Pretest & $52.1(21.5)$ & $50.1(23.2)$ & ns & $44.1(23.5)$ & $43.1(22.0)$ & ns & $48.6(22.7)$ \\
\hline 4 weeks postdischarge & $51.8(20.5)$ & $52.8(20.5)$ & ns & $49.4(22.2)$ & $51.7(21.7)$ & ns & $51.8(20.8)$ \\
\hline \multicolumn{8}{|c|}{ Symptom scales and items } \\
\hline \multicolumn{8}{|c|}{ Foogue } \\
\hline Pretest & $57.7(28.7)$ & $53.4(29.3)$ & ns & $67.5(28.8)$ & $77.8(25.9)$ & ns & $61.3(29.7)$ \\
\hline 4 weeks postdischarge & $55.2(28.6)$ & $56.1(28.7)$ & ns & $62.2(27.4)$ & $59.9(29.4)$ & ns & $57.3(28.5)$ \\
\hline \multicolumn{7}{|l|}{ Nausea and vomiting } & \\
\hline 4 weeks postdischarge & $24.9(30.6)$ & $22.1(24.8)$ & ns & $29.0(32.3)$ & $22.6(32.4)$ & ns & $24.2(29.0)$ \\
\hline \multicolumn{8}{|l|}{ Pan } \\
\hline Pretest & $65.2(27.9)$ & $66.5(24.5)$ & ns & $75.2(28.6)$ & $75.5(25.2)$ & ns & $69.0(26.7)$ \\
\hline 4 weeks postdischarge & $47.5(29.5)$ & $38.5(31.1)$ & 0.05 & $52.4(34.6)$ & $58.6(27.5)$ & ns & $46.3(31.4)$ \\
\hline \multicolumn{8}{|l|}{ Dyspnea } \\
\hline Pretest & $21.4(31.9)$ & $24.4(33.1)$ & ns & $26.1(36.7)$ & $30.2(37.1)$ & ns & $24.7(34.0)$ \\
\hline $\begin{array}{l}4 \text { weeks postdischarge } \\
\text { Sieep disturbance }\end{array}$ & $20.4(30.5)$ & $23.5(31.8)$ & \multicolumn{4}{|c|}{ Sleep disurbance } & $21.3(30.9)$ \\
\hline Pretest & $45.0(37.8)$ & $46.7(40.2)$ & ns & $44.4(39.3)$ & $40.3(43.5)$ & ns & $44.7(39.7)$ \\
\hline \multirow{2}{*}{\multicolumn{8}{|c|}{ Loss of appetite }} \\
\hline & & & & & & & \\
\hline $\begin{array}{l}\text { Pretest } \\
4 \text { weeks postdischarge }\end{array}$ & $44.6(42.2)$ & $\begin{array}{l}34.0(39.1) \\
355(38.89\end{array}$ & ns & $66.0(38.6)$ & $65.4(36.1)$ & ns & $48.1(41.6)$ \\
\hline $\begin{array}{l}4 \text { weeks postdischarge } \\
\text { Constipation }\end{array}$ & \multicolumn{6}{|c|}{ Constipation } & $38.2(39.2)$ \\
\hline Pretest & $32.0(38.1)$ & $27.0(34.9)$ & ns & $40.7(40.0)$ & $38.8(40.5)$ & ns & $32.8(37.9)$ \\
\hline $\begin{array}{l}4 \text { weeks postdischarge } \\
\text { Diartheo }\end{array}$ & $23.1(35.3)$ & $22.8(35.5)$ & ns & $25.8(38.8)$ & $21.5(36.1)$ & ns & $23.2(35.8)$ \\
\hline Pretest & $19.6(31.9)$ & $15.2(30.7)$ & ns & 24.70 & $17.0(28.2)$ & ns & Diarthea \\
\hline 4 weeks postdischarge & $18.0(30.2)$ & $12.3(27.5)$ & ns & $07.5(23.3)$ & $09.7(24.6)$ & ns & $\begin{array}{l}18.5(27.6) \\
13.1\end{array}$ \\
\hline \multicolumn{8}{|l|}{ Finanod impoce } \\
\hline Pretest & $18.3(32.4)$ & $15.9(30.7)$ & ns & $14.0(29.4)$ & $14.5(28.1)$ & ns & $16.1(30.5)$ \\
\hline 4 weeks postdischarge & $14.9(28.4)$ & $18.2(33.3)$ & ns & $14.2(26.0)$ & $08.6(19.2)$ & ns & $15.3(29.1)$ \\
\hline O with his & & ie: & & & & & \\
\hline
\end{tabular}

patients without district nursing $(p<0.05)$. No difference was found between males and females in the number of topics discussed. Neither age nor pain duration were related to the number of topics discussed with the patients.

However, significantly more topics were discussed with lower educated patients than with higher educated patients $(p<0.001)$.

Eight weeks postdischarge, patients were asked to what extent they had read the pain brochure. Of the patients, $75 \%$ reported they had read the entire pain 
Table 7. Use of the Pain Education Program by intervention group patients

\begin{tabular}{|c|c|c|c|c|}
\hline Intervention components & $\begin{array}{r}\text { Intervention } \\
\text { group } \\
\text { without } \\
\text { district } \\
\text { nursing }\end{array}$ & $\begin{array}{r}\text { Intervention } \\
\text { group } \\
\text { with } \\
\text { district } \\
\text { nursing }\end{array}$ & Total & p-value \\
\hline $\begin{array}{l}\text { Number of pain topics that } \\
\text { did apply to the patient } \\
\text { (mean (range)) }\end{array}$ & $13.7(9-16)$ & $14.1(12-16)$ & $13.8(9-16)$ & $<0.05$ \\
\hline \multicolumn{5}{|l|}{$\begin{array}{l}\text { Number of topics discussed } \\
\text { because of lack of knowledge } \\
\text { (mean (range)) }\end{array}$} \\
\hline In the hospital & $9.9(6-14)$ & $10.5(6-14)$ & $10.1(6-14)$ & $\mathrm{ns}^{*}$ \\
\hline Three days postdischarge & $3.9(0-9)$ & $4.1(0-9)$ & $4.0(0-9)$ & ns \\
\hline Seven days postdischarge & $2.9(0-6)$ & $3.6(0-7)$ & $3.1(0-7)$ & 0.01 \\
\hline Number of pain sheets (mean) & 1.9 & 2.3 & 2.0 & $<0.01$ \\
\hline Read pain brochure? $(\mathrm{N}, \%)$ & & & & ns \\
\hline No & $6(6.0 \%)$ & $3(7.5 \%)$ & $9(6.4 \%)$ & \\
\hline Leaf through & $4(4.0 \%)$ & - & $4(2.9 \%)$ & \\
\hline Partly & $14(14.0 \%)$ & $3(7.5 \%)$ & $17(12.1 \%)$ & \\
\hline Fully & $75(75.0 \%)$ & $30(75.0 \%)$ & $105(75.0 \%)$ & \\
\hline Unknown/missing & I (1.0\%) & $4(10.0 \%)$ & $5(3.5 \%)$ & \\
\hline Listen to audiocassette? $(\mathrm{N}, \%)$ & & & & ns \\
\hline Fully & $47(47.0 \%)$ & $15(37.5 \%)$ & $62(44.3 \%)$ & \\
\hline Partly & $13(13.0 \%)$ & $3(7.5 \%)$ & $16(11.4 \%)$ & \\
\hline No & $38(38.0 \%)$ & $19(47.5 \%)$ & $57(407 \%)$ & \\
\hline Unknown/missing & $2(2.0 \%)$ & $3(7.5 \%)$ & $5(35 \%)$ & \\
\hline Record pain in diary $(\mathbf{N}, \%)$ & & & & ns \\
\hline Fully & $61(61.0 \%)$ & $27(67.5 \%)$ & $88(62.9 \%)$ & \\
\hline Partly & $32(32.0 \%)$ & $9(22.5 \%)$ & $41(29.3 \%)$ & \\
\hline No & $7(7.0 \%)$ & $2(5.0 \%)$ & $9(6.4 \%)$ & \\
\hline Unknown/missing & - & $2(5.0 \%)$ & $2(1.4 \%)$ & \\
\hline
\end{tabular}

"not significant

brochure. More than $80 \%$ of the patients were positive about the content of the pain brochure. Patients received, besides the general part of the pain brochure, a mean of two sheets with targeted information about the different cancer pain treatments. Patients with and without district nursing differed significantly in the number of sheets provided $(2.3(s d=0.8)$ versus $1.9(s d=0.8) ; p<0.01)$. Although all intervention patients had already received verbal pain information in the hospital, $26.2 \%$ reported they had read new information in the pain brochure. Patients who read the pain brochure were significantly younger than patients who did not read the pain brochure $(p<0.05)$. In addition to the patients themselves, over $50 \%$ of family and friends had read the pain brochure.

In addition to the pain brochure, $55.7 \%$ of the patients reported that they fully, or in part, listened to the entire audio cassette postdischarge. Patients who reported pain complaints in an earlier phase of their life listened to the audio cassette more frequently $(p<0.05)$ than patients who did not have pain complaints 
before. Furthermore, patients who fully listened to the audio cassette had a longer pain duration compared to patients who did not, or only partially listent the cassette $(p<0.05)$.

Finally, patients in the intervention groups were instructed to document their Present Pain Intensity twice daily in a pain diary for two months. After two months, $77.8 \%$ of the patients returned the pain diary. Twenty-six patients had died without having a family member returning the pain diary, 8 patients were too ill to return it, and 3 patients had lost their pain diary. In total, $85.9 \%$ of all pain scores were filled in. Reasons given by patients for not fully completing the pain diary were: too ill $(26.7 \%)$, non-availability of the pain diary due to hospital admission $(23.3 \%)$, no pain or no severe pain $(17.5 \%)$, or other reasons $(17.4 \%$. Sixty percent of patients stated that, due to the pain diary, they were more awar of their pain problems.

\section{Outcome measures}

Patients' pain knowledge was assessed at baseline, and two weeks postdischarge. It was hypothesized that by educating patients, their knowledge about pain and pain management would increase. For the entire, combined sample, th mean pain knowledge at pretest was 54.8 on a scale from $0-100$, with higher scores indicating better knowledge. The highest level of knowledge was related on the item of "the use of non-pharmacological pain treatments (such as massage, heat, relaxation, etc.) relieve pain," the "belief that health care providers need to be consulted when changing prescriptions," and "pain can be relieved." The lowest level of knowledge related to the item "it is important to give the lowest amount of medicine possible to save larger doses for later when pain is worse," "patients are often overmedicated," and "addiction is inevitable over time." At baseline, there were no differences between the control and experimental groups, or between male and female patients. However, higher educates patients scored significantly better on the items "pain medication should be given only when pain is severe" $(p<0.01)$, and on the item of "becoming addicted" $(p<0.001)$ as compared to lower educated patients.

Repeated measures analysis (MANOVA) was conducted to determine the effec of the Pain Education Program on pain knowledge. A statistically significant increase in the score in the period from pretest to 2 weeks postdischarge (time ef. fect) was found for all groups $(p<0.001)$, indicating that pain knowledge had in proved in all patients. In addition to a time effect, a statistically significant differ ence on overall pain knowledge over time (time $x$ group interaction) was found between the control and intervention groups $(p<0.01)$, indicating that the inter vention group patients improved their pain knowledge more than the control group patients. The overall pain knowledge at 2 weeks postdischarge was 55.6 for the control groups and 62.5 for the intervention groups. Both intervention groups showed improved knowledge on the items "take the lowest amount of medicine as possible," "use of routine medication instead of on demand," and "becoming addicted." Furthermore, the intervention group without district nurs ing showed better knowledge on the item "cancer pain can be effectively relieved" compared to the control group without district nursing, whereas the intervention group with district nursing showed improved knowledge on the item 
"pain medication should be given only when pain is severe" as compared to the control group with district nursing.

To determine the effect of the Pain Education Program on quality of life, the EORTC QLQ-C30(+3) was assessed at baseline and four weeks postdischarge. Repeated measures analysis (MANOVA) was conducted to determine the effect of the Pain Education Program on quality of life for the patient groups separately. Four weeks postdischarge, a statistically significant increase over time was found for patients without district nursing for physical functioning $(p<0.05)$, role functioning $(p<0.05)$, emotional functioning $(p=0.001)$, and for patients with district nursing for cognitive functioning $(p<0.001)$, and emotional functioning $(P<0.001)$. No interaction effect (time $x$ group) was found with regard to one of the functioning scales. With regard to the symptom scales, all patient groups experienced less pain $(p<0.001)$, and sleep disturbance $(p<0.001)$ at four weeks postdischarge as compared to baseline. Furthermore, patients without district nursing were less constipated $(p<0.05)$, and patients with district nursing showed less fatigue $(p=0.01)$, appetite loss $(p<0.001)$, and diarrhea $(p=0.01)$ at four weeks postdischarge. In addition to a time effect, experimental group patients without district nursing showed less pain at four weeks postdischarge as compared to the control group patients without district nursing $(p=0.05)$, and showed less pain over time (time $x$ group interaction) $(p=0.07)$. Experimental group patients with district nursing showed less fatigue over time (time $\mathrm{x}$ group interaction) as compared to the control group patients with district nursing $(p<0.05)$. From this it can be concluded that the Pain Education Program did not affect the patients' quality of life scores except a trend for pain intensity in patients without district nursing and fatigue for patients with district nursing. Difference in fatigue scores may be attributed to differences at baseline between the patient groups with district nursing as well as the declining status of many of the patients over time.

In order to determine the effect of the Pain Education Program on pain intensity, patients' Present Pain Intensity and Average Pain Intensity was assessed four times over a two-month period. Repeated Measures Analysis (MANOVA) evaluating Present Pain Intensity from 2 weeks postdischarge to 8 weeks postdischarge with the pretest scores on Present Pain Intensity, cognitive functioning, physical functioning, and use of medication as covariates found a significant group effect $(p<0.01)$. The experimental group patients experienced less pain compared to the control group patients. No significant group effect over time was found. The significant difference between the control and experimental groups was solely caused by a significant group difference between the experimental and control group patients without district nursing $(p<0.001)$, while no group effect was found for the patients with district nursing. Results evaluating Average Pain Intensity from 2 weeks postdischarge to 8 weeks postdischarge were in equivalence to the results regarding Present Pain Intensity.

When analyzing the intervention effect, the use of classical analytic techniques might bias the results as only complete cases $(\mathrm{N}=213)$ of the 313 patients were included. Excluding pain intensity scores of patients who dropped out, mainly due to death, might change pain intensity scores postdischarge as these patients were in the pre-terminal phase while participating in the study. Furthermore, significantly more intervention group patients with district nursing died within a period of two months as compared to control group patients with district nursing, 

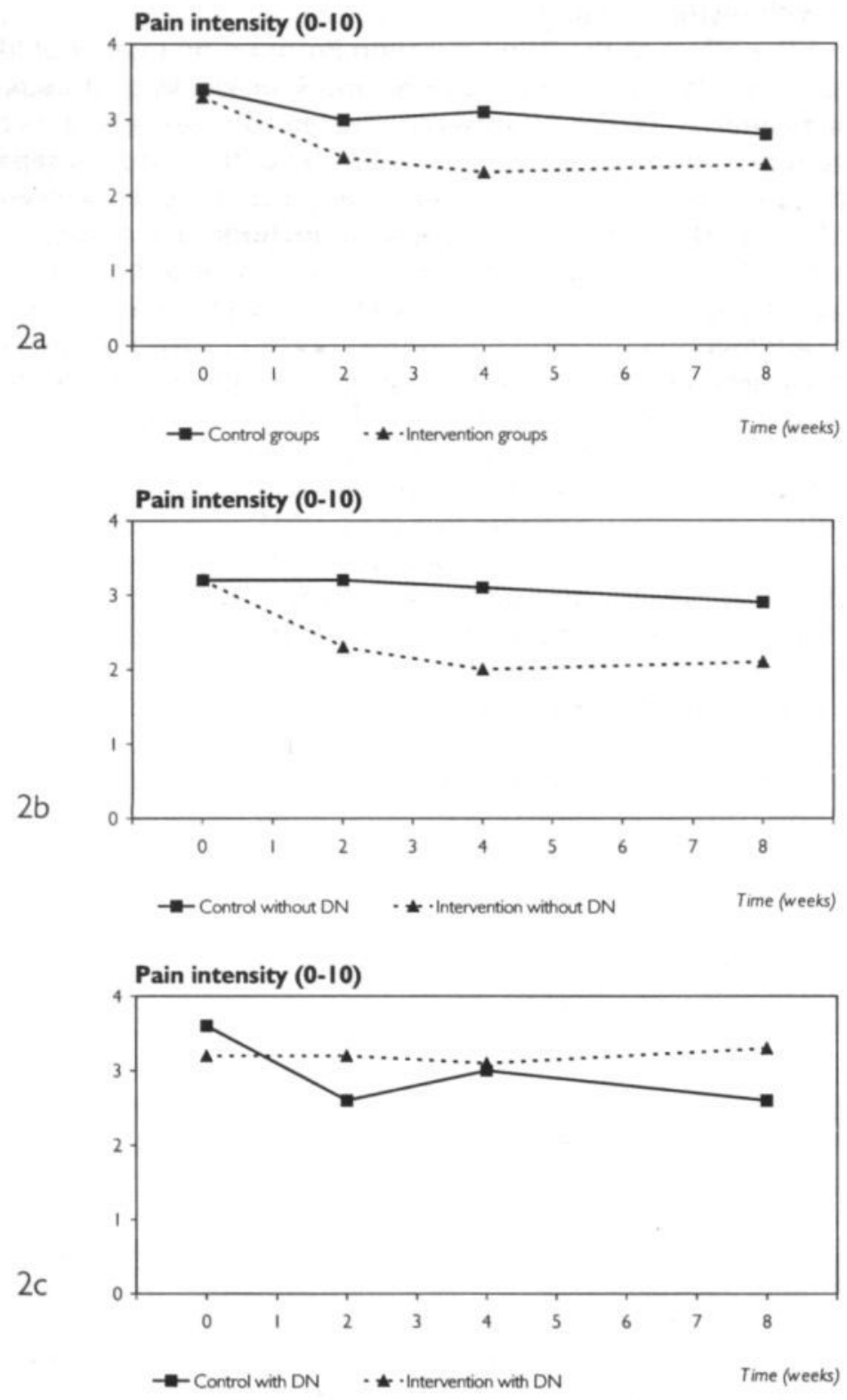

Figure 2a. Pain intensity measured by a Numeric Rating Scale (0-10) of the combined control group patients versus the intervention group patients.

Figure $2 \mathrm{~b}$. Pain intensity measured by a Numeric Rating Scale $(0-10)$ of the control group without district nursing $(D N)$ versus the intervention group without district nursing (DN).

Figure 2c. Pain intensity measured by a Numeric Rating Scale (0-10) of the control group with district nursing versus the intervention group with district nursing. 
$35.8 \%$ and $14.0 \%$, respectively $(p<0.01)$. Finally, pretest differences were found between the control and intervention groups with district nursing regarding the use of pain medication, patient's cognitive functioning, and patient's physical functioning. To correct for this latter imbalance, BMDP's Unbalanced Repeated Measures Analysis of Covariance (5V) was used. ${ }^{37}$ By means of Unbalanced Repeated Measures Analyses of Covariance, all available data of the dropouts is included in the analyses. Based on the available data of a patient, imputed values are calculated for the missing responses. The use of pain medication, patient's Present Pain Intensity at pretest, and patients' cognitive and physical functioning were used as covariates. Patients' Present Pain Intensity ratings at 2, 4, and 8 weeks postdischarge were used as dependent variables. Figure 2a show patients' Present Pain Intensity ratings. Although pain intensity scores from all patients decreased postdischarge, scores in the intervention group were significantly more decreased than in the control group patients at follow-up $(p<0.01)$. While patients' Present Pain Intensity decreased between Prestest and 2 weeks postdischarge, the pain scores remained stable between 2 and 8 weeks postdischarge.

When analyzing patients' Present Pain Intensity scores for the patient groups separately (Figure $2 \mathrm{~b}$ and $2 \mathrm{c}$ ), results showed that an intervention (group) effect was found only for patients without district nursing $(p<0.001)$. This suggests that patients without district nursing benefited significantly more from the Pain Education Program than patients with district nursing.

Regarding Average Pain Intensity, the intervention group patients without district nursing demonstrated a significant pain reduction as compared to the control group patients without district nursing, as indicated by a significant interaction (group $x$ time) effect $(p<0.001)$ (data not shown). No significant interaction effect was found for intervention patients with district nursing. Average Pain Intensity and Present Pain Intensity were moderate to highly correlated, namely $r=0.50$ at pretest, $r=0.43$ at 2 weeks postdischarge, $r=0.72$ at 4 weeks postdischarge, and $r=0.34$ at 8 weeks postdischarge $(p<0.001)$. It can be concluded that results of the Unbalanced Repeated Measures Analyses of Covariance are in equivalente to complete analyses.

Table 8. Patients with significant pain (pain rated as 5 or higher)

\begin{tabular}{|c|c|c|c|c|c|c|c|}
\hline & $\begin{array}{r}\text { Control } \\
\text { group } \\
\text { without } \\
\text { district } \\
\text { nursing }\end{array}$ & $\begin{array}{r}\text { Intervention } \\
\text { group } \\
\text { without } \\
\text { district } \\
\text { nursing }\end{array}$ & $\begin{array}{c}\text { p- } \\
\text { value }\end{array}$ & 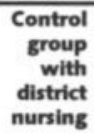 & $\begin{array}{r}\text { Intervention } \\
\text { group } \\
\text { with } \\
\text { district } \\
\text { nursing }\end{array}$ & $\begin{array}{c}\text { p- } \\
\text { value }\end{array}$ & Total \\
\hline \multicolumn{8}{|c|}{ Present Pain Intensity } \\
\hline Pretest & $31.1 \%$ & $34.6 \%$ & n* & $37.3 \%$ & 26.996 & ns & $32.6 \%$ \\
\hline 2 weeks postdischarge & $29.3 \%$ & $15.5 \%$ & $<0.05$ & $19.0 \%$ & $24.3 \%$ & ns & 22.09 \\
\hline 4 weeks postdischarge & $32.1 \%$ & $14.9 \%$ & $<0.01$ & $26.2 \%$ & $22.6 \%$ & ns & $23.5 \%$ \\
\hline 8 weeks postdischarge & $27.8 \%$ & $12.0 \%$ & 0.01 & 25.69 & $31.0 \%$ & ns & $22.0 \%$ \\
\hline \multicolumn{8}{|c|}{ Average Pain Intensity } \\
\hline Pretest & 55.99 & 58.496 & ns & $67.3 \%$ & $58.8 \%$ & rs & $59.1 \%$ \\
\hline 2 weeks postdischarge & 39.396 & $21.6 \%$ & $<0.01$ & $25.6 \%$ & 35.396 & $\mathrm{~ms}$ & $30.1 \%$ \\
\hline 4 weeks postdischarge & $36.1 \%$ & $19.1 \%$ & 0.01 & $35.0 \%$ & $32.3 \%$ & "r & $29.4 \%$ \\
\hline 8 weeks postdischarge & $39.4 \%$ & $16.9 \%$ & 0.001 & $30.6 \%$ & $32.1 \%$ & ns & $28.2 \%$ \\
\hline \multicolumn{8}{|l|}{ Worst Pain Intensity } \\
\hline Pretest & 89.296 & $92.1 \%$ & ns & 90.09 & $92.3 \%$ & ns & $90.8 \%$ \\
\hline 2 weeks postdischarge & $73.3 \%$ & $61.9 \%$ & ns & $80.5 \%$ & 69.49 & ns & $69.7 \%$ \\
\hline 4 weeks postdischarge & $62.7 \%$ & $50.5 \%$ & ns & 65.996 & $73.3 \%$ & ns & $59.9 \%$ \\
\hline 8 weeks postdischarge & $62.2 \%$ & $54.8 \%$ & ns & 59.09 & $75.0 \%$ & ns & $60.4 \%$ \\
\hline
\end{tabular}


Pain has a greater impact on a patient as it becomes more severe. The World Health Organization has recommended the use of pain severity as the primary item of information in evaluating pain treatment. Pain rated as 5 or higher on a scale of 0 to 10 corresponds to interference with function and can be defined as clinically relevant pain. $2,38-40$ of the patients, $32.6 \%(\mathrm{~N}=101)$ reported significant pain (Present Pain Intensity rated as 5 or higher) at baseline, while $59.1 \%$

$(\mathrm{N}=197)$ rated their Average Pain Intensity as 5 or higher in the past week, and $90.8 \%(N=277)$ their Worst Pain Intensity. Less patients in the intervention grou; without nursing reported significant Present Pain Intensity, and Average Pain In. tensity in the last week as compared to control group patients without district nursing (Table 8 ). No differences were found regarding Worst Pain Intensity, and for patients with district nursing.

It can be concluded that both a statistically significant change and a clinically relevant change was found. However, pain relief was mainly found in the intervention group without district nursing.

\section{Discussion and conclusion}

Pain management remains a problem for many cancer patients in chronic pain Most efforts to improve this situation have focused on educating physicians and nurses. Based on the assumption that insufficient pain knowledge among cance patients themselves is also an important reason for inadequate pain treatment, $i$ this study a patient-oriented approach was chosen. Specially trained nurses educated and instructed cancer patients in chronic pain in the hospital about pain and pain management, and how to manage their pain in the home situation. $\mathrm{Pz}$ tients were randomized to a control group and an intervention group. Patients with and without district nursing at home were randomized separately, as they differed with respect to sociodemographic variables, medical variables, and quality of life characteristics. The intervention group patients received the Pain Education Program in the hospital and two times at home by telephone.

This study showed that, despite education and instruction regarding pain and pain treatment given by regular health care providers, the overall pain knowledg of cancer patients in chronic pain was poor. The present study supports other re sults demonstrating that patients frequently cited barriers to effective pain management that include fears of addiction, drug tolerance, and lack of knowledge about pain. ${ }^{17} \mathrm{~A}$ finding corroborated by other investigators is that misconceptions about addiction continue to be one of the most problematic aspects of an algesic treatment. ${ }^{41-43}$ The overall knowledge subscale score found by Ferrell and associates ${ }^{14}$ was in agreement with our findings. Although the patient groups in our study was not completely comparable with the elderly patients studied by Ferell and associates, ${ }^{14}$ both the highest areas of knowledge (the use of non-dru: treatments, and the belief that pain can be relieved), as well as the lowest areas of knowledge (the need to take low doses of medicines) were in congruence wit our results.

A requisite for a successful Pain Education Program is that patients be active users of the different elements of the intervention: the pain brochure needs to $b$ read, the audio cassette needs to be listened to, and the pain diary needs to be filled in. We found that the intervention patients valued the Pain Education 
Program and complied with the instructions. The Pain Education Program proved to be feasible: $75.0 \%$ had read the pain brochure, and $85.6 \%$ filled in the pain diary. The percentage of patients who listened to the audio cassette was lower $(55.7 \%)$. From these results, it can be concluded that patients can be given a more active role in their own pain treatment. This is encouraging as the majority of these patients were in poor physical condition and reported low to very low scores on the quality of life scales. In addition to patients themselves, results also showed an information need by their significant others.

In contrast to other such programs, this Pain Education Program was tailored to the needs of the individual patient. Despite the fact that a tailored intervention is a more time consuming procedure, this intensive approach proved to be valuable. Overall pain knowledge was improved in the intervention group. The intervention patients gained knowledge with regard to misconceptions of tolerance, addiction, and the use of medication on a regular basis. Although the overall pain knowledge was improved, results also showed that some knowledge gaps are difficult to correct. The present study is consistent with the work of other investigators who have shown that individualized pain treatment programs have merit for cancer patients in pain. ${ }^{11,14,17,18,40}$ However, work must be continued to demonstrate scientifically the application of individualized intervention programs for the complex problem of cancer pain.

The intervention patients reported significantly less pain than the control group patients. However, a significant decrease in pain was only observed in the intervention group without district nursing. The question is why no pain relief was achieved in the group with district nursing. Several possible explanations can be given. First, patients with district nursing were older, experienced more complex pain problems, and needed more help as compared to patients without district nursing. For these patients, self-efficacy might be more difficult to accomplish and, therefore, these patients might benefit less from the Pain Education Program. Secondly, this type of intervention may not be powerful enough for patients who experience multiple chronic pain problems. Thirdly, district nurses of control group patients might have changed the way they took care of their control group patients because they knew they were participating in a study. Fourthly, the finding of no decrease in pain intensity might be due to the fact that the intervention group patients with district nursing were prescribed more analgesics and showed lower levels of physical and cognitive functioning than the control group patients with district nursing at baseline. Postdischarge, the drop-out rate in the control and intervention groups with district nursing differed. More patients died in the intervention group with district nursing as compared to the control group with district nursing. This might have resulted in finding no difference in pain relief. Although this was a randomized study, it appears that the randomization was not fully effective in yielding balanced intervention and control groups. Consequently, results in the groups with district nursing need to be interpreted with caution.

From this study, it can be concluded that the Pain Education Program was effective in relieving pain in chronic pain patients without district nursing. Although intervention group patients with district nursing showed an increase in pain knowledge and were active users of the intervention, no decrease in pain intensity was found in this group. This suggests that improved pain knowledge is not the only component responsible for a decrease in pain intensity. 
An important aspect in clinical research is the extent to which a statistically significant decrease in pain intensity is also assessed as clinically relevant. For the in tervention groups, patient's Present Pain Intensity decreased from on average 3.3 at Prestest to, respectively, 2.6 at 2 weeks postdischarge, 2.3 at 4 weeks postdis. charge, and 2.4 at 8 weeks postdischarhge, a decrease of $20-30 \%$. In the control groups, the decrease was much lower; $9-17 \%$ respectively. This decrease in pain intensity can be considered as clinically relevant when taking into consideration that these patients suffer from chronic pain (mean=14.2 months, range $=1-324$ months) that is difficult to treat, and that for most patients the survival period was relatively short. One year after data collection, only $31 \%$ of patients was still alive.

This tailored intervention was provided in a one-to-one setting. The three inter vention steps (face to face contact plus two telephone contacts) lasted approximately 60-90 minutes. Prior to the intervention, the areas in which pain knowledge was assessed as inadequate had to be determined by means of an interview lasting approximately 30-45 minutes. The strength of a tailored intervention consists of the individual approach. Consequently, patients are not bothered with re dundant education and instruction. Compared to a standardized intervention, a tailored intervention is based more on patient's cognitive abilities, is more userfriendly, and is as brief as possible. The areas in which pain knowledge and active participation are lacking need to be determined prior to the intervention. The time spent, however, is justified because patients are involved who suffer from chronic pain with a relatively short survival period.

Because of the pain relieving effects, the use of such an intervention should be seriously considered on oncology units. An important finding was that specially trained nurses can function as pain counsellors. Because nurses have regular contact with patients, they are in an ideal position to educate patients. Although this study was conducted by specially trained nurses, it is expected that oncology nurses on the wards could also carry out the Pain Education Program. Therefore, nurses should be trained as pain counsellors and the Pain Education Program should be implemented and evaluated in nursing practice.

Although the results of this study are promising, several limitations should be underscored. First, the selection of patients is based on patients from a cancer hospital in the Netherlands, where care is specially focused on cancer patients. Therefore, the results may not be directly generalizable to other cancer patients in chronic pain. Second, patients who declined participation differed from patients who participated with regard to age and sex. Although the number of patients who declined was rather low (18.3\%), this might have biased the results. Third, bias might be caused by differences at baseline in the control and interven tion group patients with district nursing and differences in drop-out rate. Finally, bias might be caused by district nurses due to the fact that district nursing of both the control and intervention group patients were extremely willing to participate in the study.

Further research is needed to validate the current study findings and to investigate the reason for finding no difference in pain relief in patients with district nursing. As only a few studies have been conducted to evaluate the effect of tailored Pain Education Programs, there is also a need to determine how to provide clear and accurate information about pain information and instruction for individual patients. More research is also needed for better understanding why 
patients without district nursing benefit more from the Pain Education Program than patient with district nursing, and to investigate what type of patient benefit most from the Pain Education Program. Finally, additional research is needed to investigate what parts of the Pain Education Program are most powerful and whether all components of this multi-method intervention need to be used to relieve pain. Because the Pain Education Program consists of different components, it is important to know whether some components are more effective in relieving pain than others. By using a multi-method approach, the effectiveness of each of the components of the Pain Education Program is difficult to disentangle. Therefore, further research to test the effectiveness of the separate components of the Pain Education Program is needed.

From this study, it can be concluded that pain remains an important problem in cancer patients in chronic pain. This study shows that a tailored Pain Education Program is applicable and effective. The most important outcome of the study was the beneficial effect of the Pain Education Program in improving pain knowledge and reducing pain intensity.

\section{Acknowledgments}

This study was supported by a grant from the Dutch Cancer Society (grant no NKI 92-469). The authors thank all patients for their cooperation. We extend special thanks to the nursing departments of the Netherlands Cancer Institute/Antoni van Leeuwenhoek Hospital for their participation in the study. 


\section{References}

1. Bonica JJ. Treatment of cancer pain: current status and future needs. In: Fields HL, Dubner F, Cervero F, eds. Advances in pain research and therapy. New York: Raven Press, Ltd., 1985: 589-616.

2. Cleeland CS, Gonin R, Hatfield AK, Edmonson JH, Blum RH, Stewart JA, Pandya KJ. Pain and its treatment in outpatients with metastatic cancer. New England Journal of Medicine, 1994;330:592-596.

3. Dorrepaal KL. Pijn bij patienten met kanker [In Dutch]: Vrije Universiteit, 1989.

4. Marks RM, Sachar EJ. Undertreatment of medical inpatients with narcotic analgesics. Annals o Internal Medicine, 1973;78:173-181.

5 Ward SE, Gordon D. Application of the American Pain Society quality assurance standards. Pai 1994;56:299-306.

6. AHCPR. Management of cancer pain. Clinical Practice Guideline. Rockville, Md. Agency for Health Care Policy and Research, Public Health Service, U.S. Department of Health and Human Services, 1994.

7. American Pain Society. Principles of analgesic use in the treatment of acute pain and chronic cancer pain: a concise guide to medical practice. Skokie, IL, 1992.

8. Nederlanse Vereniging ter Bestudering van Pijn (NVBP). Pijn en pijnbehandeling bij de patient met kanker. In: Schulkes-vd Pol JA, red. Groningen, 1990.

9. World Health Organization. Cancer pain relief and palliative care. Geneva, Switserland, 1990.

10. Levin DN, Cleeland CS, Dar R. Public attitudes toward cancer pain. Cancer, 1985;56:2337-2339

11. Rimer B, Levy M, Keintz MK, MacElwee N, Engstrom PF. Improving cancer patients' pain contro through education. Progress in Clinical \& Biological Research, 1987;248:123-127.

12. Ward SE, Goldberg N, Miller-McCauley V, Mueller C, Nolan A, Pawlik-Plank D, Robbins A, Stormoen D, Weissman DE. Patient-related barriers to management of cancer pain. Pain, 1993;52:319-324.

13. Ferrell BR, McCaffery M, Rhiner $M$. Pain and addiction: an urgent need for change in nursing education. Journal of Pain and Symptom Management, 1992;7:117-124.

14. Ferrell BR, Ferrell BA, Ahn C, Tran K. Pain management for elderly patients with cancer at home Cancer, 1994;74:2139-2146.

15. Stratton Hill C. When will adequate pain treatment be the norm? JAMA, 1995;274:1881-1882

16. Dalton JA. Education for pain management: a pilot study. Patient Education and Counseling, 1987:9:155-165.

17. Ferrell BR, Rhiner M, Ferrell BA. Development and implementation of a pain education progra Cancer, 1993;72:3426-3432.

18. Dalton JA, Lambe C. Tailoring treatment approaches to the individualized needs of cancer patients with pain. Cancer Nursing, 1995;18:180-188.

19. McCaffery M, Beebe A. Pain: Clinical manual for Nursing Practice. St. Louis, MO: CV Mosby, 1989.

20. Spross JA, McGuire DB, Schmitt RM. Oncology Nursing Society Position Paper on Cancer Pain. Part I. Oncology Nursing Forum, 1990;17:595-614.

21. Spross JA, McGuire DB, Schmitt RM. Oncology Nursing Society Position Paper on Cancer Pain. Part II. Oncology Nursing Forum, 1990;17:751-760.

22. Zandbelt LC. Pijn bij kanker en wat er aan te doen is. De ontwikkeling en pretest van een brochure over pijn en pijnbestrijding voor kankerpatienten met langdurig pijn (In Dutch): Doctoraalscriptie, Rijksuniversiteit Limburg, 1993.

23 De Wit R, van Dam FSAM. Verpleegkundige pijnmeting bij kankerpatienten: een interventiestudie. Verpleegkunde, 1991/92;2:68-75.

24. Graham KY, Longman AJ. Quality of life and persons with melanoma. Preliminary model testin Cancer Nurs., 1987; 10:338-346.

25. McGuire DB. Assessment of pain in cancer inpatients using the McGill Pain Questionnaire. Oncology Nursing Forum, 1984;11:32-37.

26. Verkes RJ, Van der Kloot WA, Van der Meij J. The perceived structure of 176 pain descriptive words. Pain, 1989;38:219-229.

27. Vanderiet K, Adriaensen H, Carton H, Vertommen H. The McGill Pain Questionnaire constructe for the Dutch language (MPQ-DV). Preliminary data concerning reliability and validity. Pain, 1987;30:395-408. 
28. Van der Kloot WA, Vertommen H. Een standaard Nederlandstalige versie van de McGill Pain Questionnaire: Achtergronden en handleiding van de MPQ-DLV. Lisse: Swets and Zeitlinger, 1990.

29. Van der Kloot WA, Oostendorp RA, Van der Meij J, van den Heuvel J. [the dutch version of the mcgill pain questionnaire: a reliable pain questionnaire]. Nederlands Tijdschrift voor Geneeskunde, 1995;139:669-673.

30. Kremer E, Atkinson JH, Jr. Pain measurement: construct validity of the affective dimension of the McGill Pain Questionnaire with chronic benign pain patients. Pain, 1981;11:93-100.

31. Jensen MP, Karoly P, Braver S. The measurement of clinical pain intensity: a comparison of six methods. Pain, 1986;27:117-126.

32. McGuire DB. Measuring pain. In: Frank-Stromborg M, ed. Instruments for clinical nursing. Norwalk, CT, 1988: 333-356.

33. Syrjala KL. The measurement of pain. In: McGuire DB, Yarbro CH, eds. Cancer pain management. Philadelphia: Saunders, 1987: 133-150.

34. Aaronson NK, Ahmedzai S, Bergman B, Bullinger M, Cull A, Duez NJ, Filiberti A, Flechtner H, Fleishman SB, de Haes JC. The European organization for research and treatment of cancer QLQ-C30: a quality-of-life instrument for use in international clinical trials in oncology. Journal of the National Cancer Institute, 1993;85:365-376.

35. Ferrell BR, Rhiner MR, Rivera LM. Development and evaluation of the family pain questionnaire. Journal of Psychosocial Oncology, 1993;10:21-35.

36. De Wit, R. Development of the Dutch Language version of Ferrell's Pain Knowledge Questionnaire. Unpublished report, The Netherlands Cancer Institute/Antoni van Leeuwenhoek huis, 1995.

37. Jennrich RI, Schluchter MD. Unbalanced repeated-measures models with structured covariance matrices. Biometrics, 1986;42:805-820.

38. American Pain Society Quality of Care Committee. Quality improvement guidelines for the treatment of acute pain and cancer pain. JAMA, 1995;274:1874-1880.

39. Serlin RC, Mendoza TR, Nakamura Y, Edwards KR, Cleeland CS. When is cancer pain mild, moderate or severe? grading pain severity by its interference with function. Pain, 1995;61:277-284.

40. Cleeland C. Research in cancer pain. What we know and what we need to know. Cancer, 1991;67:823-827.

41. Dar R, Beach CM, Barden PL, Cleeland CS. Cancer pain in the marital system: a study of patients and their spouses. Journal of Pain and Symptom Management, 1992;7:87-93.

42. Lin CC, Ward SE. Patient-related barriers to cancer pain management in Taiwan. Cancer Nursing, 1995; 18:16-22.

43. Ward SE, Hernandez L. Patient-related barriers to management of cancer pain in Puerto Rico. Pain, 1994;58:233-238. 


\section{Chapter 4}

\section{Evaluation of the use of a pain diary in chronic cancer pain patients at home}

De Wit, R., Van Dam, F., Hanneman, M., Zandbelt, L., Van Buuren, A., Van der Heijden, K., Leenhouts, G., Loonstra, S. and Huijer Abu-Saad, H. Evaluation of the use of a pain diary in chronic cancer pain patients at home, Pain, 1999;79:89-99. 


\section{Introduction}

Systematic assessment of pain is the basis for adequate control in cancer pain patients. ${ }^{1-4}$ Lack of pain assessment can lead to poor pain management. ${ }^{2,5-7}$ To monitor the patients' pain in the hospital setting, healthcare providers usually ast patients "How is your pain?" or "What was your pain intensity in the last week of in the last 24 hours?" Most cancer patients, however, are hospitalized for only a relatively short period of time during the course of their disease. The only way to assess pain systematically in the home setting is to ask patients themselves to record their own pain experiences, e.g., by means of a pain diary.

Although several international organizations ${ }^{8-10}$ have recommended the use of systematic pain assessment by means of patients' self-report, there is limited experience with self-monitoring of cancer pain by means of a pain diary. Faries and associates 11 evaluated the effect of a pain diary in hospitalized cancer patients, finding lower Average Pain Intensity ratings in the patient group with standardized pain assessment. Wagemans and associates ${ }^{12}$ used a pain diary to record the daily morphine doses, pain intensity, and the incidence of side-effects, finding that continuous intrathecal administration of morphine can be based on pain scores recorded in a pain diary. No results on its feasibility and psychometric properties were reported. Geddes and associates ${ }^{13}$ evaluated the effect of monitoring quality of life, including pain, and concluded that a pain diary is a valid and sensitive instrument to record changes over time. Kravitz and associates ${ }^{14}$ studied whether a graphical display of cancer patients' pain level might improve their treatment in hospitalized cancer patients but failed to show a beneficial effect of recording pain scores.

Although the use of a pain diary has not been thoroughly studied in chronic cancer pain patients, studies conducted in chronic benign patients showed that the use of a pain diary to measure pain intensity was valid and reliable. ${ }^{3,15,16}$ The use of pain intensity scores in a pain diary was found to be sensitive to changes over time. ${ }^{3,15}$ Although some studies have shown that past pain can be accurately recalled, ${ }^{16-18}$ it is also reported that patients overestimate their remembered pain, or that psychosocial and pain related factors have a biasing influence on the remembered pain. ${ }^{19-24}$ Daily self-recording of pain by means of a pain diary seems to be advantageous, as the risk of bias is reduced. Furthermore, according to the patients, monitoring their pain gives them a sense of control, ${ }^{25}$ moreover, a decrease in pain has been reported due to the attention focused on the pain. ${ }^{26}$ Other studies, however, did not find a reactive effect of daily self-monitoring of pain, 3,14,27 nor an decrease in pain intensity due to the attention given to the pain. ${ }^{28}$ Although it is well established that measurement of pain may affect the pain itself, these results do not elucidate whether an increase or decrease in pain intensity can be expected as a result of measurement.

The following research questions were addressed: (1) To what extent do patients record their pain scores in the pain diary? (2) What is the association between pain intensity scores obtained by the pain diary and those obtained by pa. tient interview? (3) To what extent can patients recall past pain intensity? (4) To what extent do pain intensity scores fluctuate over time? (5) What is the stability of self-monitoring of pain in a pain diary? (6) How do patients value the use of the pain diary? (7) To what extend do patients record pain information in the pain diary? 


\section{Subjects and methods}

\section{Design and patient population}

The current study was part of a prospective, randomized controlled trial using a "pretest-posttest experimental design". This study was conducted at the Antoni van Leeuwenhoek Hospital/the Netherlands Cancer Institute, a specialized cancer hospital in Amsterdam, the Netherlands. A "Pain Education Program" was implemented by specially trained nurses, and the effectiveness of the intervention was evaluated. The tailored intervention consisted of a multi-method approach in which verbal pain instruction, written pain materials, an audiocassette tape, and the use of a pain diary were combined to inform and instruct patients about pain and pain management. The intervention has been described in detail elsewhere and is only summarized in this report. ${ }^{29}$ Self-monitoring of pain in a diary was one of the components of the "Pain Education Program" that further consisted of educating patients about pain and pain treatment, and instructing them how to communicate with healthcare providers. The main purpose of the "Pain Education Program" was to empower patients in the process of relieving pain.

All cancer patients with pain caused by cancer, cancer therapy, or illness that persisted for at least 1 month and who were admitted to the cancer hospital were asked to participate in this study. Patients were excluded from the trial if their life expectancy was less than 3 months as assessed by the physician, if they were residing in a nursing home or retirement home, or if they were not accessible by telephone.

In the present study, two groups of patients, with and without district nursing in the home setting, were evaluated. This distinction was made because it was expected that patients who needed district nursing in the home setting were in a more advanced stage of their disease. Furthermore, it was hypothesized that the two groups would differ with regard to their ability to perform daily activities, and in their housing and living conditions. Patients with district nursing at home were expected to experience more complex pain problems than patients without district nursing. Consequently, patients receiving district nursing might experience the use of a pain diary different from patients receiving no district nursing at home. Before randomization, patients were stratified by gender, age, and metastatic sites.

\section{Procedure}

Prior to randomization, all patients were interviewed in the hospital at baseline with regard to demographic and medical characteristics, pain experience and pain treatment, as well as quality of life. After it was decided whether or not district nursing would be necessary postdischarge, patients with and without district nursing were randomly assigned to a control group or an experimental group.

In the present study, results of the experimental group patients only are presented because these were the only patients provided with a pain diary. The experimental group patients received the "Pain Education Program" offered by specially trained nurses. Part of the "Pain Education Program" was to register pain in a paper-and-pencil pain diary. Patients were instructed how to record their 
Present Pain Intensity on a numeric rating scale ranging from " 0 " to " 10 ", with " 0 " representing "no pain" and " 10 " representing "pain as bad as you can imag. ine". Written information about the use of the pain diary was also provided, and the patient practiced completing the pain diary with the specially trained nurse before discharge. This recording had to be done once every morning and once every evening for a period of 2 months. In addition to self-monitoring of pain, patients were asked to voluntarily record what pain medication they had taken and whether healthcare providers were contacted because of their pain complaints. As part of the "Pain Education Program," patients were telephoned at 3 and 7 days postdischarge by the same nurse to determine whether the pain information and instruction provided in the hospital were still fully understood, and whether there were any difficulties with completing the pain diary. It should be noted that patients were already accustomed to self-reporting of pain, because nurses in the hospital asked patients to record their "Present Pain Intensity twice daily. Postdischarge, the patients were interviewed by telephone about their pain complaints and pain treatment at 2 weeks, 4 weeks, and 8 weeks post discharge. After 2 months, patients in the experimental group were asked to return the pain diary.

\section{Measures}

At baseline, by means of a patient interview patients were asked about the dv ration of the pain and whether the pain was constant or intermittent (pattern). Pain treatment data provided in the hospital were collected from the medical records including the use of analgesics, invasive therapies, and physical modalities.

Quality of life was measured at baseline by means of the European Organization for Research and Treatment of Cancer Core Quality of Life Questionnaire (EORTC QLQ-C30(+3)). The EORTC-QLQ-C30(+3) contains: (1) five functioning scales (physical functioning, role functioning, emotional functioning, cognitive functioning, and social functioning); (2) three physical symptom scales (fatigue and malaise, nausea and vomiting, pain); (3) several single-item symptom meas. ures (constipation, dyspnea, difficulty with sleeping, appetite loss, diarrhea, and financial impact); (4) overall perceived health status; and (5) global quality of life The EORTC-QLQ-C30(+3) has demonstrated acceptable levels of reliability and va lidity..$^{30}$

Pain intensity scores were obtained both by patient interview and by the pain diary. On an 11-point numeric rating scale with " 0 " representing "no pain" and "10" representing "pain as bad as you can imagine," patients' Present Pain Inten sity and Average Pain Intensity during the previous week were assessed. Validity and reliability of these scales are well established. ${ }^{31-36}$ Pain intensity scores, whid were obtained from the pain diary, consisted of two Present Pain Intensity score per day for a period of 2 months, and reports of changes in pain medication. In addition to the pain scores, reports of contacts with healthcare providers and changes in pain treatment were also obtained. 


\section{Statistical analyses}

Data were analyzed using Statistical Package for the Social Science (SPSS) (1990) including descriptive statistics, Chi-square tests, and Student's t-tests. To evaluate pain intensity scores over time, multivariate analyses of variance (MANOVA) were conducted. To compare different pain intensity scores, Pearson correlation coefficients were used. The Intra Class Correlation coefficients was used as a chance corrected index of agreement. Statistical significance was set at $\mathrm{p}<0.05$.

\section{Results}

\section{Patient characteristics}

In total, 383 patients were eligible for participation of which 70 patients (18.3\%) declined participation. Of these 70 patients, $48(68.6 \%)$ found the study too burdensome, $15(21.4 \%)$ were not motivated, and $7(10.0 \%)$ were too ill. Patients who declined participation were significantly older than those who participated $(p<0.05)$, and females refused to participate more frequently than males $(p<0.01)$. Of the 313 patients, $159(50.7 \%)$ were randomized to the experimental groups and $154(49.3 \%)$ to the control groups.

In the present study, only results of the experimental group patients are reported. The experimental group patients consisted of 106 patients $(66.7 \%)$ without and 53 patients $(33.3 \%)$ with district nursing. Patient characteristics and medical information of the experimental group patients are given in Table 1. The majority of patients were female. Patients suffered most often from breast cancer or cancer of the genitourinary organs and most were in an advanced stage of the disease. On admission (Table 2), all patients had experienced pain for at least 1 month; and the mean duration of the pain was 11.1 months ( $s d=23.4$; range $1-180$ months). Most patients experienced pain in the abdominal region and in the lower back region. Pain was associated with direct tumor involvement in 125 patients (78.6\%). Most patients reported that pain was intermittent without pain-free periods. Analgesics were prescribed in $91.2 \%(\mathrm{~N}=145)$ of the cases, $26.4 \%(N=42)$ used non-opioids, $25.2 \%(N=40)$ were prescribed weak opioids, and $39.6 \%(\mathrm{~N}=63)$ strong opioids. Of the patients receiving strong opioids, $28.6 \%(\mathrm{~N}=18)$ did receive pain medication parenteral. Other pain treatments, such as TENS or a nerve block were hardly used.

Quality of life data at baseline are given in Table 3 using the EORTC QLQ-C30(+3). Patients' Average Pain Intensity correlated $r=0.57(p<0.01)$ with the pain symptom scale of the EORTC QLQ-C3O $(+3)$, which can be considered as moderate.

Overall, as compared to other studies in which quality of life was studied in patients with advanced-stage cancer, ${ }^{37,38}$ patients showed low values on the different functioning, symptom, and global quality of life scales at baseline. Besides pain, patients experienced on average 3.8 other symptoms $(s d=1.5)$. Most frequently, patients reported pain, fatigue, loss of appetite, sleep disturbance, and constipation. 
Table 1. Demographic and medical characteristics of the experimental group

Number of experimental group patients

\section{District nursing ( $\mathbf{N}, \%)$}

Without

$106(66.7 \%)$

With

$53(33.3 \%)$

Sex

Female

$96(60.4 \%)$

Male

$63(39.6 \%)$

Age

Mean in years (sd)

$55.8(13.0)$

\section{Education ${ }^{a}$}

Low

Middle

High

$63(39.6 \%)$

$56(35.2 \%)$

$40(25.2 \%)$

\section{Type of cancer ( $>100 \%)$}

Lip, oral cavity and pharynx

Digestive organs, peritoneum

$9(05.7 \%)$

Respiratory, intrathoracic

$16(10.1 \%)$

$18(11.3 \%)$

Breast

Bone, connective tissue, skin

$43(27.0 \%)$

Genitourinary organs

$25(15.7 \%)$

Other

$43(27.0 \%)$

$16(10.1 \%)$

\section{Extent of disease}

Local

$22(13.8 \%)$

Regional

$37(23.3 \%)$

Metastatic

$87(54.7 \%)$

Unknown

$3(01.9 \%)$

Not applicable

$10(06.3 \%)$

\section{Cancer treatment ( $>100 \%)$}

None

Surgery

Chemotherapy

Radiotherapy

$36(22.6 \%)$

$123(14.5 \%)$

$57(35.8 \%)$

Hormonal therapy

$21(13.2 \%)$

Other and unknown

II (06.9\%)

$10(06.3 \%)$

a Education level: low corresponds to primary school and lower vocational training; middle corresponds to low level of secondary school and intermediate vocational training; high corresponds to high level of secondary school, college graduate and university 
Table 2. Pain characteristics of the study group

Number of experimental group patients

\section{Pain duration}

Months (sd)

Range

\section{Pain location ( $>100 \%)$}

Head, face, mouth

$34(21.4 \%)$

Breast, thoracic region

$31(19.5 \%)$

Upper shoulder, upper limbs

$46(28.9 \%)$

Abdominal region

$65(40.9 \%)$

Lower back, lumbar spine

$59(37.1 \%)$

Lower limbs

$43(27.0 \%)$

Anal, perianal, genital region

$8(05.0 \%)$

Everywhere

\section{Pain locations}

Mean (sd)

\section{Source of cancer pain ( $>100 \%$ )}

Direct tumor involvement

Cancer therapy

Associated with disease

\section{Pain patterna}

Constant pain

Intermittent without pain-free periods

Intermittent with pain-free periods

Unknown

\section{Pain treatment}

None

Non-opioids

Weak opioids

Strong opioids
$32(20.1 \%)$

$113(71.5 \%)$

$12(07.6 \%)$

I (00.6\%)
$14(08.8 \%)$

$42(26.4 \%)$

$40(25.2 \%)$

$63(39.6 \%)$

a "Constant pain" means pain intensity that is stable over a period of time; "intermittent without pain-free periods" means pain intensity that fluctuates without being free of pain; and "intermittent with pain-free periods" means pain intensity that fluctuates with periods of no pain. 
Table 3. Quality of life data at baseline

Mean (sd)

\section{Functioning scales}

Physical functioning

Role functioning

Cognitive functioning

Emotional functioning

Social functioning

Global quality of life

\section{Symptom scales and items ${ }^{b}$}

Fatigue
Nausea and vomitin
Pain
Dyspnea
Sleep disturbance
Loss of appetite
Constipation
Diarrhea
Financial impact

a Range $0-100$, with higher values indicating a higher value of functioning and quality of life.

${ }^{b}$ Range $0-100$, with higher values indicating more symptoms/difficulties.

It was hypothesized that patients with district nursing would differ from patients without district nursing. Results showed that patients with district nursing were more often female $(p<0.05)$, older $(p<0.001)$, differed in marital status $(p<0.05)$, and in having a profession $(p<0.05)$ compared to patients without dis. trict nursing. As was hypothesized, the patients who received district nursing in the home setting differed in health status from patients without district nursing. Patients with district nursing showed lower levels of physical functioning $(p<0.001)$, role functioning $(p<0.001)$, cognitive functioning $(p<0.05)$, global quality of life $(p<0.05)$, and reported more fatigue $(p<0.001)$ and appetite loss $(p<0.001)$ than patients without district nursing. Furthermore, patients with district nursing received chemotherapy less frequently $(p<0.001)$. Patients with district nursing were prescribed analgesics more frequently $(p<0.05)$, and were pre scribed stronger analgesics $(p<0.05)$ than patients without district nursing. At baseline, the patient groups did not differ in Present Pain Intensity and Average Pain Intensity during the previous week (Figure 1). However, on the pain subscale of the quality of life questionnaire, patients with district nursing had more pain during the previous week compared to patients without district nursing $(p<0.05)$. Postdischarge, statistically significant differences were found between the patient groups for Present Pain Intensity at all three assessment points $(p<0.01)$, and for Average Pain Intensity in the previous week at 4 weeks postdis charge $(p<0.05)$, and 8 weeks postdischarge $(p<0.05)$. 


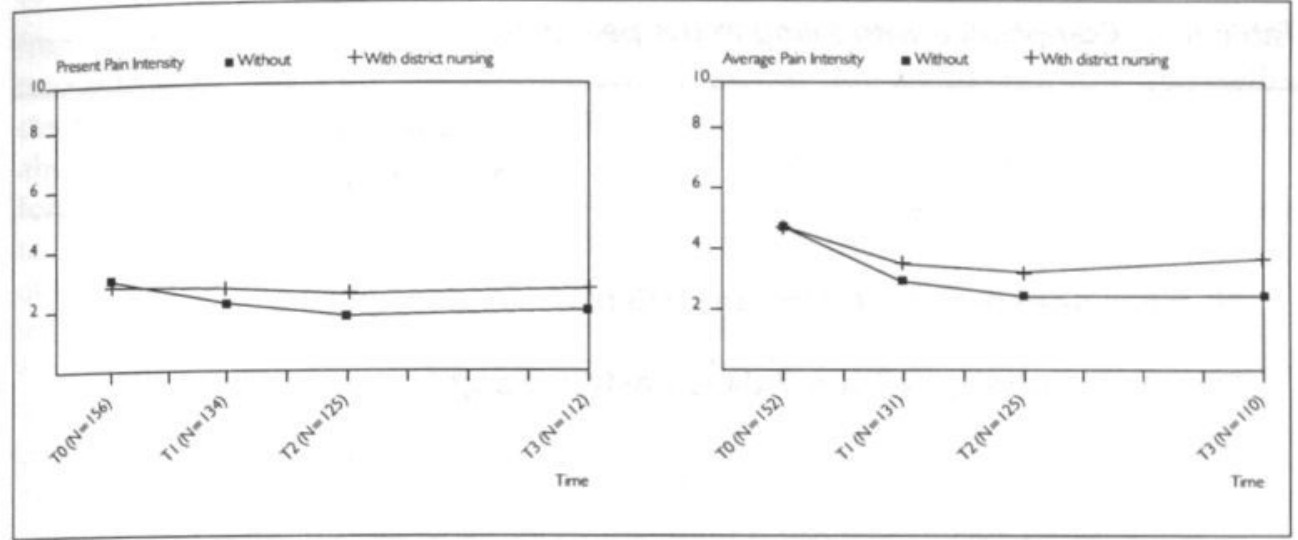

Figure 1. Patient's Present Pain Intensity and Average Pain Intensity obtained by patient interview

\section{Results of using the pain diary}

\section{Compliance}

Of the 159 patients, $17(10.7 \%)$ did not complete the pain diary because they died in the hospital before discharge or within 7 days postdischarge (Table 4). Of the remaining 142 patients, $122(85.9 \%)$ pain diaries were sent back after 2 months. Of the 20 patients whose pain diary was not returned, nine patients had died during follow-up without a family member or significant other returning the pain diary, eight stated they were too ill, and three patients had lost the pain diary.

Patients who did return the pain diary were less frequently in an advanced stage of their disease $(p<0.05)$, were less frequently prescribed analgesics $(p<0.05)$, and were prescribed weaker analge sics $(p<0.01)$ compared to patients whose pain diary was not returned.

Compliance with the pain diary was operationalized by dividing the number of pain scores recorded in the pain diary by the maximum number of pain scores possible. For patients who died during follow-up, the pain scores recorded were divided by the maximum possible pain scores until the day of death. In general, patients' compliance with the pain diary was high. In total, $85.9 \%$ of all possible pain scores were filled in. Of the pain diaries which were returned, $63(51.6 \%)$ had been filled in completely, and $31(25.4 \%)$ provided 80 to $99 \%$ of the pain intensity scores requested. Only, 19 patients $(15.6 \%)$ provided less than $60 \%$ of the scores requested. Reasons given by patients for not completing the entire pain diary were: being too ill $(26.7 \%)$, no availability of the pain diary because of hospital admission (23.3\%), experiencing no (severe) pain (17.5\%), or other reasons $(17.4 \%)$. It is remarkable that of the nine patients who died during the 2 -month follow-up, five continued recording pain in the diary until 0-5 days before dying. Thus, it can be concluded that even for patients who are seriously ill, compliance with completing the pain diary is very high. Levels of compliance were similar for patient groups with and without district nursing. Compliance was not affected 


\section{Number}

of patients

Number of experimental group patients

Died in hospital or within $\mathbf{7}$ days postdischarge

Subtotal

Returned pain diary

\section{Compliance}

$$
\begin{aligned}
& 100 \% \\
& 80-99 \% \\
& 60-79 \% \\
& 40-59 \% \\
& 20-39 \% \\
& 0-19 \%
\end{aligned}
$$

by gender, education, extent of disease, pain duration, or pain pattern. Low correlations were found between compliance and age $(r=-0.17, p<0.05)$, and between compliance and cognitive functioning $(r=-0.20, p=0.01)$. No differences were found between patients who were prescribed opioids and patients who were prescribed no opioids or non-opioids. Pain has a greater impact on a patient as it becomes more severe. ${ }^{39,40}$ The American Pain Society, ${ }^{9}$ and the Agency for Health Care Policy and Research ${ }^{8}$ have recommended the use of pain severity as the primary item of information in evaluating pain treatment. Pain rated as 5 or higher on a scale of 0 to 10 corresponds to interference with function. Results showed that levels of compliance were similar in patients reporting pain intensity scores of 5 and higher compared to patients with pain scores less than 5 . From this it can be concluded that neither pain intensity, nor pain treatment influences the extent of compliance with the pain diary.

\section{Psychometric properties of the pain diary}

Concurrent validity. Table 5 presents the mean and standard deviation of pain intensity scores obtained from patient interviews and from pain diaries over the same period of time. Present Pain Intensity scores obtained by the pain diary in the morning were compared to those obtained by patient interview the same day. Mean difference scores were computed by subtracting pain intensity scores obtained by patient interview from those obtained by the pain diary. Results showed that patients' Present Pain Intensity scores in the morning correlated between $r=0.74$ and $0.84(p<0.001)$ with those obtained by patient interviews, on the same day across the three assessment points. The overall difference ranged 
from 0.08 to 0.30 . Paired t-tests showed that there were no major differences between the two measurements during the same day. Intra Class Correlation coefficients varied from 0.76 to 0.88 . Healthcare providers may often ask patients about patients' Average Pain Intensity experienced in the previous week. Therefore, the relationship was calculated between Average Pain Intensity scores obtained from patient interviews and the mean of 14 Present Pain Intensity scores obtained from the pain diary over the same time period. The single Average Pain Intensity in the previous week obtained by the pain diary correlated with the mean Present Pain Intensity scores obtained by the diary between 0.80 and 0.91 $(p<0.001)$ across the three assessment points. The Intra Class Correlation coefficients ranged from 0.73 to 0.82 . Despite these high correlations, statistically significant differences were found between these scores. The overall difference ranged from 0.43 to $0.52(p<0.001)$, meaning a discrepancy of $18-22 \%$. In $11-24 \%$, the mean of 14 Present Pain Intensity scores obtained from the pain diary differed more than one point compared with patients' Average Pain Intensity scores obtained by patient interviews. Thus, it can be concluded that when patients were interviewed retrospectively, they tended to systematically overestimate their Average Pain Intensity compared with the scores from the pain diary. The mean difference scores did not vary between patients with and without district nursing, except at 8 weeks postdischarge $(p<0.05)$.

Influence of Present Pain Intensity on memory of pain. To further examine the accuracy of remembered Average Pain Intensity, the influence of the severity of

Table 5. Patients' pain intensity scores obtained by patient interview compared to pain intensity scores obtained by pain diary

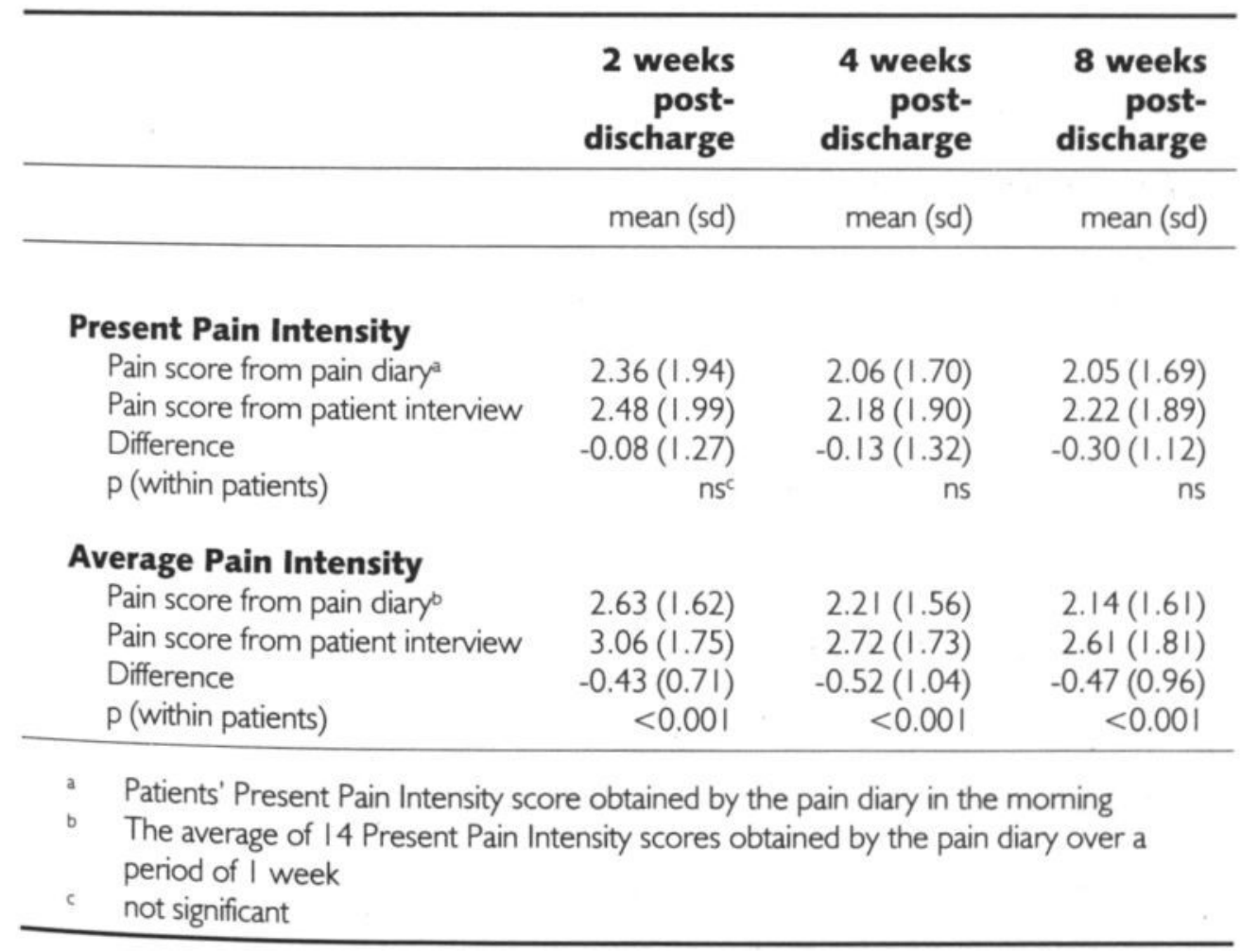


patient's Present Pain Intensity on recall of pain was analyzed. A high level of Present Pain Intensity was defined as a score obtained by patient interview of 5 and more, and a low level was defined as a Present Pain Intensity score of less than 5. ${ }^{4}$ Results showed that patients who reported high Present Pain Intensity scores did not show higher difference scores than patients with low Present Pain Intensity scores. Thus, memory of past pain was not dependent on the severity of patients' Present Pain Intensity.

Influence of changes in pain intensity on memory of pain. Another variable that might influence patient's recall of pain is fluctuation in pain. It was hypothesized that patients in whom pain changed over time may have more difficulty in grading their past pain than patients in whom pain remained stable. Therefore, increased pain was defined as a Present Pain Intensity score obtained from patient interviews that was at least 1 point or more higher than the score obtained at the preceding assessment, and stable or decreased pain was defined as a Present Pain Intensity score that was the same or lower than the score obtained at the preceding assessment. Individual comparisons with paired t-tests indicated that the discrepancy for the patient group with increased pain lasted significantly

Table 6. Patients' pain intensity scores obtained by interview compared to pain intensity scores obtained by pain diary

\begin{tabular}{rrrrr}
\hline & $\begin{array}{r}\text { Stable/ } \\
\text { Increased } \\
\text { pain }\end{array}$ & $\begin{array}{r}\text { decreased } \\
\text { pain }\end{array}$ & $\begin{array}{r}\text { Total } \\
\text { group }\end{array}$ & $\begin{array}{r}\text { p. } \\
\text { value }\end{array}$ \\
\hline mean $(\mathrm{sd})$ & mean $(\mathrm{sd})$ & mean $(\mathrm{sd})$ & \\
\hline
\end{tabular}

Average Pain Intensity

2 weeks postdischarge

Pain score from pain diary

Pain score fro patient interview

Difference

p-value (within patients)

$\begin{array}{rrr}3.26(1.44) & 2.44(1.64) & 2.36(1.94) \\ 4.09(1.78) & 2.76(1.65) & 3.06(1.75) \\ -0.82(0.69) & -0.31(0.68) & -0.43(0.71) \\ <0.001 & <0.001 & <0.001\end{array}$

\section{4 weeks postdischarge}

Pain score from pain diary

Pain score from patient interview

Difference

p-value (within patients)

$\begin{array}{rrr}2.81(1.57) & 1.99(1.52) & 2.21(1.56) \\ 3.65(1.47) & 2.82(1.68) & 2.72(1.73) \\ -0.83(1.11) & -0.33(0.90) & -0.52(1.04) \\ 0.001 & <0.05 & <0.001\end{array}$

\section{8 weeks postdischarge}

Pain score from pain diary

Pain score from patient interview

Difference

p-value (within patients)


$1.76(1.58)$
$2.15(1.67)$
$-0.39(0.77)$
$<0.01$

$2.14(1.61)$

$2.61(1.81)$

$-0.47(0.96)$

$<0.00$ । 
longer than in the group with stable or decreased pain at 2 weeks postdischarge $(p<0.01)$, and 4 weeks postdischarge $(p<0.01)$. No statistically significant difference was found at 8 weeks postdischarge. Patients whose pain increased during follow-up showed a greater discrepancy in pain memory (0.65-0.83), meaning a difference of $23-30 \%$, compared to patients whose pain intensity was stabilized or decreased $(0.31-0.39)$, meaning a difference of $13-22 \%$. Thus, patients whose pain increased showed a greater discrepancy in pain memory than patients whose pain intensity was stabilized or decreased (Table 6).

Fluctuations over time. The pain intensity scores obtained from patient interviews showed that the mean scores for Present Pain Intensity and Average Pain Intensity are stable postdischarge (Figure 1). Results showed that Present Pain Intensity correlated between 0.52 and $0.71(p<0.001)$ and Average Pain Intensity correlated between 0.31 and $0.35(p<0.001)$ across the assessment points. However, even with moderate to high correlations between pain scores at the different points in time, considerable within-patient variances in pain intensity ratings may be demonstrated. Therefore, fluctuations over time were evaluated. Results showed that the pain intensity scores reported in the morning were on average $2.4(s d=1.6)$ and in the evening $2.8(s d=1.6)$. The mean difference between morning and evening pain ratings was $-0.40(s d=0.7)$, which was statistically significant $(\mathrm{p}<0.001)$. Thus, it can be concluded that pain intensity measures fluctuate during the day, with higher scores in the evening than in the morning. Furthermore, the pattern of patients' pain over a longer period of time was analyzed. Differences between the highest and the lowest value, the standard deviation, and the variance were calculated for each patient over 2 -week periods for 2 months. Results are presented in Table 7. Results show that the mean pain intensity scores remains stable over time for the entire group.

However, when comparing patients' pain intensity scores case by case, the pain intensity scores fluctuate greatly during the weeks.

Stability. Stability refers to whether pain intensity scores can be replicated by the same observer (the patient) on more than one assessment point in time (intra-observer reliability). However, intra-observer reliability assumes that the pain that is being measured remains constant. In order to determine stability of patients' pain ratings, Pearson correlation coefficients were computed. For each patient, the pain intensity scores provided in the pain diary in the morning were correlated with the pain scores in the evening. The correlation coefficients were

Table 7. Variance in pain intensity scores obtained by pain diary

Week Mean (sd) Max.-min. sd Variance N

$\begin{array}{lrrrrr}1-2 & 2.7(1.7) & 3.8 & 1.1 & 1.6 & 118 \\ 3-4 & 2.5(1.7) & 3.1 & 0.9 & 1.2 & 114 \\ 5-6 & 2.3(1.6) & 2.9 & 0.9 & 1.2 & 100 \\ 7-8 & 2.3(1.6) & 3.0 & 0.9 & 1.5 & 97 \\ & & & & 1.8 & 119\end{array}$


compliant with recording pain intensity twice a day in the pain diary for a period of 2 months.

Few studies have evaluated the percentage of completing a pain diary in chronic pain patients; only one study ${ }^{13}$ reported the percentage of compliance $(68-85 \%)$ in cancer patients. It should be noted that the high compliance rate in the present study might be partly due to the guidance given by the specially trained nurses and the practice in completing the diary before discharge. Involving the patient's relatives in the task of completing the pain diary, may even improve the compliance rate. Another method to avoid missing data and delay of scoring pain intensity is to use a computerized pain diary. ${ }^{44}$ However, a computerized pain diary may be less attractive to, e.g., elderly patients, is more costly, and may be more complex than a paper-and-pencil pain diary. Considering the high compliance rate in the present study, there seems to be little need for a computerized version. The fact that variables such as age, level of education, pain duration, and pain pattern are not related to compliance show that there are no major constraints in using pain diaries in cancer patients with chronic pain complaints. Even seriously ill patients, such as those for whom district nursing was deemed necessary in the home situation, are able to fill in a pain diary twice a day for several months.

Accurate estimation of the patient's pain is crucial for good pain management. The daily self-descriptive records of patients offer healthcare providers a sufficiently clear picture to enable them to treat pain appropriately. If no pain diary is available, healthcare providers usually ask patient's about their pain intensity over a longer period of time. Studies have indicated that memory of pain, measured by means of Average Pain Intensity, can be influenced by various factors. ${ }^{19.24}$ Results of the present study support the hypothesis that patients are, to some extent, inaccurate in recalling their pain. Patients tend to estimate their Average Pain Intensity over the previous week about 0.5 higher than their Present Pain Intensity score, meaning a difference of about $20 \%$ of their pain score. Although memory of past pain did not depend on the severity of patient's Present Pain Intensity, Average Pain Intensity scores obtained by patient interview differed more than one point in $11-24 \%$ of patients at the different assessment points compared to pain intensity scores obtained by the pain diary. This discrepancy may be even greater because some patients used their pain diary during the telephone interview at follow-up when they were asked about their Average Pain Intensity during the previous week. Consequently, recall of their past pain may have been less accurate without the use of their pain diary. Although the results of the present study do not support previous findings that Present Pain Intensity influences the recall of past pain intensity, 20,45 the results are consistent with other findings 17,25 showing that patients who reported high Present Pain Intensity scores were not more accurate in recalling their past pain intensity than patients with low levels of present pain intensity. In the present study, however, the recall was associated with an increase in pain intensity. Patients who reported an increase in pain during the course of the study overestimated the intensity of their pain at the beginning of the study, while this was not the case in patients who reported a decrease or stabilized pattern during the study.

The question is whether this statistically significant difference can be considered as clinically relevant. Based on the idea that pain treatment is primarily based on patients' pain intensity scores, a discrepancy of $23-30 \%$ of the Present 
Pain Intensity score in the patient group with increased pain may be considered as clinically relevant. This result is in accordance with results reported by Bryant. ${ }^{19}$ From the present study, it can be concluded that recall accuracy depends, in part, on the stability of the pain. Although pain research and pain treatment relies almost entirely on patient recall in interviews, this study shows that healthcare providers should use Present Pain Intensity scores or pain scores obtained from pain diaries instead of a single rating reflecting patient's Average Pain Intensity over an earlier period.

One question that may be raised concerns how many assessments per day are necessary to obtain a measure that is reliable and valid. As expected, results of this study showed that pain intensity scores fluctuate during the day, with higher pain intensity scores in the evening than in the morning. Furthermore, the pain intensity scores fluctuate greatly during the weeks. Because of the considerable within-patient variance in pain intensity ratings, it can be concluded that at least two pain intensity scores per day are necessary. However, further research is needed to establish how many times a day pain can best be monitored.

The advantage of using a pain diary is that it is more sensitive to daily changes in pain intensity than measures obtained by patient interview, and reduces the possible distorting effects of memory on pain. However, only when pain intensity scores differ remarkably from one day to another is self-monitoring of pain in a pain diary useful. For patients with a stable pain pattern who report little fluctuation in pain level from one day to another, use of a pain diary may not be beneficial. In order to establish whether patient's pain intensity is stable over a longer period of time, one could evaluate pain intensity scores for, e.g., 1 week or more, and then decide what is required. From a clinical perspective, the pain diary is a valuable instrument for not only diagnostic evaluation, but also to assess treatment effects, and the extent to which patients are actively involved in the pain treatment.

In total, $60 \%$ of the patients reported that through the pain diary they gained insight in their pain complaints; this may give patients a sense of control over their pain. As a consequence, patients' self-care may be influenced positively. Although it is unclear to what extent the use of a pain diary helps patients cope with their pain, there is converting evidence as has also been pointed out in the literature that the use of a pain diary seem to be a helpful instrument in assessing pain.

In addition to reporting pain scores, a substantial number of patients $(84 \%)$ recorded other pain information in their diary, indicating that patients are eager to make notes related to pain and pain treatment in their diary. This points to the importance of self-management in pain patients.

Some limitations to this study should be noted. First, because the intervention consisted of different components, it was not possible to solely evaluate the effect of assessing pain by means of a pain diary. However, pain diaries are frequently used, whether the emphasis is on clinical use or research. It is for this purpose that studies on reactive effects of the measurement of pain which only focus on the use of a pain diary itself are not very useful. In our opinion the use of a pain diary should be combined with verbal instruction and education. Second, the extent to which these research findings can be generalized is unknown. Although the return rate was high $(86 \%)$, the results might have been different if all patients had completed their pain diary. It is our experience that when 
patients are well informed and instructed in the hospital, they are able and willing to fill in the pain diary, even when they are seriously ill. However, it is uncertain whether the compliance rate for the pain diary would be as high if the patients are not being followed up as part of the intervention. The follow-up phone calls might have influenced the compliance rate positively. Third, results showed individual fluctuations during the week and over time. Based on the results, the use of a pain diary in which daily pain intensity scores are reported seems to be very helpful. However, it is not completely clear to what extent the regular pain management would be changed in case patients' pain intensity was treated based on patients' Present Pain Intensity. Finally, although fluctuations over time were analyzed, more research is needed to empirically derive pain intensity profiles, and to determine whether differences exist between the profile groups for demographic, physical and psychosocial variables.

In summary, the results of the present study indicate that the pain diary is a feasible tool for cancer patients to assess and document their chronic pain. The validity and reliability of the pain diary have been well established in this study. Even seriously ill patients are able to fill in a pain diary for a long period of time. Healthcare providers should use pain intensity scores obtained by a pain diary or ask patients about their Present Pain Intensity instead of asking about patient's Average Pain Intensity. From a clinical perspective, healthcare providers should consider the use of a pain diary as a valuable instrument for not only diagnostic evaluation, but also to assess treatment effects, compliance rates and follow-up results. Finally, the use of a pain diary helps patients to gain insight in their own pain complaints. Based on the positive evaluation of patients, the authors advice to integrate the use of a pain diary with the other parts of the multi-method intervention.

\section{Acknowledgments}

This work was supported by a grant from the Dutch Cancer Society (grant no 92-469). The authors thank all patients for their cooperation. We extend special thanks to the nursing departments of the Netherlands Cancer Institute/Antoni van Leeuwenhoek Hospital and the district nurses for participating in the study. 


\section{References}

1. Cleeland CS, Cleeland LM, Dar R, Rinehardt LC. Factors influencing physician management of cancer pain. Cancer, 1986;58:796-800.

2. Grossman SA, Sheidler VR, Swedeen K, Mucenski J, Piantadosi S. Correlation of patient and caregiver ratings of cancer pain. Journal of Pain and Symptom Management, 1991;6:53-57.

3. Kerns RD, Finn P, Haythornthwaite J. Self-monitored pain intensity: psychometric properties and clinical utility. Journal of Behavioral Medicine, 1988;11:71-82.

4. World Health Organization. Cancer pain relief. Geneva, Switserland, 1986.

5. Au E, Loprinzi CL, Dhodapkar M, Nelson T, Novotny P, Hammack J, O'Fallon J. Regular use of a verbal pain scale improves the understanding of oncology inpatient pain intensity. Journal of Clinical Oncology, 1994;12:2751-2755.

6. Choiniere M, Melzack R, Girard N, Rondeau J, Paquin MJ. Comparisons between patients' and nurses' assessment of pain and medication efficacy in severe burn injuries. Pain, 1990;40:143-152.

7. Hodgkins M, Albert D, Daltroy L. Comparing patients' and their physicians' assessments of pain. Pain, 1985;23:273-277.

8. AHCPR. Management of cancer pain. Clinical Practice Guideline. Rockville, Md. Agency for health Care Policy and Research Public health Service, U.S. department of health and Human Services 1994.

9. American Pain Society. Principles of analgesic use in the treatment of acute pain and chronic cancer pain: a concise guide to medical practice. Skokie, IL, American Pain Society 1992.

10. World Health Organization. Cancer pain relief and palliative care. Geneva, Switserland, 1990.

11. Faries JE, Mills DS, Goldsmith KW, Phillips KD, Orr J. Systematic pain records and their impact on pain control. A pilot study. Cancer Nursing, 1991;14:306-313.

12. Wagemans MF, Spoelder EM, Zuurmond WW, de Lange JJ. [continuous intrathecal analgesia in terminal cancer patients within transmural health care]. [Dutch]. Nederlands Tijdschrift voor Geneeskunde, 1993;137:1553-1557.

13. Geddes DM, Dones L, Hill E, Law K, Harper PG, Spiro SG, Tobias JS, Souhami RL. Quality of life during chemotherapy for small cell lung cancer: assessment and use of a daily diary card in a randomized trial. European Journal of Cancer, 1990;26:484-492.

14. Kravitz RL, Delafield JP, Hays RD, Drazin R, Conolly M. bedside charting of pain levels in hospitalized patients with cancer: a randomized controlled trial. Journal of Pain and Symptom Management, 1996;11:81-87.

15. Follick MJ, Ahern DK, Laser Wolston N. Evaluation of a daily activity diary for chronic pain patients. Pain, 1984;19:373-382.

16. Jamison RN, Sbrocco T, Parris WC. The influence of physical and psychosocial factors on accuracy of memory for pain in chronic pain patients. Pain, 1989;37:289-294.

17. Linton SJ, Melin L. The accuracy of remembering chronic pain. Pain, 1982;13:281-285.

18. Salovey P, Smith A, Turk DC, Jobe JB, Willis GB. The accuracy of memories for pain: not so bad most of the time. American Pain Society Journal, 1993;2:184-191.

19. Bryant RA. Memory for pain and affect in chronic pain patients. Pain, 1993;54:347-351.

20. Eich E, Reeves JL, Jaeger B, Graff Radford SB. Memory for pain: relation between past and present pain intensity. Pain, 1985;23:375-380.

21. Erskine A, Morley S, Pearce S. Memory for pain: a review. Pain, 1990;41:255-265.

22. Jensen MP, Turner LR, Turner JA, Romano JM. The use of multiple-item scales for pain intensity measurement in chronic pain patients. Pain, 1996;67:35-40.

23. Pearce SA, Isherwood S, Hrouda PH, Richardson PH, Erskine A, Skinner J. Memory and pain: tests of mood congruity and state dependent learning in experimentally induced and clinical pain. Pain, 1990;43:187-193.

24. Smith WB, Safer MA. Effects of present pain level on recall of chronic pain and medication use, Pain, 1993;55:355-361.

25. Jamison RN, Brown GK. Validation of hourly pain intensity profiles with chronic pain patients. Pain, 1991;45:123-128.

26. Mikail R, VanDeursen J, von Baeyer CL. Rating pain or rating serenity: effects on cold-pressor pain tolerance. Canadian Journal of Behavioral Science, 1986;18:126-132.

27. Von Baeyer CL. Reactive effects of measurement of pain. Clinical Journal of Pain, 1994;10:18-21.

28. Haynes SN. Principles of behavioral assessment. New York: Gardner Press, 1978. 
29. De Wit R, Van Dam F, Zandbelt L, Van Buuren A, Van der Heijden K, Leenhouts G, Loonstra S. A Pain Education Program for chronic cancer patients: follow-up results from a randomized controlled trial. Pain, 1997;73:55-69.

30. Aaronson NK, Ahmedzai S, Bergman B, Bullinger M, Cull A, Duez NJ, Filiberti A, Flechtner H, Fleishman SB, de Haes JC. The European organization for research and treatment of cancer QLQ-C30: a quality-of-life instrument for use in international clinical trials in oncology. Journal of the National Cancer Institute, 1993;85:365-376.

31. De Conno F, Caraceni A, Gamba A, Mariani L, Abbattista A, Brunelli C, La Mura A, Ventafridda Pain measurement in cancer patients: a comparison of six methods. Pain, 1994;57:161-166.

32. Jensen MP, Karoly P, Braver S. The measurement of clinical pain intensity: a comparison of six methods. Pain, 1986;27:117-126.

33. Kremer E, Atkinson JH, Jr. Pain measurement: construct validity of the affective dimension of the McGill Pain Questionnaire with chronic benign pain patients. Pain, 1981;11:93-100.

34. McGuire DB. Measuring pain. In: Frank-Stromborg M, ed. Instruments for clinical nursing. Norwalk, CT, 1988: 333-356.

35. Price DD, Bush FM, Long S, Harkins SW. A comparison of pain measurement characteristics of mechanical visual analogue and simple numerical rating scales. Pain, 1994;56:217-226.

36. Syrjala KL. The measurement of pain. In: McGuire DB, Yarbro CH, eds. Cancer pain management Philadelphia: Saunders, 1987: 133-150.

37. Kaasa S, Bjordal K, Aaronson N, Moum T, Wist E, Hagen S, Kvikstad A. The EORTC core qualityo life questionnaire (QLQ-C30): validity and reliability when analysed with patients treated with palliative radiotherapy. European Journal of Cancer, 1995;31A:2260-2263.

38. Simons JP, Aaronson NK, Vansteenkiste JF, ten Velde GP, Muller MJ, Drenth BM, Erdkamp FL, Cobben EG, Schoon EJ, Smeets JB, Schouten HC, Demedts M, Hillen HF, Blijham GH, et al. Effect of medroxyprogesterone acetate on appetite, weight, and quality of life in advanced-stage non-hormone-sensitive cancer: a placebo-controlled multicenter study. Journal of Clinical Oncology, 1996;14:1077-1084.

39. Cleeland CS, Gonin R, Hatfield AK, Edmonson JH, Blum RH, Stewart JA, Pandya KJ. Pain and its treatment in outpatients with metastatic cancer. New England Journal of Medicine, 1994;330:592-596.

40. Serlin RC, Mendoza TR, Nakamura Y, Edwards KR, Cleeland CS. When is cancer pain mild, moderate or severe? grading pain severity by its interference with function. Pain, 1995;61:277-284.

41. Camp LD. A comparison of nurses' recorded assessments of pain with perceptions of pain as described by cancer patients. Cancer Nursing, 1988;11:237-243.

42. Camp Sorrell D, O'Sullivan P. Effects of continuing education. Pain assessment and documentation. Cancer Nursing, 1991;14:49-54.

43. De Wit R, van Dam FSAM. Verpleegkundige pijnmeting bij kankerpatienten: een interventiestudie. Verpleegkunde, 1991/92;2:68-75.

44. Lewis B, Lewis D, Cumming G. Frequent measurement of chronic pain: an electronic diary and empirical findings. Headache, 1995;60:341-347.

45. IASP. Pain terms: a list with definitions and notes on usage. Pain, 1979;6:249. 


\section{Chapter 5}

\section{Empirical comparison of commonly used measures to evaluate pain treatment in cancer patients with chronic pain}

De Wit, R., Van Dam, F., Huijer Abu-Saad, H., Loonstra, S., Zanbelt, L., Van Buuren, A., Van der Heijden, K., Leenouts, G.

Empirical comparison of frequently used measures to evaluate pain treatment in cancer patients with chronic pain.

Journal of Clinical Oncology, 1999;17:1280-1287. 


\section{Introduction}

Many studies show that pain due to cancer is inadequately treated.1,2 The percentage of cancer patients with inadequate treatment of pain is reported to range widely from $7-90 \% .^{2-23}$ Heterogeneity of patient groups, treatment regimens, and research designs may, in part, explain the large variance in adequacy. The present study investigates another possible cause of differences in treatment outcomes, namely, the diversity of measures used to evaluate pain treatment. Little attention has been directed toward the measurement of outcomes of effec. tive pain treatment. There are no known studies comparing commonly used measures to evaluate the adequacy of cancer pain treatment. Consequently, the lack of a gold standard to evaluate the efficacy of pain programs results in the use of various measures and makes comparison of pain studies difficult.

Because pain is a multidimensional concept, a wide variety of dimensions might be used to assess the quality of pain treatment, such as physiologic, sensory, affective, cognitive, behavioral, and sociocultural dimensions. Although the importance of multidimensional measurement of cancer pain has been acknowledged, pain treatment is most frequently evaluated unidimensionally. However, the measures described in this study primarily represent the sensory and behavioral dimensions.

In the literature, the typologic classification of commonly used outcome measures to evaluate pain treatment can be arranged into four groups. The first type of outcome measure that is frequently used to estimate treatment effects is based on patients' self-report of pain intensity. $7,8,16,17,21,24,25$ The measurement of pain intensity continues to be the most frequently used tool in monitoring pain. Several pain intensity scales are currently used to assess the pain, such as Visual Analog Scales, Numeric Rating Scales, and Verbal Rating Scales. ${ }^{26-28}$ Zech et al ${ }^{21}$ showed that $23 \%$ of patients experienced severe pain or worse for more than $10 \%$ of the treatment period as measured on a Verbal Rating Scale. In two studies, Grond et al reported that $12 \%$ and $3 \%$ of the cancer patients experienced severe pain or worse. ${ }^{7,8}$ To obtain an indication for adequate pain treatment, the American Pain Society (APS) ${ }^{29}$ and the Agency for Health Care Policy and Research $(A H C P R)^{30}$ proposed a cutoff score of 5 or higher on a Numeric Rating Scale to describe inadequate cancer pain treatment. This cutoff score is based on studies showing that higher pain scores interfere with daily functioning. ${ }^{2,10,13}$ Cleeland et $\mathrm{al}^{2}$ found that $62 \%$ of the advanced cancer patients rated their Worst Pain Intensity as 5 or higher, Larue et al ${ }^{10}$ found that $69 \%$ reported a pain score of 5 or higher on Worst Pain Intensity, whereas $54 \%$ had a score of 5 or higher on the Average Pain Intensity scale. Serlin et $\mathrm{al}^{13}$ reported that $70-90 \%$ of the patients rated their Worst Pain Intensity as 5 or higher.

The second type of frequently used outcome measure to evaluate pain treatment consists of estimating the change in pain intensity. ${ }^{31,32}$ With the Pain Relief Scale, a weighted judgment about the effect of the pain treatment is given. $\mathrm{Pa}$ tients are asked to compare themselves on a scale that starts for everyone at the same level of "no change" or "worsening pain" and ends at "complete re lief." $6,9,14,15,17$ Studies showed complete pain relief in 87 - 93\% of patients, 15,17 whereas Goisis et $\mathrm{al}^{6}$ found partial or total pain control in $93 \%$ of patients.

A third type of outcome measure to evaluate cancer pain treatment consists of measuring patient satisfaction. The Patient Satisfaction Scale measures how 
satisfied patients are with their treatment. ${ }^{33}$ The APS 29,34 and the AHCPR ${ }^{30}$ proposed the Patient Satisfaction Scale as one of the criteria by which the success of pain guidelines should be investigated. Studies measuring patient satisfaction showed modest to very extremely proportions (59-93\%) of patients who were satisfied with pain relief or cancer pain treatment or with the responsiveness of the staff. ${ }^{12,18,23}$

Finally, the fourth group of measures consists of Pain Management Indexes, which relate the level of analgesics with the patient's reported level of pain. ${ }^{2}$ Three types of Pain Management Indexes can be distinguished, 3,5,10,11,19,20,22 namely: (1) Cleeland's Pain Management Index, in which patients' Worst Pain Intensity is related to pain medication as prescribed by the clinician; (2) Ward's Pain Management Index, in which Worst Pain Intensity is related to the pain medication as used by the patient; and (3) Zelman's Pain Management Index which consists of a composite pain intensity score related to the pain medication prescribed. Cleeland et $\mathrm{al}^{2}$ found that $42 \%$ of the metastatic cancer patients were prescribed analgesics at less than optimal potency. Other studies that used one of the Pain Management Indexes to evaluate pain treatment showed that 27 $74 \%$ of patients received inadequate cancer pain treatment. 3,5,10,11,19,20,22

It is unknown, however, whether the high variance of patients not receiving adequate pain treatment is due to differences in defining adequate versus inadequate pain medication, heterogeneity of patient groups, or differences in the quality of the pain treatment itself. Pain Intensity Markers, Pain Relief Scales, Patient Satisfaction Scales, and Pain Management Indexes are used interchangeably for the evaluation of pain treatment, ${ }^{9}$ which results in substantial differences in reported adequacy of cancer pain treatment. When a Pain Relief Scale or a Patient Satisfaction Scale is used, cancer pain treatment is most frequently evaluated as adequate. However, when a Pain Intensity Marker or Pain Management Indexes are used, most studies show high percentages of inadequate cancer pain treatment. On the basis of the diversity of results, it seems that the commonly used groups of outcome measures cover different aspects of patients' pain experience.

Given the lack of systematic use of well-established criteria to evaluate the adequacy of cancer pain treatment, we compared the commonly used outcome measures to evaluate pain treatment in a cancer pain population. The aim was to elucidate whether different measures lead to different results.

\section{Patients and methods}

\section{Design and patient population}

This study was part of a randomized controlled trial in which the effect of a Pain Education Program was evaluated. Because the focus of the present study is on comparing frequently used measures to evaluate the adequacy of pain treatment in cancer patients, no description of the intervention is reported here. A detailed description of the Pain Education Program and the way patients were randomized is given elsewhere. ${ }^{35}$ The protocol was approved by the research ethics committee of the hospital. Consenting patients were assigned to either the control group, in which regular pain treatment was provided, or to the experimental 
group, in which, in addition to the regular pain treatment, the Pain Education Program was given. Both patient groups were randomly assigned after stratifica. tion for three variables: sex (male/female), age ( $<60$ years $/ \geq 60$ years), and meta static sites (yes/no/unknown).

After admission to the hospital, patients who provided informed consent participated in the study. Eligible patients had to meet the following inclusion criteria: pain related to cancer, cancer therapy, or illness; pain duration of at least 1 month; an expected hospital stay of at least 3 days; and life expectancy of at least 3 months after discharge from the hospital (as assessed by the physician). Patients were excluded if they were unable to read and speak Dutch, not accessible by telephone, or residing in a nursing or retirement home.

\section{Procedure}

All patients completed a baseline measure 2 - 4 days after hospital admission that included details of sociodemographic variables, medical history, pain experience, pain treatment, and adequacy of pain treatment. All data were obtained b patient interviews or collected from the medical and nursing records. After discharge, patients were followed up by telephone. Then, data were collected in regard to pain and adequacy of pain treatment.

\section{Measures}

Measures related to patient characteristics included sociodemographic variables (e.g., sex, age, marital status, and education), and medical variables (e.g., diagnosis, time since diagnosis, tumor stage, metastatic sites, treatment, and adverse effects). Data regarding analgesics included name, dose, frequency of nonopioids and opioids, routes of administration, schedules of analgesics, and other pain treatments (e.g., nerve blocks, transcutenous electrical nerve stimulation). Data were collected before testing from the medical record. Patients were interviewed to establish what pain medication was prescribed at baseline, and at, 2 , 4 , and 8 weeks after discharge, and what pain medication had been taken the day before at 2, 4, and 8 weeks after discharge. The four types of outcome meas ures to evaluate the adequacy of pain treatment were as follows: Pain Intensity Markers, Pain Relief Scale, Patient Satisfaction Scale, and Pain Management Indexes.

Pain Intensity Markers. Pain Intensity Markers are based on patients' pain intensity scores. Pain intensity was measured on an 11-point Numeric Rating Scale that rated patients' Present Pain Intensity, Average Pain Intensity during the last week, and Worst Pain Intensity. ${ }^{36}$ Pain Intensity was assessed by an 11-point numeric rating scale ranging from $0-10$ in which " 0 " represents "no pain" and "10" represents "pain as bad as you can imagine." The validity and reliability of the pain intensity scale are well established, ${ }^{27,37-39}$ and the scale has been found easy to administer with very few patients being unable to complete it. ${ }^{37}$ Patients with a pain score of 5 or higher are considered to have substantial pain, ${ }^{13}$ meaning that these patients are treated inadequately for their pain. In the present study, Pain Intensity Markers were based on patients' Present Pain Intensity ( 
Substantial Present Pain), Average Pain Intensity (Substantial Average Pain), and Worst Pain Intensity (Substantial Worst Pain).

Pain Relief. With the Pain Relief Scale, patients are asked "To what extent is the pain relieved by the pain treatment?" The Pain Relief Scale is rated on a 6-point scale with the anchor points "complete relief" and "worsening of pain." Patient scores ranging of 5 to 6 (no relief, worsening of pain) were considered indicators of inadequate treatment, and scores that ranged from 1 to 4 (complete relief, strong relief, moderate relief, and slight relief) were assessed as indicators of adequate treatment. ${ }^{31}$

Patient Satisfaction. The Patient Satisfaction Scale rates how satisfied patients are with the pain treatment on a 5-point scale, from very satisfied (1), somewhat satisfied (2), neither satisfied nor dissatisfied (3), somewhat dissatisfied (4), to very dissatisfied (5). The scores are then classified into inadequate (4 to 5), or adequate ( 1 to 3 ) treatment. An evaluation of patient satisfaction with pain management is one component of a total quality assurance program on pain management recommended by the APS. ${ }^{12,40}$

Pain Management Indexes. Three Pain Management Indexes were used. (Table 1). Cleeland's Pain Management Index ${ }^{2}$ is based upon the patient's level of Worst Pain Intensity and categorized as: 0 (no pain), 1 (1 - 3: mild pain), 2 (4 - 7: moderate pain), or 3 (8 - 10: severe pain). Then, the pain level is subtracted from the most potent level of analgesic drug therapies as prescribed by clinicians, scored as 0 (no analgesic drug), 1 (non-opioids), 2 (a weak opioid), or 3 (a strong opioid). Cleeland's Pain Management Index can range from -3 (a patient receiving no analgesic drugs [score 0] who is in severe pain [score 3]) to +3 (a patient receiving strong opioids [score 3] who is pain-free [score 0]). These scores are then dichotomized: negative scores indicate inadequate orders for analgesic drugs, and scores of 0 or higher are considered to be a conservative indicators of acceptable treatment. A variation on Cleeland's Pain Management Index was

Table 1. Pain Management Index according to Cleeland, Ward, and Zelman

\begin{tabular}{|c|c|c|c|c|c|}
\hline & & $\begin{array}{r}0 \\
\text { No } \\
\text { pain } \\
(0)\end{array}$ & $\begin{array}{r}1 \\
\text { Mild } \\
\text { pain } \\
(1-3)\end{array}$ & $\begin{array}{r}2 \\
\text { Moderate } \\
\text { pain } \\
(4-6)\end{array}$ & $\begin{array}{r}3 \\
\text { Severe } \\
\text { pain } \\
(7-10)\end{array}$ \\
\hline \multirow{4}{*}{\multicolumn{2}{|c|}{$\begin{array}{l}\text { No analgesics (0) } \\
\text { Non-opioids (1) } \\
\text { Weak opioids (2) } \\
\text { Strong opioids (3) }\end{array}$}} & 0 & -1 & -2 & -3 \\
\hline & & 1 & 0 & -1 & -2 \\
\hline & & 2 & I & 0 & -1 \\
\hline & & 3 & 2 & 1 & 0 \\
\hline \multicolumn{6}{|c|}{$\begin{array}{l}\text { Note. Cleeland's Pain Management: Analgesic prescribed - Worst Pain Intensity; } \\
\text { Ward's Pain Management Index: Analgesic actually used - Worst Pain Intensity; } \\
\text { Zelman's Pain Management Index: Analgesic actually used - ([Present Pain Intensity } \\
+ \text { Average Pain Intensity + Worst Pain Intensity]/3). } \\
\text { These indexes can range from - } 3 \text { (very inadequate) to } 3 \text { (very adequate). } \\
\text { The scores are dichotomized to inadequate (score }-3 \text { to }-1 \text { ) or adequate (score } 0 \\
\text { to 3). }\end{array}$} \\
\hline
\end{tabular}


developed by Ward et al. ${ }^{19,20}$ Ward's Pain Management Index is fully based on Cleeland's Pain Management Index, except that it incorporates analgesics as used by a patient instead of analgesics as prescribed by the physician.

A third Pain Management Index was developed by Zelman et al. ${ }^{22}$ Zelman's Pain Management Index consists of a pain intensity score that is computed by averaging the patient's Present Pain Intensity, Average Pain Intensity, and Worst Pain Intensity. The composite pain score is then categorized into 0 (no pain), 1 (1 - 3: mild pain), 2 (4-6: moderate pain), and 3 ( 7 - 10: severe pain) and related to medication used. Evidence of the validity of the Pain Management Indexes has been demonstrated by Ward et al. ${ }^{19}$

\section{Statistical methods}

Data were analyzed using the Statistical Package for the Social Sciences (SPSS Inc, Cary, NC), including descriptive statistics, Chi-square tests, and Student ttests. $P<0.05$ was considered significant. Three approaches were taken to investigate the agreement between the measures. First, results were analyzed by means of overall agreement, meaning the proportion of judgments in which two dichotomized measures, uncorrected for change, agree. Second, results were analyzed by means of Cohen's kappa, which is a measure of agreement corrected for chance. ${ }^{41}$ Factor analysis with oblique rotation was conducted to identify the relationships between the measures. Oblique rotation was selected because the objective was to obtain factors that were correlated and theoretically meaningful. Factors with an eigenvalue $>1$ were selected, and items were included if they loaded greater than 0.35 on it.

\section{Results}

Of the 383 patients asked to participate in the study; 313 patients $(82 \%)$ agreed. Patients who declined $(\mathrm{N}=70)$ found the study too burdensome $(\mathrm{N}=$ 48), were not motivated $(N=15)$, or were too ill $(N=7)$. Patients who declined were significantly older than those who participated $(p<0.05)$, and women refused to participate more frequently than men $(p<0.05)$. Of the participating patients, 159 patients $(51 \%)$ received the intervention and 154 patients $(49 \%)$ did not. At follow-up, $89 \%$ of the patients completed the posttest at 2 weeks after discharge, $83 \%$ completed the posttests at 2 and 4 weeks after discharge, and $75 \%$ completed all three posttests up to 8 weeks after discharge. Dropouts were due to death $(60 \%)$, being too ill $(21 \%)$, experiencing the study as too burdensome to continue $(14 \%)$, or lack of motivation $(5 \%)$.

Of all patients, $63 \%$ were woman, and the mean age was 56 years $(s d=12)$. From the total group, $41 \%$ had primary school or lower vocational training, $33 \%$ had middle- to low-level secondary school or intermediate vocational training, and $26 \%$ had high-level of secondary school, or were college or university graduates. For $33 \%$ of the patients, district nursing was planned after discharge.

The major diagnoses were breast cancer $(30 \%)$, cancer of the genitourinary organs $(24 \%)$, and bone, connective tissue or skin cancer (14\%). In total, $58 \%$ had metastases, the extent of disease was regional in $19 \%$ and local in $14 \%$, and the tumor status was unknown or not applicable in $8 \%$. Bone, liver, lung, and 


\section{Table 2. Pain characteristics of the study population}

Number of

patients

Pain location (> 100\%)

Head, face, mouth

Breast, thoracic region

Upper shoulder and upper limbs

Abdominal region

Lower back, lumbar spine, sacrum, coccyx

Lower limbs

Anal, perianal, and genital region

Everywhere

$\begin{array}{rr}66 & 21.1 \\ 64 & 20.4 \\ 91 & 29.1 \\ 124 & 39.6 \\ 122 & 39.0 \\ 85 & 6.5 \\ 17 & 5.4 \\ 2 & 0.1\end{array}$

\section{Source of cancer pain ( $>100 \%$ )}

Direct tumor involvement

Cancer therapy

Associated with cancer disease

Unknown

\section{Locations per patient}

\section{Pain duration (months)}

Mean

sd

\section{Symptomatic cancer pain treatment}

\author{
Analgesics \\ Coanalgesics \\ Transcutaneous Electrical Nerve Stimulation \\ Other
}

lymphoma metastases were reported most frequently. In $36 \%$ of the patients, chemotherapy was the main therapy, $16 \%$ received surgery, $13 \%$ received radiation therapy, $7 \%$ received hormonal therapy, and $7 \%$ received another therapy or the therapy was still not known at pretest. In $22 \%$ of the patients, no anticancer treatment was given.

Pain characteristics are listed in Table 2. Pain in the abdominal and lower back regions was experienced most frequently, in $40 \%$ and $39 \%$ of patients, respectively. The mean pain duration was 14 months (sd = 33 months; range, 1 - 324 months), and pain lasted 5 years or longer in 16 patients (4\%). Pain was associated with direct tumor involvement in $77 \%$ and with the cancer therapy in $24 \%$. Patients reported on average 1.8 pain locations. Seven percent of the patients reported that they experienced pain constantly, $73 \%$ reported that pain was intermittent without pain-free periods, $19 \%$ reported that pain was intermittent with pain-free periods, and $7 \%$ reported that pain was constant; the pattern of pain was unknown in 1\%. At prestest, patients' mean Present Pain Intensity score was $3.3(s d=2.3)$, the mean Average Pain Intensity was $4.9(s d=2.1)$, and the mean 
Worst Pain Intensity was $7.7(\mathrm{sd}=2.1)$.

At 2 weeks after discharge, patients' Present Pain Intensity, Average Pain Intensity, and Worst Pain Intensity were significantly decreased and stayed fairly constant at 4 and 8 weeks after discharge.

\section{Adequacy of pain treatment}

The percentage of missing data on the Pain Intensity Markers ranged from 1 . $8 \%$ at the different assessment points, and ranged from $3-8 \%$ for the Pain Relief and the Patient Satisfaction Scales. The single-item scales were completed easily by patients, whereas the multi-item Pain Management Indexes were relatively more time-consuming for healthcare providers to complete, because data on both pain intensity and analgesics were required. At baseline, the percentage of missing data on the Pain Management Indexes was 19\%; after discharge, the

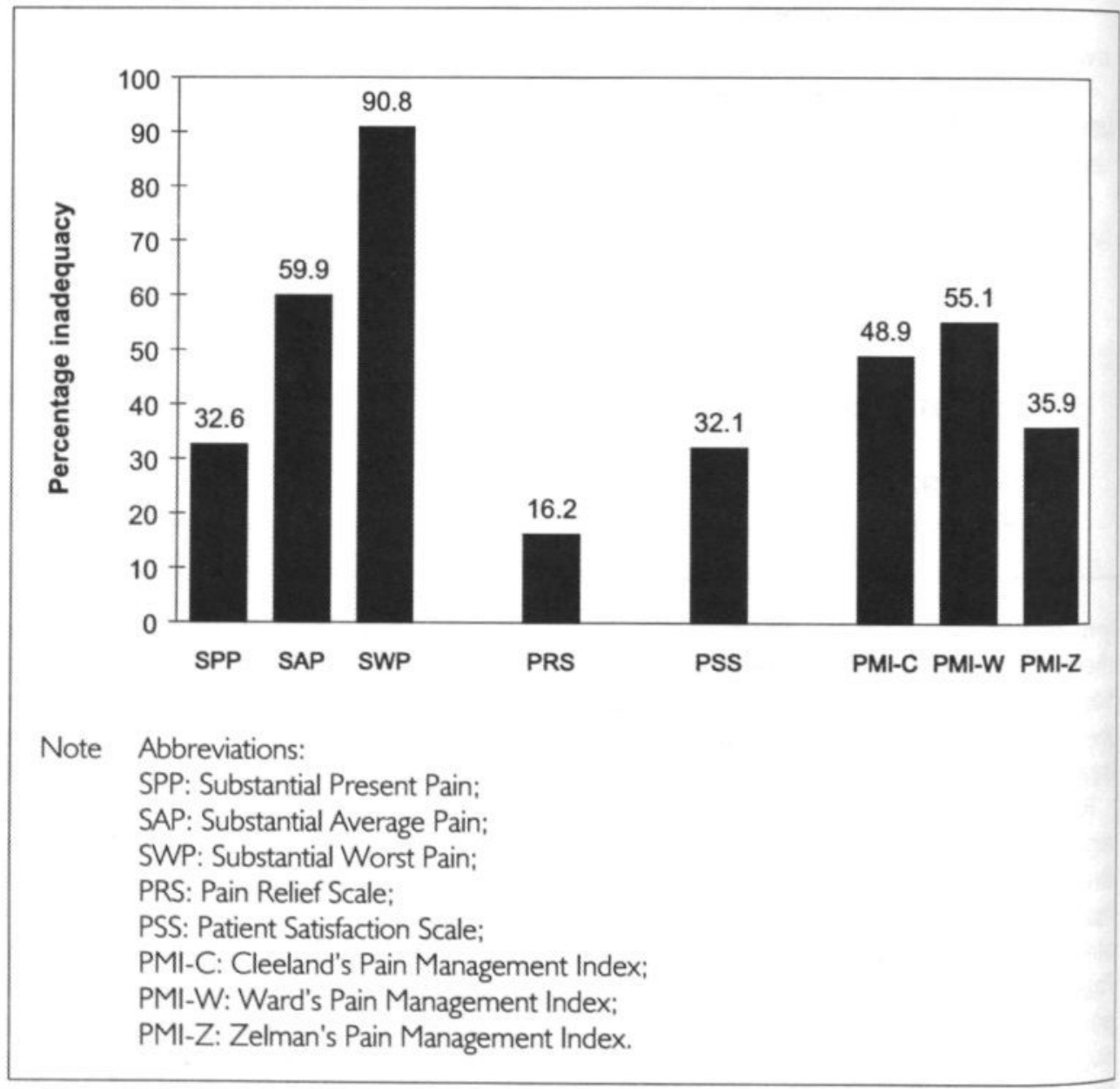

Figure 1. Inadequacy of cancer pain treatment at baseline 
rates ranged from $7-8 \%$. Overall, the percentage of missing data was low to moderate.

Results of the four types of outcome measures at pretest are shown in Figure 1. The percentage of patients who were treated inadequately ranged from 16 $91 \%$. The enormous difference in inadequacy of cancer pain treatment depended on the scale used. When Substantial Worst Pain was measured, approximately nine out of every ten patients were assessed as receiving inadequate pain treatment; in contrast, use of the Pain Relief Scale resulted in fewer than two out of every ten patients being treated inadequately.

After discharge, the highest percentage of inadequate pain treatment was again shown by the Substantial Worst Pain scale (60 - 91\%), whereas the use of the Pain Relief Scale resulted in the lowest percentages of inadequate cancer pain treatment (16-26\%) (data not shown). It is evident that the choice of measure, rather than the pain treatment itself, largely determines the proportion of inadequately treated patients.

The percentage of agreement, assessed by dichotomizing all measures and not corrected for chance, ranged from $23-96 \%$ at the four assessment points. The highest percentage of agreement was found between the three Pain Management Indexes ( $80-96 \%)$, followed by agreement between the Pain Relief Scale and the Patient Satisfaction Scale (78-83\%). Agreement between the other measures was extremely low to moderate. Except for the high agreement between the three Pain Management Indexes, one measure cannot be substituted for another measure because they seem to measure different aspects.

Because the percentage of agreement can be relatively high by chance alone when dichotomized data are analyzed, agreement between the scales was also calculated by kappa statistics. High agreement (kappa from $0.81-1.00$ ) was found in only $3 \%$, namely, between Cleeland's Pain Management Index and Ward's Pain Management Index. Substantial agreement (kappa from $0.61-0.80$ ) was found in $11 \%$, between Cleeland's Pain Management Index and Zelman's Pain Management index, between Ward's Pain Management Index and Zelman's Pain Management Index, and between Substantial Present Pain and Substantial Average Pain. Moderate agreement (kappa of $0.41-0.60$ ) was found in $11 \%$, $39 \%$ showed fair agreement (kappa of $0.21-0.40$ ), and $36 \%$ had slight or poor agreement (kappa $<0.20$ ).

To investigate whether one or more underlying constructs were emerging, all eigth measures were subjected to factor analyses with oblique rotation (Table 3). An examination of the eigenvalues suggested a three-factor structure. Across the four assessment points, three factors accounted for $78-83 \%$ of the variance. At pretest, factor 1 accounted for $45 \%$ of variance. The first factor consisted of the three Pain Management Indexes and Substantial Worst Pain. Substantial Worst Pain, however, also loaded on the second factor. At pretest, factors 2 and 3 accounted for $20 \%$ and $13 \%$, respectively. At 2,4 , and 8 weeks after discharge, the first factor consisted of the three Pain Management Indexes, the second factor consisted of the Pain Relief Scale and the Patient Satisfaction Scale, and all Pain Intensity Markers loaded on a third factor. It can be concluded that a degree of consistency in the results of the factor analyses was present, showing the same three factors at different time points. 
urgent need for identifying one or more valid and reliable outcome measures to evaluate pain treatment in cancer patients. So far, pain treatment is primarily evaluated unidimensionally. In this study, we compared outcome measures repre senting the sensory and behavioral dimensions. Because pain is a multidimensional concept, the physiologic, sensory, affective, cognitive, behavioral, and so. ciocultural dimensions should be integrated to evaluate pain treatment. Further psychometric analyses are needed to identify instruments to evaluate pain treatment in patients with cancer in a variety of situations. However, as long as the various outcomes are not consistent within one dimension, a unidimensional instrument must first be identified.

\section{Acknowledgments}

We thank the patients who participated in this study, and extend special thanks to nurses of the Antoni van Leeuwenhoek Hospital, Amsterdam. 


\section{References}

1. Bonica JJ. Treatment of cancer pain: current status and future needs. In: Fields HL, Dubner F, Cervero F, eds. Advances in pain research and therapy. New York, NY: Raven Press, Ltd., 1985: 589-616.

2. Cleeland CS, Gonin R, Hatfield AK, Edmonson JH, Blum RH, Stewart JA, Pandya KJ. Pain and its treatment in outpatients with metastatic cancer. New England Journal of Medicine, 1994;330:592-596.

3. Cleeland CS, Gonin R, Baez L, Loehrer P, Pandya KJ. Pain and treatment of pain in minority patients with cancer. Annals of Internal Medicine, 1997;127:813-816.

4. Dalton JA. Nurses' perceptions of their pain assessment skills, pain management practices, and attitudes toward pain. Oncology Nursing Forum, 1989;16:225-231.

5. Dorrepaal KL. Pijn bij patienten met kanker [Dissertation in Dutch]: Vrije Universiteit Amsterdam, The Netherlands 1989.

6. Goisis A, Gorini M, Ratti R, Luliri P. Application of a WHO protocol on medical therapy for oncologic pain in an internal medicine hospital. Tumori, 1989;75:470-472.

7. Grond S, Zech D, Lynch J, Diefenbach C, Schug SA, Lehmann KA. Validation of World Health Organization guidelines for pain relief in head and neck cancer: A prospective study. Annals of Otology, Rhinology \& Laryngology, 1993;102:342-348.

8. Grond S, Zech D, Schug SA, Lynch J, Lehmann KA. Validation of World Health Organization guidelines for cancer pain relief during the last days and hours of life. Journal of Pain and Symptom Management, 1991;6:411-422.

9. Jadad AR, Browman GP. The WHO analgesic ladder for cancer pain management. Stepping up the quality of its evaluation. JAMA, 1995;274:1870-1873.

10. Larue F, Colleau SM, Brasseur L, Cleeland CS. Multicentre study of cancer pain and its treatment in France. British Medical Journal, 1995;310:1034-1037.

11. Lin CC, Ward SE. Patient-related barriers to cancer pain management in Taiwan. Cancer Nursing, 1995; 18:16-22.

12. Miaskowski C, Nichols R, Brody R, Synold T. Assessment of patient satisfaction utilizing the American Pain Society's quality assurance standards on acute and cancer-related pain. Clinical Journal of Pain, 1994;9:5-11.

13. Serlin RC, Mendoza TR, Nakamura Y, Edwards KR, Cleeland CS. When is cancer pain mild, moderate or severe? Grading pain severity by its interference with function. Pain, 1995;61:277-284.

14. Syrjala KL, Chapman CR. Measurement of clinical pain: A review and integration of research findings. In: Benedetti C, ed. Advances in pain research and therapy. New York, NY: Raven Press, 1984: 133-150.

15. Takeda F. Results of field-testing in Japan of the WHO draft interim guidelines on relief of cancer pain. The Pain Clinic, 1986;1:83-89.

16. Ventafridda V, Tamburini M, Caraceni A, De Conno F, Naldi F. A validation study of the WHO method for cancer pain relief. Cancer, 1987;59:850-856.

17. Walker VA, Hoskin PJ, Hanks GW, White ID. Evaluation of WHO analgesic guidelines for cancer pain in a hospital-based palliative care unit. Journal of Pain and Symptom Management, 1988;3:145-149.

18. Ward S, Gatwood J. Concerns about reporting pain and using analgesics. A comparison of persons with and without cancer. Cancer Nursing, 1994;17:200-206.

19. Ward SE, Goldberg N, Miller-McCauley V, Mueller C, Nolan A, Pawlik-Plank D, Robbins A, Stormoen D, Weissman DE. Patient-related barriers to management of cancer pain. Pain, 1993;52:319-324.

20. Ward SE, Hernandez L. Patient-related barriers to management of cancer pain in Puerto Rico. Pain, 1994;58:233-238.

21. Zech DF, Grond S, Lynch J, Hertel D, Lehmann KA. Validation of World Health Organization guidelines for cancer pain relief: A 10-year prospective study. Pain, 1995;63:65-76.

22. Zelman DC, Cleeland CS, Howland EW. Factors in appropriate pharmacological management of cancer pain: A cross-institutional investigation. Pain (supplement 4), 1987:S136.

23. Zhukovsky DS, Gorowski E, Hausdorff J, Napolitano B, Lesser M. Unmet analgesic needs in cancer patients. Journal of Pain and Symptom Management, 1995;10:113-119.

24. Jamison RN, Brown GK. Validation of hourly pain intensity profiles with chronic pain patients. Pain, 1991;45:123-128. 
25. Jensen MP, Turner LR, Turner JA, Romano JM. The use of multiple-item scales for pain intensity measurement in chronic pain patients. Pain, 1996;67:35-40.

26. De Conno F, Caraceni A, Gamba A, Mariani L, Abbattista A, Brunelli C, La Mura A, Ventafridda V Pain measurement in cancer patients: A comparison of six methods. Pain, 1994;57:161-166.

27. Jensen MP, Karoly P, Braver S. The measurement of clinical pain intensity: A comparison of six methods. Pain, 1986;27:117-126.

28. Price DD, Bush FM, Long S, Harkins SW. A comparison of pain measurement characteristics of mechanical visual analogue and simple numerical rating scales. Pain, 1994;56:217-226.

29. APS. American Pain Society. Principles of analgesic use in the treatment of acute pain and chronic cancer pain: a concise guide to medical practice. Skokie, IL: American Pain Society, 1992

30. AHCPR. Agency for Health Care Policy and Reserach. Management of cancer pain. Clinical Practice Guideline. Rockville, MD: AHCPR, 1994.

31. Cleeland CS. Pain assessment in cancer. In: Osoba D, ed. Effect of cancer on quality of life. Boca Raton, FL: CRC Press, 1991: 294-305.

32. Wallenstein SL. Scaling clinical pain and pain relief. In: Bromm B, ed. Pain measurement in man. Neurophysiological correlates of pain. Amsterdam, The Netherlands: Elsevier Science Publishers, 1984: 389-396.

33. Ware J, Snyder M, Wright W, Davies A. Defining and measuring patient satisfaction with care. Evaluation and Program Planning, 1983;6:247-263.

34. APS. American Pain Society Quality of Care Committee. Quality improvement guidelines for the treatment of acute pain and cancer pain. JAMA, 1995;274:1874-1880.

35. De Wit R, Van Dam F, Zandbelt L, Van Buuren A, Van der Heijden K, Leenhouts G, Loonstra S. A Pain Education Program for chronic cancer patients: follow-up results from a randomized controlled trial. Pain, 1997;73:55-69.

36. Ward SE, Gordon D. Application of the American Pain Society quality assurance standards. Pain, 1994;56:299-306.

37. Kremer $E$, Atkinson JHJ. Pain measurement: construct validity of the affective dimension of the McGill Pain Questionnaire with chronic benign pain patients. Pain, 1981;11:93-100.

38. McGuire DB. Measuring pain. In: Frank-Stromborg M, ed. Instruments for clinical nursing. Norwalk, CT, 1988: 333-356.

39. Syrjala KL. The measurement of pain. In: McGuire DB, Yarbro CH, eds. Cancer pain management. Philadelphia, PA: WB Saunders, 1987: 133-150.

40. Ward SE, Gordon DB. Patient satisfaction and pain severity as outcomes in pain management:a longitudinal view of one setting's experience. Journal of Pain and Symptom Management, 1996;11:242-251.

41. Fleiss JL. Large sample standard errors of kappa and weighted kappa. Psyhological Bulletin, 1969;72:323-327.

42. Dietrick-Gallagher $M$, Polomano R, Carrick L. Pain as a quality management initiative. Journal of Nursing Care Quaterly, 1994;9:30-42.

43. Chrischilles EA, Helling DK, Aschoff CR. Effect of clinical pharmacy services on the quality of family practice physician prescribing and medication costs. Drug Intelligence and Clinical Pharmacy - The annals of Pharmacotherapy, 1989;23:417-421.

44. Hanlon JT, Schmader KE, Samsa GP, Weinberger M, Uttech KM, Lewis IK, Cohen HJ, Feussner JR. A method for assessing drug therapy appropriateness. Journal of Clinical Epidemiology, 1992;45:1045-1051.

45. Dorrepaal KL, Aaronson NK, van Dam FS. Pain experience and pain management among hospitalized cancer patients. A clinical study. Cancer, 1989;63:593-598.

46. Max M. American Pain Society quality assurance standards for relief of acute pain and cancer pain. Vith World Congress on Pain 1991, Amsterdam, The Netherlands: 186-189. 


\section{Chapter 6}

\section{The Amsterdam Pain Management Index compared to eight frequently used outcome measures to evaluate the adequacy of pain treatment in cancer patients with chronic pain}

De Wit, R., Van Dam, F., Loonstra, S., Zanbelt, L., Van Buuren, A., Van der Heijden, K., Leenhouts, G., Huijer Abu-Saad, H.,

The Amsterdam Pain Management Index compared to eight frequently used outcome measures to evaluate the adequacy of pain treatment in cancer patients with chronic pain.

Pain (Accepted) 


\section{Introduction}

Adequacy of pain treatment is most frequently evaluated by means of pain intensity, pain relief, patient satisfaction with the pain treatment, or composite pain management index scores. ${ }^{1}$ According to the literature, the proportion of inadequately treated cancer pain patients ranges from 7 - 74\%. . $^{2-8}$ Plausible explanations for this wide range of results might be the heterogeneity of patient groups, or variability of treatment regimens. Diversity of measures used to evaluate pain treatment may be another explanation. Psychometric properties of the various measures to evaluate pain treatment, however, are unknown. ${ }^{9,10}$ Four groups of measures are commonly used to evaluate pain treatment. Pain intensity scales are the most frequently used measures in pain research. To obtain an indication for adequate pain treatment, the use of cutoff scores to describe inadequate cancer pain treatment has been proposed by several organizations.11,12 It has been found that pain intensity rated as 5 or more on an 11-point scale interferes with daily functioning, indicating that these patients are inadequately treated for their pain. 4,13,14 However, an absolute pain score may not have the same meaning for all patients, as patients may differ in their use of the anchor points of the scale. Consequently, it remains to be seen what pain score requires a change in pain therapy. To avoid this problem, patients can be asked to assess the change in their pain experience over time by means of a pain relief scale. ${ }^{1,15-18}$ Patients are then asked to indicate whether the pain intensity remained the same, was relieved, or worsened. However, evaluating patients' pain relief has the drawback that change in pain intensity is in itself not a direct indication of adequacy of pain treatment. ${ }^{19}$ For example, a patient may indicate a decrease in pain intensity, although moderate or severe pain may still persist. Consequently, the extent of pain relief seems to measure change over time rather than adequacy of pain treatment. A way to overcome this problem is to ask patients if they are satisfied with the pain treatment. Nonetheless, research showed that patients can be satisfied with the pain treatment despite high levels of pain intensity. ${ }^{20-23}$ When patients do not know that pain relief is achievable in a majority of patients, they will not be dissatisfied with the pain treatment even when their pain is severe.

All measures mentioned above are based on patients' self-report only. This may give a rather restricted view of adequacy of the pain treatment as no direct information about the pain treatment itself is incorporated. To overcome this drawback, Pain Management Indexes have been developed. $7,8,13$ The Pain Management Indexes consist of relating the most potent analgesic given to a patient with the patient's reported level of pain, categorized in mild, moderate or severe. The categorized pain intensity score is then subtracted from the most potent level of the analgesic drug therapies. The Pain Management Indexes are different from the single-item measures, as they acknowledge the complexity of the pain treatment by incorporating the analgesics as well. However, the existing Pain Management Indexes give a rather restricted and possibly distorted overview of the outcomes of pain treatment, as only the most potent analgesic is incorporated without taking into account the dosage and frequency of all opioids and non-opioids. Consequently, the type of analgesic has the greatest effect on the final Pain Management Index score. According to the Pain Management Index, pain treatment is considered as adequate when strong opioids are prescribed, notwithstanding 
patient's high pain intensity. This may lead to incongruity, e.g., when a patient reports a pain score of 8 while he is receiving a low dosage of opioids. This paradoxical finding is caused by the fact that a patient who is prescribed strong opioids is automatically assessed as being treated adequately.

Based on the assumption that the goal of pain treatment is to allow patients to function at a level they choose, and to die relatively free of pain, ${ }^{24}$ in this study cancer pain treatment is evaluated as inadequate when substantial pain persists, independent of the reason for this failure, e.g., insufficient pain medication, insufficient procedures, lack of patients' pain knowledge, and non-adherence. In order to obtain a comprehensive and accurate picture of the outcome of pain treatment, all pain medication, including dosages as well as frequency of pain medication, should be included in the outcome measure. Furthermore, categorizing pain intensity into mild, moderate, and severe may not fully depict pain as a subjective experience, as it does not take into account the way patients give different meaning to the anchor points of the pain intensity scale. To avoid this problem, patients may be asked to indicate at what score they want something done about their pain. In this way, one gets an indication at what score the patient perceives his pain changes from tolerable into intolerable. Consequently, the treatment can be tuned more directly to the needs of the individual patient. Although differences in patients' pain tolerance has been a continuing source of interest in pain research, variability in pain tolerance has not been extensively studied.

To address some limitations of the various frequently used measures, a new measure, the Amsterdam Pain Management Index, has been developed and evaluated in this study. The Amsterdam Pain Management Index was primarily based on the Pain Management Indexes of Cleeland, Zelman, and Ward. These indexes, based on the analgesic ladder of the World Health Organization, ${ }^{25}$ provide a comparison of the most potent analgesic relative to the level of patient's reported pain. The Amsterdam Pain Management Index was further extended in 4 ways. First, it incorporates patients' Present Pain Intensity, Average Pain Intensity, and Worst Pain Intensity. Second, the individual threshold for pain was taken into account by asking patients what pain score was tolerable for them. ${ }^{26}$ Third, to address the issue that many pain patients take less pain medication than prescribed, the effect of non-adherence was incorporated in the index. Fourth, by including all opioids and non-opioids in the Amsterdam Pain Management Index, the aggregated pain score was compared with the pain medication actually taken by the patient.

The purpose of this study was to compare the Amsterdam Pain Management Index with eight commonly used measures to evaluate the adequacy of pain treatment. The ability of the Amsterdam Pain Management Index to distinguish between subgroups (known-group comparisons), equivalence between subgroups, responsiveness to clinical changes, and responsiveness to change over time in comparison to the more traditional outcome measures was described.

All the above-mentioned outcome measures were applied simultaneously in a randomized clinical study in which the adequacy of a Patient Education Program for cancer patients with chronic pain was examined. Because patient education and active participation of the patients themselves is one of the cornerstones of effective pain management, ${ }^{27,28}$ the Pain Education Program was developed to aim at empowering patients in the process of relieving pain. The Pain Education 
Program consists of enhancing patients' knowledge about pain and pain treatment, instructing patients in how to register their pain intensity in the home setting, and stimulating patients' help-seeking behavior.

\section{Methods}

\section{Design and patient population}

In a prospective, randomized controlled trial, the effectiveness of a Pain Education Program was evaluated in cancer patients with chronic pain. An institutional review board approved this intervention project. After admission to the hospital, the purpose of the study was explained to the patients who provided informed consent to participate in the study. To be included in the study, patients had to meet the following inclusion criteria: (1) pain related to cancer, cancer therapy, or illness; (2) a pain duration of at least one month; (3) a life expectancy of at least three months as assessed by physicians; (4) able to read and speak Dutch; (5) accessible by telephone; and (6) not residing in a nursing home or retirement home. Patients were randomly assigned to either a control group or an intervention group while controlling for gender (males/females), age ( $<60$ years $>60$ years), and metastatic sites (yes/no/unknown). The experimental group received the Pain Education Program in the hospital and at three and seven days postdischarge.

\section{Intervention}

The focus of this study is to evaluate the newly designed Amsterdam Pain Management Index in comparison to eight frequently used measures to evaluate the adequacy of pain treatment in cancer patients. The Pain Education Program is briefly reported here; a more detailed description is given elsewhere. ${ }^{29}$ The Pain Education Program was developed on the basis of the literature, existing educational programs, and input of pain experts. 12,25,28,30,31 The tailored intervention consisted of a multi-method approach in which verbal pain instruction, written pain materials, an audiocassette tape, and the use of a pain diary were combined to inform and instruct patients about pain and pain management. Topics discussed with the patients included, e.g., the definition of pain, pharmacological pain management, adverse effects, myths and misconceptions related to pain management, adherence, use of non-pharmacological pain treatment, and pain assessment. The verbal instruction, which was provided in the hospital, was audiotaped on a cassette so that it could be listened to at home, and was accompanied by a pain brochure. A pain diary, in which patients were instructed how to self-report pain, was provided to use at home. Finally, patients were instructed how to communicate about pain, when to contact healthcare providers, and how to use non-pharmacological pain management techniques, such as cold and heat, relaxation, and massage. Postdischarge, two telephone follow-ups took place to identify whether all information was understood by the patient. 


\section{Procedure}

All patients completed a pretest 2-4 days after hospital admission, including sociodemographic variables, medical variables, and variables related to pain and adequacy of pain treatment. After randomization, the experimental group patients received the Pain Education Program in the hospital in a face-to-face encounter with a specially trained nurse, and at three and seven days postdischarge by telephone. All control and experimental group patients were followed-up at 2 , 4 , and 8 weeks postdischarge by telephone.

\section{Measures}

Sociodemographic and medical data. Sociodemographic characteristics included, e.g., gender, age, marital status, education. Medical variables consisted of diagnosis, time since diagnosis, tumor stage, metastatic sites, treatment, and adverse effects. Sociodemographic characteristics were collected at pretest, and medical variables were assessed at all four assessment points.

Pain intensity. Patients were asked on an 11-point numeric rating scale, on which " 0 " represents "no pain" and "10" represents "pain as bad as you can imagine" regarding their Present Pain Intensity, Average Pain Intensity during the last week, and Worst Pain Intensity. The validity and reliability of the numeric rating scale are well established, ${ }^{16,32-34}$ and have been found easy to administer with only a small group of patients who are not capable of completing it. ${ }^{33}$ Patients' pain intensity scores were assessed at all four assessment points.

Pain treatment. Prescribed analgesics (name, dose, frequency, and routes of administration), and other pain treatment were collected both from the medical record and by patient interview at pretest. Postdischarge, patients were interviewed at 2,4 , and 8 weeks postdischarge about what pain medication was prescribed and what they had actually taken the day before.

The degree to which a patient voluntarily followed the medication regimen recommended by the physician (adherence) was assessed by means of patients' self-report. Sleeping problems were assessed by means of the European Organization for Research and Treatment of Cancer Core Quality of Life Questionnaire (EORTC QLQ-C30+3). ${ }^{35}$ Finally, whether a pain physician was consulted was registered.

\section{The Amsterdam Pain Management Index}

The Amsterdam Pain Management Index was originally based on Cleeland's Pain Management Index. ${ }^{13}$ The new index was further developed on the basis of the literature, input of pain experts and researchers, and the pain team in the hospital. The Amsterdam Pain Management Index is based on a composite pain intensity score of Present Pain Intensity, Average Pain Intensity, and Worst Pain Intensity (Table 1). The composite pain intensity score is then categorized into: 0 (no pain), 1 (1-3: mild pain), 2 (4-7: moderate pain), and 3 (8-10: severe pain). Based on research showing that some patients appear to tolerate more pain than others, ${ }^{36}$ the patient's level of Tolerable Pain Intensity was incorporated. The Tolerable Pain Intensity scale was developed by the researchers. On an 11-point 


\begin{tabular}{|c|c|c|c|c|c|c|c|}
\hline \multirow{2}{*}{$\begin{array}{l}\text { Pain }^{2} \\
\text { Tolerable Pain Intensity } \\
\text { (TPI) }\end{array}$} & \multirow[t]{2}{*}{0 : No } & \multicolumn{2}{|c|}{$\begin{array}{l}\text { 1: Mild pain } \\
(1-3) \\
\end{array}$} & \multicolumn{2}{|c|}{$\begin{array}{l}\text { 2: Moderate pain } \\
(4-7)\end{array}$} & \multicolumn{2}{|c|}{$\begin{array}{l}\text { 3: Severe pain } \\
(8-10)\end{array}$} \\
\hline & & TPlıpain & TPI<pain & TPlzpain & TPI $<$ pain & TPlıpain & TPI $<$ pain \\
\hline Analgesics used ${ }^{c}$ & \multicolumn{7}{|c|}{ Amsterdam Pain Management Index ${ }^{d}$} \\
\hline $0 \mathrm{mg}$ oral morphine & 0 & -1 & -2 & -2 & -3 & -3 & -4 \\
\hline $1-60 \mathrm{mg}$ oral & | & 0 & -1 & -1 & -2 & -2 & -3 \\
\hline $61-120 \mathrm{mg}$ oral & 2 & 1 & 0 & 0 & -1 & -1 & -2 \\
\hline $121-240 \mathrm{mg}$ oral & 3 & 2 & 1 & 1 & 0 & 0 & -1 \\
\hline$>240 \mathrm{mg}$ oral & 4 & 3 & 2 & 2 & 1 & | & 0 \\
\hline
\end{tabular}

a

c All opioids and non-opioids used within a 24-h period were converted to oral morphine equivalents. Therefore, the amount of oral opioids (Morphine $30 \mathrm{mg}=$ Codeine $200 \mathrm{mg}=$ Tramadol $200 \mathrm{mg}=$ Pethidine $300 \mathrm{mg}=$ Pentazocine 180 $\mathrm{mg}$ ) and the amount of parenteral opioids (Morphine $10 \mathrm{mg}=$ Pethidine $75 \mathrm{mg}$ $=$ Pentazocine $60 \mathrm{mg}=$ Dextroproxypophene $300 \mathrm{mg}=$ Nicomorphine $45 \mathrm{mg}$ $=$ Piritramide $15 \mathrm{mg}$ ) were converted to oral morphine (Parenteral Morphine 10 $\mathrm{mg}=$ Oral Morphine $30 \mathrm{mg}$ ). The one-day dose of one non-opioid was considered equianalgesic to the one-day dose of another non-opioid (Paracetamol $2000 \mathrm{mg}=$ Ibuprofen $1200 \mathrm{mg}=$ Diclofenac $100 \mathrm{mg}=$ Naproxen $500 \mathrm{mg}$ ) and $650 \mathrm{mg}$ of aspirin was considered as equianalgesic to $6 \mathrm{mg}$ of oral morphine. The total dose of analgesics per 24 hours was categorized into: no analgesic drug (0)), $1-60 \mathrm{mg}(1), 61-120 \mathrm{mg}(2), 121-240 \mathrm{mg}$ (3), and > $240 \mathrm{mg}$ (4) equianalgesic dose oral morphine.

d The Amsterdam Pain Management Index ranges from -4 (a patient receiving no analgesics who is in severe pain and experiencing intolerable pain) to +4 (a patient receiving high doses of opioids (>240 mg per day) with complete pain relief). A score of -4 to $-\mathrm{I}$ indicates inadequate use of analgesic drugs, while a score of 0 to 4 indicates adequate use of analgesics. 
numeric rating scale, patients were asked to provide an anchor point for what they consider a tolerable level of pain. Patients who assessed their Tolerable Pain Intensity below the patient's pain score were considered to experience more pain than is acceptable to them. When the pain score was above the level of patients' Tolerable Pain Intensity, the Amsterdam Pain Management Index was corrected by subtracting 1 point. When patients' pain score was equal or below the level of patients' Tolerable Pain Intensity, no correction was used. Regarding the analgesics, all pain medication that was actually used within a $24 \mathrm{~h}$ period was standardized to oral morphine equivalents using the following procedures. First, all opioids were converted to oral morphine equivalents using a standardized schedule describing how to switch from one opioid analgesic drug to another, and from one route of administration to another. ${ }^{24,37,38}$ Second, to include nonopioids, approximate equivalence between paracetamol and oral morphine was calculated. The relative equivalency of non-narcotic analgesics and narcotic analgesics, however, is difficult to compare because of differences in the working mechanism. No direct conversion information between these two types of analgesics was available. Arbitrarily, the one-day dose of one non-opioid was considered equianalgesic to the one-day dose of another non-opioid, and $650 \mathrm{mg}$ of aspirin was considered as equianalgesic to $2 \mathrm{mg}$ of morphine i.m. ( $=6 \mathrm{mg}$ of oral morphine). ${ }^{24,37,38}$ This is closely related to reports describing $30-32 \mathrm{mg}$ of codeine ( $=7 \mathrm{mg}$ of oral morphine equivalents) providing the same analgesic effect as $650 \mathrm{mg}$ of oral acetaminophen..$^{39-41}$ Based on guidelines regarding starting doses, ${ }^{30}$ patients' total dose of opioids and non-opioids per 24 hours was categorized into: 0 (no analgesic drug), 1 (1 - $60 \mathrm{mg}$ equianalgesic dose oral morphine), 2 (61 - 120 mg equianalgesic dose oral morphine), 3 (121 - $240 \mathrm{mg}$ equianalgesic dose oral morphine), and 4 (> $240 \mathrm{mg}$ equianalgesic dose oral morphine). Finally, the categorized pain scores were subtracted from the categorized level of analgesic drugs used.

\section{Table 2. Example of the Amsterdam Pain Management Index score}

\footnotetext{
Patient X describes her Present Pain Intensity as 3, her Average Pain Intensity in the previous week os 5, and her Worst Pain Intensity as 7. The aggregated Pain Intensity Score is 5 $((3+5+7) / 3)$ and is categorized as moderate (score 2). Patient X's Tolerable Pain Intensity is rated as 2, which indicates that her pain is not considered as acceptable. Because the patient's pain score is above the level of her Tolerable Pain Intensity, the Amsterdam Pain Management Index is corrected by subtracting I point. Patient $X$ is currently taking 20 mg morphine orally every $4 \mathrm{~h}$ and $200 \mathrm{mg}$ ibuprofen every $6 \mathrm{~h}$. The to tal dose morphine orally/24h consists of multiplying $20 \mathrm{mg}$ morphine $\times 6$ doses $=120 \mathrm{mg}$, and multiplying $200 \mathrm{mg} \times 4$ doses $=$ $800 \mathrm{mg}$ ibuprofen. The dosage ibuprofen is equivalent to $1333 \mathrm{mg}$ paracetamol (800/ I 200 * 2000), which can be converted to $12 \mathrm{mg}$ morphine orally $(1333 / 650 \times 6)$. The total dose morphine orally/24h consists of $132 \mathrm{mg}$ morphine orally $(120+12)$ and is categorized into 3 (121-240 mg) equianalgesic dose oral morphine. The Amsterdam Pain Management Index is composed by subtracting the aggregated Pain Intensity Score (score 2), corrected for patients' $X$ Tolerable Pain Intensity (score - I), from the andgesic drugs used (score 3). These results lead to a final score of $0(3-2-1=0)$, indicating adequate analgesic prescriptions.
} 
The Amsterdam Pain Management Index score can range from -4 (a patient receiving no analgesics who is in severe pain and experiencing intolerable pain) to +4 (a patient receiving high doses of opioids $>240 \mathrm{mg}$ per day with complete pain relief). These scores are then dichotomized into inadequate use of analgesic drugs (score -4 to -1 ), and adequate use of analgesics (score 0 to 4 ). An example of how the Amsterdam Pain Management Index is calculated is given in Table 2

\section{Measures used to evaluate pain treatment}

Pain Intensity Markers. Pain intensity rated as 5 or more on an 11-point scale is considered as substantial pain, meaning that these patients are treated inadequately for their pain. The cutoff scores can be based on patients' Present Pain Intensity (Substantial Present Pain), Average Pain Intensity during the previous week (Substantial Average Pain), and Worst Pain Intensity (Substantial Worst Pain). Cleeland et al. ${ }^{13}$ using patients' Worst Pain Intensity as a measure to evaluate cancer pain treatment, found that $62 \%$ of outpatients with metastatic cancer rated their pain as 5 or more. Larue et al. ${ }^{4}$ found that $69 \%$ of the patients with cancer reported Substantial Present Pain, whereas 54\% experienced Substantial Average Pain. Serlin et al. ${ }^{14}$ found that $70-90 \%$ of the patients rated their Worst Pain Intensity as 5 or greater.

Pain Relief Scale. On a 6-point Pain Relief Scale, the extent of pain relief was asked. The scales ranges from complete relief (1), strong relief (2), moderate relief (3), slight relief (4), no relief (5), to worsening of pain (6). Scores of 5 and 6 are considered as inadequate, and scores of 1 to 4 are assessed as adequate. ${ }^{9}$ Takeda ${ }^{17}$ reported complete pain relief in $87 \%$ of the patients, Walker et al. ${ }^{18}$ reported pain relief in $69 \%$ of the patients, and Goisis et al. ${ }^{15}$ found total or partial pain control in $93 \%$ of patients.

Patient Satisfaction Scale. Patient satisfaction measures how satisfied patients are with the pain treatment, and is indicated as one of the criteria by the American Pain Society, 12,42 and the Agency for Health Care Policy and Research." The 5 -point scale ranges from very satisfied (1), somewhat satisfied (2), neither satisfied nor dissatisfied (3), somewhat dissatisfied (4), to very dissatisfied (5). Scores 4 and 5 are classified as inadequate pain treatment, while scores of 1 to 3 are considered adequate treatment. Only few psychometric assessments of the patient Satisfaction Scale have been described in literature. ${ }^{43}$ However, it is recognized that the interpretation is difficult because patients can be in severe pain and nevertheless rate their satisfaction with the pain treatment as high. ${ }^{42}$

Cleeland's Pain Management Index. The Pain Management Index consists of a simplified method in which two parameters are included, namely patients' pain intensity and drug choice. Based on the principles of the WHO cancer pain guidelines, ${ }^{25}$ Cleeland's Pain Management Index compares the most potent analgesic for a patient with patients' reported level of pain. ${ }^{13}$ The pain score is based upon the patient's level of Worst Pain Intensity that is categorized into: 0 (no pain), 1 (1 - 3: mild pain), 2 (4 - 7: moderate pain), and 3 ( 8 - 10: severe pain). The pain score is then subtracted from the most potent level of analgesic drug therapies as was prescribed in the medical record: 0 (no analgesic drug), 1 (non-opioids), 2 (weak opioids), and 3 (strong opioids). Cleeland's Pain Management Index ranges from -3 (a patient receiving no analgesic drugs (score 0 ) who is in severe pain (score 3 )) to +3 (a patient receiving strong opioids (score 3 ) who is pain-free 
(score 0)). These scores are then dichotomized: negative scores indicate inadequate orders for analgesic drugs, while scores of 0 or higher are considered to be a conservative indicator of acceptable treatment. Research showed that, according to Cleeland's Pain Management Index, $42 \%$ of the outpatients with metastatic cancer were prescribed less than optimal potency analgesics. ${ }^{13}$

Ward's Pain Management Index. Ward's Pain Management Index is in accordance with Cleeland's Pain Management Index, except that it takes into account patients' adherence with the pain medication by relating the pain medication that is actually used instead of the pain medication prescribed.?

Zelman's Pain Management Index. Zelman's Pain Management Index consists of a pain intensity score which is computed by averaging patient's Present Pain Intensity, Average Pain Intensity, and Worst Pain Intensity. By this, a more complete picture can be given of patients with intermittent or fluctuations in pain. Especially, in patients for whom Worst Pain Intensity might not fully depict the pain experience, a composite pain score seems to be preferred. ${ }^{8}$ The composite pain score is categorized into: 0 (no pain), 1 ( 1 - 3: mild pain), 2 (4 - 6: moderate pain), and 3 ( 7 - 10: severe pain) and related to the pain medication as used by the patient. Results of studies using one of the Pain Management Indexes showed that patients received inadequate cancer pain treatment in $27-74 \%$ of the cases. ${ }^{2-8}$ Evidence of the validity of these indexes has been demonstrated by Ward et al. ${ }^{6}$

\section{Statistical methods}

Data were analyzed using the Statistical Package for the Social Sciences (SPSS) version 7.5. To describe features of scale distributions, the means and standard deviations for each of the measures to evaluate pain treatment were described. To describe the agreement between the outcome measures, agreement uncorrected for change, and Cohen's kappa, a measure of agreement corrected for chance, was estimated. A series of Student's t-tests was carried out to evaluate the ability of the outcome measures to discriminate between subgroups of patients. Patients who reported to be adherent were compared to patients who were non-adherent, and patients with high scores on sleeping problems were compared with patients with low scores on sleeping problems. Regarding equivalence between groups, patients with a local stage of disease were compared to patients with a regional stage of disease and to metastatic cancer patients, and patients who consulted a pain physician were compared to patients who did not consult a pain physician.

Responsiveness to clinical change was measured by evaluating the effect of the Pain Education Program. Multivariate analyses of variance (MANOVA) were conducted to determine whether the different measures to evaluate pain treatment changed over time in the group of patients who received the intervention. Responsiveness to change over time was examined by using paired t-tests to compare change from pretest to 2 weeks postdischarge.

To examine the relationship between the different components of the Amsterdam Pain Management and the Amsterdam Pain Management Index itself, multiple regression analyses were carried out for all four time points. In the regression model, the dependent variable was the Amsterdam Pain Management Index, and the predictor variables consisted of Present Pain Intensity, Average Pain Intensity, 
Table 3. Medical and pain characteristics of the study population

\section{Primary tumor site ( $>100 \%$ )}

Lip, oral cavity, and pharynx

Digestive organs and peritoneum

$12 \%$

Respiratory and intrathoracic organs

$11 \%$

Breast

$30 \%$

Bone, connective tissue, and skin

$14 \%$

Genitourinary organs

$24 \%$

Other (i.e., Hodgkin, non-Hodgkin Lymphoma)

$11 \%$

\section{Disease stage}

Local

$14 \%$

Regional

$19 \%$

Metastatic

$58 \%$

Unknown

Not applicable

\section{Treatment ( $>100 \%$ )}

No

$22 \%$

Surgery

$16 \%$

Chemotherapy

$36 \%$

Radiation therapy

$13 \%$

Hormonal therapy

$7 \%$

Other (i.e., hormonal, immuno, laser)

\section{Pain location (> 100\%)}

Head, face, mouth

Breast, thoracic region

Upper shoulder and upper limbs

$29 \%$

Abdominal region

$40 \%$

Lower back, lumbar spine, sacrum, coccyx

$39 \%$

Lower limbs

$7 \%$

Anal, perianal, and genital region

$5 \%$

Everywhere

$0.1 \%$

\section{Source of cancer pain (> 100\%)}

Direct tumor involvement

$77 \%$

Cancer therapy

Associated with cancer disease

$7 \%$

Unknown

$5 \%$

Locations per patient

Pain duration in months (sd)

\section{Symptomatic cancer pain treatment}

Analgesics

Coanalgesics

$56 \%$

TENS 
Worst Pain Intensity, Tolerable Pain Intensity, and the amount of oral morphine equivalents. The $R^{2}$ represents the cumulative explained variance of the dependent variable accounted for by the predictor variables taken together.

\section{Results}

A total of 383 patients was asked to participate in the study; of these, 313 patients $(82 \%)$ participated. Patients who declined $(N=70)$ found the study too burdensome $(N=48)$, were not motivated $(N=15)$, or were too ill $(N=7)$. Patients who declined were significantly older than those who participated $(\mathrm{p}<$ $.05)$. Of the participating patients, 159 patients $(51 \%)$ received the intervention and 154 patients ( $49 \%$ ) did not. At follow-up, $89 \%$ of the patients completed the posttest at 2 weeks postdischarge, $83 \%$ completed the posttest at 4 weeks postdischarge, and $75 \%$ completed all three posttests. Dropouts were due to death $(60 \%)$, being too ill ( $21 \%)$, experiencing the study as too burdensome to continue $(14 \%)$, or to lack of motivation (5\%).

Of the 313 patients who participated in the study, $63 \%$ were female, and the mean age was 56 years $(s d=12.4)$. From the total group, $41 \%$ had primary school or lower vocational training, $33 \%$ had middle to low level of secondary school or intermediate vocational training, and $26 \%$ had high level of secondary school, college graduate or university. The medical and pain characteristics of the patient population are presented in Table 3.

Patients' mean Present Pain Intensity was $3.3(s d=2.3)$ at pretest, the mean Average Pain Intensity was $4.9(\mathrm{sd}=2.1)$, and the mean Worst Pain Intensity was $7.7(s d=2.1)$. At 2 weeks postdischarge, patients' Present Pain Intensity, Average Pain Intensity, and Worst Pain Intensity was significantly decreased and remained fairly constant at 4 , and 8 weeks postdischarge.

\section{Adequacy of pain treatment}

Table 4. Range of kappas between the outcome measures to evaluate adequacy of pain treatment at pretest, 2, 4, and 8 weeks postdischarge.

\begin{tabular}{|c|c|c|c|c|c|c|c|c|}
\hline & 1 & 2 & 3 & 4 & 5 & 6 & 7 & 8 \\
\hline I. APMI & - & & & & & & & \\
\hline 2. SPP & $.15-.22$ & - & & & & & & \\
\hline 3. SAP & $.03-.19$ & $.32-.69$ & - & & & & & \\
\hline 4. SWP & $.12-.26$ & $.09-.34$ & $.25-.42$ & - & & & & \\
\hline 5. PRS & $.10-.32$ & $-.02-.20$ & $-.01-.17$ & $.01-.04$ & - & & & \\
\hline 6. PSS & $.14-.18$ & $.16-.34$ & $.12-.25$ & $.08-.10$ & $.43-.58$ & - & & \\
\hline 7. PMI-C & $.32-.55$ & $.04-.07$ & $.04-.15$ & $.13-.24$ & $.17-.32$ & $.14-.25$ & - & \\
\hline 8. PMI-W & $.34-.60$ & $.01-.05$ & $.02-.10$ & $.09-.19$ & $.17-.37$ & $.10-.30$ & $.86-.91$ & - \\
\hline 9. PMI-Z & $.15-.22$ & $.14-.21$ & $.08-.26$ & $.07-.17$ & $.30-.45$ & $.28-.35$ & $.69-.74$ & $.59-.65$ \\
\hline
\end{tabular}

Note Abbreviations:

APMI: Amsterdam Pain Management Index; SPP: Substantial Present Pain; SAP: Substantial Average Pain;

SWP: Substantial Worst Pain; PRS: Pain Relief Scale; PSS: Patient Satisfaction Scale;

PMI-C: Cleeland's Pain Management Index; PMI-W: Ward's Pain Management Index;

PMI-Z: Zelman's Pain Management Index. 


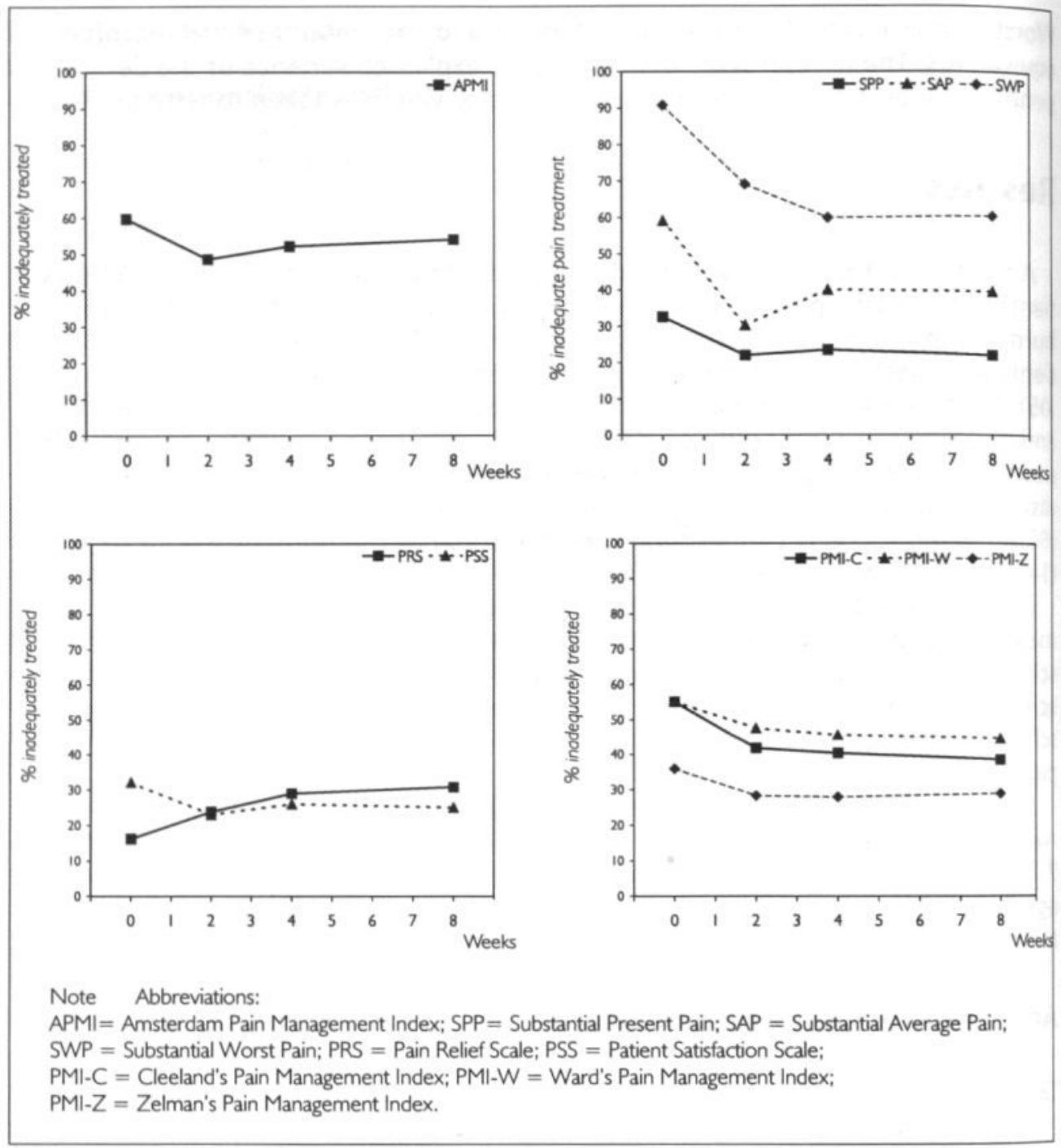

Figure 1. Adequacy of cancer pain treatment

Missing data. The percentage of missing data was low to moderate. The rates of missing data for the Pain Intensity Markers, the Pain Relief Scale, and the Patient Satisfaction Scale ranged from $1-8 \%$. When the outcome measure was based on both analgesics and pain intensity, results showed higher percentages of missing data. For the Amsterdam Pain Management Index, the percentage of missing data ranged from 7 - 15\%, while the three Pain Management Indexes were missing in 7 - $19 \%$.

Agreement between the measures. The proportion of patients who were treated inadequately for their pain ranged from $16-91 \%$ at pretest, depending on the measure used (Figure 1). ${ }^{44}$ Postdischarge, the highest percentage of inadequate cancer pain treatment was shown by Substantial Worst Pain (60-91\%), 
while the use of the Pain Relief Scale resulted in the lowest percentages of inadequate cancer pain treatment (16-26\%).

The percentage of agreement between the measures, assessed by dichotomizing all measures and uncorrected for chance, ranged from $23-96 \%$. Agreement between the measures, corrected for chance alone, is described in Table 4. The Amsterdam Pain Management Index showed moderate agreement (kappa of $0.41-0.60$ ) with the three Pain Management Indexes. Fair and poor agreement (kappa $<0.40$ ) was found among all other measures. Except for the high agreement (kappa from $0.81-1.00$ ) between Cleeland's Pain Management Index and Ward's Pain Management Index, none of the measures can be substituted for another outcome measure; and they seem to describe different aspects of pain treatment.

Table 5. Known-group comparisons with regard to percentage of inadequate pain treatment

\begin{tabular}{|c|c|c|c|c|c|c|}
\hline & \multicolumn{2}{|c|}{ Adherence } & \multirow[b]{2}{*}{$\begin{array}{c}\text { p- } \\
\text { value }\end{array}$} & \multicolumn{3}{|c|}{ Sleeping problems } \\
\hline & Yes & No & & low & high & $\begin{array}{c}\text { p- } \\
\text { value }\end{array}$ \\
\hline I. Amsterdam Pain Management Index & $33 \%$ & $77 \%$ & $<.001$ & $41 \%$ & $65 \%$ & $<.001$ \\
\hline 2. Substantial Present Pain & $23 \%$ & $24 \%$ & $n s^{c}$ & $19 \%$ & $28 \%$ & ns \\
\hline 3. Substantial Average Pain & $31 \%$ & $28 \%$ & ns & $23 \%$ & $36 \%$ & $<.05$ \\
\hline 4. Substantial Worst Pain & $72 \%$ & $64 \%$ & ns & $53 \%$ & $68 \%$ & $<.001$ \\
\hline 5. Pain Relief Scale & $18 \%$ & $31 \%$ & $<.05$ & $25 \%$ & $33 \%$ & ns \\
\hline 6. Patient Satisfaction Scale & $19 \%$ & $27 \%$ & ns & $23 \%$ & $30 \%$ & ns \\
\hline 7. Cleeland's Pain Management Index & $28 \%$ & $62 \%$ & $<.001$ & $34 \%$ & $49 \%$ & $<.05$ \\
\hline 8. Ward's Pain Management Index & $30 \%$ & $78 \%$ & $<.001$ & $38 \%$ & $55 \%$ & $<.05$ \\
\hline 9. Zelman's Pain Management Index & $17 \%$ & $44 \%$ & $<.001$ & $21 \%$ & $35 \%$ & $<.05$ \\
\hline
\end{tabular}

: Patients who reported to be adherent to pain medication versus patients who were non-adherent at 2 weeks postdischarge.

b. Low scores on sleeping problems versus high scores on sleeping problem at 2 weeks postdischarge.

¿ not significant.

Known-groups comparisons. In cancer patients with chronic pain, independent clinical variables that are expected to discriminate between subgroups of patients are difficult to define. Two variables were used to compare patient groups. First, patients who reported to be non-adherent were compared to patients who reported to be adherent. Results revealed that the Amsterdam Pain Management Index showed higher scores on inadequacy of pain treatment in non-adherent patients than in adherent patients (Table 5). Regarding the Pain Intensity Markers, no differences were found between the groups. However, adherent patients showed significantly more pain relief than non-adherent patients, while no differences were found for the Patient Satisfaction Scale. Cleeland's, Ward's, and Zelman's Pain Management Index showed higher scores on inadequacy of pain treatment in the non-adherent patient group. From this, it can be concluded that the Pain Intensity Markers and the Patient Satisfaction Scale did not distinguish between adherent and non-adherent patients. 
Second, the extent of sleeping problems was analyzed. Results showed that pa. tients' Present Pain Intensity, Average Pain Intensity, and Worst Pain Intensity was significantly higher in the group of patients who reported high scores on sleeping problems than in the patient group who reported low scores on sleeping problems ( 3.1 versus $2.3,3.7$ versus 2.8 , and 6.0 versus 4.9 , respectively). The Amsterdam Pain Management Index showed significant higher percentages of patients assessed as treated inadequately in the group with high scores on sleeping problems than in the group with low scores on sleeping problems. No statistically significant differences were found for Substantial Present Pain, the Pain Relief Scale, and the Patient Satisfaction Scale. All other measures showed significant higher percentages of patients being assessed as treated inadequately in the group with sleeping problems.

Summarizing, the Amsterdam Pain Management Index, Cleeland's, Ward's, and Zelman's Pain Management Index appears to show satisfactory results in distinguishing between subgroups of patients. With the Pain Intensity Markers, the Pain Relief Scale, and the Patient Satisfaction Scale, known-groups cannot be distinguished easily.

Equivalence between groups. In addition to the ability to discriminate between subgroups of patients known to differ on relevant variables, a series of statistical tests was carried out between subgroups of patients known not to differ on relevant variables. Equivalence between subgroups was tested for tumor stage and consultation of a pain physician. Patients with a local stage of disease were compared to patients with a regional stage of disease and to metastatic cancer patients. Results showed no significant differences regarding patients' Present Pain Intensity, Average Pain Intensity, and Worst Pain Intensity.

Table 6. Equivalent group comparisons with regard to percentage of inadequate pain treatment

\begin{tabular}{|c|c|c|c|c|c|c|c|}
\hline & \multicolumn{3}{|c|}{ Tumor stage* } & \multicolumn{4}{|c|}{ Pain physician' } \\
\hline & Local & jional & Metas- & $\begin{array}{r}\text { p- } \\
\text { yalue }\end{array}$ & No & Yes & $\underset{\text { value }}{p}$ \\
\hline I. Amsterdam Pain Management Index & $65 \%$ & $72 \%$ & $56 \%$ & $n s^{c}$ & $61 \%$ & $57 \%$ & is \\
\hline 2. Substantial Present Pain & $38 \%$ & $33 \%$ & $31 \%$ & ns & $27 \%$ & $44 \%$ & $<.01$ \\
\hline 3. Substantial Average Pain & $49 \%$ & $58 \%$ & $61 \%$ & ns & $52 \%$ & $74 \%$ & $<.001$ \\
\hline 4. Substantial Worst Pain & $91 \%$ & $88 \%$ & $92 \%$ & ns & $88 \%$ & $96 \%$ & $<.05$ \\
\hline 5. Pain Relief Scale & $26 \%$ & $19 \%$ & $13 \%$ & ns & $18 \%$ & $12 \%$ &  \\
\hline 6. Patient Satisfaction Scale & $50 \%$ & $28 \%$ & $29 \%$ & ns & $32 \%$ & $33 \%$ & is \\
\hline 7. Cleeland's Pain Management Index & $64 \%$ & $60 \%$ & $47 \%$ & $<.05$ & $62 \%$ & $29 \%$ & $<.001$ \\
\hline 8. Ward's Pain Management Index & $70 \%$ & $69 \%$ & $49 \%$ & $<.01$ & $64 \%$ & $36 \%$ & $<.001$ \\
\hline 9. Zelman's Pain Management Index & $44 \%$ & $47 \%$ & $31 \%$ & $<.05$ & $45 \%$ & $17 \%$ & $<.001$ \\
\hline
\end{tabular}

: Local stage of disease versus regional stage of disease versus metastatic stage of disease at pretest

Patients who consulted a pain physician versus not consult of a pain physician at pretest.

not significant. 
For all measures, except the Pain Management Indexes of Cleeland, Zelman, and Ward, no significant differences were found between the three tumor stage groups. Although it was possible for the Pain Management Indexes of Cleeland, Zelman, and Ward to distinguish between patient groups, the differences were not in the expected direction as results showed better cancer pain treatment in the patient groups with metastases compared to patients with a regional or local tumor stage. This was probably due to the fact that opioids determine to a larger extent the results of the indexes.

Second, patients who were treated by a pain physician were compared with patients who did not consult a pain physician. Results showed that for patients who were treated by a pain physician, patient's Present Pain intensity, Average Pain Intensity, and Worst Pain Intensity scores were significantly higher than for patients who were not treated by a pain physician ( 3.9 versus $3.0,5.7$ versus 4.5 , and 8.4 versus 7.4, respectively). The Amsterdam Pain Management Index showed no differences between patients who were and were not treated by a pain physician (Table 6). Also, no differences were found for the Pain Relief Scale, and the Patient Satisfaction Scale. Furthermore, results of the Pain Intensity Markers were in contrast with the Pain Management Indexes. The Pain Intensity Markers showed significantly more inadequately treated patients when treated by a pain physician than in the group of patients who were not treated by a pain physician. In contrast to this, according to the Pain Management Index of Cleeland, Ward, and Zelman, patients who were treated by a pain physician showed significantly lower percentages of adequately treated pain patients than those who were not treated by a pain physician. Thus, despite higher pain intensity scores, these patients showed to be treated better.

It can be concluded that, the Amsterdam Pain Management Index, the Pain Relief Scale, and the Patient Satisfaction Scale showed no differences between subgroups of patients known not to differ on relevant variables. Cleeland's, Ward's,

Table 7. Responsiveness to change over time and to clinical changes regarding inadequate pain treatment

\section{Control group Experimental group}

\begin{tabular}{lrrrrrrr}
\hline & Pretest 2 weeks & $\begin{array}{c}\text { Pretest } 2 \text { weeks } \\
\text { post- } \\
\text { discharge }\end{array}$ & $\begin{array}{c}\text { post- } \\
\text { discharge }\end{array}$ & $\begin{array}{c}\text { p- } \\
\text { value* }\end{array}$ & $\begin{array}{c}\text { p- } \\
\text { value }\end{array}$ \\
\hline 1. Amsterdam Pain Management Index & $49.4 \%$ & $57.9 \%$ & $50.6 \%$ & $42.1 \%$ & $<.01$ & $<.001$ \\
2. Substantial Present Pain & $33.1 \%$ & $26.1 \%$ & $32.1 \%$ & $17.9 \%$ & $\mathrm{~ns}$ & $<.001$ \\
3. Substantial Average Pain & $59.6 \%$ & $35.2 \%$ & $58.6 \%$ & $25.2 \%$ & $\mathrm{~ns}$ & $<.001$ \\
4. Substantial Worst Pain & $89.5 \%$ & $75.6 \%$ & $92.2 \%$ & $63.9 \%$ & $<.05$ & $<.001$ \\
5. Pain Relief Scale & $20.5 \%$ & $24.0 \%$ & $11.8 \%$ & $23.6 \%$ & $\mathrm{~ns}$ & $<.05$ \\
6. Patient Satisfaction Scale & $32.9 \%$ & $22.0 \%$ & $31.3 \%$ & $23.8 \%$ & $\mathrm{~ns}$ & $<.001$ \\
7. Cleeland's Pain Management Index & $50.0 \%$ & $41.7 \%$ & $52.3 \%$ & $41.7 \%$ & $\mathrm{~ns}$ & $<.001$ \\
8. Ward's Pain Management Index & $52.0 \%$ & $47.2 \%$ & $58.3 \%$ & $48.0 \%$ & $\mathrm{~ns}$ & $<.001$ \\
9. Zelman's Pain Management Index & $32.7 \%$ & $30.3 \%$ & $39.2 \%$ & $26.2 \%$ & $\mathrm{~ns}$ & $<.001$ \\
\hline
\end{tabular}

Control group versus experimental group at 2 weeks postdischarge, adjusted for the scores at pretest.

Pretest versus at 2 weeks postdischarge, time trend.

ns, not significant. 
and Zelman's Pain Management Index, however, differed between the patient groups.

Responsiveness to clinical change. The Pain Education Program was used as an indicator to detect clinical changes. It was assumed that the experimental group patients would experience less pain due to the Pain Education Program resulting in better pain treatment. A MANOVA evaluating patient's pain intensity scores postdischarge with the pain intensity score at pretest as a covariate showed a significant interaction (group $x$ time) effect on all three pain intensity scales. The experimental group patients experienced significantly less pain than the control group patients. Comparing the different outcome measures to evaluate pain treatment, only the Amsterdam Pain Management Index and the Substantial Worst Pain scale showed that the experimental group patients were treated more adequately than control group patients (Table 7). The other measures did not show differences between the groups.

Responsiveness to change over time. Evidence of responsiveness was assessed by comparing scores at pretest with 2 weeks postdischarge. For a substantial group of patients the reason for admission was pain; consequently, patients' pain treatment was expected to change during the hospital stay. It was hypothesized that adequacy of pain treatment would be improved at 2 weeks postdischarge for all patients, regardless the intervention. Using paired t-tests to compare pain intensity scores, results showed a statistically significant decrease in Present Pain Intensity, Average Pain Intensity, and Worst Pain Intensity. All measures describing adequacy of pain treatment showed fewer patients being treated inadequately for their pain at 2 weeks postdischarge compared to the baseline scores (Table 7). From this, it can be concluded that all scales showed good responsiveness to change over time.

\section{The Amsterdam Pain Management Index reconsidered}

The question is whether the Amsterdam Pain Management Index, a measure that compares the aggregated scores of patients' Present Pain Intensity, Average Pain Intensity, and Worst Pain Intensity, corrected for patients' Tolerable Present Pain, and compared with the analgesics used by the patient, is feasible in clinical practice. In order to make sure that all components are needed in predicting the variance of the Amsterdam Pain Management Index, multiple regression analyses have been conducted to explore the relationships between the components of which the Amsterdam Pain Management Index is based on and the Amsterdam Pain Management Index itself. The results are described in Table 8. Results showed that 79 - $97 \%$ of the variance of the Amsterdam Pain Management Index could be predicted on the basis of the combination of the variables. With the exception of the Average Pain Intensity score at 4 weeks postdischarge, all components were found to be important predictors of the degree of variance of the Amsterdam Pain Management Index. From this, it can be concluded that all components of the Amsterdam Pain Management Index are necessary for the aggregated score. 
Table 8. Adequacy of pain treatment across time for the Random Regression Model

\begin{tabular}{|c|c|c|c|c|c|c|c|c|}
\hline \multirow[t]{3}{*}{ Predictor } & \multirow{2}{*}{\multicolumn{2}{|c|}{$\begin{array}{l}\text { Pretest } \\
2^{2}=97 \%\end{array}$}} & \multicolumn{2}{|c|}{$\begin{array}{r}2 \text { weeks } \\
\text { postdischarge }\end{array}$} & \multicolumn{2}{|c|}{$\begin{array}{r}4 \text { weeks } \\
\text { postdischarge }\end{array}$} & \multicolumn{2}{|c|}{$\begin{array}{r}8 \text { weeks } \\
\text { postdischarge }\end{array}$} \\
\hline & & & & $=\mathbf{8 5} \%$ & & $=79 \%$ & & $=85 \%$ \\
\hline & Beta & $\begin{array}{c}\text { p- } \\
\text { value }\end{array}$ & Beta & $\begin{array}{c}\text { p- } \\
\text { value }\end{array}$ & Beta & $\begin{array}{c}\text { p- } \\
\text { value }\end{array}$ & Beta & $\begin{array}{c}\text { p- } \\
\text { value }\end{array}$ \\
\hline Equianalgesic dose morphine & 0.93 & $<0.001$ & 0.86 & $<0.001$ & 0.84 & $<0.001$ & 0.84 & $<0.001$ \\
\hline Present Pain Intensity & -0.35 & $<0.001$ & -0.41 & $<0.001$ & -0.20 & $<0.001$ & -0.50 & $<0.001$ \\
\hline Average Pain Intensity & -0.13 & $<0.001$ & -0.08 & $<0.01$ & -0.06 & 0.20 & -0.35 & $<0.001$ \\
\hline Worst Pain Intensity & -0.23 & $<0.001$ & -0.10 & $<0.05$ & -0.31 & $<0.001$ & 0.07 & 0.06 \\
\hline Tolerable Pain Intensity & 0.24 & $<0.001$ & 0.23 & $<0.001$ & 0.12 & $<0.001$ & 0.19 & $<0.001$ \\
\hline
\end{tabular}

\section{Conclusion and discussion}

Outcome measures of pain treatment are important to identify changes in cancer pain treatment and to describe effects of pain interventions. No single standard measure has received widespread acceptance to evaluate the adequacy of cancer pain treatment. The purpose of this study was to determine whether the new developed Amsterdam Pain Management Index, a measure that compares the aggregated scores of patients' Present Pain Intensity, Average Pain Intensity, and Worst Pain Intensity, corrected for patients' Tolerable Present Pain, with the analgesics used by the patient, is a valid and responsive measure to evaluate the adequacy of cancer pain treatment. We compared the Amsterdam Pain Management Index to other frequently used outcome measures to evaluate pain treatment. The eight commonly used measures showed that the proportion of inadequately treated pain patients varied extremely depending on the outcome measure used. In the Amsterdam Pain Management Index, patients' subjective pain assessment was corrected for what is experienced as tolerable by the patient, and combined with patients' analgesic drug therapy. The motivation behind the development of the Amsterdam Pain Management Index was not to replace the existing measures, but to offer an alternative method to overcome some of the limitations with the frequently used outcome measures. The Amsterdam Pain Management Index belongs to a group of aggregated outcome measures that take into account patients' pain intensity as well as pain medication. The Amsterdam Pain Management Index distinguishes from the Pain Management Indexes of Cleeland, Ward, and Zelman in two ways. First, both non-opioids and opioids that are actually used by the patient are included. Second, the composite pain intensity score is corrected for what a patient considers as a tolerable level of pain.

In this study, the percentage of missing data on the outcome measures was low to moderate $(1-19 \%)$. The single-item measures were completed easily by patients, while the outcome measures that are based on both pain intensity and analgesics showed relatively higher percentage of missing values. 
A number of analyses were conducted to evaluate the psychometric properties of the different measures. Results showed that high agreement between the measures was only found for the Pain Management Index of Cleeland, Ward, and Zelman. The correlations between the other measures was very low to moderate. Regarding known-group comparisons, results showed that the ability to discriminate on the basis of adherence varied substantially. It was assumed that patients who reported to be non-adherent would score lower on adequacy of cancer pain treatment than patients who reported to be adherent. Results showed that the ability of the Pain Intensity Markers and the Patient Satisfaction Scale to detect differences between patient groups was not demonstrated for adherence to pain medication. The Patient Satisfaction Scale was skewed toward the high end of the scale, even for patients who were in severe pain. A possible explanation for this finding might be that as long as patients do not know what quality of pain treatment they can expect, most patients are satisfied with the pain treatment. This result is in concurrence with other studies showing that critical concerns are raised about the appropriateness of the Patient Satisfaction Scale as an outcome measure. ${ }^{22,45}$ Results also showed no difference in adequacy of pain treatment on the Pain Intensity Markers when comparing adherent with non-adherent patients. This might be due to the fact that Pain Intensity Markers do not incorporate the pain treatment itself, but are rather crude measures of pain intensity only. It should be noted that, although the Pain Management Indexes differed between patient groups, the difference was not in the expected direction. Only the Pain Relief Scale and the Amsterdam Pain Management Index showed to discriminate between groups in the expected direction.

With regard to sleeping problems, it was expected that patients with high scores on sleeping problems would experience higher pain intensity, resulting in less adequate pain treatment than in patient groups with low scores on sleeping problems. Results showed that it was possible to distinguish between patients with low sleeping problems and patients with high sleeping problems for most of the outcome measures. However, it was not possible to distinguish between groups for Substantial Present Pain, the Pain Relief Scale, and the Patient Satisfac. tion Scale.

Variables that were expected not to differ between groups consisted of tumor stage and whether a pain physician was consulted in the hospital. Patients with a local stage of disease were compared to patients with a regional stage of disease and to metastatic cancer patients. It is often reported that a higher percentage of patients with metastases experience more pain than patients with a local or regional stage of disease. ${ }^{11,24,46}$ That they are treated less adequately was not hypothesized. Results showed that patients with a metastatic stage of disease experienced more pain, but were treated more adequately than patients with a local or regional stage of disease on the Pain Management Index of Cleeland, Ward, and Zelman. These results might be due to a higher percentage of patients being prescribed opioids in the group of patients with metastases, leading to satisfactory pain treatment. Finally, patients were treated by a pain physician were expected to experience more complex pain problems and to have more severe pain than patients for whom no pain physician was necessary. Arbitrarily, it was assumed that, although pain physicians are expected to have more expertise in treating patients' pain, the adequacy of pain treatment would not automatically be better as this is more difficult to achieve in complex pain patients. Results 
showed that according to Cleeland's Ward's, and Zelman's Pain Management Index, patients who were treated by a pain physician were evaluated as being treated more adequate than patients who were not treated by a pain physician. This points at a high percentage of adequately treated cancer patients in a group of patients who experienced high pain intensity. This paradoxical finding might be due to the fact that patients who are treated by a pain physician are more frequently prescribed strong opioids than those who were not treated by a pain physician. Consequently, they are assessed as receiving adequate cancer pain treatment according to Pain Management Indexes.

With regard to responsiveness, results showed that the difference in change scores was only statistically significant for the Amsterdam Pain Management Index and for Substantial Worst Pain. The ability of the measures to detect changes over time was clearly demonstrated by all outcome measures.

It can be concluded that there is a first support for the use of the Amsterdam Pain Management Index. Although the Amsterdam Pain Management Index seems to be cumbersome to use in clinical practice as 5 components are involved, multiple regression analyses showed that all components significantly contributed in the final score. However, in considering the use of the Amsterdam Pain Management Index as a measure for assessing the adequacy of pain treatment, further refinement is needed. Therefore, we recommend its use in research only until there is clear evidence that the Amsterdam Pain Management Index is a valid and reliable measure.

The Amsterdam Pain Management Index has a number of limitations. First, the Amsterdam Pain Management Index focuses on analgesics and does not take into account other pain treatments, e.g., TENS, invasive pain treatment, coanalgesia. Second, when evaluating the pain treatment, one should ideally also take into account patient's cancer treatment that also may reduce patient's pain. Third, to combine non-opioids with opioids, a conversion table for non-opioids was used in which relative potencies of non-opioids are compared and converted to oral morphine. This is debatable as the working mechanism of non-opioids is different from opioids. Finally, the value of including patients' Tolerable Pain Intensity has not been studied extensively. Although the results showed evidence that Tolerable Pain Intensity significantly contributed to the Amsterdam Pain Management Index, the impact of Tolerable Pain Intensity on adequacy of pain treatment is not yet clear. Further research investigating the underlying limitations of the various measures as well as further evaluation of psychometric properties is warranted.

\section{Acknowledgments}

The authors wish to thank the patients who participated in this study. Further, we extend special thanks to nurses of the Antoni van Leeuwenhoek Hospital, Amsterdam. This work was supported by a grant from the Dutch Cancer Society (grant no. 92-469). 


\section{References}

1. Jadad AR, Browman GP. The WHO analgesic ladder for cancer pain management. Stepping up the quality of its evaluation. JAMA, 1995;274:1870-1873.

2. Cleeland CS, Gonin R, Baez L, Loehrer P, Pandya KJ. Pain and treatment of pain in minority patients with cancer. Annals of Internal Medicine, 1997;127:813-816.

3. Dorrepaal KL. Pijn bij patienten met kanker [Thesis in Dutch]: Vrije Universiteit, 1989.

4. Larue F, Colleau SM, Brasseur L, Cleeland CS. Multicentre study of cancer pain and its treatment in France. British Medical Journal, 1995;310:1034-1037.

5. Lin CC, Ward SE. Patient-related barriers to cancer pain management in Taiwan. Cancer Nursing, 1995; 18:16-22.

6. Ward SE, Goldberg N, Miller-McCauley V, Mueller C, Nolan A, Pawlik-Plank D, Robbins A, Stormoen D, Weissman DE. Patient-related barriers to management of cancer pain. Pain, 1993;52:319-324.

7. Ward SE, Hernandez L. Patient-related barriers to management of cancer pain in Puerto Rico. Pain, 1994;58:233-238.

8. Zelman DC, Cleeland CS, Howland EW. Factors in appropriate pharmacological management of cancer pain: A cross-institutional investigation. Pain (supplement 4), 1987:S136.

9. Cleeland CS. Pain assessment in cancer. In: Osoba D, ed. Effect of cancer on quality of life. Boca Raton, FL: CRC Press, 1991: 294-305.

10. Dalton JA. Outcomes that provide evidence of change in cancer pain management. Nursing Clinics of North America, 1995;30:683-695.

11. AHCPR. Agency for Health Care Policy and Reserach. Management of cancer pain. Clinical Practice Guideline. Rockville, MD: Agency for Health Care Policy and Research, 1994.

12. APS. American Pain Society. Principles of analgesic use in the treatment of acute pain and chronic cancer pain: a concise guide to medical practice. Skokie, IL: American Pain Society, 1992.

13. Cleeland CS, Gonin R, Hatfield AK, Edmonson JH, Blum RH, Stewart JA, Pandya KJ. Pain and its treatment in outpatients with metastatic cancer. New England Journal of Medicine, 1994:330:592-596.

14. Serlin RC, Mendoza TR, Nakamura Y, Edwards KR, Cleeland CS. When is cancer pain mild, moderate or severe? Grading pain severity by its interference with function. Pain, 1995;61:277-284.

15. Goisis A, Gorini M, Ratti R, Luliri P. Application of a WHO protocol on medical therapy for oncologic pain in an internal medicine hospital. Tumori, 1989;75:470-472.

16. Syrjala KL, Chapman CR. Measurement of clinical pain: A review and integration of research findings. In: Benedetti C, ed. Advances in pain research and therapy. New York, NY: Raven Press, 1984: 133-150.

17. Takeda F. Results of field-testing in Japan of the WHO draft interim guidelines on relief of cancer pain. The Pain Clinic, 1986;1:83-89.

18. Walker VA, Hoskin PJ, Hanks GW, White ID. Evaluation of WHO analgesic guidelines for cancer pain in a hospital-based palliative care unit. Journal of Pain and Symptom Management, 1988;3:145-149.

19. De Conno F, Caraceni A, Gamba A, Mariani L, Abbattista A, Brunelli C, La Mura A, Ventafridda V. Pain measurement in cancer patients: A comparison of six methods. Pain, 1994;57:161-166.

20. Dietrick-Gallagher $M$, Polomano R, Carrick L. Pain as a quality management initiative. Journal of Nursing Care Quaterly, 1994;9:30-42.

21. Miaskowski C, Nichols R, Brody R, Synold T. Assessment of patient satisfaction utilizing the American Pain Society's quality assurance standards on acute and cancer-related pain. Clinical Journal of Pain, 1994;9:5-11.

22. Ward SE, Gordon D. Application of the American Pain Society quality assurance standards. Pain, 1994;56:299-306.

23. Zhukovsky DS, Gorowski E, Hausdorff J, Napolitano B, Lesser M. Unmet analgesic needs in cancer patients. Journal of Pain and Symptom Management, 1995;10:113-119.

24. Foley KM. The treatment of cancer pain. New England Journal of Medicine, 1985;313:84-95.

25. WHO. Cancer pain relief and palliative care. Geneva, Switzerland: World Health Organization, 1990.

26. De Wit R, Van Dam F, Huijer Abu-Saad H, Vielvoye-Kerkmeer A, Mattern C. The practice of pain treatment in chronic cancer pain patients in a cancer hospital in the Netherlands. Journal of Pain and Symptom Management, 1999;17:333-350. 
27. Ferrell BR, Rivera LM. Cancer pain education for patients. Seminars in Oncology Nursing, 1997;13:42-48.

28. Spross JA, McGuire DB, Schmitt RM. Oncology Nursing Society Position Paper on Cancer Pain. Part I. Oncology Nursing Forum, 1990;17:595-614.

29. De Wit R, Van Dam F, Zandbelt L, Van Buuren A, Van der Heijden K, Leenhouts G, Loonstra S. A Pain Education Program for chronic cancer patients: follow-up results from a randomized controlled trial. Pain, 1997;73:55-69.

30. NVBP. Nederlanse Vereniging ter Bestudering van Pijn. Pijn en pijnbehandeling bij de patient met kanker. Groningen: Nederlandse Vereniging ter Bestudering van Pijn, 1990.

31. Spross JA, McGuire DB, Schmitt RM. Oncology Nursing Society Position Paper on Cancer Pain. Part II. Oncology Nursing Forum, 1990;17:751-760.

32. Jensen MP, Karoly P, Braver S. The measurement of clinical pain intensity: A comparison of six methods. Pain, 1986;27:117-126.

33. Kremer E, Atkinson JHJ. Pain measurement: construct validity of the affective dimension of the McGill Pain Questionnaire with chronic benign pain patients. Pain, 1981;11:93-100.

34. McGuire DB. Measuring pain. In: Frank-Stromborg M, ed. Instruments for clinical nursing. Norwalk, CT, 1988: 333-356.

35. Aaronson NK, Ahmedzai S, Bergman B, Bullinger M, Cull A, Duez NJ, Filiberti A, Flechtner H, Fleishman SB, de Haes JC. The European organization for research and treatment of cancer QLQ-C30: a quality-of-life instrument for use in international clinical trials in oncology. Journal of the National Cancer Institute, 1993;85:365-376.

36. Woodrow KM, Friedman GD, Siegelaub AB, Collen MF. Pain tolerance: differences according to age sex and race. Psychosomatic Medicine, 1972;34:548-556.

37. Ashburn MA, Lipman AG. Management of pain in the cancer patient. Anesthesia \& Analgesia, 1993;76:402-416.

38. Haviley C, Gagnon J, MacLean R, Renz J, Jones O, De Witt W, Nyberg K, Burns C, Pohl D. Pharmacological management of cancer pain. A guide for the health care professional. Cancer Nursing, 1992;15:331-346.

39. Horgas AL, Tsai P. Analgesic drug prescription and use in cognitively impaired nursing home residents. Nursing Research, 1998;47:235-242.

40. Levy MH. Pharmacological treatment of cancer pain. New England Journal of Medicine, 1996;335:1124-1132.

41. McCaffery M. A practical "postable" chart of equianalgesic doses. Nursing, 1987;17:56-57.

42. APS. American Pain Society Quality of Care Committee. Quality improvement guidelines for the treatment of acute pain and cancer pain. JAMA, 1995;274:1874-1880.

43. Thomas H, Bond S. Measuring patients' satisfaction with nursing: 1990-1994. Journal of Advanced Nursing, 1996;23:747-757.

44. De Wit R, Van Dam F, Huijer Abu-Saad H, Loonstra S, Zanbelt L, Van Buuren A, Van der Heijden K. Empirical comparison of frequently used measures to evaluate pain treatment in cancer patients with chronic pain. Journal of Clinical Oncology, 1999;17:1280-1287.

45. Hester NO, Miller KL, Foster RL, Vojir CP. Symptom Management Outcomes. Do they reflect variations in care delivery systems. Medical Care, 1997;35:NS69-NS83.

46. Portenoy RK. Cancer pain. Epidemiology and syndromes. Cancer, 1989;63:2298-2307. 


\section{Chapter 7}

\section{Improving the quality of pain treatment by a tailored Pain Education Program for cancer patients in chronic pain}

De Wit, R., Van Dam, F., Loonstra, S., Zanbelt, L., Van Buuren, A., Van der Heijden, K., Leenhouts, G., Duivenvoorden, H., Huijer Abu-Saad, H., Improving the quality of pain treatment by a tailored Pain Education Program for cancer patients in chronic pain

European Journal of Pain (Provisionally accepted) 


\section{Introduction}

Patient education and active participation of the patients themselves toward pain and pain treatment form one of the cornerstones of effective pain management. ${ }^{1,2}$ Patient education and active participation of patients have become increasingly important in pain treatment at a time that patients' length of stay in the hospital decreases and the emphasis has shifted from hospital care to home care. ${ }^{3}$ Several organizations ${ }^{2,4-6}$ have emphasized the use of patient education and active involvement of patients in their own pain treatment.

In recent years, few education programs have been conducted in pain pa tients. ${ }^{7-13}$ Informing patients about pain and pain treatment by means of providing written pain information packages and audiotapes is usually a major element of such education programs. Other elements are instructing patients how to self-monitor pain, teaching patients how to use non-pharmacological pain management techniques (e.g., cold, heat, relaxation, massage), instructing communication skills to improve communication about pain experiences with healthcare providers, and counseling patients how to cope with the pain. With the exception of one study, ${ }^{9}$ all pain education programs ${ }^{7,8,10-13}$ have shown to be efficacious in one or more of the following outcome measures: pain intensity, compliance, patients' attitudes regarding addiction, tolerance, side-effects, and the use of pain relief methods.

However, a number of problems complicate the evaluation of such pain education programs. First, the lack of agreed upon criteria for adequate pain treatment leads to arbitrary use of different outcome measures. ${ }^{14,15}$ Usually, three types of outcome measures are suggested to assess pain treatment. $4,5,16,17$ The first group of measures consists of pain intensity scales, measuring patients' present pain, average pain in the past week, or worst pain intensity. Secondly, pain intensity markers are used, in which cutoff scores of pain intensity scales (score of 5 or more) are used to describe inadequacy of cancer pain treatmen. ${ }^{18-22}$ Finally, patient satisfaction scales, assessing patients' satisfaction with pain relief, are used to evaluate the pain treatment. ${ }^{23-29}$ Although pain treatment programs have been measured frequently by means of these outcome measures, the evaluation of pain education programs is hampered by the lack of consensus on how to evaluate the effectiveness of pain treatment. In a previous study, de Wit and associate ${ }^{30}$ showed that the percentage of inadequately treated pain patients ranged from $16.2-90.8 \%$, depending on the measure used. The enormous variability in adequacy of pain treatment showed that the outcome measures evaluate different aspects of pain treatment, and one measure cannot be easily interchanged for another.

A second limitation hampering the evaluation of educational pain programs is that most studies do not evaluate effects longitudinally or describe only shortterm changes. Research showed that all of the studies evaluating the effects of pain education programs, $, 8,8,10-13$ except for one, ${ }^{9}$ evaluated short-term effects. Studying longitudinal effects in cancer patients with chronic pain is rather paradoxical. On the one hand, longitudinal studies are important in studying chronic pain, while on the other hand, it results in substantial dropout rates due to patients dying or being too seriously ill to be followed up.

A third potential limitation is caused by the dilemma that longitudinal data are usually analyzed by means of classical analytic techniques, such as repeated 
measures analysis of variance. ${ }^{31}$ In case of missing data, a statistical approach should be applied in which the results are corrected for this imbalance due to dropouts.

In this article, the effectiveness of the Pain Education Program in cancer patients in chronic pain is evaluated. Characteristics predicting change in adequacy of pain treatment were investigated for both the short-term and long-term. The Pain Education Program consists of enhancing patients' knowledge about pain and pain treatment, instructing patients in how to register their pain intensity in the home setting, and stimulating patients' help-seeking behavior. Nurses in the hospital were specially trained as pain counselors to educate and instruct patients about pain and pain treatment.

To overcome the problem of the lack of well-defined criteria to evaluate the outcomes of pain treatment, the Amsterdam Pain Management Index was developed to address some of the limitations of the frequently used outcome measured to evaluate the adequacy of pain treatment. The Amsterdam Pain Management Index compares patients' Present Pain Intensity, Average Pain Intensity, and Worst Pain Intensity with a composite score of analgesics used, while correcting for what a patient considers as a tolerable level of pain analgesics used by the patient. In a previous study, describing the psychometric characteristics of the Amsterdam Pain Management Index, results showed that the Amsterdam Pain Management Index has good validity. ${ }^{32}$

\section{Methods}

\section{Study site and patients}

The study was conducted at the Netherlands Cancer Institute/Antoni van Leeuwenhoek Hospital, a specialized cancer center in Amsterdam. Patients were eligible for enrollment in the study if they met the following inclusion criteria: (1) pain for at least 1 month; (2) pain related to cancer, cancer therapy, or illness; (3) a life expectancy of at least 3 months as assessed by the clinician; (4) able to read and speak Dutch; (5) accessible by telephone; and (6) not residing in a nursing home or retirement home.

\section{Study design}

In a longitudinal study utilizing a "pretest-posttest experimental design," the purpose of the study was explained to the patients. Patients who provided informed consent participated in the study. Based on the assumption that patients who required district nursing postdischarge would differ from patients without district nursing with regard to the ability to perform daily activities, housing and living conditions, and pain complaints experienced, patients with and without district nursing were distinguished. Consenting patients of both groups were randomly assigned to either the control group, in which regular pain treatment was provided, or the intervention group in which, in addition to the regular pain treatment, the Pain Education Program was provided. Prior to randomization, the patients were stratified for gender (male/female), age ( $<60$ years/ $\geq 60$ years), and 
metastatic sites (yes/no/unknown). Summarizing, two control groups (with and without district nursing) and two intervention groups (with and without district nursing) were studied. After randomization, the Pain Education Program was provided to the intervention group patients.

\section{Description of the Pain Education Program}

The Pain Education Program has been described extensively elsewhere. ${ }^{33}$ The Pain Education Program was developed on the basis of the literature, existing educational programs, and input of pain experts. 2,5,6,33,34 The intervention included the use of multiple teaching methods, which were provided both in the hospital and postdischarge by telephone. The pain information and instruction was tailored to the needs and the abilities of the individual patient. The Pain Education Program consists of three components:

1) Enhancing patients' knowledge about pain and pain treatment. Twentyone pain topics were identified which are considered to be part of the patients' basic pain knowledge, e.g., causes of pain, pharmacological pain treatment, experienced side-effects, myths and misconceptions related to pain, effect of non-adherence, use of non-pharmacological pain treatment. Prior to the intervention, the pain topics in which patients were not adequately informed were determined by a nurse by means of a checklist. A patient was instructed about a specific pain topic only when that topic was assessed as applicable to the patient, and only when the patient's knowledge about pain and pain treatment was assessed as insufficient. Patients were educated about all pain topics that were assessed by the nurse as insufficient. This tailored information was provided in a one-to-one setting lasting between 30 and 60 minutes. For instance, when a patient was prescribed morphine and was afraid of becoming addicted, information was given concerning addiction in relation to pain treatment. Because patients are often unable to retain all information provided, the oral instruction was audio taped on a cassette which could be listened to at home, alone or with family. Further, the verbal instruction was accompanied by a pain brochure which was especially designed and pretested for this study. The pain brochure consisted of two parts: 1) a section with general information aimed at all cancer pain patients with chronic pain, describing possible causes of pain, pain control, non-adherence, misconceptions; and 2) a loose-leaf part, including nine supplementary sheets with targeted information about different cancer pain treatments. Patients only received those sheets that were applicable to them.

2) Instructing patients how to register their pain intensity. Patients were instructed how to register their Present Pain Intensity twice daily on a numeric rating scale from $0-10$ in a pain diary for a period of two months. Because their Present Pain Intensity was also assessed in the hospital twice daily by nurses, patients were already used to describing their pain intensity by using a score from $0-10$. In addition to reporting Present Pain Intensity, patients were instructed to document changes in type of pain and use of (non-) pharmacological pain treatment.

3) Stimulating patients' help-seeking behavior. Patients received information about what actions should be undertaken at home when pain relief was in- 
sufficient. They were encouraged to contact health care providers if necessary, to talk about their pain experience, and to discuss what bothers them. Patients were instructed how to use simple non-pharmacological pain management techniques, such as cold, heat, relaxation, and massage. Besides the instruction provided in the hospital, patients were called at home at three and seven days postdischarge by the same nurse to determine whether the pain information and instruction provided in the hospital was fully understood by the patient, and to offer the opportunity to ask questions. These phone calls took approximately 5-15 minutes each.

\section{Measures}

Sociodemographic information, pain-related clinical and treatment information, symptom information, and information regarding quality of life, nonadherence, pain knowledge, pain cognition, and contacting healthcare providers were elicited through self-report questionnaires, structured interviews, the use of medical records, and nursing records.

Sociodemographic variables were assessed regarding gender, age, marital status, and education. Medical variables consisted of e.g., diagnosis, time since diagnosis, tumor site, disease stage, treatment, and side-effects. Patients' pain experience was measured by means of the Dutch Language Version of the McGill Pain Questionnaire (MPQ-DLV), which has demonstrated acceptable levels of reliability and validity. ${ }^{35-38}$

With regard to pain treatment, both the use of causal and symptomatic pain treatment was assessed. Causal pain treatment consists of pain treatment from chemotherapy, hormonal therapy, radiation or supportive surgery. Symptomatic pain treatment was reported by means of the three-step WHO analgesic ladder, consisting of: non-opioid analgesic (step I), weak opioids with or without nonopioids (step II), and strong opioids with or without non-opioids (Step III). ${ }^{39}$

Quality of life was evaluated by means of the EORTC QLQ-C30 $(+3)$, which has demonstrated acceptable levels of reliability and validity. ${ }^{40}$ This quality of life questionnaire was used to measure physical symptoms, role functioning, emotional functioning, cognitive functioning, social functioning, fatigue and malaise, nausea and vomiting, pain, constipation, dyspnea, difficulty sleeping, appetite loss, diarrhea, financial impact, overall perceived health status, and global quality of life.

Non-adherence, the degree to which a patient does not follow the medication regimen recommended by the physician, was assessed by means of a self-report questionnaire.

Pain knowledge was assessed by using a translated version of Ferrell's Patient Pain Questionnaire." The Dutch Language Version of the Pain Knowledge Questionnaire (PKQ-DLV) has demonstrated acceptable levels of validity and reliabit ity. ${ }^{33}$

Pain cognition was measured by means of the Pain Cognition List for Cancer patients (PCL-C), measuring patients' self-reports about their pain and the extent to which patients are effective in dealing with the pain..$^{41}$ The PCL-C measures four elements: (1) pain impact, which primarily reflects the impact of pain on the patients' functioning; (2) social comparison, describing how patients relativize their situation by comparing their situation with others; (3) acquiescence, 
Table 1. The Amsterdam Pain Management Index

\begin{tabular}{|c|c|c|}
\hline $\begin{array}{l}\text { Tolerable Pain } \\
\text { Intensity }\end{array}$ & $\begin{array}{l}\text { Equianalgesic dose oral morphine } \\
\text { Tolerable Pain Intensity } \geq \\
\text { Present Pain Intensity } \\
\text { (Amsterdam Pain } \\
\text { Management Index) } \\
{ }^{d}\end{array}$ & $\begin{array}{l}\text { Tolerable Pain Intensity < } \\
\text { Present Pain Intensity } \\
\text { (Amsterdam Pain } \\
\text { Magement Index score) }\end{array}$ \\
\hline $0:$ no pain $(0)$ & $\begin{array}{l}0 \text { mg morphine }(0) \\
1-60 \mathrm{mg} \text { morphine }(1) \\
61-120 \mathrm{mg} \text { morphine }(2) \\
121-240 \mathrm{mg} \text { morphine }(3) \\
>240 \mathrm{mg} \text { morphine (4) }\end{array}$ & - \\
\hline I: Mild (I-3) & $\begin{array}{l}0 \mathrm{mg} \text { morphine }(-1) \\
1-60 \mathrm{mg} \text { morphine }(0) \\
61-120 \mathrm{mg} \text { morphine }(1) \\
121-240 \mathrm{mg} \text { morphine }(2) \\
>240 \mathrm{mg} \text { morphine }(3)\end{array}$ & $\begin{array}{l}0 \mathrm{mg} \text { morphine }(-2) \\
\text { 1-60 mg morphine }(-1) \\
61-120 \mathrm{mg} \text { morphine }(0) \\
121-240 \mathrm{mg} \text { morphine }(1) \\
>240 \mathrm{mg} \text { morphine }(2)\end{array}$ \\
\hline 2: Moderate (4-7) & $\begin{array}{l}0 \mathrm{mg} \text { morphine }(-2) \\
\text { I-60 mg morphine }(-1) \\
61-120 \mathrm{mg} \text { morphine }(0) \\
121-240 \mathrm{mg} \text { morphine }(1) \\
>240 \mathrm{mg} \text { morphine }(2)\end{array}$ & $\begin{array}{l}0 \mathrm{mg} \text { morphine }(-3) \\
\text { I-60 mg morphine }(-2) \\
61-120 \mathrm{mg} \text { morphine }(-1) \\
\text { I21-240 mg morphine }(0) \\
>240 \mathrm{mg} \text { morphine }(1)\end{array}$ \\
\hline 3: Severe $(8-10)$ & $\begin{array}{l}0 \mathrm{mg} \text { morphine }(-3) \\
\text { I-60 mg morphine }(-2) \\
61-120 \mathrm{mg} \text { morphine }(-1) \\
121-240 \mathrm{mg} \text { morphine }(0) \\
>240 \mathrm{mg} \text { morphine }(1)\end{array}$ & $\begin{array}{l}0 \mathrm{mg} \text { morphine }(-4) \\
\text { I-60 mg morphine }(-3) \\
61-120 \mathrm{mg} \text { morphine }(-2) \\
\text { 121-240 mg morphine }(-1) \\
>240 \mathrm{mg} \text { morphine }(0)\end{array}$ \\
\hline
\end{tabular}

- The mean Pain Intensity Score was computed by: (Present Pain Intensity + Average Pain Intensity + Worst Pain Intensity) 3 .

b This aggregated Pain Intensity Score is corrected for patients' Tolerable Pain Intensity. In case patient's Tolerable Pain Intensity is less than patient's Present Pain Intensity, the Amsterdam Pain Management Index is subtracted with I point (score - 1). For a patient assessing his Tolerable Pain Intensity equal or higher than his Present Pain Intensity, the score is unchanged.

All opioids and non-opioids used within a 24-h period were converted to oral morphine equivalents. Therefore, the amount of oral opioids (Morphine $30 \mathrm{mg}=$ Codeine $200 \mathrm{mg}=$ Tramadol $200 \mathrm{mg}=$ Pethidine $300 \mathrm{mg}=$ Pentazocine $180 \mathrm{mg}$ ) and the amount of parenteral opioids (Morphine $10 \mathrm{mg}=$ Pethidine $75 \mathrm{mg}=$ Pentazocine $60 \mathrm{mg}=$ Dextroproxypophene $300 \mathrm{mg}=$ Nicomorphine $45 \mathrm{mg}=$ Piritramide $15 \mathrm{mg}$ ) were converted to oral morphine (Parenteral Morphine $10 \mathrm{mg}=$ Oral Morphine 30 $\mathrm{mg}$ ). The one-day dose of one non-opioid was considered equianalgesic to the one-day dose of another non-opioid (Paracetamol $2000 \mathrm{mg}=$ Ibuprofen $1200 \mathrm{mg}=$ Diclofenac $100 \mathrm{mg}=$ Naproxen $500 \mathrm{mg}$ ) and $650 \mathrm{mg}$ of aspirin was considered as equianalgesic to $6 \mathrm{mg}$ of oral morphine. The total dose of analgesics per 24 hours was categorized into: no analgesic drug (0)), 1-60 mg (1), 61-120 mg (2), 121-240 mg (3), and > $240 \mathrm{mg}$ (4) equianalgesic dose oral morphine. ${ }^{44,46.50}$

d The Amsterdam Pain Management Index can range from -4 (a patient receiving no analgesics who is in severe pain) to +4 (a patient receiving high doses of opioids ( $>240 \mathrm{mg}$ per day) with complete pain relief). A score of -4 to -1 indicates inadequate use of analgesic drugs, while a score of 0 to 4 indicates adequate use of analgesics. 
including the locus of control patients experience over their pain, and (4) outcome efficacy, representing the expectancy that a given behavior will lead to a decrease in pain intensity.

Contacting healthcare providers was assessed by interviewing the patient about the frequency and relation with the general practitioner.

\section{Measures to assess adequacy of pain treatment}

The effectiveness of the Pain Education Program was evaluated by means of the Amsterdam Pain Management Index. ${ }^{32,42}$ A description of the Amsterdam Pain Management Index is given in Table 1. This index was originally based on the Pain Management Index as developed by Cleeland and associates ${ }^{43}$ and consists of a aggregated score of Present Pain Intensity, Average Pain Intensity, and Worst Pain Intensity, assessed on an 11-point numeric rating scale, on which 0 represents "no pain" and 10 represents "pain as bad as you can imagine." The mean pain score ((Present Pain Intensity+Average Pain Intensity+Worst Pain Intensity)/3) is then categorized into: 0 (no pain), 1 (1-3: mild pain), 2 (4-7: moderate pain), and 3 (8-10: severe pain). Because patients' pain intensity ratings may have different meanings for different patients, patients were also asked to rate their Tolerable Pain Intensity. Patients are asked to indicate at what score they want something done about their pain. In this way, one gets an indication at what score the patient perceives his pain changes from tolerable into intolerable. By rating Tolerable Pain Intensity, an anchor point is provided for what a patient considers to be an acceptable level of pain. Patients who assessed their Tolerable Pain Intensity below their Present Pain Intensity were considered to be experiencing more pain than is acceptable to them. For example, a patient with a Present Pain Intensity score of 5, and rating his Tolerable Pain Intensity as 4, is experiencing more pain than is acceptable to him. In order to correct for patients'

\section{Table 2. Example of the Amsterdam Pain Management Index score}

Patient X describes her Present Pain Intensity as 3, her Average Pain Intensity in the previous week as 5, and her Worst Pain Intensity as 7. The aggregated Pain Intensity Score is 5 $((3+5+7) / 3)$ and is categorized as moderate (score 2). Patient X's Tolerable Pain Intensity is rated as 2, which indicates that her pain is not considered as acceptable. Because the patient's pain score is above the level of her Tolerable Pain Intensity, the Amsterdam Pain Management Index is corrected by subtracting I point. Patient $X$ is currently taking 20 mg morphine orally every $4 \mathrm{~h}$ and $200 \mathrm{mg}$ ibuprofen every $6 \mathrm{~h}$. The total dose morphine orally/24h consists of multiplying $20 \mathrm{mg}$ morphine $\times 6$ doses $=120 \mathrm{mg}$, and multiplying $200 \mathrm{mg} \times 4$ doses $=$ $800 \mathrm{mg}$ ibuprofen. The dosage ibuprofen is equivalent to $133319 \mathrm{mg}$ paracetamol $(800 / 1200 * 2000)$, which can be converted to $12 \mathrm{mg}$ morphine orally $(1333 / 650 \times 6)$. The total dose morphine orally/24h consists of $132 \mathrm{mg}$ morphine orally $(120+12)$ and is categorized into 3 (121-240 mg) equianalgesic dose ord morphine. The Amsterdam Pain Management Index is composed by subtracting the aggregated Pain Intensity Score (score 2), corrected for patients' $X$ Tolerable Pain Intensity (score -1 ), from the andgesic drugs used (score 3). These results lead to a final score of $0(3-2-1=0)$, indicating adequate analgesic prescriptions. 
Tolerable Pain Intensity, the Amsterdam Pain Management Index is subtracted with 1 point when the Present Pain Intensity score is above the level of the patient's Tolerable Pain Intensity. When a patient's Present Pain Intensity score is equal or below the level of Tolerable Pain Intensity, no correction of the Amsterdam Pain Management Index is needed. To compare patients' aggregated pain intensity scores with the use of analgesics, all opioids and non-opioids used within a $24 \mathrm{~h}$ period were calculated and converted to oral morphine equiva lents. ${ }^{44-46}$ To convert non-opioids to oral morphine equivalents, the one-day dose of a non-opioid was considered equianalgesic to the day dose of another nonopioid, and $650 \mathrm{mg}$ of aspirin was considered as equianalgesic to $6 \mathrm{mg}$ of oral morphine. Based on guidelines for starting dosage, ${ }^{4}$ the patient's total analgesic dose per 24 hours was categorized into: 0 (no analgesic drug), 1 (1-60 mg equianalgesic dose oral morphine, 2 (61-120 mg equianalgesic dose oral morphine), 3 (121-240 mg equianalgesic dose oral morphine), and 4 (> $240 \mathrm{mg}$ equianalgesic dose oral morphine). The Amsterdam Pain Management Index can range from -4 (patient with severe pain receiving no analgesics) to +4 (patient receiving high doses of opioids with complete pain relief). Negative scores indicate inadequate use of analgesic drugs, and scores of 0 or higher indicate adequate use of analgesics. An example of how the Amsterdam Pain Management Index is calculated is given in Table 2. Research has shown promising levels of validity and reliabir ity. ${ }^{42}$

\section{Procedure}

Patient accrual was carried out over a twenty month period. All patients who met the inclusion criteria were asked to participate. After informed consent was obtained, patients were interviewed by a research nurse. At baseline, sociodemographic variables, medical variables, and variables related to patients' pain experience, pain treatment, quality of life, non-adherence, pain knowledge, and pain cognition were assessed. In order to assess the adequacy of pain treatment, patient's Present Pain Intensity, Average Pain Intensity, Worst Pain Intensity, Tolerable Pain Intensity, use of opioids and non-opioids, as well as the patient satisfaction with the pain treatment were assessed. After randomization, the intervention group patients received the Pain Education Program in the hospital in a face-toface encounter with a specially trained nurse. Besides the instruction provided in the hospital, intervention group patients were called at home at 3 and 7 days postdischarge by the same nurse to determine whether the pain information and instruction provided in the hospital was fully understood by the patient.

Postdischarge, all control and intervention group patients were followed-up at two weeks, four weeks, and eight weeks postdischarge by telephone. Subsequently, data were once again collected regarding patients' Present Pain Intensity, Average Pain Intensity, Worst Pain Intensity, Tolerable Pain Intensity, and use of opioids and non-opioids.

\section{Statistical analyses}

Data were analyzed using the Statistical Package for the Social Sciences (SPSS) version 7.5, and Statistical Analysis Systems (SAS) PC Statistical Package. Data are 
presented as means $\pm \mathbf{s d}$ or median and range according to distribution. Differences between groups were evaluated Student's t-test for unpaired observations or chi-square. A p-value of $<.05$ (two-tailed) was considered significant.

For analyzing longitudinal data, Random Regression Models for continuous data were used. With Random Regression Models, change over time is modeled at both the individual and group levels. Individual models of change over time were estimated and augmented using population-level trend data. Random Regression Models offers the advantage over e.g., multivariate repeated analysis that it is not restricted to modeling time as a fixed effect. With Random Regression Models, each patient can vary in both the number of measurements over time and the time course of those measurements. Therefore, Random Regression Models are more appropriate to handle missing data when evaluating longitudinal data, and patients who are missing at a given assessment time point are not excluded from the analyses. The model estimates the patient's trend across time on the basis of his/her pain data, augmented by the time trend that is estimated for the group as a whole and effects of all covariates in the model. ${ }^{47}$ Time-varying as well as time-constant variables can be entered into the model. In the Random Regression Models, the Amsterdam Pain Management Index scores at week 2, 4, and 8 were used as dependent variables. By generating the variable "dropouts" ("no missing" was coded as 0; and "missing" as 1), the influence of "dropouts" on the outcome of interest was estimated. The variable "intervention" was coded as follows: 0 for "control group" and 1 for "intervention group," and the variable "district nursing" was coded as 0 for "without district nursing," and 1 for "with district nursing." A random regression program was used to fit the models. Data were analyzed by fitting a model in which the main effects (intervention, time, district nursing, dropouts), as well as intervention $\mathrm{x}$ time, intervention $\mathrm{x}$ district nursing, intervention $x$ baseline score on the Amsterdam Pain Management Index, and intervention $x$ dropouts effects were estimated simultaneously.

To examine the relationship between a number of candidate predictors and the amount of intervention-related short-term and long-term change in adequacy of pain treatment, backward regression analyses (F-to-remove $p>.05$ ) were carried out. In the regression model the dependent variables were the gain scores, in terms of percentage of change over time on the Amsterdam Pain Management Index. The $\mathrm{R}^{2}$ represents the cumulative explained variance of the dependent variable accounted for by the predictor variables jointly. Because the number of candidate predictors to include in a regression analysis was large, the first step consisted of selecting those variables with estimated standardized regression coefficients adjusted for the intervention and the baseline score with $p<.20$. The standardized regression coefficient denotes the relative importance of the predictor: the higher the absolute value of the coefficient, the higher the contribution of the predictor to the regression equation.

\section{Results}

\section{Patient accrual}

During a 20-month study recruitment period, 383 patients were asked to participate in the study. Of these patients, $18 \%$ declined to participate: 48 patients 
Table 3. Sociodemographic and medical characteristics of the patient group at baseline

\begin{tabular}{|c|c|c|}
\hline $\begin{array}{l}\text { Control } \\
\text { groups } \\
(\mathrm{N}=154)\end{array}$ & $\begin{array}{r}\text { Inter- } \\
\text { vention } \\
\text { groups } \\
(\mathrm{N}=159)\end{array}$ & Total \\
\hline
\end{tabular}

\section{Age (years)}

Mean

$\begin{array}{rrr}55.1 & 55.8 & 55.5 \\ 11.7 & 13.0 & 12.4 \\ 21-85 & 22-81 & 21-85\end{array}$

Range (min.-max.)

$66 \%$

$34 \%$

$60 \%$

$63 \%$

$40 \%$

ns

Male

$42 \%$

$31 \%$

$40 \%$

$35 \%$

ns

Middle

$27 \%$

$25 \%$

$41 \%$

$33 \%$

High

Primary tumor site ( $>100 \%$ )

Lip, oral cavity, and pharynx

Digestive organs and peritoneum

Respiratory and intrathoracic organs

Breast

Bone, connective tissue, and skin

Genitourinary organs

Other

$6 \%$

$14 \%$

$10 \%$

$33 \%$

$12 \%$

$20 \%$

$12 \%$

$6 \%$

$6 \%$

$12 \%$

$11 \%$

$30 \%$

$11 \%$

$14 \%$

$24 \%$

$27 \%$

$11 \%$

\section{Disease stage}

Local

$15 \%$

$15 \%$

$62 \%$

Metastatic

Unknown

Not applicable

$4 \%$

$5 \%$

$14 \%$

$19 \%$

$58 \%$

$3 \%$

$5 \%$

\section{Treatment ( $>100 \%$ )}

No

Surgery

Chemotherapy

Radiation therapy

Hormonal therapy

Other and unknown

$\begin{array}{rrr}22 \% & 23 \% & 22 \% \\ 18 \% & 14 \% & 16 \% \\ 36 \% & 36 \% & 36 \% \\ 12 \% & 13 \% & 13 \% \\ 6 \% & 7 \% & 7 \% \\ 7 \% & 7 \% & 7 \%\end{array}$

${ }^{a}$ : not significant, $p>.05$; two-tailed 
$(69 \%)$ found the study too burdensome, 15 patients $(21 \%)$ were not motivated, and 7 patients $(10 \%)$ were too ill. A non-respondent analysis indicated that patients who declined to participate in the study were significantly older $(p<.01)$, and more frequently female $(p<.01)$ as compared to those who agreed to participate.

The remaining 313 patients consisted of $33 \%$ who needed district nursing at home, and $67 \%$ who did not need district nursing. At follow-up, data was collected of $89 \%$ of the patients at two weeks postdischarge, $83 \%$ at four weeks postdischarge, and $75 \%$ at all three posttests. Of the patients who dropped out, a majority $(60 \%)$ died during follow-up, 16 patients $(21 \%)$ were too ill to continue the posttests, 11 patients (14\%) experienced the study as too burdensome, and 4 patients $(5 \%)$ were not motivated.

\section{Sociodemographic and medical characteristics}

The sociodemographic and medical characteristics of the study sample are presented in Table 3. There were no differences with respect to sociodemographic and clinical variables between the control and the intervention groups. As compared to the group without district nursing, the patients in the group with district nursing differed in gender $(p<.05)$, age $(p<.001)$, marital status $(p<.05)$, having a profession $(p<.05)$, the location of the primary tumor $(p<.05)$, and the cancer treatment $(p<.05)$.

\section{Pain and pain treatment}

The patients' pain characteristics are described in Table 4. At baseline, no differences were found between the control and the intervention groups with regard to pain duration, pain location, and pain cause. At baseline, the mean score for patients' Present Pain Intensity was $3.3(s d=2.3), 4.9(s d=2.1)$ for Average Pain Intensity, and 7.7 ( $s d=2.1$ ) for Worst Pain Intensity. Patients' Tolerable Pain Intensity at baseline was $3.7(\mathrm{sd}=1.8)$. Thirty-three percent of the patients rated their pain as 5 or higher at baseline, whereas $59 \%$ rated their Average Pain Intensity, and $91 \%$ their Worst Pain Intensity as 5 or higher in the previous week Of the patients, $15 \%$ received radiation therapy, $12 \%$ chemotherapy, $3 \%$ surgery, and $2 \%$ hormonal therapy as pain treatment. Symptomatic pain treatment by means of the use of analgesics was prescribed to $88 \%$. In all, $12 \%$ were given no pain medication, $19 \%$ were receiving non-opioids, $33 \%$ were receiving weak opioids (e.g., codeine), of which $94 \%$ received it in combination with nonopioids, and $36 \%$ were taking morphine or a similar analgesic drug, either with $(57 \%)$ or without non-opioids $(43 \%)$. Only $4 \%$ received nerve blocks or other non-pharmacological pain treatments (e.g., TENS). Of the patients who reported that their Worst Pain Intensity was 8 or more $(66 \%)$, only $40 \%$ were prescribed strong opioids, while $9 \%$ were not prescribed any pain medication, $19 \%$ were prescribed non-opioids, and $32 \%$ were prescribed weak opioids. Patients' Worst Pain Intensity was rated between 4 - 7 in $30 \%$ of the patients. Of these patients, $15 \%$ were not prescribed analgesics, $20 \%$ were prescribed non-opioids, $33 \%$ weak opioids, and $32 \%$ strong opioids. Of the patients with a Worst Pain 
Intensity score of $1-3,23 \%$ were prescribed no pain medication, $15 \%$ were prescribed non-opioids, and $62 \%$ were prescribed opioids.

Table 4. Pain characteristics of the patient group at baseline

\begin{tabular}{|c|c|c|c|c|}
\hline (1) & $\begin{array}{l}\text { Control } \\
\text { groups } \\
(\mathrm{N}=154)\end{array}$ & $\begin{array}{r}\text { Inter- } \\
\text { vention } \\
\text { groups } \\
(\mathbf{N}=159)\end{array}$ & $\begin{array}{r}\text { Total } \\
(N=313)\end{array}$ & $\begin{array}{c}\text { p- } \\
\text { value }\end{array}$ \\
\hline \multicolumn{5}{|l|}{ Pain duration (months) } \\
\hline Mean & 17.3 & 11.1 & 14.2 & $\mathrm{~ns}^{\mathrm{a}}$ \\
\hline sd & 41.0 & 23.4 & 33.4 & \\
\hline Range & $1-324$ & $1-180$ & $1-324$ & \\
\hline \multicolumn{5}{|l|}{ Pain location (> 100\%) } \\
\hline Head, face, mouth, cenvical region & $21 \%$ & $21 \%$ & $21 \%$ & ns \\
\hline Breast, thoracic region & $21 \%$ & $20 \%$ & $20 \%$ & \\
\hline Upper shoulder and upper limbs & $29 \%$ & $29 \%$ & $29 \%$ & \\
\hline Abdominal region & $38 \%$ & $41 \%$ & $40 \%$ & \\
\hline Lower back, lumbar spine, sacrum & $41 \%$ & $37 \%$ & $39 \%$ & \\
\hline Lower limbs & $27 \%$ & $27 \%$ & $27 \%$ & \\
\hline Anal, perineal, and genital region & $6 \%$ & $5 \%$ & $5 \%$ & \\
\hline Everywhere & $1 \%$ & $1 \%$ & $1 \%$ & \\
\hline \multicolumn{5}{|l|}{ Pain cause } \\
\hline Tumor involvement & $64 \%$ & $65 \%$ & $65 \%$ & ns \\
\hline Cancer therapy & $12 \%$ & $11 \%$ & $12 \%$ & \\
\hline Tumor involvement and cancer therapy & $7 \%$ & $6 \%$ & $7 \%$ & \\
\hline Related to disease or debility & $11 \%$ & $14 \%$ & $13 \%$ & \\
\hline Unknown & $5 \%$ & $4 \%$ & $6 \%$ & \\
\hline
\end{tabular}

\section{Effects of the Pain Education Program}

The use of the Pain Education Program has been described extensively in a previous study. ${ }^{33}$ Briefly, follow-up results showed that the Pain Education Program proved to be feasible: $75 \%$ of the patients had read the entire pain brochure, $56 \%$ had listened to the audiocassette, and $86 \%$ of pain scores were completed in the pain diary at 8 weeks postdischarge.

The different components of the Amsterdam Pain Management Index are presented in Table 5. When evaluating the differences in an univariate way, statistically significant differences were found at week 2 for Present Pain Intensity, Average Pain Intensity, and Worst Pain Intensity, at week 4 for Present Pain Intensity, Average Pain Intensity, and Worst Pain Intensity, and at week 8 for Worst Pain Intensity, and Tolerable Pain Intensity. The aggregated Pain Intensity Score was 5.3 
Table 5. Average and standard deviations scores across time of the Amsterdam Pain Management Index

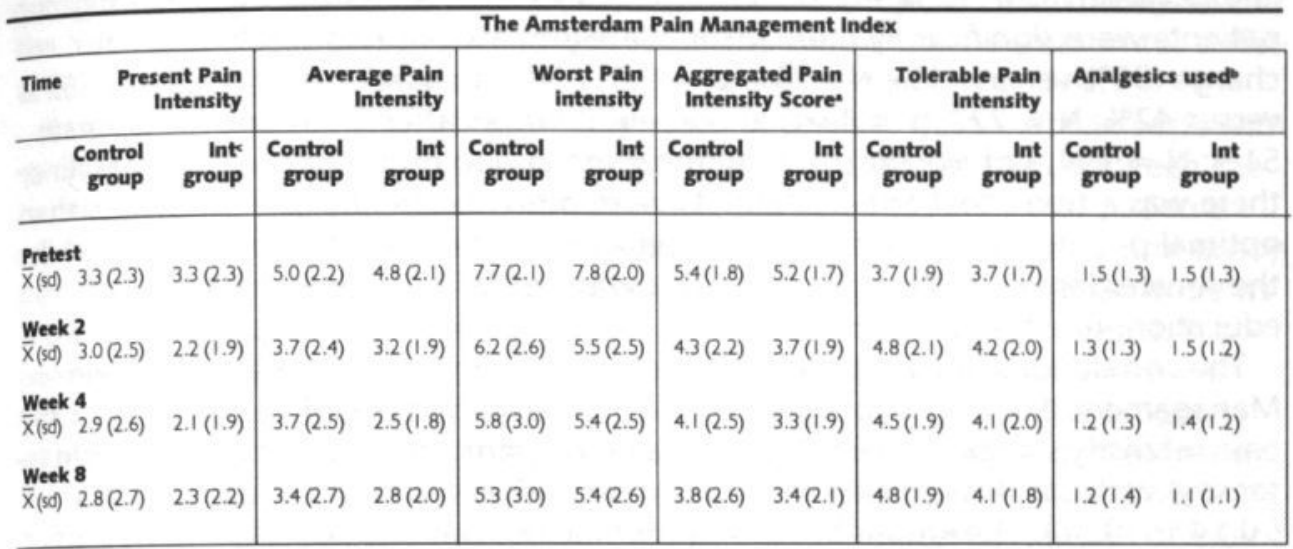

The aggregated Pain Intensity Score was computed by ((Present Pain Intensity + Average Pain Intensity +
Worst Pain Intensity)/3).
Patient's total analgesic dose per 24 hours was categorized into: 0 (no analgesic drug), I (I-60 mg
equianalgesic dose oral morphine, 2 (6I- - $20 \mathrm{mg}$ equianalgesic dose oral morphine), 3 (I2I-240 mg
equianalgesic dose oral morphine), and 4 (>240 mg equianalgesic dose oral morphine).
Intervention group.

$(s d=1.8)$ at pretest $(5.4$ for the control group, and 5.2 for the intervention group, respectively).

The effects of the Pain Education Program are described in Figure 1. Results showed that $60 \%$ of the patients received less than optimal potency analgesics (score -1 to -4 ): $28 \%$ received relatively inadequate pain treatment (score of -1 ), and $32 \%$ were more severely undertreated (score $\leq-2)$. When evaluating the

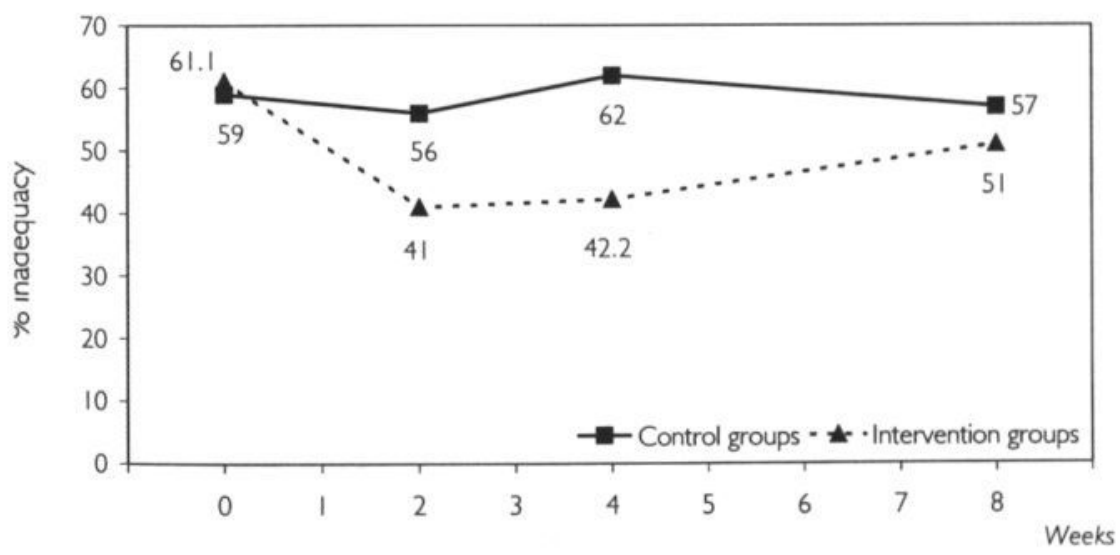

Figure 1. Effect of the Pain Education Program on the Amsterdam Pain Management Index 
differences in outcomes by means of univeriate t-tests, no differences in adequacy were found between the control and intervention group patients at baseline ( $59 \%$ versus $61 \% ; N=291$, not significant). Postdischarge, the control group patients were significantly more inadequately treated at two weeks after discharge $(56 \%$ versus $41 \% ; \mathrm{N}=234, \mathrm{p}=0.01)$, at four weeks after discharge $(62 \%$ versus $42 \% ; \mathrm{N}=222, \mathrm{p}<0.01)$ and at eight weeks after discharge $(57 \%$ versus $51 \% ; N=194$, not significant) than the intervention group patients. At baseline, there was a trend that female patients were more frequently prescribed less than optimal potency analgesics than male patients $(64 \%$ versus $53 \%, p=.08)$, while the Amsterdam Pain Management Index was not affected by gender, patient education, or pain duration.

The correlations between the different components of the Amsterdam Pain Management Index are provided in Table 6. The magnitude of correlations of the pain intensity scores (Present Pain intensity, Average Pain Intensity, Worst Pain Intensity) with the Amsterdam Pain Management Index was generally comparable $(-0.14$ to -0.38$)$. The amount of oral morphine equivalents was somewhat higher correlated with the Amsterdam Pain Management Index (0.29 to 0.59). Patients' Tolerable Pain Intensity was low correlated with the Amsterdam Pain Management Index $(r<.14)$.

Table 6. Intercorrelations between components of the Amsterdam Pain Management Index and the Amsterdam Pain Management Index

\begin{tabular}{|c|c|c|c|c|}
\hline $\begin{array}{l}\text { Amsterdam Pain } \\
\text { Management Index }\end{array}$ & Pretest & Week 2 & Week 4 & Week 8 \\
\hline $\begin{array}{l}\text { Present Pain Intensity } \\
\mathrm{N}\end{array}$ & $\begin{array}{c}-.29 \cdots \\
(N=291)\end{array}$ & $\begin{array}{r}-.33 \cdots \\
(N=234)\end{array}$ & $\begin{array}{r}-.26^{\cdots} \\
(\mathrm{N}=222)\end{array}$ & $\begin{array}{r}-.38^{* *} \\
(\mathrm{~N}=190)\end{array}$ \\
\hline $\begin{array}{l}\text { Average Pain Intensity } \\
\mathrm{N}\end{array}$ & $\begin{array}{c}-.16^{\cdots} \\
(N=291)\end{array}$ & $\begin{aligned}-.25 \cdots \\
(\mathrm{N}=234)\end{aligned}$ & $\left(\begin{array}{rl}-.27^{\cdots} \\
(\mathrm{N}=222)\end{array}\right.$ & $\begin{array}{r}-.31^{\cdots} \\
(\mathrm{N}=194)\end{array}$ \\
\hline $\begin{array}{l}\text { Worst Pain Intensity } \\
\mathrm{N}\end{array}$ & $\begin{array}{c}-.14 \cdots \\
(N=291)\end{array}$ & $\begin{array}{l}-.31 \cdots \\
(N=234)\end{array}$ & $\begin{array}{r}-.28 \cdots \\
(\mathrm{N}=222)\end{array}$ & $\begin{array}{r}-.22^{* *} \\
(\mathrm{~N}=188)\end{array}$ \\
\hline $\begin{array}{l}\text { Tolerable Pain Intensity } \\
\mathrm{N}\end{array}$ & $\begin{array}{c}.14^{\circ} \\
(N=291)\end{array}$ & $\begin{array}{c}-.03 \\
(\mathrm{~N}=234)\end{array}$ & $\begin{array}{c}-.02 \\
(N=222)\end{array}$ & $\begin{array}{c}-.02 \\
(N=294)\end{array}$ \\
\hline $\begin{array}{l}\text { Amount of oral morphine equivalents } \\
\mathrm{N}\end{array}$ & $\begin{array}{c}.43 \cdots \\
(N=269)\end{array}$ & $(\mathrm{N}=220)$ & $(\mathrm{N}=215)$ & $\begin{array}{r}.59^{\cdots} \\
(\mathrm{N}+187)\end{array}$ \\
\hline
\end{tabular}

Inspection of the completion rates of the Amsterdam Pain Management Index scores at follow-up revealed that, despite randomization, the longitudinal portion of the study was unbalanced as there were differences in the percentage of missing data in the patient groups. Overall, for $28 \%$ of the patients at least two of the four measurements were incomplete. However, the dropout rate in the 
intervention group with district nursing $(41 \%)$ was significantly higher at eight weeks postdischarge $(p<.001)$ as compared to the other three groups $(25 \%$, $20 \%$ and $20 \%$, respectively). This high percentage of dropouts was mainly due to the high percentage of patients who died during follow-up. The reason for differences in dropout rates between the groups, however, remains unclear.

Random Regression Models have been used to analyze data that can cope with missing data and take into account the difference in dropout rates between the patient groups (Table 7). Results showed that the intervention group patients scored higher on the Amsterdam Pain Management Index than the control group patients postdischarge $(p<.001)$, meaning that the intervention group patients were treated significantly more adequate than the control group patients. It appeared that, postdischarge, the Amsterdam Pain Management Index was markedly and positively associated with the baseline score $(p<.001)$. The dropouts were marginally significantly related to the Amsterdam Pain Management Index $(p=.08)$. While the level of inadequacy in the control groups remained relatively static at its original level for all assessment points, an increased number of intervention group patients were found inadequately treated at week 8 as compared to week 2 and 4. Although the Amsterdam Pain Management Index differed significantly between the intervention and control group patients, the trend in adequacy of pain treatment decreased significantly more in the intervention group patients than in the control group patients $(p<.05)$. Control group patients without district nursing who completed the study scored relatively low on adequacy of pain treatment, whereas the intervention group patients without district nursing scored discernibly higher. However, the difference between these two groups of patients was modified and lower when the dropouts were taken into account. This pattern was similar for the patient groups with district nursing. Again, the control group patients with district nursing who completed the

Table 7. Adequacy of pain treatment across time for the Random Regression Model

Amsterdam Pain Management Index $\begin{gathered}\text { Parameter } \\ \text { Estimate }\end{gathered} \underset{\begin{array}{c}\text { Standard } \\ \text { Error }\end{array}}{\text { p-value }}$

Intervention ( 0 = control; I=intervention)

0.76

$0.22<.001$

Time

District nursing ( 0 =without; I = with)

0.00

0.02

0.30

0.19

$\mathrm{ns}^{\mathrm{a}}$

Amsterdam Pain Management Index at pretest

0.31

0.06

ns

Dropouts $(0=$ no; $\quad I=$ yes $)$

0.62

0.36

$<.001$

Intervention $\times$ Time

$-0.06$

0.03

.08

Intervention $\times$ District nursing

$-0.13$

0.29

$<.05$

Intervention $\times$ Amsterdam Pain Management

Index at pretest

Intervention $\times$ Dropouts

$-0.05$

0.09

ns

Intercept

$-1.02$

0.49

ns

$-0.47$

0.15

$<.05$

$<.01$

a. not significant 
follow-up study achieved the lowest score on the Amsterdam Pain Management Index, while the score for the intervention group patients with district nursing, without dropouts, was relatively high. From this it can be concluded that the tailored Pain Education Program was effective in improving the adequacy of pain treatment.

\section{Factors related to short-term and long-term change}

The second aim of the study was to investigate characteristics that predict intervention-related change in adequacy of pain treatment. Several factors may contribute to a positive change in adequacy. Change in adequacy of pain treatment was measured by calculating short-term and long-term change on the Amsterdam Pain Management Index. Short-term change in adequacy of pain treatment was measured by comparing the Amsterdam Pain Management Index at week 2 with the pretest, while long-term change was calculated by comparing week 8 with the pretest.' For ease of interpretation, the Amsterdam Pain Management Index scores were transformed from a scale from -4 to +4 to a scale from 0 to 8 by adding a constant (i.e. 4).

Multiple regression analyses were conducted to explore relationships between candidate predictor variables and the amount of change in adequacy of pain treatment. In the backward-regression analyses, the dependent variables were the short-term and long-term change scores in adequacy of pain treatment. The independent variables comprised of sociodemographic variables (e.g., gender, age, level of education, religion), medical variables (primary tumor site, disease stage, treatment), pain-related variables (e.g., duration, location, quality, cause, McGill's sensory, affective and evaluative component, number of side-effects), pain treatment (e.g., oral morphine equivalents, causal pain treatment, nonadherence), quality of life (e.g., physical functioning, cognitive functioning, emotional functioning, role functioning, global quality of life), pain cognition (e.g., pain impact, social comparison, acquiescence, outcome efficacy), and other variables, such as pain knowledge, and relation with the general practitioner. The first step consisted of selecting variables with a standardized regression coefficient with $p<.20$. After accounting for the effect at baseline of the Pain Education Program and the Amsterdam Pain Management Index at baseline, the backward regression analyses showed that $60 \%$ of the variance in the short-term change scores of the Amsterdam Pain Management Index could be predicted on the basis of a combination of the predictor variables (Table 7). It became apparent that the intervention $(p<.05)$ and the Amsterdam Pain Management Index



Change score with positive scores indicating an improvement and negative scores indicating a decline in adequacy of pain treatment

Amsterdam Pain Management Index at two weeks postdischarge

Amsterdam Pain Management Index at prestest

Amsterdam Pain Management Index at eight weeks postdischarge
} 
score at baseline $(p<.001)$ are important predictors of the degree of short-term change. Of the sociodemographic characteristics, education and marital status were associated with change, meaning that lower educated patients and patients who are widowed gained most from the Pain Education Program. Of the medical variables, disease stage, tumor site, and cancer treatment were related to a change in adequacy of pain treatment. Patients with metastases, with a tumor of the genitourinary organs, with non-Hodgkin or Hodgkin Lymphoma, and with low levels of pain knowledge gained most short-term change on the Amsterdam Pain Management Index. Furthermore, it was found that patients who reported to take no pain medicines or only "as needed" improved short-term. The amount of morphine predicted a significant proportion of variance in change of pain treatment, meaning that the higher the amount of oral morphine prescribed in the hospital, the better the adequacy of pain treatment. Finally, patients with low scores on physical functioning, and with high scores on the impact the pain has on the patients' functioning at baseline also had improved scores on the Amsterdam Pain Management Index.

Results regarding long-term change on the Amsterdam Pain Management Index showed that $56 \%$ of the variance could be predicted. After accounting for the effect of the intervention and the Amsterdam Pain Management Index score at baseline, results showed that patients with lower role functioning had

Table 8. Regression analyses predicting change in quality of pain treatment

Predictor

Short-term change: $R^{2}=60 \%$

Intervention

Amsterdam Pain Management Index at pretest

Physical functioning

Adherence

Pain knowledge

Amount of oral morphine equivalents

Disease stage

Pain impact

Education

Marital status

Tumor site

Treatment

Long-term change: $R^{2}=56 \%$

Intervention

Amsterdam Pain Management Index at prestest

Role functioning

Amount of oral morphine equivalents postdischarge

Education

Relation with general practitioner

Pain location
Beta p-value

$\begin{array}{rr}0.12 & <.05 \\ -0.47 & <.001 \\ -0.19 & <.01 \\ -0.14 & <.01 \\ 0.12 & <.01 \\ -0.33 & <.001 \\ 0.17 & <.01 \\ 0.11 & <.05 \\ -0.13 & <.01 \\ 0.10 & <.05 \\ -0.13 & <.01 \\ 0.20 & <.01\end{array}$

$0.23<.001$

$-0.14<.01$

$-0.12<.05$

$-0.20<.001$ 
improved scores on the Amsterdam Pain Management Index. Regarding pain treatment, the amount of analgesics used postdischarge was a significant predic. tor of the score on the Amsterdam Pain Management Index. Education was again associated with change, meaning that lower educated patients gained more than higher educated patients. Furthermore, patients who had a good relationship with their general practitioner gained more than patients who reported to have a bad relationship. Finally, patients with pain in the upper shoulder and upper limbs, as well as in the abdominal region gained less than patients with other pain locations.

\section{Discussion}

Starting point in this study was that quality of pain treatment in cancer patients with chronic pain can be enhanced by educating patients about pain and pain treatment and improving active participation in patients' pain treatment. $\mathrm{P}$. tients stay at home for a great part of their disease period. Consequently, it is of paramount importance that patients become skilled in how to handle their own pain problems. Therefore, patients' understanding of available opioids, management of side effects, and use of non-drug interventions should be enhanced.

Based on research evaluating the main current outcome measures to assess the adequacy of pain treatment in cancer patients, commonly used outcome measures show limited levels of validity. ${ }^{42}$ In previous research, it was found that adequacy of pain treatment can be best captured by means of the Amsterdam Pain Management Index. This index consists of an aggregated pain score, that is corrected for patients' Tolerable Pain Intensity, and compared with the analgesics used by the patient. Negative scores indicate inadequate use of analgesic drugs, and positive scores indicate adequate use of analgesics. Results showed that $60 \%$ of the patients were using less than adequate amounts of analgesics at baseline. Patients who received the Pain Education Program scored better on the Amsterdam Pain Management Index than the control group patients. The effect of the Pain Education Program, however, decreased slightly over time, and was somewhat diminished by the dropouts.

An important aspect in clinical research is the extent to which a statistically significant increase in quality of pain treatment is also assessed as clinically relevant. The differences in percentages of inadequately treated patients decreased over time. Taking into consideration that these patients suffer from chronic pain that is frequently difficult to treat, and that for most patients the survival period was relatively short, as only $31 \%$ of the patients was still alive after one year, the differences between the control and intervention groups are considered as relevant. If one takes into consideration the percentage of inadequately treated patients at eight weeks postdischarge, the difference is not obvious. However, the results were biased by the high percentage of dropouts, with Random Agression Models showing significant differences over time.

The need for evaluating long-term effects was confirmed as results showed that the effect of the Pain Education Program decreased slightly over time. This also urges for pain education that continues after patients have been discharged from the hospital. 
It is obvious that longitudinal studies occupy an important role in the evaluation of interventions in chronic pain patients. Evaluating short-term usefulness of an education program is limited as it does not automatically lead to comparable long-term effects. The urge for evaluating longitudinal effects in chronic pain patients, however, leads to a paradoxical dilemma as it to all probability results in a substantial number of dropouts. Outcomes that provide evidence of change in cancer pain management are usually restricted because of excluding missing data in the statistical analyses. In the present study, excluding patients who dropped out mainly due to death or being too ill, resulted in an analysis of less than 200 of the 313 patients. A substantial number of the dropouts were in the "(pre-)terminal" phase while participating in the study. Excluding these patients in the analysis leads to biased results. For a study to be of clinical relevance, one should correct for imbalance caused by incomplete data. A way to overcome this paradoxical dilemma is the use of Random Regression Models, allowing for the presence of missing data. Results indicated that patients having received the Pain Education Program were more likely to receive adequate pain treatment. Although the main results of the Random Regression Models are in congruence with the classical Repeated Measures Analysis, it can be concluded that the assumption that patients dropout randomly is not substantiated in this study. The differences between the control and intervention group patients were reduced when the "dropouts" were included. When evaluating long-term effects of the Pain Education Program, statistical analyses correcting for incomplete data should be used. Furthermore, the result found by means of classical Repeated Mmeasures Analysis that no differences were found between the control and intervention group patients with district nursing was not confirmed by the Random Regression Model. Both in the group with and without district nursing, the Pain Education Program showed to be effective.

The second research question concerned whether it is possible to predict effectiveness of the Pain Education Program. Some patients may profit more from the Pain Education Program than others, whereas intervention-related improvement may continue for only a short-term or also a long-term period. This study demonstrated that several sociodemographic aspects (marital status, level of education), medical aspects (tumor site, disease stage, treatment), pain treatment aspects (use of analgesics, extent of non-adherence), quality of life (physical functioning), pain cognition (pain impact), and pain knowledge were linked with short-term gain in adequacy of pain treatment. When evaluating long-term effects, none of the medical variables were linked with gain in adequacy of pain treatment. The use of analgesics and the level of education continued to be of importance in predicting those patients who gained most from the intervention. Furthermore, role functioning, patients' relation with the general practitioner, and pain location were related to a change in adequacy of pain treatment.

Many scales were used in this study. It was expected that the use of multiple scales would be difficult in severly ill patients. Nevertheless, it is encouraging that such an intervention study can be easily conducted in seriously ill patients. The majority of patients were able and willing to participate in the intervention study and research study, and were also actively involved in the intervention.

This study provides direction for future research in overcoming barriers to optimal pain treatment. Substantially more knowledge is needed to understand the interaction between knowledge, attitudes, and behavior related to pain. ${ }^{48}$ The 
Pain Education Program is an integrated multi-method intervention, consisting of different components. Because the effectiveness of each of the components of the Pain Education Program cannot be disentangled separately, it is important to know whether some components are more effective than others in relieving pain. While this study focused on improving patients' pain knowledge and making them more aware of pain treatment, further research is needed to determine means for implementing the Pain Education Program. Additional efforts need to concentrate on improving strategies to implement educational interventions in cancer pain patients by nurses. Finally, additional research is needed to investigate what type of patient benefits most from the Pain Education Program.

Limitations of our study should be considered when interpreting the results. One limitation is caused by the fact that a high percentage of patients were included who were in a poor condition, resulting in a high percentage of dropouts, mainly due to patients death. On the one hand, analyzing data is hampered by dropouts; on the other hand, to conduct a clinical relevant study, dropouts are the price to pay when evaluating longitudinal effects in chronic cancer pain patients. This dilemma cannot be easily solved. A second limitation is that this study is limited by the fact that the Amsterdam Pain Management Index has not been used before as a measure to evaluate the adequacy of pain treatment. Additional study is needed to confirm the appropriateness of the Amsterdam Pain Management Index as a measure to assess adequacy of pain treatment. In clinical settings, the APS, 5,16 and the AHCPR ${ }^{4}$ emphasize the importance of focusing on patient satisfaction with pain management when evaluating pain treatment. Critical concerns, however, are raised about its appropriateness as an end-result outcome. ${ }^{25}$ Although patient satisfaction is a commonly used outcome measure in clinical settings, ${ }^{23,26-28,49}$ the concept of patient satisfaction remains unclear as these studies found that even though patients experienced moderate to severe pain intensity, they tend to be highly satisfied. This so-called "high pain high satisfaction paradox," 25 makes the interpretation of patient satisfaction difficult. A final limitation is that in this study the cost-effectiveness of the Pain Education Program seems to be acceptable, but was not addressed. The Pain Education Program consisted of tailored information that was provided by specially trained nurses in a one-to-one setting lasting between 30 and 60 minutes in the hospital, and the two phone calls taking approximately 5-15 minutes each. The overall $1-1 \frac{1}{2}$ hour seems to be acceptable for accomplishing the goals, but the costeffectiveness needs to be further studied.

A final limitation might include selection bias because of eligible patients refusing to participate in the study. Although the number of patients who refused in this group of patients was rather low $(18 \%)$, patients who declined participation were significantly older than those who participated, and females refused to participate more frequently than males. It is also possible that contamination bias was caused by the attention paid to the patients' pain in the control groups. Patients in the control groups were interviewed four times. For patients, the attention paid to their pain might have been an intervention in itself. 


\section{Acknowledgments}

This study was supported by a grant from the Dutch Cancer Society (grant no. NKI 92-469). The authors thank all patients for their cooperation. We extend special thanks to the nursing departments of the Netherlands Cancer Institute/Antoni van Leeuwenhoek Hospital for their participation in the study. 


\section{References}

1. Ferrell BR, Rivera LM. Cancer pain education for patients. Seminars in Oncology Nursing, 1997;13:42-48.

2. Spross JA, McGuire DB, Schmitt RM. Oncology Nursing Society Position Paper on Cancer Pain. Part I. Oncology Nursing Forum, 1990;17:595-614.

3. Cleeland CS. Strategies for improving cancer pain management. Journal of Pain and Symptom Management, 1993;8:361-364.

4. AHCPR. Agency for Health Care Policy and Reserach. Management of cancer pain. Clinical Practice Guideline. Rockville, MD: Agency for Health Care Policy and Research, 1994.

5. APS. American Pain Society. Principles of analgesic use in the treatment of acute pain and chronic cancer pain: a concise guide to medical practice. Skokie, IL: American Pain Society, 1992.

6. WHO. Cancer pain relief and palliative care. Geneva, Switzerland: World Health Organization, 1990.

7. Dalton JA. Education for pain management: a pilot study. Patient Education and Counseling, 1987:9:155-165.

8. Dalton JA, Lambe C. Tailoring treatment approaches to the individualized needs of cancer patients with pain. Cancer Nursing, 1995;18:180-188.

9. Desbiens NA, Wu AW, Yasui Y, Lynn J, Alzola C, Wenger NS, Connors AF, Philips RS, Fulkerson W. Patient empowerment and feedback did not decrease pain in seriously ill hospitalized adults. Pain, 1998;75:237-246.

10. Ferrell BR, Ferrell BA, Ahn C, Tran K. Pain management for elderly patients with cancer at home. Cancer, 1994;74:2139-2146.

11. Ferrell BR, Rhiner M, Ferrell BA. Development and implementation of a pain education program. Cancer, 1993;72:3426-3432.

12. Rimer B, Levy M, Keintz MK, MacElwee N, Engstrom PF. Improving cancer patients' pain control through education. Progress in Clinical \& Biological Research, 1987;248:123-127.

13. Rimer BK, Kedziera P, Levy MH. The role of patient education in cancer pain control. Hospice Journal, 1992;8:171-191.

14. Dalton JA. Outcomes that provide evidence of change in cancer pain management. Nursing Clinics of North America, 1995;30:683-695.

15. Jadad AR, Browman GP. The WHO analgesic ladder for cancer pain management. Stepping up the quality of its evaluation. JAMA, 1995;274:1870-1873.

16. APS. American Pain Society Quality of Care Committee. Quality improvement guidelines for the treatment of acute pain and cancer pain. JAMA, 1995;274:1874-1880.

17. Max M. American Pain Society quality assurance standards for relief of acute pain and cancer pain. Vith World Congress on Pain 1991, Amsterdam, The Netherlands: 186-189.

18. Grond S, Zech D, Lynch J, Diefenbach C, Schug SA, Lehmann KA. Validation of World Health Organization guidelines for pain relief in head and neck cancer: A prospective study. Annals of Otology, Rhinology \& Laryngology, 1993;102:342-348.

19. Grond S, Zech D, Schug SA, Lynch J, Lehmann KA. Validation of World Health Organization guidelines for cancer pain relief during the last days and hours of life. Journal of Pain and Symptom Management, 1991;6:411-422.

20. Ventafridda V, Tamburini M, Caraceni A, De Conno F, Naldi F. A validation study of the WHO method for cancer pain relief. Cancer, 1987;59:850-856.

21. Walker VA, Hoskin PJ, Hanks GW, White ID. Evaluation of WHO analgesic guidelines for cancer pain in a hospital-based palliative care unit. Journal of Pain and Symptom Management, 1988;3:145-149.

22. Zech DF, Grond S, Lynch J, Hertel D, Lehmann KA. Validation of World Health Organization guidelines for cancer pain relief: A 10-year prospective study. Pain, 1995;63:65-76.

23. Bookbinder M, Coyle N, Kiss M, Layman Goldstein M, Holritz K, Thaler H, Gianella A, Derby S, Brown M, Racolin A, Nah Ho M, Portnoy RK. Implementing national standards for cancer pain management: program model and evaluation. Journal of Pain and Symptom Management, 1996;12:334-347.

24. Dietrick-Gallagher M, Polomano R, Carrick L. Pain as a quality management initiative. Journal of Nursing Care Quaterly, 1994;9:30-42.

25. Hester NO, Miller KL, Foster RL, Vojir CP. Symptom Management Outcomes. Do they reflect variations in care delivery systems. Medical Care, 1997;35:NS69-NS83. 
26. Miaskowski C, Nichols R, Brody R, Synold T. Assessment of patient satisfaction utilizing the American Pain Society's quality assurance standards on acute and cancer-related pain. Clinical Journal of Pain, 1994;9:5-11.

27. Ward SE, Gordon D. Application of the American Pain Society quality assurance standards. Pain, 1994;56:299-306.

28. Ward SE, Gordon DB. Patient satisfaction and pain severity as outcomes in pain management: a longitudinal view of one setting's experience. Journal of Pain and Symptom Management, 1996;11:242-251.

29. Zhukovsky DS, Gorowski E, Hausdorff J, Napolitano B, Lesser M. Unmet analgesic needs in cancer patients. Journal of Pain and Symptom Management, 1995;10:113-119.

30. De Wit R, Van Dam F, Huijer Abu-Saad H, Loonstra S, Zandbelt L, Van Buuren A, Van der Heijden $\mathrm{K}$, Leenhouts $\mathrm{G}$. Emperical comparison of commonly used measures to evaluate pain treatment in cancer patients with chronic pain. Journal of Clinical Oncology, 1999;17:1280-1287.

31. Zwinderman AH. Statistical analysis of longitudinal quality of life data with missing measurements. Quality of Life Research, 1992;1:219-224.

32. De Wit R, Van Dam F, Huijer Abu-Saad H, Vielvoye-Kerkmeer A, Mattern C. The practice of pain treatment in chronic cancer pain patients in a cancer hospital in the Netherlands. Journal of Pain and Symptom Management, 1999;17:333-350..

33. De Wit R, Van Dam F, Zandbelt L, Van Buuren A, Van der Heijden K, Leenhouts G, Loonstra S. A Pain Education Program for chronic cancer patients: follow-up results from a randomized controlled trial. Pain, 1997;73:55-69.

34. Spross JA, McGuire DB, Schmitt RM. Oncology Nursing Society Position Paper on Cancer Pain. Part II. Oncology Nursing Forum, 1990;17:751-760.

35. Van der Kloot WA, Oostendorp RA, Van der Meij J, van den Heuvel J. [the dutch version of the mcgill pain questionnaire: a reliable pain questionnaire]. [dutch]. Nederlands Tijdschrift voor Geneeskunde, 1995;139:669-673.

36. Van der Kloot WA, Vertommen H. Een standaard Nederlandstalige versie van de McGill Pain Questionnaire: Achtergronden en handleiding van de MPQ-DLV. Lisse: Swets and Zeitlinger, 1990.

37. Vanderiet K, Adriaensen H, Carton H, Vertommen H. The McGill Pain Questionnaire constructed for the Dutch language (MPQ-DV). Preliminary data concerning reliability and validity. Pain, 1987;30:395-408.

38. Verkes RJ, Van der Kloot WA, Van der Meij J. The perceived structure of 176 pain descriptive words. Pain, 1989;38:219-229.

39. WHO. Cancer pain relief. Geneva, Switzerland: World Health Organization, 1986.

40. Aaronson NK, Ahmedzai S, Bergman B, Bullinger M, Cull A, Duez NJ, Filiberti A, Flechtner $H$, Fleishman SB, de Haes JC. The European organization for research and treatment of cancer QLQ-C30: a quality-of-life instrument for use in international clinical trials in oncology. Journal of the National Cancer Institute, 1993;85:365-376.

41. Vlaeyen JWS. The development of a pain cognition questionnaire. Chronic low back pain: assessment and treatment from a behavioral rehabilitation perspective. Amsterdam: Swets and Zeitlinger B.V., 1991: 109-120.

42. De Wit R, Van Dam F, Loonstra S, Zanbelt L, Van Buuren A, Van der Heijden K, Leenhouts G, Huijer Abu-Saad $\mathrm{H}$. The Amsterdam Pain Management Index compared to eight frequently used outcome measures to evaluate the adequacy of pain treatment in cancer patients with chronic pain. Pain (Provisionally accepted).

43. Cleeland CS, Gonin R, Hatfield AK, Edmonson JH, Blum RH, Stewart JA, Pandya KI. Pain and its treatment in outpatients with metastatic cancer. New England Journal of Medicine, 1994;330:592-596.

44. Ashburn MA, Lipman AG. Management of pain in the cancer patient. Anesthesia \& Analgesia, 1993;76:402-416.

45. Foley KM. The treatment of cancer pain. New England Journal of Medicine, 1985;313:84-95.

46. Haviley C, Gagnon J, MacLean R, Renz J, Jones O, De Witt W, Nyberg K, Burns C, Pohl D. Pharmacological management of cancer pain. A guide for the health care professional. Cancer Nursing, 1992;15:331-346.

47. Hedeker D, Gibbons RB. Application of random-effects pattern-mixture models for missing data in longitudinal studies. Psychological Methods, 1997;2:64-78.

48. Janjan NA, Martin CG, Payne R, Dahl JL, Weissman DE, Stratton Hill C. Teaching cancer pain management: durability of educational effects of a role model program. Cancer,

1996;77:996-1001. 
49. Ward SE, Goldberg N, Miller-McCauley V, Mueller C, Nolan A, Pawlik-Plank D, Robbins A, Stormoen D, Weissman DE. Patient-related barriers to management of cancer pain. Pain, 1993;52:319-324.

50. Foley KM. Pharmacologic approaches to cancer pain management. In: Fields HL, Dubner F, Cervero F, eds. Advances in pain research and therapy. New York: Raven Press, Ltd., 1985: 629-651. 


\section{Chapter 8}

\section{Adherence with the pain medication prescription: effects of a Pain Education Program to assist cancer patients to follow pain medication prescriptions}

De Wit, R., Van Dam, F., Zandbelt, L., Van Buuren , A., Van der Heijden, K., Huijer Abu-Saad, $\mathrm{H}$. 


\section{Introduction}

Little attention has been paid to the issue of adherence to pain medication. At first sight, pain patients are not expected to take fewer analgesics than prescribed as this results in more discomfort and pain. This might be the reason that so few data on the use of pain medication in patients with pain exist, and are even more scarce in cancer pain patients. ${ }^{1,2}$ In cancer pain patients, Austin and associates $^{3}$ found that $45 \%$ of the terminally ill cancer patients were compliant with the pain medication regimens, Dorrepaal ${ }^{4}$ found that approximately onethird of the patients were non-adherent to what was prescribed, Trotter and associates ${ }^{5}$ reported that $71 \%$ were taking their analgesics as prescribed, and Du Pen ${ }^{6}$ and associates found that patients adhered to their prescribed opioid therapy only 62 to $72 \%$.

In general, when studying adherence with medication, similar data were found. Patient adherence to medication is low, with reported average rates of about $50 \%$ for non-adherence with the medication regimen. ${ }^{7,8}$ Thus, adherence with pain medication seems to follow the same pattern as other therapies or diseases.

An issue that complicates the problem of evaluating adherence concerns the dividing line between adherent and non-adherent patients. Is a patient nonadherent when he or she stops taking the analgesic drugs because of severe adverse effects? Or a patient who stops taking pain medicine when feeling better because the physician did not explain the importance of continuing the course of treatment to maintain the analgesic concentration in the blood, is he or she non-adherent?

In recent years, the term adherence has been preferred over the term compliance. Compliance presumes that the responsibility lies with the patient only, with compliant patients seen as "unreliable" and "blameworthy."9,10 On the other hand, adherence points at a more active role of the patient, ${ }^{11-15}$ and refers to the ability or willingness to follow a medication prescription. Reasons for failing to adhere properly to a pain medication prescription can be related to both patients and healthcare providers. ${ }^{16}$ Patients' failure to adhere to pain medication can be due to a lack of knowledge, adverse drug reactions, impracticality of the use of pills, or the lack of beneficial results. ${ }^{17}$ Healthcare professionals can be responsible for adherence due to ineffective or harmful medication dosage prescriptions, or because of a failure in communication with the patient. ${ }^{18,19}$

In the present study, the term adherence was preferred over the term compliance as it describes the active role of patients. To describe the process of adherence, three stages can be distinguished ${ }^{20,21}$ (Figure 1). The first stage consists of the pain medication prescription. In the second stage, the patient must be informed, aware, and comprehend the medication prescription (comprehension). Non-comprehension is primarily caused by poor communication and insufficient interaction between the healthcare professionals and the patient, or by patients' limited intellectual capacity to understand the prescription. In the third stage, the patient needs to adhere to the medication prescription (adherence). Nonadherence may be due to discrepancy in the proportion of medications used as prescribed ("medication-taking discrepancy"), or discrepancy in the proportion of taking the medication according to the prescribed schedule ("medication-timing discrepancy"). 


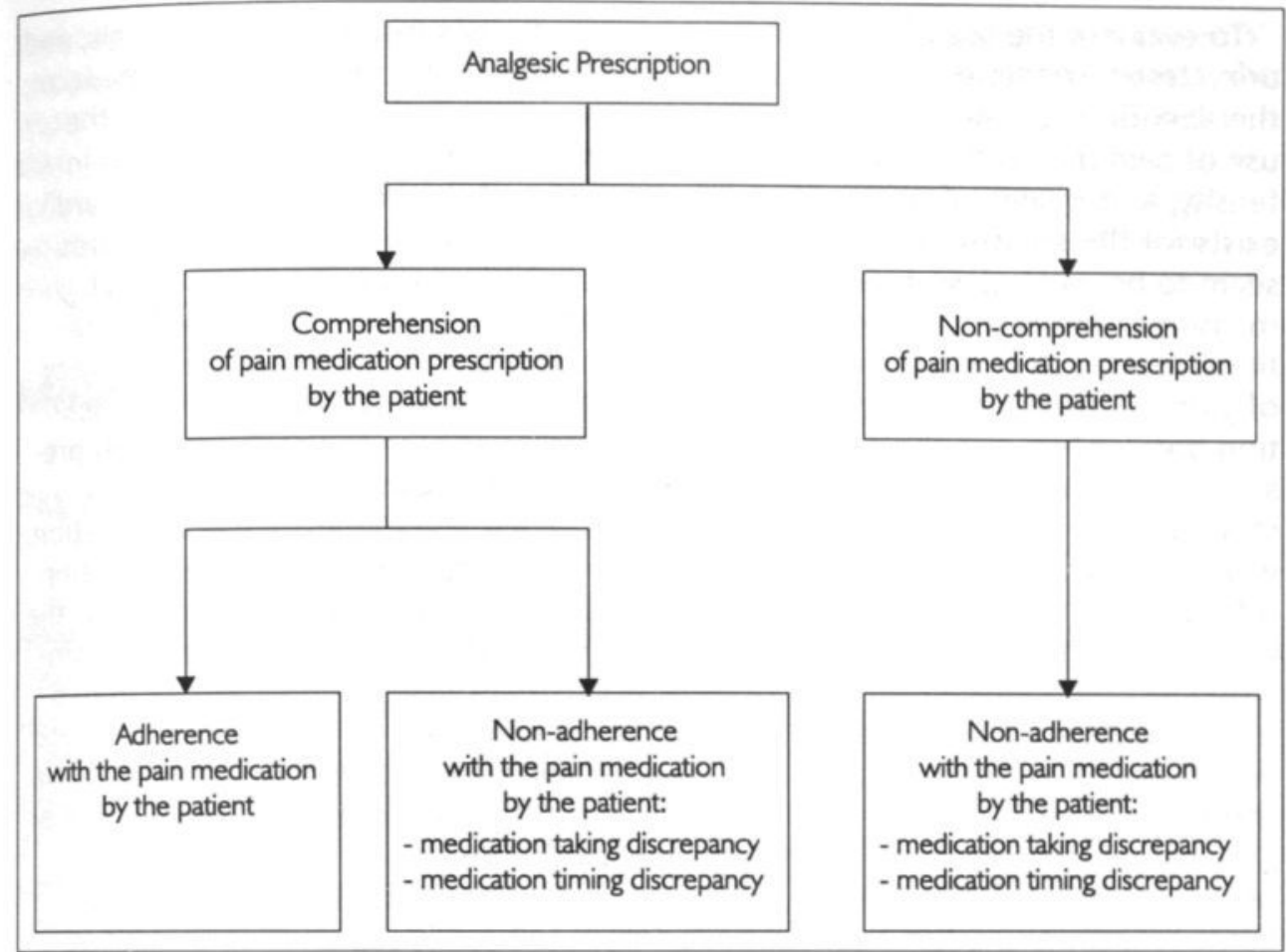

Figure 1. Model to describe patients' analgesic use

Non-adherence is associated with more frequent medical emergencies, ${ }^{22}$ lower quality of care, ${ }^{23,24}$ and decreased health outcomes. ${ }^{25,26}$ In addition, the impact of the three stages on healthcare outcomes may vary depending on the patients' situation.

In the hospital, the patient's role in medication adherence is of less relevance than in the home setting. In the hospital, nurses play an important role in promoting and maintaining adherence to prescribed medication regimens as they deliver the analgesics in precise dosages at given times, and monitor the effectiveness and adverse effects of the pain treatment. Although physicians are primarily responsible for proper medication prescription and instruction about the use of pain medication, nurses have a central role because of their position and their regular contact with patients. ${ }^{27.28}$ Compared to hospital care, the patient is more responsible for his or her own pain treatment in the home setting. In the Netherlands, healthcare is traditionally organized by its strong emphasis on primary care. Primary care providers are the general practitioners, the district nurses, and the home help. In the home setting, the general practitioner is mainly responsible for adequate pain treatment. Primary care is highly accessible, covered by compulsory or private insurances, and requires no or only limited contributions. ${ }^{29,30}$ In case patients receive district nursing, the nurse can establish and sustain a teaching and monitoring relationship, as well as identify side-effects. ${ }^{10}$ However, a substantial degree of patients at home consult a physician or pain expert in the hospital for pain control. Consequently, an exact overview of what pain medication has been prescribed in the home setting is frequently lacking. 
To evaluate the use of pain medication, direct measures (e.g., blood levels, and urine tests), or indirect measures (e.g., patient interview, impression of physician, therapeutic outcome, and pill counts) can be used. ${ }^{31}$ A third way to assess the use of pain medication is by means of the outcome of treatment (e.g., pain intensity, and quality of pain treatment). Until now, however, no "gold standard" exists for the measurement of adherence. ${ }^{15,32}$ At a first glance, direct measures seem to be most advantageous because these are less subject to bias. Direct measures, however, are not useful in pain patients because of individual variations, and because most analgesics are short-acting. ${ }^{31,33,34}$ Although the efficacy of pain treatment depends upon both the appropriateness of the pain medication prescription and the extent to which patients adhere to the medication prescription, ${ }^{35}$ the relationship is by no means linear. ${ }^{36,37}$ A more easily obtained strategy to evaluate medication adherence is to ask the patient what medication is taken. ${ }^{38}$ Although indirect questioning is most commonly used, one limitation is the chance of bias caused by patients being unaware of their "mistakes" in the way they use their pain medication. Studies on medication adherence that compared self-report with other methods of assessment have yielded substantial intercorrelations, ${ }^{23}$ whereas others evaluating the accuracy of patient self-reported adherence have found that patients seem to overestimate their adherence. ${ }^{31,38}$ In some studies, it was found that patients who admit failure to take medication as prescribed are generally more reliable in their answers than those who deny non-adherence. ${ }^{39,40}$ In addition, Epstein and associates ${ }^{25}$ found that when patients actually had taken their medications, they usually report that they have done so, whereas patients who have failed to take their medication tend to report that they have consumed them.

An important question is how to enhance medication adherence? A key element is empowering the patient by means of providing patient education, counseling, involving patients in their care, sending reminders, reinforcement, and other forms of additional supervision. ${ }^{38,41-43}$ Open discussions how to incorporate the use of analgesics into daily life and possible problems like, e.g., taking medication in the middle of the night, constipation as a consequence of opioids, and the risk of becoming addicted to opioids leading to non-adherence may prepare the patient for adequate use of analgesics. Another useful but rather neglected tool is to instruct patients to monitor their own pain complaints on a daily basis to give them more insight in their own pain complaints and to increase selfcontrol. 44

In a review on interventions to increase adherence with prescribed medications, Haynes and associates ${ }^{45}$ showed that 8 of the 16 randomized controlled trials were associated with significant increases in medication adherence. ${ }^{45}$ The interventions that were most effective for long-term care included various combinations of interventions. No randomized trials, however, have been published in which an attempt was made to improve the adherence with the analgesic therapy of cancer patients with chronic pain. ${ }^{46}$

It can be concluded that more attention should be given to the extent of longterm adherence in cancer patients with chronic pain in the home situation. The goal of the present study was to improve adherence with the pain medication prescription by implementing a Pain Education Program. The Pain Education Program, partly aimed at improving adherence with pain medication, was evaluated in a randomized controlled study. The purpose of this study was twofold. First, 
the stages consisting of the pain medication prescription, the degree of patients' comprehension, and the extent of patients' adherence are described. Second, the impact of the Patient Education Program was evaluated. It was hypothesized that: (1) patients are frequently unaware of what pain medication has been prescribed in the hospital; (2) a low proportion of comprehension and adherence would occur in the home setting; and (3) medication adherence would be increased in patients who received the Pain Education Program.

\section{Methods}

\section{Patient population and design}

A total of 383 patients, referred to a specialized cancer hospital in the Netherlands, were investigated. Patients with pain caused by cancer, cancer therapy, or illness, who had a pain duration of more than one month, a life expectancy of at least three months as assessed by the physician, the ability to read and speak Dutch, access to a telephone, and who were not residing in a nursing or retirement home, were included in the study. Of those who met the inclusion criteria, 313 patients $(82 \%)$ provided informed consent to participate in the study. $\mathrm{Pa}$ tients who declined participation $(\mathrm{N}=70)$ found the study too burdensome $(69 \%)$, were not motivated $(21 \%)$, or were too ill $(10 \%)$.

In a prospective, longitudinal, pretest-posttest experimental study, patients were assigned to either a control group or an intervention group. Control patients received regular pain treatment, while the Pain Education Program was implemented in the intervention group patients. Patients with and without district nursing in the home setting were distinguished before randomization as they were expected to differ regarding medical variables and pain experience. Both patient groups were randomized after stratifying for gender (male/female), age $(<60$ years $>60$ years), and metastatic sites (yes/no/unknown). In total, 2 control groups (with and without district nursing) and 2 intervention groups (with and without district nursing) were studied. The follow-up took place at 2, 4, and 8 weeks postdischarge.

Overall, $89 \%$ of the patients completed follow-up assessments at 2 weeks postdischarge, $83 \%$ at 4 weeks postdischarge, and $75 \%$ completed all follow-up assessments. Of the patients who dropped out during the follow-up period $(25 \%)$, $60 \%$ died, $21 \%$ were too ill, $14 \%$ found the study too burdensome, and $5 \%$ were not motivated.

\section{Intervention}

The Pain Education Program consisted of components to improve patients' knowledge of pain and pain treatment, to enhance patients' motivation to adhere to the pain medication, to daily monitor pain in a diary, and to stimulate patients help-seeking behavior. The Pain Education Program has been described in detail elsewhere. ${ }^{47}$ Briefly, the Pain Education Program was tailored to the needs of the individual patient and was provided by specially trained nurses. Topics discussed with the patient included, e.g., pharmacological pain treatment, adverse 
effects, and myths and misconceptions related to pain management. Patients were educated about the pain topics that were assessed by the nurse as insufficient. For instance, when a patient was prescribed morphine and was afraid of becoming addicted, information was given concerning addiction in relation to pain treatment. This tailored information was provided in a one-to-one setting lasting between 30 and 60 minutes. Part of the intervention was specifically aimed at enhancing patients' adherence with the pain medication prescription. The verbal instruction was provided in a one-to-one setting in the hospital, audiotaped on a cassette, accompanied by a pain brochure, and a pain diary. After it was ascertained whether the patient could recall the information, and questions were answered, patients received information about what actions should be undertaken at home when pain relief was insufficient, and how they could use simple non-pharmacological pain management techniques. In addition to the intervention provided in the hospital in a face-to-face encounter, two telephone follow-ups took place at 3 and 7 days postdischarge, when the nurses checked whether the pain information was understood.

\section{Procedure}

At pretest, data were collected by the use of a patient interview, and review of the medical and nursing records. After randomization, the intervention group patients received the Pain Education Program in the hospital. The follow-up took place at 2, 4, and 8 weeks postdischarge by telephone. The amount of analgesics prescribed and used were calculated at all assessment points. Patients' self-report of medication adherence was assessed at pretest, 2 , and 8 weeks postdischarge.

\section{Measures}

Demographic data were collected on, e.g., gender, age, marital status, employment, and education.

Medical variables that were evaluated consisted of tumor site, disease stage, diagnoses, and treatment.

Pain experience was assessed by means of the Dutch Language Version of the McGill Pain Questionnaire (MPQ-DLV), consisting of, e.g., pain location, duration, and pain quality. ${ }^{48-50}$

Pain intensity was recorded on a numerical rating scale anchored at one end with "no pain" and at the other end with "pain as bad as you can imagine" The validity, reliability and feasibility of these scales are well established. ${ }^{51-53}$

\section{Measures to describe patients' use of pain medication}

Analgesic prescription was assessed by means of drug names, dosages, routes of administration, and routine and/or as-needed status. To describe the opioid medication prescription, all opioids used within a $24-h$ period were expressed in terms of oral morphine equivalents using a standardized schedule in which is described how to switch from one opioid analgesic drug to another, and from one 
route of administration to another. ${ }^{54-56}$ For non-opioids, the one-day dose of one non-opioid was considered equianalgesic to the one-day dose of another nonopioid. ${ }^{54-56}$ All non-opioids were converted to paracetamol equivalents. In the hospital, the amount of analgesics prescribed was collected both from the medical record and by patient interview. Postdischarge, patients were interviewed about the amount of analgesics prescribed and actually used. It should be noted that no accurate information was available about patients' pain medication prescription at home as neither the hospital physician nor the general practitioner is fully informed about the pain treatment of patients. Consequently, the results of the pain medication prescription after discharge were limited to those patients who were able to report on their pain medication prescription.

Comprehension was defined as the discrepancy between what was prescribed by the physician and what the patient knew about the pain medication he or she was supposed to take. In the hospital, "comprehension" was evaluated by means of comparing the pain medication as prescribed in the medical record with the pain medication as reported by the patient. The percentage of patients being unaware of the medication prescription was determined. For those who were (partly) able to report on the medication prescription, the absolute and relative difference between the prescribed pain medication and what was reported by the patient was calculated for both opioids and non-opioids. Relative difference was calculated by subtracting the amount of analgesic equivalents described by the patient from the amount of analgesic equivalents as was prescribed in the medical record, and dividing it by the prescribed dosage multiplied by $100^{\mathrm{a}}$. The relative difference scores may range from 0 to 100 percent, with higher scores representing a higher level of difference, meaning that these patients show an increased lack of comprehension regarding the pain medication prescription.

Adherence was assessed by means of patient self-report of medication adherence including the proportion of medication in which the dose was taken as prescribed ("medication-taking discrepancy"), and the timing of pain medicines taken according to the prescribed schedule ("medication-timing discrepancy"). The proportion of "medication-taking discrepancy" was assessed by asking how patients usually take their pain medication. The answers were then classified as fully adherent or non-adherent. Non-adherence can be caused by overmedication, under-medication, fluctuation in the use of pain medication, and no use of pain medication at all. The degree of "medication-timing discrepancy" was assessed by asking patients about the intervals of analgesic dosing. Patients' answers were classified as: (1) around-the-clock, (2) on-demand, (3) not at all, or (4) no prescription of pain medication. Patients who reported to deviate from what was prescribed were further questioned about the reasons for this by means of the Self-reported Medication-taking Scale. ${ }^{57}$ The Self-reported Medication-taking Scale consists of items regarding forgetting, being careless, and stopping to take the medication prescribed. In patients with asthma, the Self-reported Medication-taking Scale demonstrated concurrent and predictive validity, and 
Regarding non-opioids, 100 patients (32\%) were prescribed non-opioids on a regular basis. Of these patients, $65 \%(\mathrm{~N}=65)$ reported the exact prescription as in the medical record, $7 \%(\mathrm{~N}=7)$ reported more non-opioids than in the medical record, and $28 \%(\mathrm{~N}=28)$ reported fewer non-opioids than was recorded. Eighteen percent of the patients were unaware of the non-opioid prescription. Accord. ing to the patients, the mean dosage of paracetamol equivalents was $3300 \mathrm{mg}$ $(s \mathrm{~d}=1679 \mathrm{mg})$. On average, patients reported a difference of $798 \mathrm{mg}(\mathrm{sd}=$ 1486) compared to the medical record, resulting in a relative difference of $19 \%$. At pretest, no differences were found between the control and intervention group.

When combining results on both opioids and non-opioids, approximately onefourth of the patients were not able to recall the pain medication prescription. Of the patients who partly or fully reported the medication prescription, $40 \%$ were

\section{Table 1. Comprehension at pretest: comparison of analgesic prescriptions} according to the medical record versus patient report

\begin{tabular}{lc}
\hline Opioids (mg oral morphine equivalents) & $\mathbf{N}^{*}$ (\%) \\
\hline No opioid prescription reported by patient, while prescribed in medical record & $78(25 \%)$ \\
No opioid prescription according to medical record & $47(15 \%)$ \\
Exact agreement on opioids between medical record and patient report & $67(21 \%)$ \\
More or less opioids prescribed according to medical record & $38(12 \%)$ \\
Only medication on-demand & $82(26 \%)$ \\
Missing & $1(1 \%)$ \\
\hline Opioids prescribed according to patient & $77 \mathrm{mg} \quad(\mathrm{sd}=98)(\mathrm{N}=106)$ \\
\hline Absolute difference between medical record and patient report & $13 \mathrm{mg} \quad(\mathrm{sd}=30)(\mathrm{N}=105)$ \\
\hline Relative difference (\%) & $20 \% \quad(\mathrm{~N}=105)$ \\
\hline
\end{tabular}

\section{Non-opioids (in mg paracetamol equivalents)}

$\mathbf{N}(\%)$

$\begin{array}{lr}\text { No non-opioid prescription reported by patient, while prescribed in medical record } & 57(18 \%) \\ \text { No non-opioid prescription according to medical record } & 88(28 \%) \\ \text { Exact agreement on non-opioids between medical record and patient report } & 65(21 \%) \\ \text { More or less non-opioids prescribed according to medical record } & 35(11 \%) \\ \text { Only medication on-demand } & 67(21 \%) \\ \text { Missing } & 1(1 \%)\end{array}$

Non-opioids prescribed according to patient

$3300 \mathrm{mg}(\mathrm{sd}=1564)(\mathrm{N}=103)$

Absolute difference between medical record and patient report

$798 \mathrm{mg}(\mathrm{sd}=1486)(\mathrm{N}=100)$

Relative difference $(\%)$

$18 \%(\mathrm{~N}=100)$

\footnotetext{
Number of patients

Two patients were excluded because of high dosage epidural morphine (> $600 \mathrm{mg}$ equianalgesic dose oral morphine). When including all patients $(\mathrm{N}=108)$ the mean dose was $110 \mathrm{mg}$ (sd 283)
}

not able to accurately describe the regular pain medication, indicating a substantial proportion of non-comprehension. 


\section{Adherence at pretest}

In the hospital, nurses are usually responsible for the delivery of pain medication. In some cases, however, the patient is responsible for his or her own pain medication intake. Consequently, the extent of adherence could not be determined exactly. In order to gain insight in patients' medication intake, patients were interviewed about how they usually take their pain medication at home. Fifty-one percent of the patients reported to be mainly adherent with the prescribed pain medication (Table 2). Of the patients who reported to be nonadherent $(49 \%)$, under-medication was reported most frequently $(81 \%)$, overmedication was reported in $15 \%$, and fluctuation in the use of pain medication was mentioned in $4 \%$. Patients who reported that they usually deviate from what is prescribed were questioned about the reasons for this. Patients mentioned most frequently that they do not want to become accustomed to pain medication $(52 \%)$, deviate from the medication prescription because of severe pain $(15 \%)$, take less medication because of decreased pain intensity $(11 \%)$, fear addiction ( $8 \%$ ), experience adverse effects $(6 \%)$, want to experience what happens when they stop or delay taking the pain medication $(2 \%)$, are able to reduce the dosage because of effective medication ( $2 \%)$, or reported other reasons $(4 \%)$. From this, it can be concluded that experiencing adverse effects was reported by only a small group of patients as a reason for being non-adherent. No differences were found between the control group and the intervention group at pretest. Gender, age, and education were also unrelated to adherence. Patients who needed district nursing after discharge reported to be more adherent than those who did not receive district nursing $(p<.01)$.

Table 2. Adherence of the population with analgesics at pretest

\begin{tabular}{|c|c|c|c|c|}
\hline Medication-taking discrepancy & & & & \\
\hline Use of medication & $\begin{array}{c}\text { Control } \\
\text { groups } \\
N^{*}(\%)\end{array}$ & $\begin{array}{r}\text { Intervention } \\
\text { groups } \\
\mathbf{N}(\%) \\
\end{array}$ & $\begin{array}{l}\text { Total } \\
\text { N (\%) }\end{array}$ & $\begin{array}{l}\text { P. } \\
\text { value }\end{array}$ \\
\hline $\begin{array}{l}\text { Fully adherent } \\
\text { Non-adherent } \\
\text { No use at all }\end{array}$ & $\begin{array}{l}80(52 \%) \\
58(38 \%) \\
16(10 \%)\end{array}$ & $\begin{array}{l}78(49 \%) \\
65(41 \%) \\
15(10 \%)\end{array}$ & $\begin{array}{r}158(51 \%) \\
123(39 \%) \\
31(10 \%)\end{array}$ & $n s^{b}$ \\
\hline \multicolumn{5}{|l|}{ Medication-timing discrepancy } \\
\hline $\begin{array}{l}\text { Interval of } \\
\text { analgesic dosing }\end{array}$ & $\begin{array}{r}\text { Control } \\
\text { groups } \\
\mathbf{N}(\%)\end{array}$ & $\begin{array}{r}\text { Intervention } \\
\text { groups } \\
\mathbf{N}(\%)\end{array}$ & $\begin{array}{l}\text { Total } \\
\text { N (\%) }\end{array}$ & P-value \\
\hline $\begin{array}{l}\text { Around-the-clock } \\
\text { On-demand } \\
\text { Not at all } \\
\text { No prescription }\end{array}$ & $\begin{array}{r}70(45 \%) \\
69(45 \%) \\
12(8 \%) \\
3(2 \%)\end{array}$ & $\begin{array}{r}89(56 \%) \\
55(35 \%) \\
10(6 \%) \\
4(3 \%)\end{array}$ & $\begin{array}{r}159(51 \%) \\
124(40 \%) \\
22(7 \%) \\
7(2 \%)\end{array}$ & ns \\
\hline
\end{tabular}

Number of patients

not significant 
Regarding the intervals of analgesic dosing, the so-called "medication-timing discrepancy," $51 \%$ of the patients reported to use the pain medication aroundthe-clock. No differences were found regarding gender, age, and education. $\mathrm{Pa}$. tients who received district nursing postdischarge, however, reported to use the pain medication significantly more around-the-clock than those who did not receive district nursing $(\mathrm{p}<.05)$.

\section{Effects of the Pain Education Program}

A total of 159 patients were assigned to the intervention groups. In the hospital, $6 \%$ did not receive any part of the Pain Education Program because of death, being too ill, or experiencing the intervention as too burdensome. Patients were only educated about pain topics that were assessed by the nurse as insufficient. Of the 21 pain topics that could be discussed with the patient, a mean of 14 top. ics was identified as relevant for the patients. Of these relevant topics, on average approximately 10 topics $(73 \%)$ were discussed with the patient because of a lack of knowledge. The importance of adherence with the pain medication was discussed with $91 \%$ of the patients for whom this topic was identified as relevant. Patients were informed about the name, doses, schedule, and mechanism of the analgesics prescribed with $85 \%$ of the patients, misconceptions about tolerance was discussed with the patient in $69 \%$ of the patients, and misconceptions about addiction with $63 \%$ of the patients. Eight weeks postdischarge, $75 \%$ of the patients reported that they had read the entire pain brochure, $56 \%$ reported that they fully, or in part, listened to the audiocassette. Of the $78 \%$ of the patients who returned the pain diary after 2 months, $86 \%$ of all pain scores were filled in.

\section{Results of the Pain Education Program}

\section{Analgesic prescription postdischarge as reported by the patient}

The total daily doses of prescribed oral morphine equivalents was 57,89 , and $61 \mathrm{mg}$ per day at 2, 4, and 8 weeks postdischarge, respectively (Table 3). Comparison of dosage equivalents between control and intervention groups was complicated because a substantial group of patients was not able to describe their medication prescription or were only prescribed opioids on-demand. Student's t-tests indicated no significant differences in the prescribed dosage between the control and intervention group patients. The mean dosage of paracetamol equivalents was approximately $1500 \mathrm{mg}$ per day. Differences were found between the control and intervention groups at 4 weeks $(p=.01)$ and 8 weeks $(p<.05)$ postdischarge. From this it can be concluded that the pain medication prescription remained stable over time, with intervention group patients being prescribed more non-opioids than control group patients. 
Table 3. Effects of the Pain Education Program on the analgesic prescription

\begin{tabular}{|c|c|c|c|c|}
\hline $\begin{array}{l}\text { Opioids prescribed } \\
\text { according to patient } \\
\text { (mg oral morphine } \\
\text { equivalents) }\end{array}$ & $\begin{array}{r}\text { Control } \\
\text { groups } \\
\text { mg (sd), } \mathrm{Na}^{a}\end{array}$ & $\begin{array}{r}\begin{array}{r}\text { Intervention } \\
\text { groups }\end{array} \\
\text { mg (sd), N }\end{array}$ & mg (sd), $N$ & $\begin{array}{r}\text { P- } \\
\text { value }\end{array}$ \\
\hline 2 weeks postdischarge & $52(\mathrm{sd} \mid 17) \mathrm{N}=130$ & $63(\mathrm{sd} 170) \mathrm{N}=129$ & $57($ sd I 46) $N=259$ & ns ${ }^{b}$ \\
\hline 4 weeks postdischarge & $65(\mathrm{sd} 227) \mathrm{N}=120$ & $113(\mathrm{sd} 630) \mathrm{N}=120$ & $89($ sd 473$) N=240$ & ns \\
\hline 8 weeks postdischarge & $67(\operatorname{sd} 230) N=111$ & $56($ sd 147$) N=108$ & $61($ sd 193) $N=219$ & ns \\
\hline
\end{tabular}

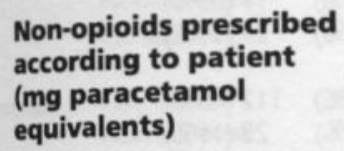

2 weeks postdischarge 1403 (sd 2068) $N=129$

4 weeks postdischarge 1118 (sd 2079) $\mathrm{N}=123$

8 weeks postdischarge 1092 (sd 1922) $\mathrm{N}=115$

1755 (sd 2339) $N=1301580($ sd 2211$) \mathrm{N}=259$

$1810($ sd 2221) $\mathrm{N}=1231464($ sd 2174$) \mathrm{N}=246$

.01

$1823($ sd 2520) $N=|13| 454($ sd 2263) $N=228$

\section{' number of patients}

b not significant

\section{Comprehension postdischarge}

Results on opioid and non-opioid prescriptions were evaluated by means of what patients themselves reported being prescribed (Table 4). There was a trend that more patients in the intervention groups reported an opioid prescription at 8 weeks postdischarge, and patients in the intervention groups reported significantly more non-opioid prescriptions at 2,4 , and 8 weeks postdischarge than control group patients. Of the patients, $11 \%$ were not prescribed opioids, $7 \%-10 \%$ of the patients were not able to recall an opioid prescription, $43 \%-44 \%$ reported to have an opioid prescription around-the-clock, and 35\%-39\% reported being prescribed opioids on-demand only. Regarding non-opioids, $4 \%-7 \%$ were not able to remember the non-opioid prescription, while $31 \%-36 \%$ were prescribed non-opioids on-demand only. Approximately one-fifth of the patients were not prescribed non-opioids.

From this, it can be concluded that less than half of the patients reported being prescribed opioids on a regular basis. The Pain Education Program showed to be effective in the extent to which patients were able to report their use of nonopioids and to a lesser extent their use of opioid prescription.

\section{Adherence postdischarge}

Patients' extent of adherence was evaluated in two ways: by asking patients how they usually take their pain medication, and by comparing patients' medication prescription with the medication that was actually taken. Results of patients' self-report are given in Table 5. On average, $51 \%$ of control patients reported that they were adherent with the pain medication at 2 weeks postdischarge, and $43 \%$ at 8 weeks postdischarge, whereas these values were $69 \%$ and $58 \%$, respectively, for intervention patients. Thus patients' "medication-taking behavior" 
Table 4. Effects of the Pain Education Program on patients' comprehension of analgesics

\begin{tabular}{|c|c|c|c|c|c|}
\hline Time & Opioid prescription & $\begin{array}{r}\text { Control } \\
\text { groups } \\
\mathbf{N}(\%)\end{array}$ & $\begin{array}{l}\text { Inter- } \\
\text { vention } \\
\text { groups } \\
\mathbf{N}(\%)\end{array}$ & $\begin{array}{l}\text { Total } \\
\text { N (\%) }\end{array}$ & $\begin{array}{c}\text { P. } \\
\text { value }\end{array}$ \\
\hline week 2 & $\begin{array}{l}\text { Opioids prescription reported by patient } \\
\text { No opioid prescription according to patient } \\
\text { Only opioids on-demand } \\
\text { Unknown }\end{array}$ & $\begin{array}{l}57(41 \%) \\
23(16 \%) \\
48(34 \%) \\
12(9 \%)\end{array}$ & $\begin{array}{r}65(46 \%) \\
9(7 \%) \\
51(36 \%) \\
15(11 \%)\end{array}$ & $\begin{array}{r}122(44 \%) \\
32(11 \%) \\
99(35 \%) \\
27(10 \%)\end{array}$ & nst \\
\hline week 4 & $\begin{array}{l}\text { Opioids prescription reported by patient } \\
\text { No opioid prescription according to patient } \\
\text { Only opioids on-demand } \\
\text { Unknown }\end{array}$ & $\begin{array}{l}52(40 \%) \\
17(13 \%) \\
50(38 \%) \\
12(9 \%)\end{array}$ & $\begin{array}{l}60(46 \%) \\
11(9 \%) \\
48(37 \%) \\
12(8 \%)\end{array}$ & $\begin{array}{r}112(43 \%) \\
28(11 \%) \\
98(38 \%) \\
23(8 \%)\end{array}$ & ns \\
\hline week 8 & $\begin{array}{l}\text { Opioids prescription reported by patient } \\
\text { No opioid prescription according to patient } \\
\text { Only opioids on-demand } \\
\text { Unknown }\end{array}$ & $\begin{array}{l}46(39 \%) \\
14(12 \%) \\
49(41 \%) \\
10(8 \%)\end{array}$ & $\begin{array}{r}55(48 \%) \\
12(10 \%) \\
41(36 \%) \\
7(6 \%)\end{array}$ & $\begin{array}{l}101(43 \%) \\
26(11 \%) \\
90(39 \%) \\
17(7 \%)\end{array}$ & .06 \\
\hline
\end{tabular}

Time Non-opioid prescription

\begin{tabular}{|c|c|c|c|c|c|}
\hline week 2 & $\begin{array}{l}\text { Non-opioids prescription reported by patient } \\
\text { No non-opioid prescription according to patient } \\
\text { Only non-opioids on-demand } \\
\text { Unknown }\end{array}$ & $\begin{array}{l}48(34 \%) \\
31(22 \%) \\
49(35 \%) \\
12(9 \%)\end{array}$ & $\begin{array}{l}59(42 \%) \\
32(23 \%) \\
37(26 \%) \\
12(9 \%)\end{array}$ & $\begin{array}{r}107(38 \%) \\
63(22 \%) \\
86(31 \%) \\
24(9 \%)\end{array}$ & $<.01$ \\
\hline 4 weeks & $\begin{array}{l}\text { Non-opioids prescription reported by patient } \\
\text { No non-opioid prescription according to patient } \\
\text { Only non-opioids on-demand } \\
\text { Unknown }\end{array}$ & $\begin{array}{r}48(29 \%) \\
35(27 \%) \\
49(37 \%) \\
9(7 \%)\end{array}$ & $\begin{array}{r}58(44 \%) \\
28(22 \%) \\
35(27 \%) \\
9(7 \%)\end{array}$ & $\begin{array}{l}96(37 \%) \\
63(24 \%) \\
84(32 \%) \\
18(7 \%)\end{array}$ & $<.01$ \\
\hline week 8 & $\begin{array}{l}\text { Non-opioids prescription reported by patient } \\
\text { No non-opioid prescription according to patient } \\
\text { Only non-opioids on-demand } \\
\text { Unknown }\end{array}$ & $\begin{array}{r}34(28 \%) \\
26(22 \%) \\
51(43 \%) \\
8(7 \%)\end{array}$ & $\begin{array}{r}50(43 \%) \\
29(25 \%) \\
34(30 \%) \\
2(2 \%)\end{array}$ & $\begin{array}{l}84(36 \%) \\
55(24 \%) \\
85(36 \%) \\
10(4 \%)\end{array}$ & $<.01$ \\
\hline ; & $\begin{array}{l}\text { Number of patients } \\
\text { not significant }\end{array}$ & & & & \\
\hline
\end{tabular}

significantly improved in the intervention group patients compared with the control group patients at 2 weeks $(p<.01)$ and 8 weeks postdischarge $(p<.05)$. Regarding the "medication-timing discrepancy," patients were asked about the intervals of analgesic dosing. Both at 2 and 8 weeks postdischarge, the intervention groups were significantly different from the control groups, with intervention patients reporting to use their medication more frequently around-the-clock than control group patients. Of the patients who reported to be fully adherent at pretest, $75 \%$ also reported to use the medication around-the-clock after discharge. Of the patients who reported to be partly adherent or non-adherent in the hospital, $34 \%$ stated that they used the medication on a regular basis after discharge.

Patients were further questioned about the reasons for their non-adherence by means of the Self-reported Medication-taking Scale. At 2 weeks postdischarge, 
Table 5. Effect of the Pain Education Program on patients' medication adherence

\begin{tabular}{|c|c|c|c|c|c|}
\hline \multicolumn{6}{|c|}{ Medication-taking discrepancy } \\
\hline Time & $\begin{array}{l}\text { Use of pain } \\
\text { medication }\end{array}$ & $\begin{array}{r}\begin{array}{r}\text { Control } \\
\text { groups }\end{array} \\
N(\%)\end{array}$ & $\begin{array}{r}\text { Inter- } \\
\text { vention } \\
\text { groups } \\
\mathbf{N}(\%)\end{array}$ & $\begin{array}{l}\text { Total } \\
\text { N (\%) }\end{array}$ & $\begin{array}{r}\text { P. } \\
\text { value }\end{array}$ \\
\hline week 2 & $\begin{array}{l}\text { Fully adherent } \\
\text { Non-adherent } \\
\text { No use at all }\end{array}$ & $\begin{array}{l}70(50 \%) \\
42(31 \%) \\
25(18 \%)\end{array}$ & $\begin{array}{l}95(69 \%) \\
29(21 \%) \\
14(10 \%)\end{array}$ & $\begin{array}{r}165(60 \%) \\
71(26 \%) \\
39(14 \%)\end{array}$ & $<.01$ \\
\hline week 8 & $\begin{array}{l}\text { Fully adherent } \\
\text { Non-adherent } \\
\text { No use at all }\end{array}$ & $\begin{array}{l}50(43 \%) \\
33(28 \%) \\
33(29 \%)\end{array}$ & $\begin{array}{l}67(58 \%) \\
29(25 \%) \\
20(17 \%)\end{array}$ & $\begin{array}{r}117(50 \%) \\
62(27 \%) \\
53(23 \%)\end{array}$ & $<.05$ \\
\hline
\end{tabular}

Medication-timing discrepancy

\begin{tabular}{llrrrr}
\hline week 2 & Around-the-clock & $80(58 \%)$ & $96(70 \%)$ & $176(64 \%)$ & .05 \\
On-demand & $32(24 \%)$ & $22(16 \%)$ & $54(19 \%)$ & \\
Not at all & $18(13 \%)$ & $14(10 \%)$ & $32(12 \%)$ & \\
No prescription & $9(5 \%)$ & $6(4 \%)$ & $13(5 \%)$ & \\
& & & & \\
week 8 & Around-the-clock & $52(44 \%)$ & $70(60 \%)$ & $122(52 \%)$ & $<.05$ \\
On-dernand & $26(23 \%)$ & $22(19 \%)$ & $48(21 \%)$ & \\
Not at all & $30(26 \%)$ & $12(16 \%)$ & $48(21 \%)$ & \\
No prescription & $9(8 \%)$ & $6(5 \%)$ & $15(6 \%)$
\end{tabular}

results showed that $38 \%$ of the patients sometimes stopped to take the medication when they felt better, $22 \%$ forgot to take pain medication, $19 \%$ ceased to take the pain medication when they felt worse, and $13 \%$ was careless with the medication (data not shown).

When evaluating the daily doses of analgesics, the mean dosage of opioids taken ranged from $46-81 \mathrm{mg}$ per day postdischarge. No significant differences were found between the control and intervention group patients for the medication that was reported to be actually taken. The relative difference between the opioids prescribed compared to what had been taken according to the patient was $11 \%$ at 2 weeks postdischarge $(\mathrm{N}=122), 8 \%$ at 4 weeks postdischarge $(N=112)$, and $10 \%$ at 8 weeks postdischarge $(N=101)$. At 4 weeks postdischarge, significantly less discrepancy $(\mathrm{p}<.05)$ was found in the intervention group patients compared to the control group patients (Figure $2 a$ ). No differences in the discrepancy were found at 2 and 8 weeks postdischarge.

The mean dosage of non-opioids ranged from $1487-1679 \mathrm{mg}$ equivalents paracetamol per day. Differences were found between the control and intervention groups at 2 weeks $(p<.05), 4$ weeks $(p<.05)$ and 8 weeks $(p=.01)$ postdischarge. The relative difference between the non-opioids prescribed compared to what had been taken according to the patient the day before was $19 \%$ $(\mathrm{N}=105), 18 \%(\mathrm{~N}=94)$, and $19 \%(\mathrm{~N}=83)$ at 2,4 and 8 weeks postdischarge, respectively. Although the mean dosage of actually taken non-opioids differed at all time points, only at 2 weeks postdischarge, significantly less discrepancy was 

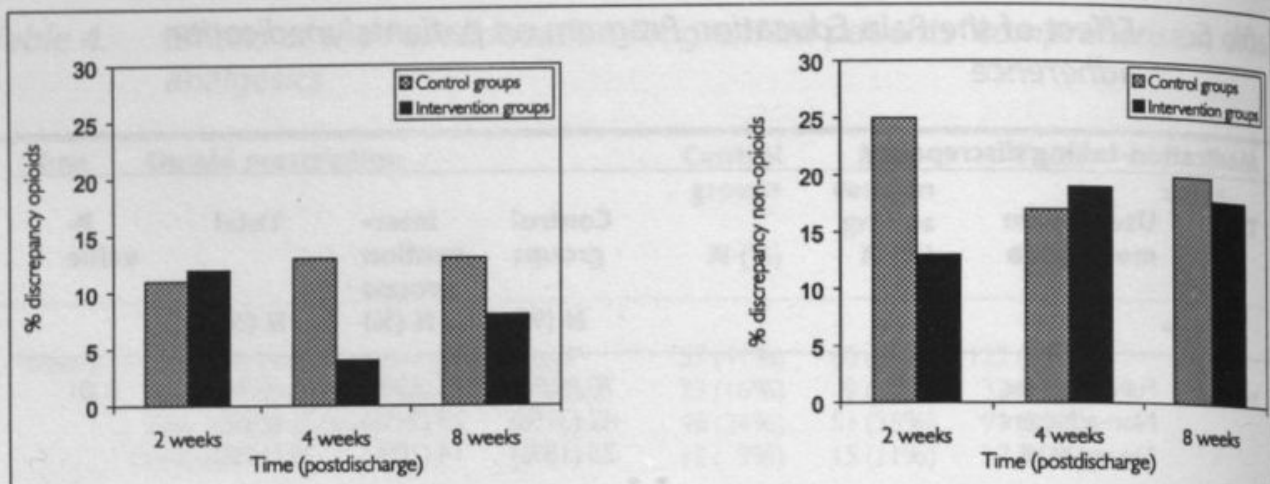

Figure 2a: Opioid discrepancy between prescribed analgesics and what was actually taken according to patients

Figure 2b: Non-opiods discrepancy between prescribed analgesics and what was actually taken according to patients

found in the intervention group patients compared to the control group patients $(p<.05)$ (Figure $2 b)$.

From this, it can be concluded that the intervention group patients reported significantly less discrepancy both in their "medication-taking" and "medicationtiming" behavior. However, when comparing the differences in the medication prescribed with the medication actually taken, the effect of the Pain Education Program was less obvious: significant differences were only found for opioids at 4 weeks postdischarge, and for non-opioids at 2 weeks postdischarge.

\section{Discussion and conclusions}

Previous research has documented low rates of medication adherence, with only few data on medication adherence in cancer pain patients. The goal of this study was to describe the use of pain medication in cancer patients in chronic pain both in the hospital and at home. Because patient education by nurses is an important factor in helping to improve medication adherence, the effectiveness of the Pain Education Program in cancer patients with chronic pain was studied. The first step towards an intervention for patients who are non-adherent to pain medication is to identify these patients. Adherence in this study was operationalized in three stages: (1) describing the prescribed pain medication; (2) evaluating the degree of patients' understanding of the analgesic prescription (comprehension); and (3) evaluating patients' adherence to the pain medication when the correct prescription is known (adherence).

In the hospital, results showed that of the cancer patients in pain, $12 \%$ were not prescribed any analgesics, and $19 \%$ were only prescribed non-opioids. Of the patients being prescribed analgesics, $56 \%$ received opioids, and $49 \%$ received non-opioids on a regular basis. A major finding was that, one out of every four patients was not able to recall the analgesics prescribed. Furthermore, of those patients who were partly or fully able to report on the medication prescription, 
about $40 \%$ were found to be deviating from the prescribed pain medication according to the medical record. When combining the results on opioid and nonopioid prescriptions, less than half of the patients were able to accurately recall the medication prescription. From this, it can be concluded that the extent of patients' comprehension of the pain medication prescription is a major problem. During patients' stay in the hospital, nurses are primarily responsible for the medication delivery. As a consequence, patients are frequently unaware of changes in dosage and frequency of pain medication. Giving patients more responsibility for the administration of their own pain medication, while under supervision of the nurses in the hospital, may reduce the percentage of patients being unaware of the medication prescription, and may increase the extent of adherence postdischarge.

When interviewing patients in the hospital about their usual "medicationtaking behavior" and "medication-timing behavior," results showed that there is a high percentage of patients who are aware that they are not adherent to the analgesics at home: $49 \%$ reported not to be fully adherent to the pain medication, and $47 \%$ reported that the interval of analgesic dosing was on-demand or that they did not take any of the pain medication prescription. It is striking that so many chronic pain patients reported to use their medication on-demand, while the use of analgesics on a regular basis is strongly recommended. ${ }^{55,59,60}$ Most patients who reported to be non-adherent reported under-medication, while a small group of patients reported over-medication. Although it is often stated that patients deviate from their pain medication prescription because of misconceptions, ${ }^{61,62}$ adverse effects, ${ }^{34,63}$ and fear of addiction was only reported by $8 \%$, and experiencing adverse effects by $6 \%$ of the patients as a reason for being non-adherent.

The Pain Education Program showed to be effective in promoting medication adherence with cancer pain patients. Regarding comprehension, results showed that there was a trend that the intervention group patients reported more frequently an opioid prescription than control group patients at 8 weeks, and significantly more non-opioids at all assessment points postdischarge. Regarding the effects of the Pain Education Program on medication adherence, results showed that both patients' "medication-taking behavior" and "medicationtiming behavior" was significantly improved in the intervention group compared to the control group. Reasons for non-adherence that were most frequently cited were stopping the medication when feeling better (38\%), forgetting $(22 \%)$, starting the drug medication when feeling worse $(19 \%)$, or carelessness $(13 \%)$.

Although many researchers have stated that an indirect way of questioning patients has several limitations, ${ }^{31}$ our results show that is a high percentage of patients are aware that they have non-adherent behavior. However, nothing can be said for those patients denying non-adherence. Based on the results that a large group of patients admitted to be non-adherent, it can be concluded that selfreport is a useful manner in tracing non-adherence. A non-judging and nonthreatening way of questioning, however, is prerequisite when interviewing patients about their medication use.

Patients were further questioned about the distinction between analgesics prescribed and analgesics that were actually taken by the patient the day before. This discrepancy is important because it provides some insight into the medication practices of patients in the home setting. When comparing the difference 
between analgesics prescribed with what had been taken the day before, results showed a relative difference of approximately $10 \%$ for opioids, and $20 \%$ for non-opioids. Effects for the Pain Education Program were found between the control and intervention groups for non-opioids at all three assessment points in time, and for opioids at 2 weeks postdischarge only.

As demonstrated, the Pain Education Program showed an increase in the extent of comprehension and adherence regarding pain medication. Although the Pain Education Program did not have a strong impact on increasing the comprehension rates and adherence rates, the trend was in the predicted direction. There are several possible explanations for finding no strong alteration in long. term adherence behavior. First, the intervention may have been of insufficient intensity to strongly affect behavior. A second explanation may be attributed to the patient population being studied. The population consisted of a substantial number of patients who experienced complex pain problems, and who were in bad health. One year after data collection, only $31 \%$ of the patients were still alive. Seriously ill patients might gain less from an educational intervention than less seriously ill patients. Third, the Pain Education Program, as implemented by nurses, might not be powerful enough because hospital physicians and general practitioners were not involved in the intervention. Although several studies have been reported that physicians' communication style is a crucial element in patients' ability to follow treatment advice, this was not part of the intervention. Future research should also incorporate the effect of patient education by physicians.

The results of the present study demonstrate that a relatively brief Pain Education Program can significantly improve medication compliance among cancer patients in pain. This is an important finding taking into consideration that the intervention was implemented in cancer patients with severe pain complaints.

However, several aspects deserve special attention as this study is hampered by some limitations. One limitation was caused by the fact that no accurate adherence data was available for all patients as neither the hospital physician nor the general practitioner was fully informed about the pain treatment of patients at home. Consequently, we were not able to fully evaluate the extent of comprehension regarding the pain medication prescription postdischarge. This might have biased the results as the analyses were restricted to only those patients who reported pain medication. A second limitation is caused by the way adherence was evaluated in the hospital. We were not able to exactly evaluate the extent of adherence as some patients are given responsibility for their own medication intake in the hospital. Most patients, however, play a minor role in their use of pain medication in the hospital. As a result, the exact degree of adherence could not be determined. In order to gain insight in patients' medication adherence behavior, patients were interviewed about their usual medication behavior prior to admission. Because of differences in the way comprehension and adherence was evaluated in the hospital and at home, results from inpatients cannot be directly compared with those from patients at home. A third limitation was caused by the different outcome measures used. Medication adherence was assessed by: 1) patient self- report of the proportion of medication in which the dose was taken as prescribed; 2) the timing of pain medication taken according to the prescribed schedule; and 3) the discrepancy between what the patient was supposed to take and what was actually taken. Results demonstrated different percentages of 
adherence for the same group of patients. The extent of comprehension was not strongly related to the extent of adherence; also, there was not a strong correlation between the results of medication-taking discrepancy and "medicationtiming discrepancy." It seems that the measures used consist of multiple discrete behaviors that are not necessarily closely related to one another. Although this is in congruence with other studies finding different results when using different outcome measures, ${ }^{64}$ what measure is most appropriate is unknown. Strategies for assessing adherence with long-term medication prescriptions should be further studied.

Regarding the intervention, it is unknown whether all elements are required to improve medication adherence. Further research is needed to explore the influence of nurses' communication skills on medication adherence. Second, the intervention concentrated on patients only, while no attention had been paid to patients' relatives. In future research, relatives should also be provided with information and instruction about the use of the medication. Improving the coordination of hospital and home care might also contribute to a reduction in the problem of non-adherence. Examples of how continuity of care might be improved are training patients before discharge how and when to take pain medication, or introducing a medication card or diary describing the details of the medication regimen. Such a medication card should contain details of all pain medication which can be shown to the patient's general practitioner, physician, and district nurse. In future research, the number of tablets used should also be taken into account. Finally, in research it is frequently found that the higher the number of tablets, the higher the level of non-adherence. ${ }^{1,22}$ In the present study, the complexity of the prescribed regimen was not investigated. Patients in an advanced stage of their disease are usually administered different types of medicines and pain medication. Consequently, this might have lowered the extent of adherence.

In reviewing the results of this study, it can be concluded that noncomprehension and non-adherence are significant problems in the use of pain medication. The results suggest that the Pain Education Program can be implemented successfully, even in seriously ill cancer pain patients. The Pain Education Program is effective in improving the level of comprehension and adherence, therefore implementation of the Pain Education Program by nurses should be considered.

\section{Acknowledgments}

The authors extend special thanks to the nursing departments of the Netherlands Cancer Institute/Antoni van Leeuwenhoek Hospital, and the district nurses who participated in the study for their invaluable contribution. 


\section{References}

1. Berndt S, Maier C, Schutz HW. Polymedication and medication compliance in patients with chronic non-malignant pain. Pain, 1993;52:331-9.

2. Packard RC, O'Connell P. Medication compliance among headache patients. Headache, 1986;26:416-419.

3. Austin C, Cody CP, Eyres PJ, Hefferin EA, Krasnow RW. Hospicce home care pain management. Cancer Nursing, 1986;9:58-65.

4. Dorrepaal KL. Pijn bij patienten met kanker [Thesis in Dutch]: Vrije Universiteit Amsterdam, The Netherlands 1989.

5. Trotter JM, Scott R, MacBeth FR, McVie JG, Calman KC. Problems on the oncology outpatient: role of the liason health visitor. British Medical Journal, 1981;282:122-124.

6. Du Pen SL, Du Pen AR, Polissar N, Hansberry J, Miller Kraybill B, Stillman M, Panke J, Everly R, Syrjala K. Implementing guidelines for cancer pain management: results of a randomized controlled clinical trial. Journal of Clinical Oncology, 1999;17:361-370.

7. Grilli R, Lomas J. Evaluating the message: the relationship between compliance rate and the subject of a practice guideline. Medical Care, 1994;32:202-13.

8. Sackett DL, Snow JC. The magnitude of compliance and noncompliance. In: Haynes RB, Taylor DW, Sackett DL, eds. Compliance in health care. Baltimore: Johns Hopkins University Press, 1979: 11-22.

9. Haynes RB. Introduction. In: Haynes RB, Taylor DW, Sackett DL, eds. Compliance in health care. Baltimore, MD: Johns Hopkins University Press, 1979: 1-7.

10. Ross FM. Patient compliance-Whose responsibility? Social Science and Medicine, 1991;32:89-94.

11. Bakker RH, Kastermans M. Is compliance part of selfcare or is noncompliance a selfcare deficit? (in Dutch). Verpleegkunde, 1994;9:83-90.

12. Dunbar J. Adherence to medical advice: a review. Internal Journal of Mental Health, 1980;9:70-87.

13. McFarland GK, McFarlane EA. Nursing diagnosis and intervention. St. Louis, Missouri: C.V. Mosby Company, 1989.

14. Roter DL, Hall JA, Merisca R, Nordstrom B, Cretin D, Svarstad B. Effectiveness of interventions to improve patient compliance. Medical Care, 1998;36.

15. Turk DC, Rudy TE. Neglected topics in the treatment of chronic pain patients - relapse, noncompliance, and adherence enhancement. Pain, 1991;44:5-28.

16. Wright EC. Non-compliance — or how many aunts has Matilda? Lancet, 1993;342:909-913.

17. Hanlon JT, Schmader KE, Samsa GP, Weinberger M, Uttech KM, Lewis IK, Cohen HJ, Feussner JR. A method for assessing drug therapy appropriateness. Journal of Clinical Epidemiology, 1992;45:1045-1051.

18. DiMatteo MR, Sherbourne D, Hays RD, Ordway L, Kravitz RL, McGlynn EA, Kaplan S, Rogers WH. Physicians' characteristics influenced patients' adherence to medical treatment: results from tyhe medical outcomes study. Health Psychology, 1993;12:93-102.

19. Hall JA, Roter DL, Katz NR. Meta-analysis of correlates of provider behavior in medical encounters. Medical Care, 1988;26:657-675.

20. Barofsky I. Therapeutic compliance and the cancer patient. Health Education Quarterly. 1984;10:43-56.

21. Parkin DM, Henney CR, Quirk J, Crooks J. Deviation from prescribed drug treatment after discharge from hospital. British Medical Journal, 1976;2:686-688.

22. Greenberg RN. Overview of patient compliance with medication dosing: a literature review. Clinical Therapy, 1984;6:592-599.

23. Becker MH. Patient adherence to prescribed therapies. Medical Care, 1985;23:539-555.

24. Becker MH, Maiman LA. Strategies for enhancing patient compliance. Journal of Community Health, 1980;6:113-35.

25. Epstein LH. The direct effects of compliance on health outcome. Health Psychology, 1984;3:385-393.

26. Horowitz RI, Horowitz SM. Adherence to treatment and health outcomes. Archives of Internal Medicine, 1993;153:1863-1868.

27. Bulechek GM, McCloskey JC. Nursing interventions. Essential nursing treatments. Philadelphia: W.B. Saunders, 1992.

28. De Geest S, Abraham I, Gemoets H, Evers G. Development of the long-term medication behaviour self-efficacy scale: qualitative study for item development. Journal of Advanced Nursing, 1994;19:233-238. 
29. Schrijvers A.P. Health and health care in the Netherlands. A critical self-assessment by Dutch experts in the medical and health sciences. Utrecht: De Tijdstroom, 1997.

30. Van der Zee J, Kramer K, Derksen A, Kerkstra A, Stevens FC. Community nursing in Belgium, Germany, and the Netherlands. Journal of Advanced Nursing, 1994;20:791-801.

31. Gordis L. Conceptual and methodologic problems in measuring patient compliance. In: Haynes RB, Taylor DW, Sackett DL, eds. Compliance in health care. Baltimore: Johns Hopkins University Press, 1979: 23-45.

32. Cramer JA, Mattson RH, Prevey ML, Scheyer RD, Ouellette VL. How often is medication taken as prescribed? A novel assessment technique. JAMA, 1989;261:3273-3277.

33. Cummings KM, Kirscht JP, Becker MH, Levin NW. Construct validity comparisons of three methods for measuring patient compliance. Health Services Research, 1984;19:103-116.

34. Haynes RB. Determinants of compliance: the disease and the mechanics of treatment. In: Haynes RB, Taylor D, Sackett DL, eds. Compliance in health care. Baltimore: Johns Hopkins University Press, 1979: 49-109.

35. Cluss PA, Epstein LH. The measurement of medical compliance in the treatment of disease. In: Karoly P, ed. Measurement strategies in health psychology. Singapore: John Wiley \&Sons, 1985.

36. Hays RD, Kravitz RL, Mazel RM, Sherbourne CD, DiMatteo MR, Rogers WH, Greenfield S. The impact of patient adherence on health outcomes for patients with chronic disease in the Medical Outcomes Study. Journal of Behavioral Medicine, 1994;17:347-60.

37. Taylor SE. Health Psychology. New York: McGraw-Hill, 1991.

38. Cramer JA. Overview of methods to measure and enhance patient compliance. In: Cramer JA, Spilker B, eds. Patient compliance in medical practice and clinical trials. New York: Raven Press, 1991: 3-10.

39. Cramer JA. Optimizing long-term patient compliance. Neurology, 1995;45 (suppl 1):S25-\$28.

40. Hasford J. Biometric issues in measuring and analyzing practical compliance in clinical trials. In: Cramer JA, Spilker B, eds. Patient compliance in medical practice and clinical trials. New York: Raven Press, 1991: 265-281.

41. Besch CL. Compliance in clinical trials. Aids, 1995;9:1-10.

42. MacDonald ET, MacDonald JB, Phoenix M. Improving drug compliance after hospital discharge. British Medical Journal, 1977;2:618-622.

43. Spilker B. Methods of assessing and improving patient compliance in clinical trials. In: Cramer JA, Spilker B, eds. Patient compliance in medical practice and clinical trials. New York: Raven Press, 1991: 47-49.

44. De Wit R, Van Dam F, Hanneman M, Zandbelt L, Van Buuren A, Van der Heijden K, Leenhouts G, Loonstra S, Huijer Abu-Saad H. Evaluation of the use of a pain diary in chronic cancer pain patients at home. Pain, 1999;79:89-99.

45. Haynes RB, McKibbon KA, Kanani R, Brouwers RC, Oliver T. Interventions to assist patients to follow prescriptions for medications. In: Bero L, Grilli L, Grimshaw J, Oxman A, eds.

Collaboration on effective professional practice module of the cochrane database of systematic reviews. Oxford: The Cochrane Collaboration, 1998.

46. Rimer B, Levy M, Keintz MK, MacElwee N, Engstrom PF. Improving cancer patients' pain control through education. Progress in Clinical \& Biological Research, 1987;248:123-127.

47. De Wit R, Van Dam F, Zandbelt L, Van Buuren A, Van der Heijden K, Leenhouts G, Loonstra S. A Pain Education Program for chronic cancer patients: follow-up results from a randomized controlled trial. Pain, 1997;73:55-69.

48. Van der Kuy A. Farmacotherapeutisch kompas 1995: medisch farmaceutische voorlichting. Amstelveen: Centrale Medisch Pharmaceutische Commissie van de Ziekenfondsraad, 1995.

49. Vanderiet K, Adriaensen H, Carton H, Vertommen H. The McGill Pain Questionnaire constructed for the Dutch language (MPQ-DV). Preliminary data concerning reliability and validity. Pain, 1987;30:395-408.

50. Verkes R, Van der Kloot WA, Van der Meij J. The perceived structure of 176 pain descriptive words. Pain, 1989;38:219-229.

51. Jensen MP, Karoly P, Braver S. The measurement of clinical pain intensity: A comparison of six methods. Pain, 1986;27:117-126.

52. Kremer $E$, Atkinson JHJ. Pain measurement: construct validity of the affective dimension of the McGill Pain Questionnaire with chronic benign pain patients. Pain, 1981;11:93-100.

53. McGuire DB. Measuring pain. In: Frank-Stromborg M, ed. Instruments for clinical nursing. Norwalk, CT, 1988: 333-356.

54. Ashburn MA, Lipman AG. Management of pain in the cancer patient. Anesthesia \& Analgesia, 1993;76:402-416.

55. Foley KM. The treatment of cancer pain. New England Journal of Medicine, 1985;313:84-95. 
56. Haviley C, Gagnon J, MacLean R, Renz J, Jones O, De Witt W, Nyberg K, Burns C, Pohl D. Pharmacological management of cancer pain. A guide for the health care professional. Cancer Nursing, 1992;15:331-346.

57. Morisky DE, Green LW, Levine DM. Concurrent and predictive validity of a self-reported measure of medication adherence. Medical Care, 1986;24:67-74.

58. Brooks CM, Richards JM, Kohler CL, Soong S, Martin B, Windsor R, Bailey W. Assessing adherence to asthma medication and inhaler regimens: a psychometric analysis of adult self-report scales. Medical Care, 1994;32:298-307.

59. McGuire DB, Barbour L, Boxler J, Braun D, Flynn B, Hagle M, Hange P, Kelley C, Trippon M, Bressler L. Fixed-interval versus as-needed analgesics in cancer outpatients. Journal of Pain and Symptom.Management, 1987;2:199-205.

60. Portenoy RK, Coyle N. Controversies in the long-term management of analgesic therapy in patients with advanced cancer. Journal of Pain and Symptom Management, 1990;5:307-319.

61. Ferrell BR, Ferrell BA, Ahn C, Tran K. Pain management for elderly patients with cancer at home. Cancer, 1994;74:2139-2146.

62. Ward SE, Goldberg N, Miller-McCauley V, Mueller C, Nolan A, Pawlik-Plank D, Robbins A, Stormoen D, Weissman DE. Patient-related barriers to management of cancer pain. Pain, 1993;52:319-324.

63. Richardson JL, Marks G, Levine A. The influence of symptoms of disease and side effects of treatment on compliance with cancer therapy. Journal of Clinical Oncology, 1988;6:1746-1752.

64. Elixhauser A, Eisen SA, Romeis JC, Homan SM. The effects of monitoring and feedback on compliance. Medical Care, 1990;28:882-893. 


\section{Chapter 9}

\section{The role of district nurses in the care of cancer patients with chronic pain at home}




\section{Introduction}

Pain is a major symptom for patients in an advanced stage of their disease. It is estimated that approximately $60-80 \%$ of cancer patients in an advanced stage of their disease suffer from pain. ${ }^{1,2}$ At a time that the average period of hospitalization is decreasing and emphasis has shifted from hospital care to home care, ${ }^{3}$ cancer has become a disease with emphasize placed on outpatient care. As a result, pain treatment may be initiated in the hospital or outpatient clinic, while continuation of treatment in the home is primarily fulfilled by the patient, the family, and healthcare professionals.

Pain control in the home situation, however, is more complicated than in the hospital for a number of reasons. First, communication between the different healthcare providers and the patient, the co-ordination of the care, and continuity of care are often inadequate, ${ }^{4}$ resulting in fragmented healthcare. ${ }^{5}$ Second, there is a lack of monitoring pain systematically, and patient self-report of pain is infrequently used. Significant differences between caregivers' observations and patients' self-reports of pain make it difficult to determine the exact course of patients' pain complaints and the efficacy of the pain treatment. ${ }^{6-9} \mathrm{~A}$ third obstacle to adequate pain treatment is patients' lack of knowledge, fear of drug tolerance, concerns about side effects, and fear of drug addiction. ${ }^{10-13}$ This often results in non-adherence to the pain medication. Dorrepaal ${ }^{14}$ reported that $40 \%$ of cancer outpatients using analgesics did not adhere to the pain medication prescription, and De Wit et al. ${ }^{15}$ found that more than half of the study patients were non-adherent with the analgesic therapy. Although education programs in pain can improve patients' pain knowledge, 10,16-22 such educational programs are hardly studied in outpatients.

In the Netherlands, healthcare has a strong emphasis on primary care, which can include the general practitioner, community nurses, and home help. Primary care is highly accessible, covered by compulsory or private insurances, and requires no or minimal financial contributions. ${ }^{23,24}$ Authorization from a physician is not needed to use community nursing services in the Netherlands, but the general practitioner functions as a "gatekeeper" for most community and institutional services. District nursing is usually offered to patients who are not able to care for themselves. Although responsibility for the co-ordination of care formally belongs to the physician or general practitioner, nurses play a prominent role in assessing pain, observing symptoms and reactions, carrying out pain relieve methods, and educating patients. ${ }^{25}$ In primary care, district nurses' role has become even more important, because they have an important signaling task with regard to monitoring patients' pain experience and the efficacy of the pain treatment; they carry out pharmacological and non-pharmacological pain treatment, identify the need for change in pain management, educate and inform patients, and evaluate the effectiveness of the pain treatment given. Furthermore, an important task of district nurses is to co-ordinate the primary care.

Up to now, research on the management of cancer pain has mainly focused on the inpatient setting. Empirical studies on the quality of district nurses in the home setting, as well as their role in pain relief, are scarce ${ }^{26,27}$ Smets et al. ${ }^{28}$ found that nurses consider themselves as playing a minor role in the pain management of cancer patients; most were unable to relieve patients' pain through the interventions, and rarely contacted physicians or general practitioners about 
patients' pain. De Schepper et al. ${ }^{29}$ found that Dutch community nurses feel powerless with regard to pain management. Powerlessness was primarily caused by problems in communication between caregivers, dilemmas concerning physical care, and discrepancies between nurses' goals and what can be achieved realistically.

Pain management in the home situation can only be of high quality if there is effective discharge planning to assist patients, their families, and the caregivers to meet the healthcare needs. ${ }^{30,31}$ Thus, good continuity of care is a prerequisite for effective pain management, but precisely this is lacking in the current situation. In recent years several educational programs in pain patients have been shown to be efficacious. However, such programs are usually not integrated with the home care provided. ${ }^{11,16-22,32}$

The present study evaluates the role of the district nurse in the treatment of patients' pain at home, and the effectiveness of the Pain Education Program for both district nurses and patients. The Pain Education Program consisted of three components: enhancing patients' knowledge about pain and pain treatment, instructing patients how to register their pain intensity at home by means of a pain diary, and stimulating patients' help-seeking behavior. In addition to the intervention focusing on patients, district nurses caring for the intervention group patients were informed about the additional instruction and information that patients received. By informing district nurses about patients' pain treatment, the purpose of the Pain Education Program for district nurses was to improve the knowledge and understanding of district nurses regarding patients' pain experience, to enhance their involvement in the pain treatment, and to ensure optimal continuity of care.

In this study, it was hypothesized that: (1) the Pain Education Program would result in more communication between healthcare providers about patients' pain; (2) the level of agreement between nurses' estimations of patients' pain and patients' pain intensity would be improved in the intervention group; (3) the Pain Education Program would lead to increased satisfaction with the pain treatment and pain relief on the part of the district nurse; and (3) the Pain Education Program would lead to an increased number of pain relieving interventions used by district nurses.

\section{Methods}

\section{Design and subjects}

A longitudinal study involving a "pretest-posttest experimental design" was conducted. Patients and their district nurses were included in the study. The Netherlands Cancer Institute/Antoni van Leeuwenhoek Hospital, a 180-bed cancer center in the western part of the Netherlands, was chosen as the co-ordinating center.

Patients were included in the study if they were admitted to the hospital and were: (1) in pain for at least 1 month; (2) experiencing pain related to cancer, cancer therapy, or illness; (3) expecting to live for at least 3 months as assessed by the clinician; (4) able to read and speak Dutch; (5) accessible by telephone; and (6) not residing in a nursing home or retirement home. Patients who 
provided informed consent participated in the study. Patients were randomly assigned to a control group, in which regular pain treatment was provided, or an intervention group in which the Pain Education Program for patients and district nurses was provided in addition to the regular pain treatment. Prior to randomization, the patients were stratified for gender (male/female), age ( $<60$ years $\$ 60$ years), and metastatic sites (yes/no/unknown).

Originally, patients with and without district nursing in the home setting were randomized. This distinction was made because it was expected that patients who needed district nursing at home were in a more advanced stage of their disease. In the present study, only results of the patients for whom district nursing was organized are reported.

Postdischarge, a follow-up interview was arranged for both patients and nurses at 2, 4, and 8 weeks postdischarge. The patients and district nurses were then interviewed individually.

\section{The Pain Education Program}

The Pain Education Program was developed on the basis of published reports, existing educational programs, and input of pain experts. ${ }^{33-37}$ Three nurses were specially trained as pain counselors to educate and instruct patients about pain and pain treatment. The Pain Education Program included the use of multiple teaching methods, which was provided both in the hospital and postdischarge by telephone.

The Pain Education Program for patients consisted of pain information and instruction that was tailored to the needs and the abilities of the individual patient. The purposes of the Pain Education Program for patients were: (1) to improve patients' knowledge of their pain and pain treatment; (2) to enhance patients' motivation to adhere to the drug regimen; (3) to daily monitor pain by means of a pain diary; and (4) to stimulate patients' help-seeking behavior. Topics discussed with the patients included, e.g., the definition of pain, pharmacological pain management, side-effects, myths and misconceptions related to pain management, non-adherence, use of non-pharmacological pain treatment, and pain assessment. The verbal instruction, which was provided in the hospital, was audiotaped on a cassette so that it could be listened to at home. The verbal instruction was accompanied by a pain brochure and a pain diary in which patients were instructed how to self-report pain. Finally, patients were instructed how to communicate about pain, when to contact healthcare providers, and how to use simple non-pharmacological pain management techniques, such as cold, heat, relaxation, and massage. Postdischarge, two telephone follow-ups took place at three and seven days postdischarge as part of the intervention, to identify whether all information was understood by the patient, and to assess whether the patient was able to complete the pain diary.

In addition to the Pain Education Program for patients, specially trained hospital nurses made the initial contact with the district nurses and determined their interest in participating in the study. Once the patient was included in the study, district nurses were informed about patients' pain complaints, what pain knowledge was lacking, how patients' pain knowledge was lacking, the extent of patients' medication adherence, and how patients were stimulated to monitor pain 
in a pain diary. District nurses received this information both by telephone and by means of a written summary.

\section{Measures}

\section{District nurses}

Data were collected through self-report questionnaires, structured interviews, the use of medical records, and nursing records. District nurses were interviewed about their sociodemographic data (e.g., gender, age, years in nursing, and educational background).

Regarding the nursing care provided, the reason for being referred to district nursing, the type of nursing care provided, the pain interventions applied, the frequency of visits, the frequency in contacting other healthcare providers, and referrals to other primary care services.

Pain intensity was assessed by means of an 11-point numeric rating scale, on which "0" represents "no pain" and " 10 " represents "pain as bad as you can imagine." Reliability of the numeric rating scale is well established. ${ }^{38,39}$

Nurses' satisfaction with the pain treatment, which is indicated as one of the criteria by the American Pain Society, 37,40 and the Agency for Health Care Policy and Research, ${ }^{41}$ was measured on a 5-point scale, ranging from: very satisfied (1), somewhat satisfied (2), neither satisfied nor dissatisfied (3), somewhat dissatisfied (4), to very dissatisfied (5).

Nurses' assessment of patients' pain relief was assessed on a 6-point scale, ranging from complete relief (1), strong relief (2), moderate relief (3), slight relief (4), no relief (5), to worsening of pain (6). ${ }^{42}$

\section{Patients}

Patients were interviewed about demographic variables (e.g., gender, age, and education), medical data (e.g., cancer type, disease stage, and cancer treatment), and pain experience (e.g., pain location, time since onset).

Quality of life was measured by means of the EORTC QLQ-C30(+3).43 This quality of life questionnaire contains: (1) five functioning scales (physical functioning, role functioning, emotional functioning, cognitive functioning, and social functioning); (2) three physical symptom scales (fatigue and malaise, nausea and vomiting, pain); (3) several single-item symptom measures (constipation, dyspnea, difficulty with sleeping, appetite loss, diarrhea, and financial impact); (4) overall perceived health status; and (5) global quality of life.

Patients' pain intensity, satisfaction with the pain treatment, and pain relief were assessed in the same way as district nurses were asked to assess patients' pain intensity, satisfaction with the pain treatment, and pain relief.

Finally, pain treatment was reported by means of the three-step WHO analgesic ladder, consisting of: non-opioid analgesics (step I), weak opioids with or without non-opioids (step II), and strong opioids with or without non-opioids (step III). ${ }^{44}$ 


\section{Statistical analyses}

Data were analyzed using the Statistical Package for the Social Sciences (SPSS). Data are presented as means $\pm \mathrm{sd}$, or median and range, according to distribution. Differences between groups were evaluated by means of a Student's t-test for unpaired observations or chi-square. A p-value of $<.05$ (two-tailed) was considered significant.

\section{Results}

\section{Sample demographics}

A total of 383 patients were invited to participate in the study, of these $18 \%$ declined. Reasons for declining were: study was too burdensome (69\%), not motivated $(21 \%)$, or too ill $(10 \%)$. The remaining 313 patients consisted of $104 \mathrm{pa}$ tients who needed district nursing at home, and 209 patients who did not need district nursing. Here, we only report on the 104 patients who received district nursing in the home setting, and on the district nurses caring for them.

The patient group consisted of 104 patients. The sample size decreased to 83 patients $(80 \%)$ at week 2,76 patients $(73 \%)$ at week 4 , and 72 patients $(69 \%)$ at week 8 , due to patient deaths (67\%), being too ill ( $24 \%)$, and experiencing the study as too burdensome ( $9 \%)$. The dropout rate in the intervention group was significantly higher than in the control group at week $4(p=.01)$, and week 8 ( $p$ $<.05$ ). At week 8 , the dropout rate in the intervention group patients with district nursing was $41 \%$ compared with $20 \%$ in the control group. This was mainly due to the high percentage of patients who died during follow-up. After randomization, 51 patients were in the control group and 53 patients in the intervention group.

In total, 115 district nurses were caring for 104 patients. Data were collected of 110 of the 115 district nurses. For 22 patients, more than one district nurse was interviewed about the care for the patient. At week 2, data were collected from 88 district nurses ( $84 \%)$. No data were collected from district nurses caring for patients who died within one week after discharge, or who were readmitted to hospital within 2 weeks. Demographic data of the nurses are given in Table 1. The majority of the district nurses was female (93\%); $58(53 \%)$ caring for patients in the control group, and $52(47 \%)$ for patients in the intervention group.

In approximately $30 \%$ of the patients, no other primary caregiver, besides the general practitioner, was involved in the primary care. In all other patients, the district nurse participating in the study was not the only caregiver taking care of the patient: $43 \%$ of the patients received care of more than one district nurse, and home help was needed in $35 \%$. The use of home care services remained stable over time, and no differences in referrals were found between the control and intervention group patients. 
Table 1. Demographic data on district nurses participating in the Pain Education Program

\section{Gender}

Female

102

$93 \%$

Male

Age in years (sd)

Years qualified (sd)

Hours of work per week (sd)

\section{Education}

District nurse

Registered nurse

$37(10)$

$15(10)$

Practical nurse
$87 \%$

$3 \%$

$6 \%$

Patient characteristics are described in Table 2. Of the 104 patients, there were 32 males (31\%) and 72 females (69\%). The patients ranged in age from 21 to 79 years $(s d=13)$. The most common neoplasm was breast cancer, and genitourinary cancer. No differences were found between the control and intervention group for sociodemographic and medical parameters, except that patients in the intervention group were prescribed more analgesics than those in the control group $(\mathrm{p}<.001)$.

At pretest, the mean score for patients' Present Pain Intensity was 3.4 (sd = 2.5). Patients' Average Pain Intensity during the previous week was 5.1 (sd = 2.2), and patients' Worst Pain Intensity was $8.0(s d=2.2)$. No differences were found between the groups.

Overall, patients showed low values on the different functioning scales of quality of life, especially on physical functioning and role functioning (data not shown). Despite randomization, intervention patients showed lower levels of physical functioning $(p=.05)$, and cognitive functioning $(p<.05)$ than control group patients. In addition to pain, patients reported a broad spectrum of symptoms, and experienced on average 4.4 symptoms $(s d=1.5)$ Most frequently, patients reported fatigue, pain, loss of appetite, sleep disturbance, and constipation. No differences were found between the control and intervention group. 
Table 2. Sociodemographic, medical, and pain charateristics of the patients at pretest

\begin{tabular}{|c|c|c|c|}
\hline & $\begin{array}{c}\text { Control } \\
\text { group }\end{array}$ & $\begin{array}{r}\begin{array}{r}\text { Intervention } \\
\text { group }\end{array} \\
\end{array}$ & $\begin{array}{c}\text { p- } \\
\text { value }\end{array}$ \\
\hline \multicolumn{4}{|l|}{ Gender } \\
\hline Female & $\begin{array}{l}31 \% \\
69 \%\end{array}$ & $\begin{array}{l}30 \% \\
70 \%\end{array}$ & ns \\
\hline Male & & & \\
\hline Age (mean in years (sd)) & $58(12)$ & $61(13)$ & ns \\
\hline \multicolumn{4}{|l|}{ Education } \\
\hline Low & $43 \%$ & $38 \%$ & ns \\
\hline Middle & $31 \%$ & $36 \%$ & \\
\hline High & $26 \%$ & $26 \%$ & \\
\hline \multicolumn{4}{|l|}{ Primary tumor site (> $100 \%$ ) } \\
\hline Lip, oral cavity, and pharynx & $2 \%$ & $9 \%$ & ns \\
\hline Digestive organs and peritoneum & $12 \%$ & $8 \%$ & \\
\hline Respiratory and intrathoracic organs & $4 \%$ & $6 \%$ & \\
\hline Breast & $29 \%$ & $34 \%$ & \\
\hline Bone, connective tissue, and skin & $12 \%$ & $8 \%$ & \\
\hline Genitourinary organs & $37 \%$ & $32 \%$ & \\
\hline Other (i.e., Hodgkin, non-Hodgkin lymphoma) & $16 \%$ & $13 \%$ & \\
\hline \multicolumn{4}{|l|}{ Disease stage } \\
\hline Local & $8 \%$ & $8 \%$ & ns \\
\hline Regional & $22 \%$ & $23 \%$ & \\
\hline Metastatic & $61 \%$ & $60 \%$ & \\
\hline Unknown/not applicable & $9 \%$ & $9 \%$ & \\
\hline Treatment (>100\%) & & & ns \\
\hline No & $20 \%$ & $26 \%$ & \\
\hline Surgery & $22 \%$ & $11 \%$ & \\
\hline Chemotherapy & $28 \%$ & $17 \%$ & \\
\hline Radiation therapy & $18 \%$ & $23 \%$ & \\
\hline Hormonal therapy & $10 \%$ & $13 \%$ & \\
\hline Other (i.e., hormonal, immuno, laser) & $4 \%$ & $9 \%$ & \\
\hline Pain duration (mean in months (sd)) & $10(14)$ & $8(14)$ & ns \\
\hline \multicolumn{4}{|l|}{ Pain location (> 100\%) } \\
\hline Head, face, mouth, cervical region & $16 \%$ & $23 \%$ & ns \\
\hline Breast, thoracic region & $39 \%$ & $17 \%$ & \\
\hline Upper shoulder, and upper limbs & $20 \%$ & $30 \%$ & \\
\hline Abdominal region & $41 \%$ & $\begin{array}{l}42 \% \\
40 \%\end{array}$ & \\
\hline $\begin{array}{l}\text { Lower back, lumbar spine, sacrum } \\
\text { Lower limbs }\end{array}$ & $\begin{array}{l}45 \% \\
35 \%\end{array}$ & $\begin{array}{l}40 \% \\
25 \%\end{array}$ & \\
\hline Anal, perineal, and genital region & $10 \%$ & $4 \%$ & \\
\hline \multicolumn{4}{|l|}{ Pain cause } \\
\hline Tumor involvement & $71 \%$ & $68 \%$ & ns \\
\hline Cancer therapy & $8 \%$ & $6 \%$ & \\
\hline Tumor involvement and cancer therapy & $10 \%$ & $9 \%$ & \\
\hline Related to disease or debility & $8 \%$ & $13 \%$ & \\
\hline Unknown & $4 \%$ & $4 \%$ & \\
\hline Analgesics & $82 \%$ & $98 \%$ & $<.001$ \\
\hline
\end{tabular}

ns: not significant, $p>0.05$; two-tailed. 


\section{Nursing care}

Continuity of care is achieved by providing a link between the hospital nurse and the district nurse in the home setting. District nurses were asked about the extent to which they were informed by hospital nurses about patients' pain complaints. Results showed that only $36 \%$ of the district nurses were informed by hospital nurses about any aspect of patients' pain before discharge. There was no difference between control group patients and intervention group patients in the extent of information provided. The severity of patients' pain intensity was not related to informing district nurses patients about patients' pain intensity.

After discharge, patients were visited by district nurses on average 9 times during the first 2 weeks ( $s d=8$; range $0-42$ ). The number of visits remained stable over a 2-month period; no differences were found between the control group patients and the intervention group patients (Table 3 ). At two weeks postdischarge, $30 \%$ of the district nurses had not contacted another healthcare provider in the previous two weeks, $39 \%$ had contacted a colleague, $26 \%$ had contacted a general practitioner, and $6 \%$ had contacted another healthcare provider. No differences were found between the control and intervention group.

\section{Table 3. Contacts with patients at home}

\begin{tabular}{lrrrr}
\hline $\begin{array}{l}\text { Number of contacts } \\
\text { with patient in } \\
\text { previous 2 weeks }\end{array}$ & $\begin{array}{r}\text { Control } \\
\text { group }\end{array}$ & $\begin{array}{r}\text { Intervention } \\
\text { group }\end{array}$ & Total & $\begin{array}{r}\text { p- } \\
\text { value }\end{array}$ \\
\hline Mean (sd) & Mean (sd) & Mean (sd) & \\
\hline Week 2 & $7.4(6.6)$ & $9.1(6.6)$ & $8.8(8.1)$ & $\mathrm{ns}^{*}$ \\
Week 8 & $7.9(7.6)$ & $7.6(5.6)$ & $7.3(6.3)$ & $\mathrm{ns}$ \\
\hline
\end{tabular}

' not significant

The most important reasons for home visits mentioned by district nurses were: moral support $(58 \%)$, hygienic care or technical nursing care $(48 \%)$, wound care or dressings $(23 \%)$, health education $(20 \%)$, observation $(11 \%)$, medication administration $(8 \%)$, and miscellaneous $(9 \%)$. Pain was hardly mentioned as the main reason for the provision of services by district nurses. The main reasons for visiting the patient remained stable over time with moral support as the most frequently mentioned type of care provided. No significant differences were found between the control and intervention group patients.

District nurses were also asked what services were provided regarding patients' pain control. Results are given in Table 4. Although pain control was not the main reason for visiting patients at home, pain was subject for discussion in the majority of the patients (76\%). Furthermore, the use of pain medication was discussed in $36 \%$, and information on side-effects was provided in $21 \%$ at two weeks after discharge. No significant differences were found between the control and intervention patients. It is striking that nurses most frequently discussed the pain problem with the patient. Interventions that form an important foundation in pain treatment, such as non-pharmacological pain interventions (e.g., heat, 
cold, massage, relaxation, and distraction), cognitive interventions (e.g., attention-diversion, instructions for self-care, structured educational programs, and support in coping), behavioral interventions (e.g., family counseling, and self-monitoring pain), and affective intervention (e.g., reduction of anxiety, anger, guilt, and depression) were rarely mentioned by the district nurses.

Table 4. Most important services provided by district nurses

\begin{tabular}{|c|c|c|c|}
\hline $\begin{array}{l}\text { Most important services provided } \\
(>100 \%)\end{array}$ & $\begin{array}{r}\text { Control } \\
\text { group }\end{array}$ & $\begin{array}{r}\begin{array}{r}\text { Intervention } \\
\text { group }\end{array} \\
\end{array}$ & Total \\
\hline \multicolumn{4}{|l|}{ Discuss pain } \\
\hline week 2 & $71 \%$ & $81 \%$ & $76 \%$ \\
\hline week 4 & $80 \%$ & $67 \%$ & $73 \%$ \\
\hline week 8 & $79 \%$ & $74 \%$ & $77 \%$ \\
\hline \multicolumn{4}{|c|}{ Discuss use of medication and adherence } \\
\hline week 2 & $32 \%$ & $39 \%$ & $36 \%$ \\
\hline week 4 & $37 \%$ & $30 \%$ & $33 \%$ \\
\hline week 8 & $46 \%$ & $30 \%$ & $37 \%$ \\
\hline \multicolumn{4}{|l|}{ Provide relaxation, massage, etc. } \\
\hline week 2 & $0 \%$ & $6 \%$ & $3 \%$ \\
\hline week 4 & $7 \%$ & $7 \%$ & $7 \%$ \\
\hline week 8 & $8 \%$ & $11 \%$ & $10 \%$ \\
\hline \multicolumn{4}{|l|}{ Provide aids to reduce pain } \\
\hline week 2 & $19 \%$ & $17 \%$ & $18 \%$ \\
\hline week 4 & $7 \%$ & $7 \%$ & $7 \%$ \\
\hline week 8 & $8 \%$ & $7 \%$ & $8 \%$ \\
\hline \multicolumn{4}{|l|}{ Administer analgesics } \\
\hline week 2 & $0 \%$ & $6 \%$ & $6 \%$ \\
\hline week 4 & $3 \%$ & $7 \%$ & $5 \%$ \\
\hline week 8 & $0 \%$ & $0 \%$ & $0 \%$ \\
\hline \multicolumn{4}{|l|}{ Inform about side-effects } \\
\hline week 2 & $29 \%$ & $14 \%$ & $21 \%$ \\
\hline week 4 & $10 \%$ & $30 \%$ & $20 \%$ \\
\hline week 8 & $8 \%$ & $15 \%$ & $12 \%$ \\
\hline \multicolumn{4}{|l|}{ Consult other caregivers } \\
\hline week 2 & $7 \%$ & $3 \%$ & $5 \%$ \\
\hline week 4 & $10 \%$ & $0 \%$ & $5 \%$ \\
\hline week 8 & $4 \%$ & $7 \%$ & $6 \%$ \\
\hline \multicolumn{4}{|l|}{ Reduce anxiety } \\
\hline week 2 & $3 \%$ & $3 \%$ & $3 \%$ \\
\hline week 4 & $7 \%$ & $0 \%$ & $3 \%$ \\
\hline week 8 & $4 \%$ & $4 \%$ & $4 \%$ \\
\hline \multicolumn{4}{|l|}{ Provide wound care } \\
\hline week 2 & $3 \%$ & $6 \%$ & $5 \%$ \\
\hline week 4 & $3 \%$ & $10 \%$ & $7 \%$ \\
\hline week 8 & $0 \%$ & $4 \%$ & $2 \%$ \\
\hline
\end{tabular}

- Values are percentages of total services. 


\section{Effects of the Pain Education Program}

District nurses were asked at week 4 and 8 to give their opinion about the additional pain information and instruction that was provided for the patients and themselves. Overall, district nurses were positive about the additional information and instruction received: $94 \%$ evaluated the Pain Education Program for district nurses as (very) good at week 4 , and $93 \%$ at week 8 . In addition, $87 \%$ of the district nurses evaluated the Pain Education Program for patients as (very) good at week 4 , and $50 \%$ at week 8 . In only 1 patient, the additional pain information was evaluated as bad.

The effectiveness of the Pain Education Program was evaluated by the district nurses as (very) good in $45 \%$, not good/not bad in $32 \%$, bad in $3 \%$, and $19 \%$ did not have an opinion at week 4. Nurses' opinion remained stable over time as $50 \%$ evaluated the effect of the Pain Education Program as (very) good at week 8.

It was hypothesized that the agreement between patients' and nurses' estimation of pain intensity would be better in the intervention group than in the control group. Agreement was defined as a nurses' estimation of patients' pain that was equal to or within a range of \pm 1 on a scale from 0 - 10 with patients' pain intensity. Non-agreement was defined as a discrepancy of 2 or more between nurses' estimation of patients' pain and patients' pain score. Overall, the Pearson correlations between patients' pain intensity scores and the nurses' estimation of patients' pain were $r=0.44$ at 2 weeks, $r=0.54$ at 4 weeks, and $r=0.53$ at 8 weeks. Nurses accurately assessed patients' pain intensity in $57 \%$ at week $2,64 \%$ at week 4 , and $59 \%$ week 8 . For district nurses who were inaccurate in assessing



Figure 1. Agreement between patients' pain intensity and nurses' estimation of patients' pain 
patients' pain, pain intensity was most frequently overestimated $(72 \%, 68 \%$, and $61 \%$ at week 2,4 , and 8 , respectively).

Results showed that district nurses in the intervention group significantly better estimated patients' pain intensity at 2 weeks postdischarge than in the control group (Figure 1). At week 4 and 8, there was a trend that district nurses of patients in the intervention group better estimated patients' pain than district nurses of patients in the control group.

Table 5. Nurses' estimation of satisfaction with pain treatment and pain relief

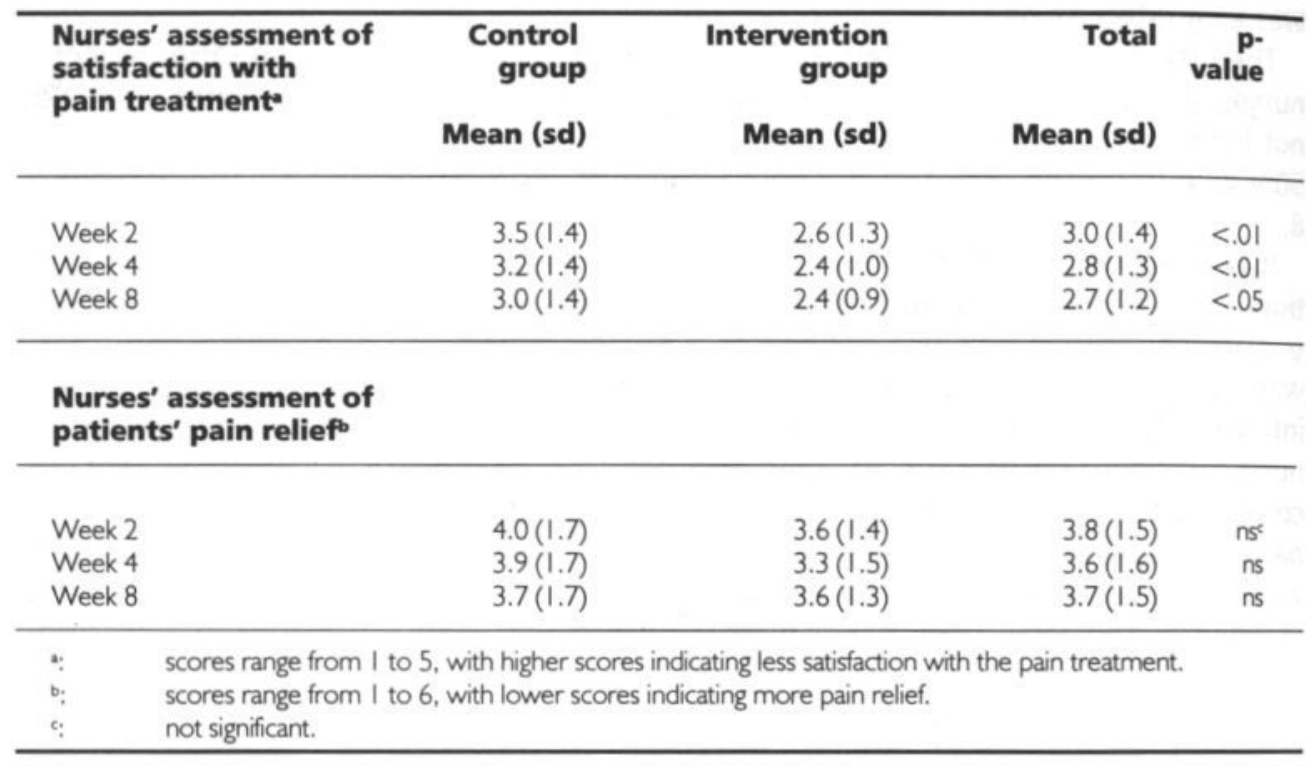

District nurses were dissatisfied with the pain treatment in only a minority of patients: $21 \%$ at week $2,21 \%$ at week 4 , and $4 \%$ at week 8 . At all assessment points, district nurses of patients in the intervention group were significantly more satisfied with patients' pain treatment than the nurses in the control group (Table 5).

When examining the differences between the answers from the patients and the nurses' perceptions, the exact agreement between the nurse and the patient varied from $15-24 \%$ at the three assessment points. Two weeks after discharge, significantly less difference was found in the intervention group in the estimation of patients' satisfaction with the pain treatment compared with the control group $(p=.05)$. No differences were found between the control and intervention group at week 4 and 8 .

Nurses were asked to assess patients' relief with the pain treatment. Two weeks after discharge, the district nurses reported that $44 \%$ of the patients had complete, strong, or moderate relief from the pain treatment. At week 4 and 8 , pain relief was reported by $53 \%$ and $52 \%$, respectively. The exact agreement between what the patient reported about the extent of pain relief and how nurses estimated patient's pain relief varied from $19-28 \%$ at the three assessment points. A large discrepancy between patient's pain relief and nurse's estimation of patient's pain reiief was found: the discrepancy varied from $39-47 \%$, meaning that nurses frequently assess the relief from pain treatment differently 
compared with the patients. No differences in discrepancy between district nurses and patients were found between the control and intervention group.

\section{Discussion and conclusion}

In this study, the role of district nurses in the care of cancer patients with chronic pain at home was investigated, as well as the effect of the Pain Education Program. In total, 115 district nurses and 104 patients were enrolled in a prospective, longitudinal, randomized controlled study. Both patients and district nurses were followed-up for two months postdischarge.

Results showed that, despite randomization, patients in the intervention group differed at pretest from patients in the control group with respect to analgesics administered, physical functioning and cognitive functioning. Postdischarge, more patients died in the intervention group (41\%) compared with the control group $(20 \%)$. It appeared that the randomization was not fully effective in yielding balanced intervention and control groups. This high percentage of dropouts, mainly due to patients deaths, might have biased the results. Consequently, results in the groups with district nursing need to be interpreted with caution. Possible bias might also be caused by district nurses and patients in the control groups being interviewed four times. Consequently, district nurses of control group patients might have increased their care for control group patients because they became aware of participating in a pain study. For patients, the attention paid to their pain might have been an intervention in itself. If so, the results might be an underestimation of the effects found in this study, as the control group patients might do it better than less intensively studied control groups.

Because advanced cancer patients with pain are often cared for by various healthcare providers, co-ordination and continuity of care is a requisite. Results showed that continuity of care was poor as only $36 \%$ of the district nurses were informed by hospital nurses about patients' pain. This result is in agreement with other Dutch studies finding reporting that co-ordination between hospital caregivers and primary caregivers was low. 4,30

Pain was rarely the reason for referring the patient to district nurses. Most frequently, patients were referred to district nurses for moral support and hygienic or technical nursing care. We were surprised by the result, that pain was rarely the main reason for provision of district nurses, while most patients experienced moderate to severe pain at home. Nevertheless, district nurses considered patients' pain problems as very important. All district nurses were willing to participate in the study and frequently underlined the importance of adequate pain control. However, besides discussing the pain problem with the patient, results showed that district nurses rarely applied pain-relieving interventions.

The evaluation of the Pain Education Program showed that district nurses were positive about the additional information and instruction received, and evaluated the effectiveness of the Pain Education Program as good or very good in approximately half of the patients. Results showed the district nurses are not well informed about patients' pain. In the control group, more than half of the district nurses could not accurately estimate patients' pain. Although it is often found that nurses have difficulty estimating patients' pain, this result is striking because the district nurses visited the patients on average once per day or every other 
day. District nurses in the intervention group significantly better estimated patients' pain intensity; however, the difference between the control and intervention group results decreased over time.

Most district nurses were satisfied with patients' pain treatment, with only approximately $20 \%$ being dissatisfied. District nurses in the intervention group were more satisfied with patients' pain treatment than those in the control group, and showed less discrepancy with patients in the assessment of satisfaction with pain treatment. Regarding nurses' estimation of pain relief, it was found that patients' pain was relieved in approximately half of the patients. Results showed no differences between control and intervention patients. The agreement between what pain relief was reported by patients compared with what was reported by district nurses about patients' pain relief was low. This study showed that district nurses of patients who received the Pain Education Program were hardly more actively involved in the treatment of pain compared with nurses in the control group.

The findings in this study suggest a significant but moderate effect of the Pain Education Program with district nurses playing only a minor role in the treatment of cancer pain. This result is in agreement with a recent review article evaluating the beneficial effect of aftercare in chronic patients, in which it was found that a majority of the studies reported no clear beneficial effects of the interventions. 45

We also found a limited extent of communication between district nurses and other healthcare providers. District nurses don't frequently contact general practitioners about patients' pain problems and visa versa. In view of the huge number of patients who are dependent on a combination of healthcare professionals, more intense teamwork in the home situation should be stimulated. The district nurses should consider the general practitioner and other caregivers as their partners to whom they can refer for help and advise without much ado.

Results showed that the intervention did not fully work as intended for the district nurses. What are the reasons for finding no strong effects in district nurses' use of pain interventions? The Pain Education Program for district nurses was entirely built around the patients that were cared for by district nurses. The district nurses received no separate training, but were "only" informed. It might be that in order to involve district nurses more actively in the pain treatment, they should be trained in applying nursing interventions. This means that in order to transfer pain relieving techniques from the hospital in the home situation, it is insufficient to provide merely verbal or written information. A more extensive program seems to be necessary. This result is in congruence with a Dutch study in which general practitioners received unsolicited written suggestions, finding no change in patients' pain intensity. ${ }^{46}$ From this, it can be concluded that improving the pain knowledge in healthcare providers does not automatically lead to a change in their behavior. 


\section{References}

1. Brescia FJ, Portenoy RK, Ryan M, Krasnoff L, Gray G. Pain, opioid use, and survival in hospitalized patients with advanced cancer. Journal of Clinical Oncology, 1992;10:149-155.

2. Higginson IJ, Hearn J. A multicenter evaluation of cancer pain control by palliative care teams. Journal of Pain and Symptom Management, 1997;14:29-35.

3. Maloney CH, Preston F. An overview of home care for patients with cancer. Oncology Nursing Forum, 1992;19:75-80.

4. Courtens AM. Kenmerken van zorg en kwaliteit van leven bij patienten met kanker (Characteristics of care and quality of life in cancer patients) [Thesis in Dutch]: University of Maastricht, 1993.

5. Philipsen H, Stevens FCJ. Modernization, rationality, and continuity of care: Theoretical concepts and empirical findings. Sociological Focus, 1997;30:189-204.

6. Au E, Loprinzi CL, Dhodapkar M, Nelson T, Novotny P, Hammack J, O'Fallon J. Regular use of a verbal pain scale improves the understanding of oncology inpatient pain intensity. Journal of Clinical Oncology, 1994;12:2751-2755.

7. Carpenter JS, Brockopp D. Comparison of patients' ratings and examination of nurses' responses to pain intensity rating scales. Cancer Nursing, 1995;18:292-298.

8. Grossman SA, Sheidler VR, Swedeen K, Mucenski J, Piantadosi S. Correlation of patient and caregiver ratings of cancer pain. Journal of Pain and Symptom Management, 1991;6:53-57.

9. Holmes S, Eburn E. Patients' and nurses' perceptions of symptom distress in cancer. Journal of Advanced Nursing, 1989;14:840-846.

10. Ferrell BR, Ferrell BA, Ahn C, Tran K. Pain management for elderly patients with cancer at home. Cancer, 1994;74:2139-2146.

11. Ferrell BR, McCaffery M, Rhiner M. Pain and addiction: an urgent need for change in nursing education. Journal of Pain and Symptom Management, 1992;7:117-124.

12. Ward SE, Goldberg N, Miller-McCauley V, Mueller C, Nolan A, Pawlik-Plank D, Robbins A, Stormoen D, Weissman DE. Patient-related barriers to management of cancer pain. Pain, 1993;52:319-324.

13. Levin DN, Cleeland CS, Dar R. Public attitudes toward cancer pain. Cancer, 1985;56:2337-2339.

14. Dorrepaal KL. Pijn bij patienten met kanker [Thesis in Dutch]: Vrije Universiteit, 1989.

15. De Wit R, Van Dam F, Zandbelt L, Van Buuren A, Van der Heijden K, Huijer Abu-Saad H. Non-adherence with the pain medication prescription: Effects of a Pain Education Program to assist cancer patients to follow pain medication prescriptions. (Submitted).

16. Clotfelter CE. The effect of an educational intervention on decreasing pain intensity in elderly people with cancer. Oncology Nursing Forum, 1999;26:27-33.

17. Dalton JA. Education for pain management: a pilot study. Patient Education and Counseling, 1987;9:155-165.

18. Rimer B, Levy M, Keintz MK, MacElwee N, Engstrom PF. Improving cancer patients' pain control through education. Progress in Clinical \& Biological Research, 1987;248:123-127.

19. Rimer BK, Kedziera P, Levy MH. The role of patient education in cancer pain control. Hospice Journal, 1992;8:171-191.

20. Ferrell BR, Rhiner M, Ferrell BA. Development and implementation of a pain education program. Cancer, 1993;72:3426-3432.

21. Dalton JA, Lambe $C$. Tailoring treatment approaches to the individualized needs of cancer patients with pain. Cancer Nursing, 1995;18:180-188.

22. Desbiens NA, Wu AW, Yasui Y, Lynn J, Alzola C, Wenger NS, Connors AF, Philips RS, Fulkerson W. Patient empowerment and feedback did not decrease pain in seriously ill hospitalized adults. Pain, 1998;75:237-246.

23. Van der Zee J, Kramer K, Derksen A, Kerkstra A, Stevens FO. Community nursing in Belgium, Germany, and the Netherlands. Journal of Advanced Nursing, 1994;20:791-801.

24. Schrijvers AJP. Health and health care in the Netherlands. A critical self-assessment by Dutch experts in the medical and health sciences. Utrecht: De Tijdstroom, 1997.

25. McCaffery M, Beebe A. Pain: Clinical manual for Nursing Practice. St. Louis, MO: CV Mosby, 1989.

26. Khalifa M. Inducing the quality of home health care theory through the use of grounded theory methodology. International Journal of Nursing Studies, 1993;30:269-286.

27. Goodman C, Knight D, Machen I. Emphasizing terminal care as district nursing work: a helpful strategy in a purchasing environment. Journal of Advanced Nursing, 1998;28:491-498. 
28. Smets EMA, van Dam FSAM, Dorrepaal KL, Lapre F. De wijkverpleegkundige en de kankerpatiênt met pijn. Verpleegkunde, 1989/90;2:85-94.

29. De Schepper, AM, Francke AL, Abu-Saad HH. Feeling the powerlessness in relation to pain: ascribed causes and reported strategies. A qualitative study among Dutch community nurses caring for cancer patients with pain. Cancer Nursing, 1997;20:422-429.

30. Smeenk FWJM. Transmural care of terminal cancer patients. An evaluation study in the Eindhoven region: University of Maastricht, 1998.

31. Yost LS, McCorkle R, Buhler-Wilkerson K, Schultz D, Lusk E. Determinants of subsequent home health care nursing service use by hospitalized patients with cancer. Cancer, 1993;72:3304-3312.

32. Rhiner $M$, Ferrell $B R$, Ferrell $B A$, Grant $M M$. A structured nondrug intervention program for cancer pain. Cancer Practice, 1993;1:137-143.

33. NVBP. Nederlanse Vereniging ter Bestudering van Pijn. Pijn en pijnbehandeling bij de patient met kanker. Groningen: Nederlandse Vereniging ter Bestudering van Pijn, 1990.

34. Spross JA, McGuire DB, Schmitt RM. Oncology Nursing Society Position Paper on Cancer Pain. Part I. Oncology Nursing Forum, 1990;17:595-614.

35. Spross JA, McGuire DB, Schmitt RM. Oncology Nursing Society Position Paper on Cancer Pain. Part II. Oncology Nursing Forum, 1990;17:751-760.

36. WHO. Cancer pain relief and palliative care. Geneva, Switzerland: World Health Organization, 1990.

37. APS. American Pain Society. Principles of analgesic use in the treatment of acute pain and chronic cancer pain: a concise guide to medical practice. Skokie, IL: American Pain Society, 1992.

38. Jensen MP, Karoly P, Braver S. The measurement of clinical pain intensity: A comparison of six methods. Pain, 1986;27:117-126.

39. McGuire DB. Measuring pain. In: Frank-Stromborg M, ed. Instruments for clinical nursing. Norwalk, CT, 1988: 333-356.

40. APS. American Pain Society Quality of Care Committee. Quality improvement guidelines for the treatment of acute pain and cancer pain. JAMA, 1995;274:1874-1880.

41. AHCPR. Agency for Health Care Policy and Reserach. Management of cancer pain. Clinical Practice Guideline. Rockville, MD: Agency for Health Care Policy and Research, 1994.

42. Cleeland CS. Pain assessment in cancer. In: Osoba D, ed. Effect of cancer on quality of life. Boca Raton, FL: CRC Press, 1991: 294-305.

43. Aaronson NK, Ahmedzai S, Bergman B, Bullinger M, Cull A, Duez NJ, Filiberti A, Flechtner H, Fleishman SB, de Haes JC. The European organization for research and treatment of cancer QLQ-C30: a quality-of-life instrument for use in international clinical trials in oncology. Journal of the National Cancer Institute, 1993;85:365-376.

44. WHO. Cancer pain relief. Geneva, Switzerland: World Health Organization, 1986.

45. Bours JJW, Ketelaars CA, Frederiks CAM, Huyer Abu-Saad H, Wouters EFM. The effects of aftercare on chronic patients and frail patients when discharged from hospital: A systematic review. Journal of Advanced Nursing, 1998;27:1076-1086.

46. Schuit KW. Palliative care in general practice. Groningen, The Netherlands, 1999. 


\section{Chapter 10}

\section{Assessment of pain cognitions in cancer patients with chronic pain}

De Wit, R., Van Dam, F., Litjens,M., Huijer Abu-Saad, H. Assessment of pain cognitions in cancer patients with chronic pain Journal of Pain and Symptom Management (Submitted) 


\section{Introduction}

Cancer pain has characteristics of both chronic and acute pain. Like acute pain, cancer pain is directly associated with tissue damage. When cancer pain persists and gets worsens, it can serve as a sign of the progression of disease, 1,2 and can produce feelings of hopelessness and helplessness, emotional distress, and can have a negative impact on coping techniques. Cancer pain is best described as a complex, multidimensional model. Pain, and especially cancer pain, is not only a nociceptive, physical experience, but involves affective, cognitive, behavioral, and sociocultural dimensions. The cognitive dimension refers to the way patients think of their pain and what the pain means for them, in terms of thoughts, beliefs, attitudes, and self-efficacy expectations. Although a considerable body of knowledge exists on the role of pain cognitions in non-cancer patients, only a few studies in cancer pain patients have shown that pain beliefs are associated with increased pain intensity. ${ }^{3-5}$ Turk and associates ${ }^{6}$ found that patients with cancer-related pain reported significantly higher levels of cognitive and behavioral fear-responses to pain than did patients with non-cancer pain. The meaning patients ascribe to their pain may differ from perceiving pain as a challenge ("I am going to fight as long as I can"), as an enemy ("It is like being attacked"), or as a punishment ("Why is God punishing me?").

In chronic non-cancer pain, it is generally agreed that the meaning assigned to pain can play an important role in the experience of pain and in the response to treatment. Several studies have demonstrated the impact of pain cognition on patients' pain experience, disability, distress, non-adherence, and outcome of treatment. $6,8-17$ Particularly, catastrophizing has been associated most strongly with depression, poorer adjustment, and higher intensity of pain. ${ }^{11,18-24}$ Studies on catastrophizing have been conducted only in chronic benign pain. Although numerous studies have demonstrated that treatment of cancer pain is often inadequate, ${ }^{25-27}$ the impact of pain cognition on patients' cancer pain experience remains unknown. ${ }^{28}$ Whatever importance pain cognition may have in the multidimensional model of cancer pain, the patient is best treated when none of these aspects are neglected in the treatment of pain. A better understanding of the role of pain cognitions might have important implications for the treatment of cancer pain.

In the past two decades, over one dozen instruments have been developed to measure the cognitions, beliefs, and attributions patients have about the cause of the pain and their self-efficacy expectations, e.g., Cognitive Error Questionnaire, ${ }^{29,30}$ Pain Cognitions Questionnaire, ${ }^{8}$ Cognitive Evaluative Questionnaire, ${ }^{31}$ Survey of Pain Attitudes, ${ }^{32-34}$ Pain-Related Control Scale, ${ }^{11,35}$ Pain Beliefs Questionnaire, ${ }^{10}$ Pain Beliefs and Perceptions Inventory; $16,36,37$ Pain Information and Beliefs Questionnaire, ${ }^{38}$ Pain Catastrophizing Scale, ${ }^{39,40}$ Inventory of Negative Thoughts in Response to Pain ${ }^{41}$ and Pain Cognition List-Experimental version. ${ }^{42}$

Although a variety of self-report measures are nowadays available, most measures have not been used extensively in different research settings, in many scales of these measures, the scales show considerable overlap, not all measures have been psychometrically well constructed, and some measures have shown disappointing results regarding validity aspects. ${ }^{43}$ In only a few studies, psychometric 
properties of the various measures to assess pain cognitions have been compared. 22,34

of all measures available, only the Pain Cognition List-Experimental version, measuring patients' self-statements about the pain and the extent to which patients are effective in dealing with the pain, has been developed in the Dutch language. The Pain Cognition List has only been studied in chronic benign pain patients, ${ }^{44}$ and was recently further validated in an extended population diagnosed with e.g., back pain, fybromyalgia, Complex Regional Pain Syndrome, and rheumatoid arthritis. ${ }^{45}$

In the present study, we assessed pain cognitions in cancer patients with chronic pain. To our knowledge, the present study represents a first effort to validate a questionnaire measuring pain cognitions in cancer patients with chronic pain. Because the Pain Cognition List consisted of an experimental version and has only been studied in chronic benign patients, the psychometric properties of the Pain Cognition List-Experimental version were first investigated. The purpose of the present study was twofold. First, the psychometric properties of the Pain Cognition List-Experimental version were described. By means of confirmatory factor analysis, the factor structure, reliability, and validity aspects of the Pain Cognition List, as originally described by Vlaeyen and associates, ${ }^{46}$ was replicated. To validate the factor structure in cancer pain patients, an exploratory factor analysis was conducted to find the best fit. Second, the occurrence of cognitions in cancer patients with chronic pain was assessed, and the association with sociodemographic variables, medical variables, pain variables, and quality of life was investigated. The study presented here was part of a larger study on the effects of a Pain Education Program, with a follow-up of two months.

\section{Methods}

\section{Design and patient population}

The current study was part of a prospective, randomized trial in which the effect of a tailored "Pain Education Program" was investigated. Because the focus of the present study is on comparing frequently used measures to evaluate the adequacy of pain treatment in cancer patients, a detailed description about the Pain Education Program is given elsewhere, ${ }^{47}$ and is only summarized in this report. Briefly, the tailored intervention consisted of a multi-method approach in which verbal pain instruction, written pain materials, an audiocassette tape, and the use of a pain diary were combined to inform and instruct patients about pain and pain management. The main purpose of the "Pain Education Program" was to empower patients in the process of relieving pain. The Pain Education Program consisted of educating patients about pain and pain treatment, instructing them to self-monitor pain in a diary, and instructing them how to communicate with healthcare providers.

The patients in this study were admitted to the Antoni van Leeuwenhoek Hospital/the Netherlands Cancer Institute, a specialized cancer hospital in Amsterdam, the Netherlands. Patients who provided informed consent were enrolled in the study if they met the following criteria: 1) pain related to cancer, or cancer therapy; 2) a pain duration of at least one month; 3) a life expectancy of at least 
three months (assessed by physicians); 4) able to read and speak Dutch; 5) accessible by telephone; and 6) not residing in nursing home or retirement home. Based on the assumption that patients who required district nursing after postdischarge would differ from patients without district nursing with regard to the ability to perform daily activities, housing and living conditions, and pain complaints experienced, patients with and without district nursing were distinguished.

\section{Procedure}

Patients who met the inclusion criteria were approached to participate in the study. Data were collected from the medical record and from interviews with patients who were willing to complete the informed consent form. The interview was conducted by nurses. Data collected at baseline included information on patient demographics, medical variables, pain experience and pain treatment, quality of life, and patients' pain cognitions. Patients who were not able to fill in the 77-item Pain Cognition List-Experimental version on their own received help from a nurse.

\section{Measures}

Pain cognition was measured by means of the Pain Cognition List-Experimental version. ${ }^{42,44}$ The original Pain Cognition List-Experimental version consists of 77items describing the factors Pain Impact, Catastrophizing, Outcome Efficacy, Acquiescence, and Reliance on Health Care. The Pain Cognition List-Experimental version consists of 5-point Likert self-report items with answer categories: total agreement, relative agreement, neither agreement nor disagreement, relative disagreement, and total disagreement. The initial version has been tested by Vlaeyen and associates ${ }^{44}$ in a study among 188 chronic benign patients. ${ }^{44}$ Preliminary analyses led to elimination of 27 items that were either too skewed, correlated on more than one factor, or did not significantly correlate with one of the subscales. After testing, $\mathbf{5 0}$ items finally remained consisting of five factors. The first factor, Pain Impact, describes the impact the pain has on the patients' functioning, by means of items such as: "I feel less and less capable of doing something". The second factor, Catastrophizing, describes the aversive aspect of the pain experience, by means of items such as "The word pain frightens me." Outcome Efficacy, the third factor, represents the patient's expectation that a given behavior will lead to certain outcomes. An example of this factor is: "relaxation exercises decrease the pain". The fourth factor, Acquiescence, describes a certain passivity and the expectation that responding in a different way is futile and unnecessary, by means of e.g., "I think the best thing to do is to wait and see what happens." The last factor, Reliance on healthcare, shows the expectation that change is possible, but can only be brought about by others. An example of the last factor is "Somebody must be able to help me." Results showed that the five factors accounted for $39.9 \%$ of the total variance, internal consistency ranged from $0.61-0.88$, and test-retest reliability ranged from $0.42-0.92$.

In a subsequent study, the Pain Cognition List was further validated in an extended population of more than 900 patients. ${ }^{48,49} \mathrm{~A}$ revised factor structure 
provided support for four factors with 39 items accounting for $35.4 \%$ of the variance. The internal consistency ranged from $0.64-0.88$. The intercorrelations between the factors ranged from $0.01-0.45$, and the test-retest reliability ranged from 0.51-0.73. The former factors Catastrophizing, and Reliance on Health corresponded closely to the original factors. The factor Pain Impact was partly modified. The new factor that emerged was labeled Optimism, describing the positive attitude of the patients despite their pain complaints. The factor Outcome Efficacy emerged in a somewhat different way, and was newly labeled Internal Control. Internal Control describes the extent to which pain can be influenced. The original factor Acquiescence was not confirmed in the revised version. Finally, the factor Pain Disability emerged, describing the impact the pain has on the patients' functioning. It is concluded that the original reported factor structure could only be partly replicated.

Sociodemographic data included e.g., gender, age, education, and employment. Medical variables consisted of variables such as diagnosis, time since diagnosis, tumor site, disease stage, and treatment.

Pain experience was measured by means of the Dutch Language Version of the McGill Pain Questionnaire (MPQ-DLV). This measure consists of a self-report instrument with sensory, affective and evaluative categories describing the multidimensional components of pain. Reliability, and validity of the questionnaire have been established. ${ }^{50-53}$

Pain intensity was assessed using an 11-point Numerical Rating Scale. Patients were asked to indicate Present Pain Intensity, Average Pain Intensity in the past 24 hours, and Worst Pain Intensity from 0 (no pain) to 10 (pain as bad as you can imagine). The Numeric Rating Scale has been demonstrated to be a reliable and valid measure of pain intensity. ${ }^{54}$

Pain treatment. Pharmacological pain treatment was evaluated by assessing the pharmacological pain treatment received. Non-pharmacological pain treatment was measured by assessing the use of e.g., massage, heat, relaxation to relieve pain.

Quality of life, including functioning scales such as: physical functioning, cognitive functioning, role functioning, emotional functioning, and social functioning was evaluated by the European Organization for Research and Treatment of Cancer Core Quality of Life Questionnaire (EORTC QLQ-C30+3), which has demonstrated acceptable levels of reliability and validity. ${ }^{55}$

\section{Statistical analysis}

Analyses were carried out using the statistical package SPSS for Windows version 7.5. Statistical significance was at $\mathrm{p}<.05$ level, two-tailed. In the analyses, all reverse-scored items on the pain Cognition List were recoded. Means, standard deviations, and frequencies were estimated to describe the patient population. Comparisons were made using Student's t-tests. Internal consistency reliability of the Pain Cognition List-Experimental version was assessed by Cronbach's alpha coefficients.

Construct validity, the degree to which an instrument measures the construct under investigation, was assessed by: (1) factor analysis; (2) correlations between subscale scores; (3) correlations between the Pain Cognition List and sociodemographic variables, e.g. age, and gender, (4) correlations between the Pain 
Cognition List and variables regarding pain duration, pain intensity, quality of life, and use of non-pharmacological pain treatment (concurrent validity); and (5) the degree to which a measure can distinguish between individuals (discriminant validity).

The internal structure of the Pain Cognition List-Experimental version was assessed through factor analyses. First, confirmatory factor analysis was conducted. In a confirmatory factor analysis, the relations between variables are specified a priori and based on previous research. The aim is to confirm the fit between the previous found model and the actual structural model in the current data set. ${ }^{56}$ In case of an unsatisfying fit a new exploratory factor analysis with oblique (Oblimin) rotation has been carried out. Multitrait Analysis Program (MAP), a technique based on the examination of item-scale correlations, was used to examine the internal structure. ${ }^{57}$ Kaiser Meyer Olkin measure of sampling adequacy was performed to determine whether the data were appropriate for an exploratory factor analysis. Items that were not quasi-normal distributed because of skewness $>1$ or $<-1$ were deleted. Oblique rotation rather than orthogonal rotation was selected because the objective was to obtain factors that were correlated and theoretically meaningful. Factors were identified until the eigen-value fell below 1.0. Items were included in the factor if they loaded $>.40$ on either, but not both, factors. Of those items having high factor loadings on two factors, correlations between the item and the factor were calculated. When the correlation coefficients differed less than .05 , the item was excluded. When the difference was more than .05 , the item was assigned to the factor with which it correlated most highly.

To demonstrate validity, correlations among the factors and data regarding sociodemographic variables, medical variables, pain, quality of life, pain knowledge, and pain treatment were described by means of Pearson product-moment correlations.

\section{Results}

\section{Patient characteristics}

A total of 383 patients satisfied the selection criteria. Seventy patients (18\%) declined to participate in the study for the following reasons: 48 patients $(69 \%)$ found the study too burdensome, 15 patients $(21 \%)$ were not motivated, and 7 patients $(10 \%)$ were too ill. Of the 313 participating patients, $63 \%$ were female $(N=196)$. The mean age was 56 years $(s d=12)$, and almost three fourth of the patients was married (74\%). Patients' education level ranged from low $(41 \%)$, middle $(33 \%)$ to high school education $(26 \%)$. Only $12 \%$ of the patients $(\mathrm{N}=38)$ were employed.

Patients suffered from cancer of different sites (Table 1), most frequently in an advanced stage (58\%). Although various cancer treatments were provided, no anticancer treatment was provided in $22 \%$ of the patients. Pain in the abdominal region and in the lower back region was reported most frequently. The mean pain duration was 14 months ( $s d=33$, range $=1-324$ months). Patients' Present Pain Intensity was on average $3.3(s d=2.3)$, the Average Pain Intensity was $4.9(s d=2.1)$, and the Worst Pain Intensity was $7.7(s d=2.1)$. In total, $88 \%$ of 
Table 1. Characteristics of the study population

Number of

(\%)

patients

\section{Type of cancer (>100\%)}

Lip, oral cavity, and pharynx

Digestive organs and peritoneum

Respiratory and intrathoracic organs

Breast

one, connective tissue, and skin

Genitourinary organs

Other (e.g., non Hodgkin's lymphoma)

\section{Extent of disease}

Local

Regional

Metastatic

Unknown

Not applicable

\section{Cancer treatment ( $>100 \%)$}

None

Surgery

Chemotherapy

Radiotherapy

Hormonal therapy

Other and unknown

\section{Pain location (> 100\%)}

Head, face, mouth

Breast, thoracic region

Upper shoulder and upper limbs

Abdominal region

Lower back, lumbar spine, sacrum, coccyx

122

Lower limbs

Anal, perianal, and genital region

Everywhere

\section{Source of cancer pain ( $>100 \%$ )}

Direct tumor involvement

Cancer therapy

Associated with cancer disease

Unknown 
the patients were prescribed analgesics: $72 \%$ received non-opioids (WHO step I), $38 \%$ received weak opioids (WHO step II), and $36 \%$ received strong opioids (WHO step III/IV). In the hospital, patients were asked to fill in the Pain Cognition ListExperimental version. Of the 313 participating patients, 21 patients did not fill in the Pain Cognition List: 6 patients died before discharge, 6 patients did not return the questionnaire by mail, 8 patients considered filling in the questionnaire too burdensome, and 1 patient considered the questionnaire too long. In addition to these patients, 4 patients were excluded from further analyses because of missing values that consisted of 8 or more of the 77 items. Patients with less than 8 missing values were included in the analyses by recoding the missing item to "neither agreement nor disagreement" (score 3). Altogether, the analyses were performed on 288 patients (92\%).

\section{Replication of the confirmatory factor analysis}

A replication study of the Pain Cognition List-Experimental version was carried out to evaluate the five-factor structure. The original structure, as tested by Vlaeyen and associates, ${ }^{44}$ consisted of the factors Pain Impact (17 items), Catastrophizing (17 items), Outcome Efficacy (7 items), Acquiescence (4 items), and Reliance on Health Care (5 items). Results of exploratory principal component factor analysis with Oblique rotation showed that the five-factor structure could not be replicated. An examination of the eigen-values, however, suggested a fourfactor instead of a five-factor structure. When forcing the initial five-factor structure, Kaiser's measure of sampling was unsatisfactorily high. Of the 50 items, 7 were not normally distributed, and 5 items loaded on more than one factor while the correlation coefficient difference was less than 0.05 . The factors "Outcome Efficacy," "Acquiescence," and "Reliance on health care" showed marginal levels of reliability: $0.59,0.55$, and 0.43 , respectively. The inter-factor correlations were high ( $r=-0.08$ to 0.53 ), meaning some overlap between the factors. Table 2

Table 2. Summary statistics of the confirmatory factor analysis for the subscales of the Pain Cognition List-Cancer patients

\begin{tabular}{|c|c|c|c|c|c|c|c|c|}
\hline \multirow[t]{2}{*}{ Factor } & \multirow{2}{*}{$\begin{array}{l}\text { Number } \\
\text { of items }\end{array}$} & \multirow{2}{*}{$\begin{array}{l}\text { Scale } \\
\text { mean }\end{array}$} & \multirow[t]{2}{*}{ sd } & \multirow{2}{*}{$\begin{array}{r}\text { Cronbach's } \\
\text { alpha }\end{array}$} & \multicolumn{4}{|c|}{ Scale intercorrelations } \\
\hline & & & & & 1 & 2 & 3 & 4 \\
\hline \multicolumn{9}{|c|}{ Exploratory factor analysis } \\
\hline Pain Impact (I) & 17 & 46.3 & 13.3 & 0.86 & & & & \\
\hline Catastrophizing (2) & 17 & 49.5 & 13.3 & 0.83 & $0.53 * *$ & & & \\
\hline Outcome Efficacy (3) & 7 & 21.6 & 5.3 & 0.59 & $-0.29 * *$ & 0.02 & & \\
\hline Acquiescence (4) & 5 & 13.7 & 3.8 & 0.55 & $0.16 * *$ & $0.35 * *$ & -0.08 & \\
\hline Reliance on Health Care (5) & 4 & 19.3 & 3.4 & 0.43 & $-0.38 * *$ & $-0.15 *$ & $0.19 *$ & $-0.14^{*}$ \\
\hline $\begin{array}{l}\because p<0.01 \\
\cdots p<0.001\end{array}$ & & & & & & & & \\
\hline
\end{tabular}


presents the mean and standard deviations for the Pain Cognition List subscales and total score.

It is concluded that the five-factor structure was not confirmed in this population of cancer pain patients. The obvious difference in the factor structure needs to be further explored. Although the differences may, in part, be due to

\section{Table 3. Factor structure of the Pain Cognition List for cancer patients}

\begin{tabular}{llrrrr}
\hline Item & \multicolumn{3}{c}{ Factor Factor Factor Factor } \\
& & 1 & 2 & 3 & 4 \\
\hline
\end{tabular}

\section{Factor 1. Pain Impact (22 items)}

21

\section{Factor 2. Social Comparison (4 items)}

25 I like to talk with people who have the same problems as me, because I can learn a lot from them

I find it important to talk a lot with my partner/family/ friends about my pain

\section{Factor 3. Acquiescence (4 items)}

I think the best thing to do is to wait and see what happens

\section{Factor 4. Active Coping (4 items)}

52 I think tension increases the pain 
differences in patient population, questions are also raised about the psychometric qualities of the Pain Cognition List.

\section{Results of the exploratory factor analysis}

In subsequent analyses, the factor structure of the original 77 item Pain Cognition List was analyzed to find the best fit. Based on the examination for skewness $(>1$ or $<-1), 15$ items were deleted from further analyses. Because of linear dependency, meaning that a variable can be perfectly explained by another variable, 7 items were deleted in sequence of their multiple R. To determine whether the data were appropriate for an explanatory factor analysis, Kaiser Meyer Olkin was calculated as 0.82 , which can be valued as "meritorious." 58 Based on the scree plot, an examination of the eigen-values suggested a modified model with four factors. Thirty-four items finally remained and constituted the Pain Cognition List for Cancer patients. The four factors accounted for a total of $39 \%$ of the variance. Results of the factor analysis are given in Table 3. Factor 1, Pain Impact, accounted for $20 \%$ of the variance. This factor, primarily concerning the impact the pain has on the patients' functioning, consisted of 22 items. High scores on this factor indicate that patients think that their behavior is not effective in dealing with their pain. The 4 items of factor 2, Social Comparison, accounted for $8 \%$ of the variance. Patients with high scores on this factor relativize their situation by comparing their situation with others. The third factor, Acquiescence, includes 4 items resembling a certain degree of passivity and accounted for $6 \%$ of the variance. This factor describes the locus of control that people experience over their pain. Patients with high scores on this factor have a certain degree of passivity and the expectation that responding in a different way will not help to de-

Table 4. Summary statistics of the exploratory factor analysis for the subscales of the Pain Cognition List-Cancer patients

\begin{tabular}{|c|c|c|c|c|c|c|c|}
\hline \multirow[t]{2}{*}{ Factor } & \multirow{2}{*}{$\begin{array}{l}\text { Number } \\
\text { of items }\end{array}$} & \multirow{2}{*}{$\begin{array}{l}\text { Scale } \\
\text { mean }\end{array}$} & \multirow[t]{2}{*}{ Sd } & \multirow{2}{*}{$\begin{array}{r}\text { Cronbach's } \\
\text { alpha }\end{array}$} & \multicolumn{3}{|c|}{ Scale intercorrelations } \\
\hline & & & & & 1 & 2 & 3 \\
\hline \multicolumn{8}{|c|}{ Confirmatory factor analyses } \\
\hline Pain Impact (I) & 22 & 61.4 & 17.3 & 0.89 & & & \\
\hline Social Comparison (2) & 4 & 12.4 & 3.7 & 0.51 & 0.08 & & \\
\hline Acquiescence (3) & 4 & 12.3 & 4.0 & 0.59 & 0.07 & -0.03 & \\
\hline Active Coping (4) & 4 & 10.9 & 3.6 & 0.53 & -0.01 & -0.05 & -0.03 \\
\hline
\end{tabular}

crease their pain. The last factor, Active Coping, includes 4 items representing the expectancy that a given behavior will lead to a decrease in pain intensity; this factor accounted for $5 \%$ of the variance.

Compared to the original factor structure reported by Vlaeyen and associates, ${ }^{44}$ and Nooyen-Haazen and associates, ${ }^{45}$ in the present study a different structure was found. The main finding was that the factor Catastrophizing, focusing on the aversive aspect of the pain experiences, did not emerge as a factor. Items like 
"I often think back to the days when I had no pain," "I consider myself as an unlucky person," "I think that fate hit me," and "I consider myself to be a hopeless case" did not load on any factor. When comparing the results of our study with those of Vlaeyen and associates, ${ }^{44}$ only 6 of the 17 items, originally representing the factor "Catastrophizing," were loading on one of the scales: 5 items loaded on the factor Pain Impact, and 1 item on the Social Comparison. When comparing the results of the present study with those of Nooyen-Haazen and associates, $^{45}$ only 6 of the 16 items emerged. Items loading on the factors Social Comparison, Acquiescence, and Active Coping were only partly found in the original factor structure.

Table 4 presents summary statistics for the four factors and the total scale structure. The Cronbach's alpha coefficient for Pain Impact was high $(r=0.89)$, while the other three scales demonstrated low reliability estimates: $0.51,0.59$, and 0.53 , respectively. The finding of low internal consistency of the factors Social Comparison, Acquiescence, and Active Coping might be partly due to the small number of items representing the factors. The means of scale intercorrelations indicate that each scale provides unique information and is factorially distinct. The intercorrelations ranged from -0.05 to 0.08 , suggesting that each scale is tapping a separate factor.

\section{Relationships of Pain Cognition List for cancer patients to sociodemographic variables}

Analyses were conducted to determine how patients' pain cognition was related to sociodemographic variables, such as gender, age, and level of education. Results showed no significant differences across gender for all factors (Table 5). Pearson product-moment correlations showed that older patients were more passive (Acquiescence) in the way they respond to the pain than younger patients $(r=0.33, p<0.01)$. Age had a slight but significant correlation with Pain Impact $(r=0.14, p<0.01)$ and Social Comparison $(r=-0.19, p<0.01)$, but not with Acquiescense and Active Coping. Regarding education, the results showed that higher educated patients had higher scores on Acquiescence $(r=-0.31, p<$

Table 5. Relationship between the Pain Cognition List- Cancer patients and gender

\begin{tabular}{lccc}
\hline Factor & $\begin{array}{c}\text { Male } \\
\text { Mean (sd) }\end{array}$ & Female & $\begin{array}{r}\text { P- } \\
\text { value }\end{array}$ \\
& Mean (sd) & \\
\hline Pain Impact (1) & $60.8(18.8)$ & $61.8(16.5)$ & $\mathrm{ns}^{\mathrm{a}}$ \\
Social Comparison (2) & $12.2(3.7)$ & $12.5(3.7)$ & $\mathrm{ns}$ \\
Acquiescence (3) & $12.5(4.0)$ & $12.1(3.9)$ & $\mathrm{ns}$ \\
Active Coping (4) & $11.1(3.7)$ & $10.8(3.7)$ & $\mathrm{ns}$
\end{tabular}

a: not significant 
Table 6. Correlations between the Pain Cognition List- Cancer patients and pain variables, pain treatment, and quality of life

\begin{tabular}{|c|c|c|c|c|}
\hline . & $\begin{array}{r}\text { Pain } \\
\text { Impact }\end{array}$ & $\begin{array}{c}\text { Social } \\
\text { Comparison }\end{array}$ & Acquiescence & $\begin{array}{l}\text { Active } \\
\text { Coping }\end{array}$ \\
\hline Pain duration & -0.02 & -0.04 & $0.16 * *$ & 0.04 \\
\hline Present Pain Intensity & $0.30 *$ & 0.02 & $0.15 * *$ & -0.02 \\
\hline \multicolumn{5}{|l|}{ McGill Pain Questionnaire } \\
\hline Pain Rating Index-Sensory & $0.19 * *$ & 0.08 & 0.06 & 0.02 \\
\hline Pain Rating Index-Affective & $0.48 * *$ & $0.17^{* * *}$ & 0.03 & -0.07 \\
\hline Pain Rating Index-Evaluative & $0.35 *$ & $0.18 * *$ & 0.05 & 0.00 \\
\hline \multicolumn{5}{|l|}{ Quality of Life } \\
\hline Physical functioning & $-0.44 * *$ & 0.08 & -0.13 & 0.06 \\
\hline Role functioning & $-0.42 * *$ & 0.01 & -0.12 & 0.08 \\
\hline Cognitive functioning & $-0.25 * *$ & -0.03 & 0.00 & 0.02 \\
\hline Emotional functioning & $-0.46 * *$ & $-0.23 * *$ & -0.02 & $0.16 * *$ \\
\hline Social functioning & $-0.32 * *$ & -0.05 & $0.12^{*}$ & -0.01 \\
\hline Global quality of life & $-0.54 * *$ & 0.06 & -0.08 & -0.01 \\
\hline Non-pharmacological pain treatment & -0.06 & 0.09 & $-0.29 * *$ & $-0.17 * *$ \\
\hline $\begin{array}{l}: p<0.05 \\
* p<0.01 ; \text { two-tailed }\end{array}$ & & & & \\
\hline
\end{tabular}

0.01), while Pain Impact, Social Comparison, and Active Coping were not significantly correlated with level of education.

To demonstrate concurrent validity, the subscales of the Pain Cognition List for Cancer patients need to demonstrate significant relationships to measures of the same type of construct. In this study, a variety of scales was evaluated. Arbitrarily, pain duration, pain intensity, the 3 subscales of the McGill Pain Questionnaire, the 7 functioning scales of the Quality of Life scale, and the use of nonpharmacological pain treatment were chosen as relevant variables to validate the scale construct. Results are given in Table 6 . Only those correlations with $r>0.25$ $(p<0.01)$ are described in the text, as these are considered of practical clinical significance. Higher pain intensity scores were significantly related to Pain Impact $(r=0.30)$. Both the affective and evaluative categories of the McGill Pain Questionnaire were significantly correlated to Pain Impact $(r=0.48$, and $r=0.35$, respectively). Regarding quality of life, all functioning subscales were significantly related to Pain Impact ( $r=-0.25$ to -0.54 ), indicating that the higher the value on the functioning scales and global quality of life, the higher the pain impact. Finally, the number of non-pharmacological pain treatments was significantly correlated to Acquiescence, meaning that the higher the amount of nonpharmacological pain treatments used by patients, the lower the patients' scores on Acquiescence. From this, it can be concluded that scores on each of the cognitive factors, except for Active Coping, were significantly correlated with pain 
intensity, the McGill Pain scales, the quality of life functioning scales, and the use of non-pharmacological pain treatment.

Discriminant validity was assessed by means of differentiating the responses of patients for whom district nursing was necessary in the home setting and patients for whom no district nursing was needed. Results showed that patients with district nursing were more often female $(p<.05)$, older $(p<.001)$, differed in marital status $(p<.05)$, and in having a profession $(p<.05)$, differed with regard to the location of the primary tumor $(p<.05)$, and treatment $(p<.001)$. Results regarding the cognitions subscale showed that patients with district nursing differed from patients without district nursing with regard to Pain Impact ( $p$ $<.001)$, and Acquiescence $(p<.05)$, meaning that patients who needed district

\section{Table 7. Relationship between Pain Cognition List for Cancer patients and district nursing care}

\begin{tabular}{lcrr}
\hline Factor & $\begin{array}{c}\text { With } \\
\text { district nursing } \\
\text { Mean (sd) }\end{array}$ & $\begin{array}{c}\text { Without } \\
\text { district nursing } \\
\text { Mean (sd) }\end{array}$ & p-value \\
\hline & & & \\
Pain Impact (1) & $66.4(19.1)$ & $59.0(15.9)$ & $<.001$ \\
Social Comparison (2) & $12.1(3.5)$ & $12.5(3.8)$ & $\mathrm{ns}^{\mathbf{2}}$ \\
Acquiescence (3) & $12.9(4.2)$ & $11.9(3.8)$ & $<.05$ \\
Active Coping (4) & $10.7(3.8)$ & $11.0(3.6)$ & $\mathrm{ns}$ \\
& & & \\
\hline
\end{tabular}

: not significant

nursing in the home setting showed more behavior that was not effective in dealing with the pain, showed a higher degree of passivity, and scored higher on the total scale compared to patients for whom district nursing was not deemed necessary (Table 7).

\section{Discussion and conclusion}

The impact of cognitions on the pain experience in cancer patients is hardly studied. The Pain Cognition List-Experimental version, measuring patients' selfstatements about the pain and the extent to which patients are effective in dealing with the pain, was developed in the Dutch language, but tested only in Dutch non-cancer pain patients. In the present study, the factor structure, reliability, and validity of the Pain Cognition List-Experimental version was studied for the first time in cancer patients with chronic pain.

Based on previous research, 44 a confirmatory factor analysis was conducted to compare the fit between the previous model studied in non-cancer pain patients and the actual structure among variables in a cancer pain population. The results showed an unsatisfying fit. An exploratory factor analysis showed that the four factors Pain Impact, Social Comparison, Acquiescence, and Active Coping, explained $39 \%$ of the variance. The main finding was that Catastrophizing, focusing on the aversive aspects of the pain experiences, did not emerge as a factor. This 
is striking because catastrophizing thinking styles are found to be most strongly associated with increased pain in non-cancer pain patients. Several reasons might explain this result. First, an explanation for finding differences in factor structure might be due to methodological weaknesses. Although the Pain Impact subscale showed to be powerful, low alpha coefficients were found for the factors Social Comparison, Acquiescence, and Active Coping. The low correlations indicate a need for further revision of the Pain Cognition Questionnaire for cancer patients. The Pain Cognition List is further limited by the fact that it originally consisted of 77 items of which only 34 items remained in the final analysis. Since only 34 items in this dataset loaded on four factors, 43 items were removed.

A second explanation might be that cancer patients present different pain cognitions compared to non-cancer pain patients. It is reasonable to assume that cancer pain patients place greater emphasis on the physical aspects of pain than non-cancer pain patients. Consequently, cancer patients might focus more on the nociceptive components of the pain and less on the aversive aspects of the pain experience. Cancer patients know the cause of their pain and, thus, they can deal with their pain complaints whereas non-cancer patients in pain frequently cannot identify the source of pain. As a result, the degree of catastrophizing might differ between these two groups of patients. That cancer and non-cancer pain patients react differently was suggested by Turk and associates, ${ }^{6}$ finding that cancer patients appeared to think and worry more about pain, avoid activities, and generally feel more hopeless than patients with non-cancer related pain. However, until well-established, convenient, valid, and reliable measures are available to assess patients' pain cognitions, the difference might also be explained by other reasons. From this, it can be concluded that pain cognitions in cancer pain patients cannot be easily compared with those in non-cancer pain patients.

Further research is needed to investigate whether the factor structure as found in the present study can be confirmed in another cancer pain population. Second, we need to evaluate whether differences between cancer and non-cancer pain patients can be replicated. Furthermore, it should be investigated whether pain cognitions are stable over time, and whether cognitive-behavioral interventions can alter patients' pain cognitions over time. It is also necessary to establish whether certain patients are more able to change their pain cognitions than others. Knowledge on the role of pain cognitions related to outcome of pain treatment may also further enhance treatment effectiveness. Given the fact that many pain protocols are used in pain treatment, certain patient groups may not receive the most appropriate treatment. The present study, however, was not conducted to examine the value of pain cognitions in predicting response to regular pain treatment. Despite the fact that the relative value of the factors Social Comparison, Acquiescence, and Active Coping was not fully understood, it seems advantageous to include a measure to assess pain cognition in cancer pain patients. It appears to be useful to assess patient's pain cognition on admission and then tailor a treatment program to fit the patient's individual needs. Patients should then be provided with different strategies to relieve pain depending on their beliefs and perceptions of pain. To provide evidence for validity, the correlations of a measure with related measures need to be further examined. Furthermore, the methodology used in the present study to investigate the association between pain cognitions and pain intensity and other variables was correlational and thus 
causal relations could not be derived. Finally, the test-retest reliability of the Pain Cognition List should be determined in future research.

Caregivers most suited for assessing and changing patients' pain cognitions are nurses, who should be alerted to the importance of assessing patients' cognitions and beliefs. These assessments should provide the basis for tailored interventions, Because nurses play an important role in changing patients' pain cognitions, they should be educated how to assess patients' pain cognitions and be instructed how to analyze interacting variables that increase patients' pain.

It is concluded that patients' cognitions and beliefs about pain are poorly studied. This is the first study to validate the Pain Cognition List for cancer patients, and the results suggest that this measure has potential for understanding variance in cancer pain. Initial support is provided for the validity of the Pain Cognition List for Cancer patients. However, as noted before, further developmental work is needed on this measure. The original factor structure of the experimental version of the Pain Cognition List, as found in non-cancer patients, was not confirmed in this cancer pain population.

\section{Acknowledgments}

This study was supported by a grant from the Dutch Cancer Society (grant no NKI 92-469). The authors thank all patients for their cooperation. We extend special thanks to the nursing departments of the Netherlands Cancer Institute/Antoni van Leeuwenhoek Hospital for their participation in the study. The authors thank Anneke van Buuren, Karin van der Heijden, Gerleen Leenhouts, Simone Loonstra, and Linda Zandbelt for recruiting and interviewing the patients, and Dr. J.W.S. Vlaeyen for his valuable contribution. 


\section{References}

1. Ahles TA, Blanchard EB, Ruckdeschel JC. Multidimensional nature of cancer pain. Pain, 1983;17:277-288.

2. Fishman $\mathbf{B}$. The cognitive behavioral perspective on pain management in terminal illness. Hospital Journal, 1992;8:73-88.

3. Arathuzik MD. The appraisal of pain and coping in cancer patients. Western Journal of Nursing Research, 1991;13:714-731.

4. Arathuzik D. Effects of cognitive-behavioral strategies on pain in cancer patients. Cancer Nursing, 1994;17:207-214.

5. Zimmerman L, Turner Story K, Gaston-Johansson F, Rowles JR. Psychological variables in cancer pain. Cancer Nursing, 1994;19:44-53.

6. Turk DC, Sist TC, Okifuja A, Miner MF, Florio G, Harrison P, Massey J, Lema ML, Zevon MA. Adaptation to metastatic cancer pain, regionallocal cancer pain and non-cancer pain: role of psychological and behavioral factors. Pain, 1998;74:247-256.

7. Blackwell BP. Ascribed meaning: a critical factor in coping and pain attenuation in patients with cancer-related pain. Journal of Palliative Care, 1991;1991:5-14.

8. Boston K, Pearce SA, Richardson PH. The Pain Cognitions Questionnaire. Journal of Psychosomatic Research, 1990;34:103-109.

9. Brown GK, Nicassio PM. Development of a questionnaire for the assessment of active and passive coping strategies in chronic pain patients. Pain, 1987;31:53-64.

10. Edwards LC, Pearce SA, Turner-Stokes L, Jones A. The Pain Beliefs Questionnaire: an investigation of beliefs in the causes and consequences of pain. Pain, 1992;51:267-272.

11. Flor $\mathrm{H}$, Behle DJ, Birbaumer N. Assessment of pain-related cognitions in chronic pain patients. Behaviour Research on Therapy, 1993;31:63-73.

12. Härkäpää, K., Järvikoski A, Mellin G, Hurri H, Luoma J. Health locus of control beliefs and psychological distress as predictors for treatment outcome in low-back pain patients: results of a 3-month follow-up of a controlled intervention study. Pain, 1991;46:35-41.

13. Jensen MP, Turner JA, Romano JM, Karoly P. Review article, coping with chronic pain: a critical review of the literature. Pain, 1991;47:249-283.

14. Philips HC. The effects of behavioural treatment on chronic pain. Behaviour Research on Therapy, 1987; 25:365-377.

15. Ter Kuile MM, Spinhoven P, Linssen AC, van Houwelingen HC. Cognitive coping and appraisal processes in the treatment of chronic headaches. Pain, 1996;64:257-264.

16. Williams DA, Keefe FJ. Pain beliefs and the use of cognitive-behavioral coping strategies. Pain, 1991:46:185-190.

17. Turk DC, Rudy TE. Cognitive factors and persistent pain: A glimpse into Pandora's box. Cognitive Therapy and Research, 1992;16:99-122.

18. Chaves JF, Brown JM. Spontaneous cognitive strategies for the control of clinical pain and stress. Journal of Behaviour Medicine, 1987;10:263-276.

19. Crisson JE, Keefe FJ. The relationship of locus of control to pain coping strategies and psychological distress in chronic pain patients. Pain, 1988;35:147-154.

20. Geisser ME, Robinson ME, Henson CD. The Coping Strategies Questionnaire and chronic pain adjustment: a conceptual and empirical reanalysis. Clinical Journal of Pain, 1994;10:98-106.

21. Jensen MP, Turner JA, Romano JM, Lawler BK. Relationship of pain-specific beliefs to chronic pain adjustment. Pain, 1994;57:301-309.

22. Main C, Waddell G. A comparison of cognitive measures in low back pain: statistical structure and clinical validity at initial assessment. Pain, 1991:46:287-298.

23. Gil KM, Abrams MR, Phillips G, Keefe FJ. Sickle cell disease pain: relation of coping strategies to adjustment. Journal of Consulting and Clinical Psychology, 1989;57:725-731.

24. Rosenstiel AK, Keefe FJ. The use of coping strategies in chronic low back pain patients: relationship to patient characteristics and current adjustment. Pain, 1983;17:33-44.

25. Bonica JJ. Treatment of cancer pain: current status and future needs. In: Fields HL, Dubner F, Cervero F, eds. Advances in pain research and therapy. New York, NY, Raven Press, Ltd., 1985: 589-616.

26. Cleeland CS, Gonin R, Hatfield AK, Edmonson JH, Blum RH, Stewart JA, Pandya KJ. Pain and its treatment in outpatients with metastatic cancer. New England Journal of Medicine, 1994;330:592-596.

27. Ward S, Gatwood J. Concerns about reporting pain and using analgesics. A comparison of persons with and without cancer. Cancer Nursing, 1994;17:200-206. 
28. Turk DC, Fernandez E. On the putative uniqueness of cancer pain: do psychological principles apply? Behaviour Research on Therapy, 1990;28:1-13.

29. Lefebvre MF. Cognitive distortion and cognitive errors in depressed psychiatric and low back pain patients. Journal of Consulting and Clinical Psychology, 1981;49:517-25.

30. Smith TW, JL OK, Christensen AJ. Cognitive distortion and depression in chronic pain: association-with diagnosed disorders. Journal of Consulting and Clinical Psychology, 1994;62:195-198.

31. Philips HC. Thoughts provoked by pain. Behaviour Research on Therapy, 1989;27:469-473.

32. Jensen MP, Karoly P, Huger R. The development and preliminary validation of an instrument to assess patients' attitudes toward pain. Journal of Psychosomatic Research, 1987;31:393-400.

33. Shutty MS, Jr., DeGood DE, Tuttle DH. Chronic pain patients' beliefs about their pain and treatment outcomes. Archives of Physical Medicine and Rehabilitation, 1990;71:128-32.

34. Strong J, Ashton R, Chant D. The measurement of attitudes towards and beliefs about pain. Pain, 1992;48:227-36.

35. Flor H, Turk DC. Chronic back pain and rheumatoid arthritis: predicting pain and disability from cognitive variables. Journal of Behavioral Medicine, 1988;11:251-65.

36. Williams DA, Thorn BE. An empirical assessment of pain beliefs. Pain, 1989;36:351-8.

37. Herda CA, Siegeris K, Basler HD. The Pain Beliefs and Perceptions Inventory: further evidence for a 4-factor structure. Pain, 1994;57:85-90.

38. Schwartz DP, DeGood DE, Shutty MS. Direct assessment of beliefs and attitudes of chronic pain patients. Archives of Physical Medicine and Rehabilitation, 1985;66:806-809.

39. Sullivan MJL, Bischop SR, Pivik J. The pain catastrophizing scale: development and validation. Psychological Assessment, 1995:524-532.

40. Osman A, Barrios FX, Kopper BA, Hauptmann W, Jones J, E ON. Factor structure, reliability, and validity of the Pain Catastrophizing Scale. Journal of Behavioral Medicine, 1997;20:589-605.

41. Gil KM, Williams DA, Keefe FJ, Beckham JA. The relationship of negative thoughts to pain and psychological distress. Behavior Therapy, 1990;21:349-362.

42. Vlaeyen JWS. The development of a pain cognition questionnaire. Chronic low back pain: assessment and treatment from a behavioral rehabilitation perspective. Amsterdam, Swets and Zeitlinger B.V., 1991: 109-120.

43. DeGood DE, Shutty MS. Assessment of pain beliefs, coping, and self-efficacy. In: Turk DC, Melzack, R., eds. Handbook of pain assessment. New York, The Guilford Press, 1992.

44. Vlaeyen JWS, Geurts SM, Kole-Snijders AMJ, Schuerman JA, Groenman NH, Van Eek H. What do chronic pain patients think of their pain? Towards a cognition questionnaire. British Journal of Clinical Psychology, 1990;29:383-394.

45. Nooyen-Haazen IWC, Vlaeyen JWS, Kole-Snijders AMJ, van Breukelen G. Pijn Cognitie Lijst (PCL) nieuwe versie. (In Dutch) Nederlands Tijdschrift voor Pijn en Pijnbestrijding, 1997;17:45-48.

46. Vlaeyen JWS, Geurts SM, Van Eek H, Snijders AMJ, Schuerman JA, Groenman NH. Pijn Cognitie Lijst Experimentele Versie, Handleiding. Lisse, Swets \& Zeitlinger B.V., 1989.

47. De Wit R, Van Dam F, Zandbelt L, Van Buuren A, Van der Heijden K, Leenhouts G, Loonstra S. A Pain Education Program for chronic cancer patients: follow-up results from a randomized controlled trial. Pain, 1997;73:55-69.

48. Nooyen-Haazen IWC, Vlaeyen JWS, Kole-Snijders AMJ, van Breukelen G. Pijn Cognitie Lijst (PCL) nieuwe versie (In Dutch). Nederlands Tijdschrift voor Pijn en Pijnbestrijding, 1997;17:45-48. After extensive analyses, some corrections were made. Changes were based on personal communication with the authors of the original article.

49. Vlaeyen JW, van Breukelen G, Nooyen-Haazen IWC, van den Berg S, Kole-Snijders AMJ. Further validation of the Pain Cognition List patients with chronic musculoskeletal pain (Submitted).

50. Van der Kloot WA, Vertommen H. Een standaard Nederlandstalige versie van de McGill Pain Questionnaire: Achtergronden en handleiding van de MPQ-DLV. Lisse, Swets and Zeitlinger, 1990.

51. Van der Kloot WA, Oostendorp RA, Van der Meij J, van den Heuvel J. [The Dutch version of the McGill pain questionnaire: a reliable pain questionnaire]. [In Dutch]. Nederlands Tijdschrift voor Geneeskunde, 1995;139:669-673.

52. Vanderiet K, Adriaensen H, Carton H, Vertommen H. The McGill Pain Questionnaire constructed for the Dutch language (MPQ-DV). Preliminary data concerning reliability and validity. Pain, 1987;30:395-408.

53. Verkes R, Van der Kloot WA, Van der Meij J. The perceived structure of 176 pain descriptive words. Pain, 1989;38:219-229.

54. Jensen MP, Karoly P, Braver S. The measurement of clinical pain intensity: A comparison of six methods. Pain, 1986;27:117-126. 
55. Aaronson NK, Ahmedzai S, Bergman B, Bullinger M, Cull A, Duez NJ, Filiberti A, Flechtner H, Fleishman SB, de Haes JC. The European organization for research and treatment of cancer QLQ-C30: a quality-of-life instrument for use in international clinical trials in oncology. Journal of the National Cancer Institute, 1993;85:365-376.

56. Long JS. Confirmatory Factor Analysis - A preface to LISREL. Beverly Hills, CA, SAGE Publicatisns, 1984.

57. Hays RD, Hayashi T, Carson S, WareJ.E. User's guide for a Multitrait Analyses Program (MAP) Santa Monica, CA, 1988.

58. Kaiser HF. An index of factorial simplicity. Psychometrica, 1974;39:31-36. 
Chapter 11

Conclusions and general discussion 


\section{Introduction}

In the Netherlands, approximately one out of every three persons will develop cancer at some stage in life, ${ }^{1}$ and the majority of these patients will experience pain at some time during their disease trajectory. ${ }^{2,3}$ Pain has been identified as a complex phenomenon that is highly subjective and unique to the individual patient experiencing it. 4,5 Poorly controlled pain leads not only to deterioration of physical functioning, emotional distress, and overall quality of life, but also influences sleep, fatigue, appetite, and other patient outcomes. Besides, severe pain can lead to an increase in the number of hospital admissions or, on the other hand, can lead to withdrawing from treatment. ${ }^{6}$

In the literature, approximately $50-75 \%$ of pain patients are reported to receive inadequate pain treatment. ${ }^{7-28} \mathrm{~A}$ number of barriers have been recognized for inadequate pain, including obstacles related to healthcare professionals, the healthcare system, and patients. ${ }^{29-32}$ Much of the research on pain and cancer has focused on the knowledge and expertise of healthcare providers, while less attention has been paid to the role of the patients themselves in managing their own pain. Barriers related to patients concern attitudes toward opioid addiction, dependency, side-effects, tolerance, the use of pain medication around-the-clock, the reluctance to report pain, and non-adherence with the pain treatment.

In this thesis, the development and effects of the Pain Education Program in hospitalized cancer patients with chronic pain is investigated in a randomized controlled clinical trial. The Pain Education Program, offered by specially trained nurses, was tailored to the needs of the individual patient and was set up to teach patients to cope better with their pain in the home situation.

In this chapter, the main conclusions are described. The discussion, which aims to integrate methodological and theoretical aspects from the different chapters of this thesis, is organized along the topics described in the overview of the Pain Education Program (Chapter 1). These topics are related to: design, patient characteristics, Pain Education Program, (district) nurses, and the measures used to evaluate the effectiveness of the intervention. Implications for clinical practice and research, and an epilogue conclude this chapter.

\section{Main conclusions}

The many factors influencing the practice of pain treatment can be organized by means of Donabedian's structure-process-outcome framework, ${ }^{33}$ describing structural resources, process components, and outcome measures relevant for adequate pain treatment. Results showed that, whether the quality of pain treatment was evaluated by means of pain relief, ${ }^{34}$ patient satisfaction, ${ }^{35-37}$ or with pain management indexes, $8,25,27$ the level of pain treatment was found to be inadequate in $31-60 \%$ of the patients. Except for the limited availability of pain education and refresher courses for healthcare providers, the structural resources were not the major cause of the suboptimal level of pain treatment. The process components, such as the prescription of analgesics, use of patient education, continuity of care, and communication between patient and healthcare providers were shown to be more responsible for the suboptimal level of pain treatment. 
Patient education and empowering patients in their own pain treatment form one of the cornerstones of effective pain management. ${ }^{38,39}$ In recent years, a few studies have shown that educational interventions play a valuable role in pain treatment. ${ }^{40-48}$ However, no studies have been conducted in which the effect of a tailored educational intervention is evaluated longitudinally. In this study, the Pain Education Program consisted of a cognitive-behavioral approach to inform and instruct patients about pain. The content of the Pain Education Program consisted of: 1) educating patients about the basic principles of pain and pain management; 2 ) instructing patients how to report their pain in a pain diary; and 3) instructing patients how to communicate about pain and how to contact the most appropriate healthcare provider. Specially trained nurses were chosen as patient educators, because patient education is a well-recognized responsibility of nursing.

The intervention proved to be feasible: $75 \%$ of the patients had read the entire pain brochure, $56 \%$ had listened to the audiocassette, and $86 \%$ of pain scores were completed in the pain diary. The Pain Education Program resulted in an increase in patients' pain knowledge. A pain-reducing effect of the Pain Education Program was found, however, this effect was primarily found in patients without district nursing.

One component of the Pain Education Program was the use of a pain diary. Patients were asked to record their Present Pain Intensity on a numeric rating scale from 0 to 10 , once every morning and once every evening. Overall, patients were conscientious with filling in the pain diary. Reporting Present Pain Intensity showed to be more accurate than Average Pain Intensity as recalling pain intensity depended, in part, on the stability of the pain over time. Of the patients, $60 \%$ reported that the pain diary itself helped them to gain more insight in their pain complaints.

Based on the assumption that the goal of pain treatment is to allow patients to function at a level they choose, and to die relatively free of pain, ${ }^{49}$ pain treatment was evaluated as inadequate when substantial pain persists, independent of the reason for this failure, e.g., insufficient pain medication, lack of patients' pain knowledge, and non-adherence with the pain medication. Measuring adequacy of pain treatment is important to provide evidence for the effectiveness of the Pain Education Program. When evaluating the effects of the Pain Education Program, several commonly used outcome measures were compared. Results showed that, when evaluating these measures simultaneously, the proportion of inadequately treated pain patients varied extremely (16-91\%). The choice of measure, rather than pain treatment itself, determined the proportion of inadequacy. Furthermore, the evaluation of the psychometric characteristics showed limitations for all outcome measures.

To address some limitations of measuring adequacy of pain treatment, the Amsterdam Pain Management Index was developed and evaluated. This index compares patients' Present Pain Intensity, Average Pain Intensity, and Worst Pain Intensity with a composite score of analgesics used, while correcting for what a patient considers as a tolerable level of pain. The Amsterdam Pain Management Index showed promising results regarding validity and responsiveness.

In patients who received the Pain Education Program, the adequacy of pain treatment was improved compared to those who did not receive the intervention. A percentage of $56-60 \%$ of the variance in change on adequacy of pain 
treatment after discharge could be predicted with variables, e.g., the Pain Education Program, the Amsterdam Pain Management Index score at pretest, patients' physical functioning, patients' social functioning, adherence to pain medication, patients' pain knowledge, and the amount of analgesics used.

Adherence with pain medication is an underestimated problem in pain management. This was confirmed in this study as results showed that $25 \%$ of the patients was not able to recall the pain medication prescription during their hospital stay, and less than half of the patients were able to report the pain medication correctly. Postdischarge, the extent of medication adherence remained low: $49 \%$ of the patients reported not to be adherent to the pain medication, and only $51 \%$ reported that the interval of analgesic dosing was around-the-clock. The Pain Education Program proved to be effective in increasing the extent to which patients comprehend the pain medication prescription, and the degree of adherence with the pain medication. However, the intervention did not have a strong impact on medication adherence.

Because continuation of the pain treatment is primarily fulfilled in the home, the role of the district nurse at home and the effectiveness of the Pain Education Program was evaluated. In general, the continuity of care proved to be poor, as a minority of district nurses was informed about patients' pain. Pain was rarely the main reason for referring patients to district nursing. Although pain was discussed with the majority of patients, district nurses provided only few painrelieving interventions, such as relaxation, cold, heat, and anxiety reduction. District nurses of patients who received the Pain Education Program provided a better estimation of patients' pain intensity than district nurses of patients in the control group. Improved satisfaction with the pain treatment was also found, but no change was found in the extent of observed pain relief.

Finally, patient-related factors that can have an important impact on cancer pain management such as patients' cognitions and beliefs toward pain and pain treatment were studied. The original factor structure of the experimental version of the Pain Cognition List, as found in non-cancer patients, was not confirmed in this cancer pain population. Nevertheless, results indicated that patients' pain cognitions play an important role in patients' pain experience and in the extend of change on adequacy of pain treatment.

\section{Methodological and theoretical reflections}

\section{Design}

When investigating the effects of an intervention, a randomized controlled trial is considered as the most appropriate design. Even in advanced cancer patients, such design is requisite. ${ }^{50}$ In this study, we conducted a prospective, randomized longitudinal study utilizing a 'pretest-posttest experimental design.' Patients with and without district nursing were distinguished. These two groups were randomly assigned to either a control group, in which regular pain treatment was provided, or an intervention group in which, in addition to the regular pain treatment, the Pain Education Program was provided. Results showed that despite randomization, patients in the intervention group with district nursing differed from patients in the control group with district nursing with respect to analgesics 
administered, physical functioning and cognitive functioning. It appeared that the randomization was not fully effective in yielding balanced intervention and control groups. This might have caused some bias.

Possible bias might also include selection bias because of eligible patients refusing to participate in the study. The number of patients who refused was rather low $(18 \%)$, but patients who declined participation were significantly older than those who participated, and females refused to participate more frequently than males. Finally, it is possible that contamination bias was caused by the attention paid to the patients' pain in the control groups. Both district nurses and patients in the control groups were interviewed four times. District nurses of control group patients might have increased their care for control group patients because they became aware of participating in a pain study. For patients, the attention paid to their pain, by means of interviewing them, might have been an intervention in itself. If that was the case, the results might be an underestimation of the effects found in this study, as the control group patients might do it better than less intensively studied control groups.

\section{Patients}

Patients with and without district nursing in the home setting were included in the study if they had pain related to cancer, cancer therapy, or illness; a pain duration of at least one month; an expected hospital stay of at least three days; and were expected to live at least three months after discharge from the hospital (as assessed by the physician). Results showed that the majority of patients included in the study were in a poor physical condition and reported low scores on the quality of life scales. Overall, $25 \%$ dropped out during the follow-up period of two months.

Although longitudinal studies are needed in the evaluation of interventions in advanced cancer patients with chronic pain, they have the inevitable drawback of larger number of dropouts. In addition to the high percentage of dropouts in the total patient population, more patients died in the intervention group with district nursing $(41 \%)$ than the control group with district nursing (20\%). This high percentage of dropouts, mainly due to patients death, might have biased the results. Consequently, results in the groups with district nursing need to be interpreted with caution.

It can be argued that there is a field of tension between, on the one hand, the importance of limiting the number of dropouts which is preferred for analyzing the results, and, on the other hand, the ethical considerations caused by the considerable burden for those patients in the last period of life. Both the high dropout rate and the bad health status of patients might have been avoided by including patients with a better health status, e.g., by means of including patients with a life expectancy of 6 months or more. However, that would have made the study less clinically relevant. Nevertheless, it is encouraging that such an intervention study can be conducted in seriously ill patients. The majority of patients were able and willing to participate in the study and were also actively involved in the intervention.

The present study was carried out at the Netherlands Cancer Institute/Antoni van Leeuwenhoek Hospital, a cancer hospital where care is specially focussed on cancer patients. Compared with non-cancer specific hospitals, not only are the 
patients different, but the nursing and physician personnel may also differ from their colleagues elsewhere. ${ }^{51}$ In the Netherlands Cancer Institute/Antoni van Leeuwenhoek Hospital, all registered nurses received a special oncology nursing training. Consequently, the results from this study may not be directly generalizable ${ }^{51}$ to cancer pain patients in other settings.

The effect of a tailored Pain Education Program depends on the extent to which patients are active users of the different parts of the intervention, and whether the patients have time to use the instructions in the home setting. Results showed that, despite the high percentage of patients complying with the use of the intervention, some patients found it difficult to comply with reading the pain brochure, listening to the audiocassette, and filling in the pain diary. This might be due, in part, to the demands of self-efficacy that are more difficult to achieve in patients who are seriously ill.

\section{Pain Education Program}

Most cognitive-behavioral interventions have been studied in chronic noncancer patients. There are very few such interventions for cancer pain patients. Educational interventions for cancer patients primarily concentrate on increasing cancer knowledge, decreasing concerns about taking pain medication, improving adherence with the pain medication prescription, and increasing the prevention of side-effects. ${ }^{40-45,47,48}$ Because patient education is one of the cornerstone of pain control, ${ }^{29}$ it is striking that only a few studies have been conducted on the longitudinal effects, and on strategies for relieving pain in hospitalized patients. In this study, the Pain Education Program was refined by tailoring the intervention to the needs of the individual patient. One disadvantage of a tailored intervention is that it is a relatively time-consuming and intensive procedure compared to an intervention that is standardized and applied to all patients in the same way. The Pain Education Program was provided in a one-to-one setting lasting between 30 and 60 minutes in the hospital, followed by two phone calls taking approximately 5-15 minutes each. It is not clear whether a tailored intervention, which takes approximately $1-1 \frac{1}{2}$ hours, is more valuable than a standardized intervention that is applied to all patients. Therefore, the time expended on each patient during the implementation of the Pain Education Program should be weighed against the time spent on other educational interventions. Other intervention studies, however, did not mention the time needed to conduct the intervention. Furthermore, the cost-effectiveness of the Pain Education Program should be studied. The extra hour spent per patient should be compared with the improved pain knowledge, decreased pain intensity, increased medication adherence, and improved quality of pain treatment.

It remains to be established what sections of the Pain Education Program are most powerful, and whether all components of the multi-method intervention are needed to relieve pain: some components may be more effective in relieving pain than others. For example, one important component of the Pain Education Program was to let patients self-monitor pain in a pain diary. Research evaluating the effects of monitoring pain twice daily in the hospital showed that monitoring pain was effective in improving nurses' pain knowledge and attitudes, and decreasing patients' pain intensity. ${ }^{52,53}$ Monitoring pain alone may be sufficiently effective to decrease patients' pain. On the other hand, for patients with a stable 
pain pattern who report little fluctuation in pain level, the use of a pain diary seems to be of less relevance. Investigations are needed to test the effects of the separate components of the Pain Education Program separately, and to investigate what type of patient benefits most from the Pain Education Program. However, it might be possible that the total Pain Education Program is more effective than the separate components.

Finally, the intervention was carried out by specially trained nurses. It remains to be seen if the Pain Education Program can be successfully carried out by nurses on the ward, who have to carry out the intervention during their daily work.

\section{(District) nursing}

Results showed that the intervention was beneficial for all intervention group patients, with less convincing results in patients with district nursing than in those without district nursing. Although the intervention groups showed to be treated more adequately for their pain, a significant decrease in pain intensity was found in the intervention group without district nursing. The question arises why less pain relief was achieved in the group with district nursing? A first explanation might be due to differences between patients with and without district nursing: patients who received district nursing at home were older, experienced more complex pain problems, and needed more help than patients without district nursing. Second, this type of intervention may not have been powerful enough for patients with a progressive disease experiencing multiple chronic pain problems. Self-efficacy is perhaps more difficult to accomplish in seriously ill patients and, therefore, these patients benefit less from the Pain Education Program. A third explanation might be that for some patients, a more aggressive pain treatment may be needed. Finally, it might be that for some patients the goal of complete pain relief cannot be achieved. Despite the fact that many studies have shown that cancer pain can be controlled in approximately $90 \%$ of the patients, no sufficient evidence is provided regarding the effectiveness of the World Health Organization analgesic ladder by means of randomized controlled trials. ${ }^{14}$

Nurses and district nurses play a significant role in the assessment and management of cancer pain. This study showed that district nurses of both the control and intervention group patients were willing to participate in the study. However, district nurses of the control group patients might have paid extra attention to the pain of the control group patients, because they were triggered by being interviewed about patients' pain complaints. If so, this might have caused some bias resulting in an underestimation of the effects of the Pain Education Program for district nurses. 


\section{Measures}

Several valid and reliable measures were used to evaluate pain-related outcomes in patients. However, when evaluating the effects of the Pain Education Program, critical concerns were raised about the appropriateness of the available outcome measures to assess adequacy of pain treatment. Because there were no appropriate single-item scales for measuring adequacy of pain treatment, and the existing multi-item measures showed psychometric limitations, the Amsterdam Pain Management Index was developed to evaluate the adequacy of pain treatment. The results supported the use of this index. One single study, however, does not provide sufficient evidence that the Amsterdam Pain Management Index is a valid and reliable measure. Prospective, longitudinal studies are needed to further disentangle the issue of how to measure adequacy of pain treatment.

To assess the extent of adherence to pain medication, no well-established measures were available. In this study, a potential limitation to the evaluation of comprehension and adherence to pain medication was the reliance on patient self-report. ${ }^{54,55}$ Self-report methods are, on the one hand, the standard for evaluating medication adherence, but on the other hand, their accuracy might be limited. In the hospital, the discrepancy between what was prescribed by the physician and what the patient knew about the pain medication can be assessed relatively easily. Results showed that patients were frequently not aware of the pain medication prescription. At home, no accurate data on medication adherence was available, because neither the physician in the hospital nor the general practitioner was fully informed about the medication prescriptions. Although it is expected that patients at home are more aware of their pain medication prescription than in the hospital, a substantial group of patients was expected to be inaccurate in describing the medication prescription. In this study, a large group of patients admitted to be non-adherent. Nevertheless, the extent of noncomprehension and non-adherence might have been even higher had we known the exact medication prescription in the home situation.

Based on the multidimensional conceptualization of pain, it is assumed that cognitions determine how patients experience pain and react to pain treatment. Because few studies have examined patients' beliefs and expectations about pain and pain treatment, we could have chosen not to measure patients' pain cognition or to adapt the Pain Cognition List-Experimental version to cancer patients. In this study, we first evaluated the psychometric characteristics of the Pain Cognition List. Results showed that the Pain Cognition List for non-cancer patients cannot be easily used in cancer pain patients. Four factors emerged, namely Pain Impact, Social Comparison, Acquiescence, and Active Coping. The factor Catastrophizing, that is usually found as an important factor in non-cancer patients, was not found in cancer pain patients. Nevertheless, there is an implication that evaluating pain cognitions in cancer patients is useful, as the factors Pain Impact and Social Comparison were predicting change in adequacy of pain treatment. Although the exact relationship between pain cognition and pain experience needs to be further studied, there is an indication that patients' pain cognition might influence the effectiveness of an educational intervention. 


\section{Implications for clinical practice and research}

This study demonstrated the beneficial effects of the Pain Education Program in improving pain knowledge, decreasing non-adherence, reducing pain intensity, and increasing the adequacy of pain treatment. Therefore, the use of the Pain Education Program should be seriously considered on units with oncology patients. Because nurses have regular contact with patients, they are in an ideal position to educate patients. In order to implement the Pain Education Program, ward nurses should be more intensively trained as pain consultants. Thus, by means of this project, the utilization of research findings in clinical practice can be facilitated. Furthermore, utilization of research findings helps shed more light on areas where research is still warranted. Finally, it provides evaluative information on the clinical utility of such results for practice. For example, the Pain Education Program may be experienced as too time-consuming to be applied on nursing wards. The implementation of the Pain Education Program in nursing practice will urge the researchers and nursing staff to further develop more userfriendly components of the Pain Education Program.

Currently, there is a growing emphasis on creating a research-based nursing practice. Focus on the need for "evidence-based medicine" or "evidence-based nursing" is based on the assumption that this will improve the quality of care. This research study showed that the Pain Education Program is well applicable in a research setting. However, in daily nursing practice, the applicability of the Pain Education Program is not yet established.

Recently, a grant has been received from the Dutch Cancer Society to implement the Pain Education Program in cancer patients with chronic pain in nursing practice of several hospitals. By means of this implementation project, a userfriendly version of the Pain Education Program will be developed and implemented in different hospitals in the Netherlands.

As part of this implementation project, further research needs to be conducted for a better understanding of the use of the different components of the intervention in nursing practice, how to continue the process of implementation the Pain Education Program, and how to further improve the continuity of care.

The Pain Education Program was primarily developed to empower the patient. In addition to a more active role of patients, results also showed an information need by family members whose lack of pain knowledge may have a negative impact on the extent of patient's adherence to the pain medication. ${ }^{44,56,57}$ Because patients in the home situation are highly dependent on their family, both the patients and their families should be involved in an educational intervention program.

In addition, it may be worthwhile to further investigate the application of the Amsterdam Pain Management Index. When healthcare providers receive more information about the quality of their pain treatment by means of the Amsterdam Pain Management Index, it is expected that this will positively improve nurses' and physicians' pain practice. Simultaneously, there is a need to study the psychometric properties in different cancer pain populations and in different settings.

To confirm the initial findings that cancer patients present different pain cognitions compared to non-cancer pain patients, further research is necessary in which the Pain Cognition List is tested in both cancer and non-cancer patients. In 
addition, norm scores should become available for clinical use. Only then will it become clear whether patients are able to change their cognitions, and whether cognitive-behavioral interventions can alter patients' pain cognitions over time.

Pain treatment is primarily focused on analgesics and, to a lesser extent on other pain-relieving treatments. Although the main form of pain treatment consists of pharmacological treatment, non-pharmacological techniques are rarely applied by nurses. This does not concur with the current insight in pain relief, ${ }^{58}$ or with the advice of nursing societies. ${ }^{59}$ Attention should be paid to the effectiveness of non-pharmacological pain treatment, e.g., massage, relaxation, heat, and cold. In addition, how non-pharmacological pain treatment can be applied in nursing practice by both hospital nurses and district nurses need to be further studied.

For optimal pain management it is necessary that both the hospital and the home care services remain continuously involved throughout the patients' disease. In this study, general practitioners and hospital physicians, responsible for the treatment of intervention patients received only limited written information about the outline of the Pain Education Program. No specific information and instruction was given about patients' individual pain experience. This was done to tease out the effects of the Pain Education Program as offered by specially trained nurses. For optimal pain management, however, one might argue that it is necessary that all caregivers need to be intensively involved with patients' pain experience throughout the patients' disease. Consequently, when implementing the Pain Education Program into clinical practice, it is advised to involve both the general practitioners and the hospital physicians about the different aspects of the intervention. The Pain Education Program will then become more integrated with the regular pain treatment. Most cancer treatment is provided in an outpatient setting, and this trend will increase in the future. The continuity of care is frequently jeopardized by fragmentation in healthcare. ${ }^{60}$ The present study showed that about one-third of the cancer patients with pain needed district nursing at home. In the future, more effort should be paid to the important role of district nurses in the home situation. Hospital nurses should coordinate the discharge of the patient, and district nurses may become more important in coordinating care at home. A transfer of information in a patient dossier, by telephone, or e-mail might increase the continuity of care. Thus, a change in attitude is required by both patients and caregivers. To achieve this, more effort should be paid to patients' self-care. ${ }^{61}$ By encouraging self-care, patients will become more active and conscious about their own treatment. This attitude change will not be easy to realize, because patients and their relatives themselves need to have a good understanding of all pain aspects in order to comply with the medication prescription.

\section{Epilogue}

Cancer-related pain is a multidimensional experience, consisting of sensory, physiological, affective, cognitive, and behavioral dimensions. ${ }^{62-64}$ Each dimension consists of several components. The physiological components encompasses the etiology of specific pain syndromes, and the duration of the pain. The sensory component encompasses the location of pain, the intensity, and the quality of 
the pain. The affective component includes anxiety, depression, mood, anger, worry, fear, suffering, and psychiatric disorders. The cognitive component consists of the manner in which pain influences the individual's thought processes and how the meaning of the pain is viewed. The behavioral dimension consists of behaviors that are related to pain, such as activity level, verbal and non-verbal behaviors to express pain, use of medication, and associated symptoms. Finally, the sociocultural dimension comprises variables such as age, gender, education, religion, cultural background, and social support. This multidimensional conceptualization of pain is based on the Gate Control Theory of pain of Melzack and Wall. ${ }^{65}$ which has led to the recognition that the various components of the pain experience are interrelated. This theory has had a great impact on the assessment, management, and evaluation of cancer pain.

Despite the current knowledge that pain is a multidimensional phenomenon for which a variety of interventions can be effective, a multidimensional approach in which educational and cognitive-behavioral interventions are integrated are scarce in cancer pain patients. To relieve pain, analgesic administration continues to be the most common and, frequently, the only intervention used. Consequently, research on the efficacy of analgesics continues to be the primary activity, while less attention has been paid to educational interventions to patients. Studies on pharmacological pain treatment should be extended to include other interventions, with more emphasis on educational and cognitive-behavioral interventions.

Efforts to improve pain treatment have mainly focussed on the development and administration of new pain medication, and enhancing the expertise and techniques used by healthcare providers. Less attention has been paid to the role of the patients themselves in managing their own pain. From this study, it can be concluded that, in addition to the development of new pain medicines and hightechnology pain treatments, more priority should be given to implementing the extensive possibilities that are already available to relieve pain in cancer patients. It is for this reason that the World Health Organization ${ }^{66}$ stated that "nothing would have a greater impact on improving cancer pain treatment than implementing existing knowledge." When patients are further empowered to become active participants in pain treatment they, and their families, will more frequently demand adequate pain treatment. It should become the norm that patients have access to the best level of pain relief. ${ }^{29}$ Therefore, inadequate pain treatment should not be accepted any longer. ${ }^{67}$

However, despite the availability of pain relieving facilities, and advanced knowledge on cancer pain control, and despite the effects of the Pain Education Program, cancer pain remains too often inadequately managed. This is striking because the present study was conducted in a specialized hospital where registered nurses received special training, and a multidisciplinary pain team was available for complex pain problems. From this, it can be concluded that in addition to empowering patients, other changes are necessary to further improve the treatment of cancer pain. Recently, several quality assurance and improvement programs have been developed and implemented. ${ }^{29,36,37,68,69}$ These programs included the implementation of standards and evaluating the impact of these standards. In addition, more attention needs to be given to formal training in pain and pain treatment for both physicians and nurses. 


\section{References}

1. Visser O, Coebergh JWW, Schouten U. Incidence of cancer in the Netherlands 1993. Utrecht: SIG Health Care Information, 1996.

2. Brescia FJ, Portenoy RK, Ryan M, Krasnoff L, Gray G. Pain, opioid use, and survival in hospitalized patients with advanced cancer. Journal of Clinical Oncology, 1992;10:149-155.

3. Higginson IJ, Hearn J. A multicenter evaluation of cancer pain control by palliative care teams. Journal of Pain and Symptom Management, 1997;14:29-35.

4. McCaffery M. Nursing management of the patient with pain. Philadelphia, PA: Lippincott, 1979.

5. McGuire DB. The perception and experience of pain. Seminars in Oncology Nursing, 1985;1:83-86.

6. Cleeland CS. Pain assessment in cancer. In: Osoba D, ed. Effect of cancer on quality of life. Boca Raton, FL: CRC Press, 1991: 294-305.

7. Cleeland CS, Gonin R, Baez L, Loehrer P, Pandya KJ. Pain and treatment of pain in minority patients with cancer. Annals of Internal Medicine, 1997;127:813-816.

8. Cleeland CS, Gonin R, Hatfield AK, Edmonson JH, Blum RH, Stewart JA, Pandya KJ. Pain and its treatment in outpatients with metastatic cancer. New England Journal of Medicine, 1994;330:592-596.

9. Dalton JA. Nurses' perceptions of their pain assessment skills, pain management practices, and attitudes toward pain. Oncology Nursing Forum, 1989;16:225-231.

10. Dorrepaal KL. Pijn bij patienten met kanker [Thesis in Dutch]: Vrije Universiteit, 1989.

11. Goisis A, Gorini M, Ratti R, Luliri P. Application of a WHO protocol on medical therapy for oncologic pain in an internal medicine hospital. Tumori, 1989;75:470-472.

12. Grond S, Zech D, Lynch J, Diefenbach C, Schug SA, Lehmann KA. Validation of World Health Organization guidelines for pain relief in head and neck cancer: A prospective study. Annals of Otology, Rhinology \& Laryngology, 1993;102:342-348.

13. Grond S, Zech D, Schug SA, Lynch J, Lehmann KA. Validation of World Health Organization guidelines for cancer pain relief during the last days and hours of life. Journal of Pain and Symptom Management, 1991;6:411-422.

14. Jadad AR, Browman GP. The WHO analgesic ladder for cancer pain management. Stepping up the quality of its evaluation. JAMA, 1995;274:1870-1873.

15. Larue F, Colleau SM, Brasseur L, Cleeland CS. Multicentre study of cancer pain and its treatment in France. British Medical Journal, 1995;310:1034-1037.

16. Lin CC, Ward SE. Patient-related barriers to cancer pain management in Taiwan. Cancer Nursing, 1995; 18:16-22.

17. Miaskowski C, Nichols R, Brody R, Synold T. Assessment of patient satisfaction utilizing the American Pain Society's quality assurance standards on acute and cancer-related pain. Clinical Journal of Pain, 1994;9:5-11.

18. Serlin RC, Mendoza TR, Nakamura Y, Edwards KR, Cleeland CS. When is cancer pain mild, moderate or severe? Grading pain severity by its interference with function. Pain, 1995;61:277-284.

19. Syrjala KL, Chapman CR. Measurement of clinical pain: A review and integration of research findings. In: Benedetti C, ed. Advances in pain research and therapy. New York: Raven Press, 1984: 133-150.

20. Takeda F. Results of field-testing in Japan of the WHO draft interim guidelines on relief of cancer pain. The Pain Clinic, 1986;1:83-89.

21. Ventafridda V, Tamburini M, Caraceni A, De Conno F, Naldi F. A validation study of the WHO method for cancer pain relief. Cancer, 1987; 59:850-856.

22. Walker VA, Hoskin PJ, Hanks GW, White ID. Evaluation of WHO analgesic guidelines for cancer pain in a hospital-based palliative care unit. Journal of Pain and Symptom Management, 1988;3:145-149.

23. Ward S, Gatwood J. Concerns about reporting pain and using analgesics. A comparison of persons with and without cancer. Cancer Nursing, 1994;17:200-206.

24. Ward SE, Goldberg N, Miller-McCauley V, Mueller C, Nolan A, Pawlik-Plank D, Robbins A, Stormoen D, Weissman DE. Patient-related barriers to management of cancer pain. Pain, 1993;52:319-324.

25. Ward SE, Hernandez L. Patient-related barriers to management of cancer pain in Puerto Rico. Pain, 1994;58:233-238.

26. Zech DF, Grond S, Lynch J, Hertel D, Lehmann KA. Validation of World Health Organization guidelines for cancer pain relief: A 10-year prospective study. Pain, 1995;63:65-76. 
27. Zelman DC, Cleeland CS, Howland EW. Factors in appropriate pharmacological management of cancer pain: A cross-institutional investigation. Pain (supplement 4), 1987:S136.

28. Zhukovsky DS, Gorowski E, Hausdorff J, Napolitano B, Lesser M. Unmet analgesic needs in cancer patients. Journal of Pain and Symptom Management, 1995;10:113-119.

29. AHCPR. Agency for Health Care Policy and Reserach. Management of cancer pain. Clinical Practice Guideline. Rockville, MD: Agency for Health Care Policy and Research, 1994.

30. Grossman SA. Undertreatment of cancer pain: barriers and remedies. Supportive Care in Cancer, 1993;1:74-78.

31. Max MB. Improving outcomes of analgesic treatment: is education enough. Annals of Internal Medicine, 1990;113:885-889.

32. Vortherms R, Ryan P, Ward S. Knowledge of, attitudes toward, and barriers to pharmacologic management of cancer pain in a statewide random sample of nurses. Research in Nursing and Health, 1992;15:459-466.

33. Donabedian A. Institutional and professional responsibilities in quality assurance. Quality Assurance in Health Care, 1989;1:3-11.

34. Wallenstein SL. Measurement of pain and analgesia in cancer patients. Cancer, 1984;53:2260-2263.

35. APS. American Pain Society. Principles of analgesic use in the treatment of acute pain and chronic cancer pain: a concise guide to medical practice. Skokie, IL: American Pain Society, 1992.

36. APS. American Pain Society Quality of Care Committee. Quality improvement guidelines for the treatment of acute pain and cancer pain. JAMA, 1995;274:1874-1880.

37. Ward SE, Gordon DB. Patient satisfaction and pain severity as outcomes in pain management: a longitudinal view of one setting's experience. Journal of Pain and Symptom Management, 1996;11:242-251.

38. Ferrell BR, Rivera LM. Cancer pain education for patients. Seminars in Oncology Nursing, 1997;13:42-48.

39. Spross JA, McGuire DB, Schmitt RM. Oncology Nursing Society Position Paper on Cancer Pain. Part I. Oncology Nursing Forum, 1990;17:595-614.

40. Clotfelter CE. The effect of an educational intervention on decreasing pain intensity in elderly people with cancer. Oncology Nursing Forum, 1999;26:27-33.

41. Dalton JA. Education for pain management: a pilot study. Patient Education and Counseling, 1987;9:155-165.

42. Dalton JA, Lambe C. Tailoring treatment approaches to the individualized needs of cancer patients with pain. Cancer Nursing, 1995;18:180-188.

43. Desbiens NA, Wu AW, Yasui Y, Lynn J, Alzola C, Wenger NS, Connors AF, Philips RS, Fulkerson W. Patient empowerment and feedback did not decrease pain in seriously ill hospitalized adults. Pain, 1998;75:237-246.

44. Ferrell BR, Ferrell BA, Ahn C, Tran K. Pain management for elderly patients with cancer at home. Cancer, 1994;74:2139-2146.

45. Ferrell BR, Rhiner M, Ferrell BA. Development and implementation of a pain education program. Cancer, 1993;72:3426-3432.

46. Rhiner M, Ferrell BR, Ferrell BA, Grant MM. A structured nondrug intervention program for cancer pain. Cancer Practice, 1993;1:137-143.

47. Rimer B, Levy M, Keintz MK, MacElwee N, Engstrom PF. Improving cancer patients' pain control through education. Progress in Clinical \& Biological Research, 1987;248:123-127.

48. Rimer BK, Kedziera P, Levy MH. The role of patient education in cancer pain control. Hospice Journal, 1992;8:171-191.

49. Foley KM. The treatment of cancer pain. New England Journal of Medicine, 1985;313:84-95.

50. McQuay $\mathrm{H}$, Moore A. Need for rigorous assessment of palliative care. Although difficult, randomised controlled trials are mandatory. British Medical Journal, 1994;309:1315-1316.

51. Czaplinski C, Diers D. The effect of staff nursing on length of stay and mortality. Medical Care, 1998;36:1626-1638.

52. De Rond M, De Wit R, Van Dam F, Van Campen B, Den Hartog Y, Klievink R, Nieweg R, Noort J, Wagenaar M, van Campen B. Daily pain assessment: value for nurses and patients. Journal of Advanced Nursing, 1999;29,436-444.

53. De Wit R, van Dam FSAM. Verpleegkundige pijnmeting bij kankerpatienten: een interventiestudie. Verpleegkunde, 1991/92;2:68-75.

54. Cramer JA. Overview of methods to measure and enhance patient compliance. In: Cramer JA, Spilker B, eds. Patient compliance in medical practice and clinical trials. New York: Raven Press, 1991: 3-10. 
55. Gordis L. Conceptual and methodologic problems in measuring patient compliance. In: Haynes RB, Taylor DW, Sackett DL, eds. Compliance in health care. Baltimore: Johns Hopkins University Press, 1979: 23-45.

56. Ferrell BR, Rhiner M, Cohen MZ, Grant M. Pain as a metaphor for illness. Part I: Impact of cancer pain on family caregivers. Oncology Nursing Forum, 1991;18:1303-1309.

57. Ferrell BR, Rhiner MR, Rivera LM. Development and evaluation of the family pain questionnaire. Journal of Psychosocial Oncology, 1993;10:21-35.

58. McCaffery M, Beebe A. Pain: Clinical manual for Nursing Practice. St. Louis, MO: CV Mosby, 1989.

59. VWR/CBO. Verpleegkundige Wetenschappelijke Raad/ Centraal Begeleidingsorgaan voor de Intercollegiale Toetsing. Consensusbijeenkomst verpleegkunde bij pijn: resultaat van de tweede verpleegkundige consensusbijeenkomst. Utrecht: CBO, 1994.

60. Smeenk FWJM. Transmural care of terminal cancer patients. An evaluation study in the Eindhoven region: University of Maastricht, 1998.

61. Orem DE. Nursing: concepts of practice. New York: McGraw Hill, 1971.

62. Ahles TA, Blanchard EB, Ruckdeschel JC. Multidimensional nature of cancer pain. Pain, 1983;17:277-288.

63. McGuire DB. The multidimensional phenomenon of cancer pain. In: McGuire DB, Yarbo CH, eds. Cancer pain management. Orlando: Grune \& Sratton, 1987.

64. McGuire DB, Yarbro CH, Ferrell BR. Cancer pain management: Grune \& Stratton, 1995.

65. Melzack R, Wall PD. The challenge of pain: New York Basic Books, 1982.

66. WHO. Cancer pain relief. Geneva, Switzerland: World Health Organization, 1986.

67. Cleeland CS. Undertreatment of cancer pain in elderly patients. JAMA, 1998;279:1914-1915.

68. Bookbinder M, Coyle N, Kiss M, Layman Goldstein M, Holritz K, Thaler H, Gianella A, Derby S, Brown M, Racolin A, Nah Ho M, Portnoy RK. Implementing national standards for cancer pain management: program model and evaluation. Journal of Pain and Symptom Management, 1996;12:334-347.

69. Ward S, Donovan M, Max MB. A survey of the nature and perceived impact of quality improvement activities in pain management. Journal of Pain and Symptom Management, 1998;15:365-373. 
Summary 


\section{Introduction}

The research described in this thesis was initiated to develop and evaluate the Pain Education Program in cancer patients with chronic pain in a randomized controlled clinical trial. The first phase of this work addresses the current practice of pain treatment. In the second phase, the randomized study described in this thesis was performed with the main aim to evaluate the effects of the Pain Education Program. Much effort was put into the development of an outcome measure to evaluate the adequacy of pain treatment. The new approach was validated and evaluated. Finally, the impact of patients' pain cognitions, patients' adherence to pain medication, and the role of district nurses in the care of pain patients at home were evaluated. This summary presents the main results of this work.

\section{Summary of results}

Chapter 1 gives an introduction to the scope of the dissertation. The rationale for this work is given and the research questions are discussed. An overview of all components influencing the effect of the Pain Education Program is presented.

Chapter 2 describes the current practice of pain treatment, which was evaluated in $\mathbf{3 1 3}$ patients in the Netherlands Cancer Institute/Antoni van Leeuwenhoek Hospital.

The practice of pain treatment was evaluated by means of Donabedian's structure-process-outcome framework. The practice of pain treatment was assessed by: (1) structural resources, describing the setting in which pain treatment is provided; (2) process components describing the clinical practice; and (3) outcome measures referring to patients' pain intensity, patients' satisfaction, or composite pain management index scores.

The results showed that, depending on the outcome measure used to evaluate the adequacy of pain treatment, $31-60 \%$ of the cancer pain patients received less than optimal pain treatment. When using patient satisfaction as the outcome measure, results showed the lowest percentage of patients being treated inadequately, while according to "Cleeland's Pain Management Index" and the "Amsterdam Pain Management Index," $51 \%$ and $60 \%$ of the patients, respectively, received less than optimal potency analgesics.

Results showed that almost all resources necessary for good clinical practice, such as the availability of e.g., procedure manuals, analgesics, pain assessment tools, and patient education materials were available in the hospital. Although pain education and refresher courses for healthcare providers are scarce, structural resources were not the major cause of the suboptimal level of pain treatment. Rather, the major cause were the process components. Only $36 \%$ of the patients received strong opioids, and $23 \%$ of the patients received analgesics "as needed." Of the patients, $66 \%$ stated that they were (very) well informed about pain and pain treatment, even though written pain information was given to only $16 \%$ of the patients. A pain physician was consulted by $32 \%$ of the patients. Patients' pain knowledge was far from optimal (54.8 on a 0-100 scale). After 
discharge, the extent to which information about patients' pain was provided by hospital nurses to district nurses was also not optimal: only $36 \%$ of the nurses were informed about patients' pain. In addition, communication between the patient and the general practitioner was not very regular because most patients reported that they had communicated with their general practitioner about 6 weeks previously.

Based on components relevant for pain treatment, it can be concluded that the current treatment of pain provides only partial relief and is not adequate for a substantial group of pain patients. These results emphasize that continuing efforts are needed to improve the practice of pain treatment. To achieve this, a commitment by the entre organization with more emphasis on proces component related to pain are needed.

Chapter 3 presents the main aims of this work, namely the development and evaluation of the Pain Education Program in cancer patients with chronic pain. The Pain Education Program was tailored to the needs of the individual patient and consisted of three elements: 1) educating patients about the basic principles regarding pain and pain management; 2 ) instructing patients how to report their pain in a pain diary; and 3 ) instructing patients how to communicate about pain and how to contact the most appropriate healthcare provider. A multi-method approach was used in which verbal instruction, written materials, an audiocassette tape, and the use of a pain diary were combined to inform and instruct patients about pain and pain management.

Following pretesting, patients who did or did not need district nursing at home were randomly assigned to a control or intervention group. Intervention group patients received the Pain Education Program in the hospital, and at 3 and 7 days postdischarge by telephone. Follow-up assessments were at 2, 4, and 8 weeks postdischarge.

Results of the pretest showed that many patients lacked knowledge about pain and pain management during the hospital stay. Consequently, a majority of pain topics had to be discussed with the patient. The Pain Education Program proved to be feasible: $75 \%$ of the patients had read the entire pain brochure, $56 \%$ had listened to the audiocassette, and $86 \%$ of pain scores was completed in the pain diary.

Results showed a significant increase in pain knowledge in patients who received the Pain Education Program, and a significant decrease in pain intensity. However, the pain-reducing effect of the Pain Education Program was primarily found in patients not receiving district nursing rather than in patients with district nursing.

Chapter 4 outlines a specific part of the Pain Education Program, namely the use of a pain diary by patients at home. A group of 159 intervention patients were instructed to record their pain on a numeric rating scale once every morning and once every evening for a period of 2 months in a paper-and-pencil pain diary. The purpose of this study was to evaluate: (1) the association between pain intensity scores obtained by the pain diary and those obtained by patient interview; (2) the ability to recall past pain intensity; (3) the fluctuation of pain intensity scores over time; and (4) the effects of the use of the pain diary. 
Results showed that even seriously ill patients were conscientious with filling in the pain diary. When comparing pain scores obtained by patient interview with scores obtained by the pain diary, results showed that Present Pain Intensity scores, rather than Average Pain Intensity scores, should be used in both the clinical and the home setting. Results also showed that patients' recall accuracy depended, in part, on the stability of the pain. Because the pain intensity scores fluctuated greatly during the day and over a period of time, the use of a pain diary was useful in the home setting. In $60 \%$ of the patients, completing the pain scores helped them to cope with the pain.

Chapter 5 describes and compares the outcome measures, which are frequently reported in the literature, to assess the adequacy of pain treatment. Because there are no known studies describing commonly used measures to simultaneously evaluate the adequacy of cancer pain treatment, the purpose of this study was to compare measures which are frequently reported in the literature. Adequacy of cancer pain treatment was evaluated by means of four different types of outcome measures. The four types included three Pain Intensity Markers based on patients' pain intensity scores, a Pain Relief Scale, a Patient Satisfaction Scale, and three Pain Management Indexes in which patients' pain intensity is related to pain medication.

When evaluating the eight different outcome measures, results showed a wide variation in the proportion of inadequately treated pain patients. Depending on the outcome measure used, the percentage of inadequately treated patients ranged from $16-91 \%$. Based on this striking result, it can be concluded that the choice of measure, rather than pain treatment itself, determined the proportion of inadequacy. From this it can be concluded that studies that evaluate adequacy of pain treatment should be interpreted with caution.

Chapter 6 describes the psychometric properties of a newly designed measure, the Amsterdam Pain Management Index, compared with eight frequently used outcome measures. The Amsterdam Pain Management Index was developed to address some of the limitations of the frequently used outcome measures to evaluate the adequacy of pain treatment. The Amsterdam Pain Management Index compares patients' Present Pain Intensity, Average Pain Intensity, and Worst Pain Intensity with a composite score of analgesics used, while correcting for what a patient considers as a tolerable level of pain. The frequently used measures included three Pain Intensity Markers based on patients' pain intensity scores, a Pain Relief Scale, a Patient Satisfaction Scale, and three Pain Management Indexes consisting of relating patients' pain medication with pain intensity.

Results showed that, except for Cleeland's, Ward's, and Zelman's Pain Management Index, the level of correspondence between the measures was very low to moderate. The test of known-groups comparisons and equivalence between groups indicated that the Amsterdam Pain Management Index showed the most promising results. All five components were important in predicting the degree of variance of the index. The Pain Intensity Markers and the Pain Relief Scale were limited in discriminating between groups, while the Patient Satisfaction Scale showed no differences between patient groups. Although Cleeland's, Ward's, and Zelman's Pain Management Index differed between patient groups, the differences were not in the expected direction. The ability of the outcome measures 
to detect changes over time was demonstrated by all outcome measures, while effects of the intervention were only found for the Amsterdam Pain Management Index and the Pain Intensity Marker based on patients' Substantial Worst Pain score. Based on the results, support for the use of the Amsterdam Pain Management Index was provided.

Chapter 7 outlines the effects of the Pain Education Program on adequacy of pain treatment, and describes characteristics predicting change in adequacy. The long-term effects of the Pain Education Program were evaluated by Random Regression Models which allow for the presence of incomplete data due to dropouts.

At pretest, results showed that $60 \%$ of the patients were treated inadequately for their pain. Postdischarge, the intervention group patients were treated significantly more adequate than the control group patients. The difference between the groups was smaller when the dropouts were taken into account. While the level of inadequacy in the control groups remained relatively stable at all assessment points, an increased number of intervention group patients were found inadequately treated at 8 weeks postdischarge. A beneficial effect of the Pain Education Program was found for patients both with and without district nursing.

Subtypes of patients who respond differentially to the Pain Education Program were identified. Variables that could predict a high amount of the variance of the Amsterdam Pain Management Index consisted of, e.g. the Pain Education Program, the Amsterdam Pain Management Index score at pretest, patients' physical functioning, patients' social functioning, adherence to pain medication, pain knowledge, and the amount of analgesics: $56-60 \%$ of the variance was predicted with these variables.

Chapter 8 addresses the issue of adherence to pain medication. The aim of the study was to assess the extent of medication adherence in cancer pain patients, and to evaluate the impact of the Pain Education Program on medication adherence.

Three stages were distinguished to evaluate the process of adherence to pain medication: (1) the pain medication prescription; (2) the degree to which patients are informed and comprehend the medication prescription; and (3) the extent to which patients adhere to the medication prescription at home.

Data were collected on all prescribed pain medications by means of self-report questions. Patients' medication use was evaluated prospectively over a period of 2 months after discharge from the hospital. Results showed that one out of every four patients was not able to recall any of the pain medication prescribed in the hospital. Of those patients who were able to report on the pain medication prescription, less than half of the patients were able to recall the medication prescription correctly. After discharge, $49 \%$ reported being non-adherent to the pain medication, and only $51 \%$ reported that the interval of analgesic dosing was around-the-clock.

The Pain Education Program proved to be effective in improving the extent of comprehension and adherence after discharge. Postdischarge, the intervention group patients were prescribed more non-opioids than the control group patients. Furthermore, more patients in the intervention groups reported an opioid and non-opioid prescription than control group patients. After discharge, 
patients' "medication-taking behavior" and "medication-timing behavior" significantly improved in the intervention group. However, when evaluating the differences between the medication prescribed according to the patient and the medication actually taken, the effects of the Pain Education Program were less obvious: significant differences were only found for opioids at 4 weeks postdischarge.

It can be concluded that, although the Pain Education Program was effective, the intervention did not have a strong impact on the extent of comprehension and adherence. Overall, the degree of adherence with pain medication remained low.

Chapter 9 addresses the role of the district nurse in the care of cancer patients' pain at home, and the effects of the Pain Education Program for both district nurses and their patients. One hundred and fifteen district nurses and their 104 patients were studied. The primary outcome of interest was: type of pain intervention provided, pain intensity, satisfaction with pain treatment, and patients' pain relief.

Results showed that continuity of care was poor as only $36 \%$ of the district nurses were informed about patients' pain by hospital nurses. Pain was rarely the reason for referring the patient to district nursing. Although pain control was not a main reason for visiting the patient, pain was subject for discussion in $76 \%$ of the patients. Besides discussing the pain problem with the patients, district nurses provided only a few pain-relieving interventions. District nurses randomized to the intervention group significantly better estimated patients' pain intensity, and were more satisfied with patients' pain treatment, but no differences were found in nurses' assessment of patients' pain relief. These findings suggest a significant but moderate effect of the Pain Education Program with district nurses only playing a minor role in the treatment of cancer pain.

One of the patient-related factors that can play an important role in the experience of pain and the response to treatment is patients' beliefs and attitudes toward pain. However, the impact of cognitions on the pain experience is unknown in cancer patients, and no measures are available to assess cognitions and beliefs in Dutch cancer patients.

Chapter 10 describes the psychometric characteristics of the Pain Cognition List-Experimental version. This Dutch measure was developed to assess patients' self-statements about pain and the extent to which they deal with the pain and was only used in non-cancer patients The Pain Cognition List-Experimental version was applied in cancer patients during hospitalization. Confirmatory factor analysis was conducted to evaluate the adequacy of fit for the factor structure. Because of a failure to replicate the original factor structure, exploratory factor analysis was conducted. Four factors emerged: Pain Impact, Social Comparison, Acquiescence, and Active Coping. The internal consistency for the factor Pain Impact was high $(r=0.89)$, while the other three factors showed low reliability. The factor Catastrophizing, usually an important factor in non-cancer patients, did not emerge. No differences were found across gender, while patients with district nursing had higher scores on Pain Impact and than patients without district nursing. Higher pain intensity scores were significantly related to Pain Impact ( $r=$ 0.30 ). The affective and evaluative pain indexes, and the functioning scales 
describing quality of life were significantly correlated to Pain Impact. The number of non-pharmacological treatments was significantly correlated to Acquiescence.

The results give a strong indication that healthcare providers evaluating pain in cancer patients need to be aware of the impact that pain cognitions have on patients' pain experience. The use of the Pain Cognition List, however, cannot be easily used in cancer pain patients.

Chapter 11 presents the conclusions and general discussion, which addresses methodological and theoretical reflections, and implications for clinical practice and research. An epilogue concludes the chapter. 


\section{Samenvatting}




\section{Introductie}

Pijn is een veelvoorkomend symptoom bij kankerpatiënten. Hoewel er in de afgelopen jaren talloze pogingen zijn gedaan om de kwaliteit van de pijnbestrijding te verbeteren, variërend van het opstellen van protocollen en behandelingsrichtlijnen, opleidings- en trainingsprogramma's voor artsen en verpleegkundigen en het implementeren van registratiesystemen voor pijnklachten, krijgen nog veel patiënten onvoldoende pijnbestrijding.

Tot nu toe is nauwelijks aandacht besteed aan de rol die patiënten zelf hebben bij de behandeling van pijnklachten. Dit is opvallend aangezien uit onderzoek blijkt dat ook patiënten mede verantwoordelijk zijn voor een falende pijnbestrijding. Onvoldoende kennis over pijn en pijnbestrijding bij de patiënt, angst voor gewenning en verslaving aan morfine-achtige pijnstillers, angst voor bijwerkingen, gebrek aan communicatie met (huis)artsen en (wijk)verpleegkundigen en slechte medicatietrouw zijn vaak meer regel dan uitzondering. Ontoereikende pijnbestrijding is met name in de thuissituatie een probleem. Huisartsen, specialisten, verpleegkundigen, wijkverpleegkundigen en andere hulpverleners zijn voor het vaststellen van een adequate pijnbestrijding in belangrijke mate afhankelijk van wat patiënten daar zelf over melden. Door de steeds teruglopende opnameduur brengen patiënten het belangrijkste deel van hun ziekteperiode thuis door en dienen zij zelf aan te geven wanneer de pijnbestrijding tekort schiet. Scholing van patiënten over pijn en pijnbestrijding en hen actief betrekken bij de pijnbestrijding zou de kwaliteit van de pijnbestrijding, met name in de thuissituatie, kunnen verbeteren. Daartoe is het Pijn Instructie Programma voor kankerpatiënten met langdurige pijn ontwikkeld.

In dit onderzoek worden de resultaten gepresenteerd van een longitudinaal onderzoek naar de effecten van een Pijn Instructie Programma bij kankerpatiënten met langdurige pijnklachten. Het Pijn Instructie Programma, dat ter voorbereiding voor ontslag uit het ziekenhuis werd gegeven, bestaat uit drie elementen, namelijk: (1) het geven van informatie en instructie op maat over pijn en pijnbestrijding; (2) het introduceren van een pijndagboek waarin de pijnintensiteit twee maal daag wordt gerapporteerd; en (3) het bevorderen van het hulpzoekgedrag (zelfredzaamheid). Omdat verpleegkundigen een belangrijke taak hebben bij de pijnbestrijding, kregen speciaal getrainde verpleegkundigen de taak om patiënten "op maat" te informeren en instrueren over pijn en pijnbestrijding. Nadat bekend was of de patiënt wijkverpleegkundige hulp zou ontvangen in de thuissituatie, werden patiënten met en zonder wijkverpleging gerandomiseerd in een controleen een interventiegroep. De controlegroepen kregen de reguliere pijnbestrijding, terwijl de interventiegroepen het Pijn Instructie Programma (interventie) kregen in aanvulling op de reguliere pijnbestrijding. Het Pijn Instructie Programma bestond uit een individueel gesprek met de patiënt waarin relevante ontbrekende pijnkennis werd aangevuld. Tevens kreeg de patiënt een pijnbrochure, getiteld "Pijn bij kanker en wat er aan te doen is". Deze pijnbrochure bestaat uit een algemeen deel met daarin uitleg over de basisprincipes van pijn en pijnbestrijding en pijn bij kanker. In aanvulling op het algemene deel kreeg de patiënt ook een aantal inlegvellen met daarop informatie over de verschillende methoden van pijnbestrijding die alleen op hem of haar van toepassing waren. Hiermee werd voorkomen dat de patiënt overspoeld werd met informatie die voor hem of haar overbodig is. Het gesprek in het ziekenhuis werd opgenomen op een cassettebandje, 
zodat de patiënt en zijn naasten het gesprek (thuis) nog eens konden beluisteren. Ook werd een pijndagboek geïntroduceerd. In het pijndagboek kan de pijnintensiteit twee maal daags worden gerapporteerd door de patiënt, evenals informatie over de pijnbestrijding en het aantal contacten met hulpverleners. Drie en zeven dagen na ontslag uit het ziekenhuis ging de verpleegkundige telefonisch na hoe het met de pijn van de patiënt ging en werd hij of zij in de gelegenheid gesteld vragen te stellen. De verpleegkundige stimuleerde de patiënt contact op te nemen met de behandelend arts of huisarts indien dit nodig was. Het gesprek tussen de patiënt en de verpleegkundige in het ziekenhuis duurde 30 - 60 minuten en de telefonische gesprekken 5 - 15 minuten. In aanvulling op de interventie voor patiënten werden ook wijkverpleegkundigen geïnformeerd over de pijnklachten van de patiënt. Om het effect van de interventie te onderzoeken werden zowel bij patiënten als bij wijkverpleegkundigen nametingen verricht na 2, 4 en 8 weken na ontslag uit het ziekenhuis.

Het onderzoek dat in dit proefschrift wordt beschreven is uitgevoerd in het Antoni van Leeuwenhoek huis/Nederlands Kanker Instituut en bestaat uit twee delen. In het eerste deel van het proefschrift wordt de pijnbestrijding in het Antoni van Leeuwenhoek huis/Nederlands Kanker Instituut beschreven (hoofdstuk 2). In het tweede deel wordt het Pijn Instructie Programma beschreven en de effecten geëvalueerd (hoofdstuk 3 en 4). Ten einde de kwaliteit van de pijnbestrijding te beschrijven is een maat ontwikkeld om de adequaatheid van de pijnbestrijding te beoordelen (hoofdstuk 5). De nieuw ontwikkelde maat, de "Amsterdam Pijn Management Index," is gevalideerd (hoofdstuk 6) en het longitudinale effect van het Pijn Instructie Programma is beschreven (hoofdstuk 7). Tenslotte wordt de invloed van pijncognities (hoofdstuk 8), de mate van medicatietrouw (hoofdstuk 9) en de rol van wijkverpleegkundigen bij de zorg en verpleging van pijnpatiënten in de thuissituatie geëvalueerd (hoofdstuk 10). Het proefschrift wordt afgesloten met conclusies en een discussie (hoofdstuk 11).

\section{Samenvatting}

Hoofdstuk 1 bestaat uit een algemene inleiding op het onderwerp van dit proefschrift. Een beknopt overzicht van de literatuur over pijnbestrijding bij kankerpatiënten wordt gegeven. De doel- en vraagstellingen van het onderzoek worden beschreven en een overzicht van alle onderzoeksvragen wordt gepresenteerd.

In hoofdstuk 2 wordt de huidige wijze van pijnbestrijding bij kankerpatiënten beschreven. Het onderzoek is uitgevoerd bij 313 patiënten met pijnklachten die waren opgenomen ten gevolge van kanker of de kankertherapie, met een pijnduur van tenminste één maand en een levensverwachting van tenminste drie maanden. Om de kwaliteit van de pijnbestrijding te beoordelen worden in de literatuur diverse maten gebruikt, zoals tevredenheid met de pijnbestrijding, pijnintensiteit en pijn management indexen. Wanneer tevredenheid van de patiënt met de pijnbestrijding als maat wordt gehanteerd om de kwaliteit van de pijnbestrijding te beschrijven, blijkt $31 \%$ van de patiënten geen adequate pijnbehandeling te krijgen. Uitgaande van de Pijn Management Index van Cleeland, een maat waarbij de voorgeschreven pijnmedicatie zoals ingedeeld volgens de analgetische 
ladder van de World Health Organization (WHO) wordt gerelateerd aan de ernst van de pijn, krijgt $51 \%$ van de patiënten geen adequate pijnbestrijding. Omdat de bestaande meetinstrumenten beperkt zijn in de mate van validiteit en betrouwbaarheid, is in dit onderzoek een nieuw meetinstrument ontwikkeld. De Amsterdam Pijn Management Index is een maat waarbij de huidige pijnintensiteit, gemiddelde pijnintensiteit in de afgelopen week en de ergste pijnintensiteit worden gerelateerd aan de hoeveelheid pijn die de patiënt draaglijk vindt. Deze samengestelde pijnintensiteitsscore wordt vervolgens gerelateerd aan de totale hoeveelheid pijnmedicatie zoals uitgedrukt in equianalgetische dosis morfine. De Amsterdam Pain Management Index laat zien dat $60 \%$ van de kankerpatiënten met pijn in het ziekenhuis niet adequaat wordt behandeld.

Omdat veel factoren de pijnbeleving kunnen beïnvloeden heeft een inventarisatie plaatsgevonden naar de belangrijkste knelpunten. Om de verschillende factoren te ordenen is gebruik gemaakt van het model van Donabedian. In het model van Donabedian, zoals toegepast op de pijnbestrijding, worden structuuraspecten (de voorwaarden waaronder de pijnbestrijding plaatsvindt), procesaspecten (het medisch en verpleegkundig handelen) en resultaataspecten (het resultaat van de pijnbestrijding) onderscheiden. Uit dit onderzoek blijkt dat structuuraspecten, zoals de beschikbaarheid van pijnprotocollen en richtlijnen, de aanwezigheid van pijnmedicatie, meetinstrumenten om pijn te registreren en voorlichtingsmateriaal voor patiënten, voldoende aanwezig zijn in het ziekenhuis. Hoewel hulpverleners nauwelijks bijscholingscursussen volgen op het gebied van pijn en pijnbestrijding, zijn structuurvariabelen niet de belangrijkste oorzaak van het suboptimale niveau van de pijnbestrijding. De belangrijkste tekortkoming in de pijnbestrijding lijkt te worden veroorzaakt door procesaspecten. Slechts $36 \%$ van de patiënten krijgt morfine-achtige pijnstillers. Van de patiënten krijgt $23 \%$ alleen analgetica met een "zo-nodig" voorschrift. Hoewel $66 \%$ van de patiënten aangeeft (zeer) goed geïnformeerd te zijn over pijn en pijnbestrijding, heeft slechts $16 \%$ schriftelijke pijninformatie ontvangen. In $32 \%$ van de patiënten is een pijnarts geconsulteerd. De kennis van patiënten over pijn en pijnbestrijding blijkt verre van optimaal: 54 op een schaal van $0-100$. Na ontslag uit het ziekenhuis blijkt de continuïteit van zorg onvoldoende te zijn: slechts ruim één derde van de wijkverpleegkundigen heeft informatie ontvangen over de pijnklachten van de patiënt van verpleegkundigen uit het ziekenhuis. Het contact tussen de patiënt en de huisarts is niet intensief, daar het laatste contact met de huisarts gemiddeld 6 weken geleden heeft plaatsgevonden.

Geconcludeerd kan worden dat de kwaliteit van de pijnbestrijding niet optimaal is, waardoor een aanzienlijke groep kankerpatiënten slechts gedeeltelijk pijnverlichting ondervindt. Het probleem lijkt vooral te worden veroorzaakt door procesaspecten.

In hoofdstuk 3 wordt de ontwikkeling, implementatie en evaluatie van het Pijn Instructie Programma beschreven. Verondersteld werd dat patiënten met het Pijn Instructie Programma (interventiegroep) een verbeterd pijnkennisniveau hebben, resulterend in een meer adequate toepassing van pijnbestrijdingsmethoden en een lagere pijnintensiteit vergeleken met patiënten die alleen de reguliere pijnbestrijding krijgen (controlegroep). Het Pijn Instructie Programma is een programma "op maat". Een patiënt krijgt alleen informatie en instructie over pijn en pijnbestrijding die relevant is voor hem of haar en indien er sprake is van een 
kennistekort. De pijnklachten zijn door middel van de McGill Pijn Vragenlijst gemeten. De patiënt is gevraagd zijn of haar pijnintensiteit weer te geven aan de hand van een numerieke schaal van 0 - 10, waarbij " 0 " geen pijn is en " 10 " de ergst denkbare pijn. Pijnkennis is met behulp van de Nederlandstalige versie van de Pijn Kennis Vragenlijst gemeten.

Van de 383 patiënten die voldeden aan de inclusiecriteria weigerden $18 \%$ deel te nemen aan het onderzoek. De metingen na 2, 4 en 8 weken na ontslag uit het ziekenhuis werden verricht bij respectievelijk $89 \%, 83 \%$ en $75 \%$. Het merendeel van de uitval wordt veroorzaakt door overlijden (60\%). Van de patiënten is $63 \%$ vrouw, de gemiddelde leeftijd is 56 jaar ( $s d=12$ jaar). Een meerderheid van de patiënten heeft metastasen op afstand (58\%). De meest voorkomende primaire tumor is mammacarcinoom (30\%). Van de patiënten krijgt 36\% radiotherapie, $22 \%$ krijgt geen enkele kankerbehandeling, $16 \%$ krijgt chemotherapie, $13 \%$ een chirurgische ingreep en $13 \%$ wordt op een andere wijze behandeld. Gemiddeld hebben de patiënten op twee locaties pijn. Pijnklachten in de buik en rug worden het meest frequent gerapporteerd. De gemiddelde pijnduur is 14 maanden ( $s d=$ 33 ; range 1 - 324 maanden). Van de patiënten is aan $88 \%$ pijnstillers voorgeschreven en $56 \%$ aanvullende medicatie (co-analgetica).

Uit de resultaten van de voormeting blijkt dat bijna de helft van de patiënten onterecht bang is om verslaafd te raken aan morfine-achtige pijnstillers, ongeveer $40 \%$ is niet op de hoogte van het belang van het slikken van pijnstillers op vaste tijden en ruim drie vierde van de patiënten denkt dat ze zo weinig mogelijk dienen te slikken zodat pijnmedicatie voorhanden blijft wanneer de pijn erger wordt. Hieruit blijkt de noodzaak voor het geven van aanvullende informatie en instructie.

Een Pijn Instructie Programma is alleen effectief wanneer patiënten ook daadwerkelijk gebruik maken van de verschillende onderdelen van de interventie. Van de patiënten uit de interventiegroep heeft $75 \%$ de pijnbrochure volledig gelezen, $56 \%$ heeft naar het cassettebandje geluisterd en $86 \%$ heeft het pijndagboek gedurende twee maanden ingevuld. Hieruit blijkt dat patiënten uit de interventiegroep goed gebruik maakten van het Pijn Instructie Programma.

$\mathrm{Na}$ implementatie van het Pijn Instructie Programma is de pijnkennis van patiënten in de interventiegroepen significant verbeterd in vergelijking tot de controlegroepen. Vóór invoering van het Pijn Instructie Programma was de "huidige pijnintensiteit" gemiddeld $3.3(\mathrm{sd}=2.3$ ) en de "gemiddelde pijn in de afgelopen week" $4.9(s d=2.1)$. Na invoering van het Pijn Instructie Programma rapporteren patiënten uit de interventiegroepen significant minder "pijn op dit moment" en minder "gemiddelde pijn in de afgelopen week". De interventiegroep zonder wijkverpleging rapporteert een significant lagere "pijnintensiteit op dit moment" en "gemiddelde pijn in de afgelopen week" vergeleken met de controlegroep zonder wijkverpleging, terwijl geen significante verschillen zijn gevonden tussen de controle- en interventiegroep met wijkverpleging.

Geconcludeerd kan worden dat informatie en instructie bij kankerpatiënten met langdurige pijnklachten goed kan worden toegepast. Patiënten maken gebruik van het Pijn Instructie Programma en stellen dit op prijs. Na ontslag uit het ziekenhuis hebben patiënten uit de interventiegroep meer kennis over hun pijnklachten en ervaren zij minder pijn, met name patiënten die in de thuissituatie geen wijkverpleging nodig hebben. 
In hoofdstuk 4 wordt ingegaan op het gebruik en het effect van het pijndagboek. In totaal werden 159 patiënten geïnstrueerd om iedere morgen en avond een cijfer tussen 0 en 10 aan de pijn te geven en dit gedurende een periode van twee maanden te noteren in een pijndagboek. Het doel van dit onderzoek was het evalueren van: (1) het verband tussen pijncijfers uit het pijndagboek en pijncijfers verkregen door middel van een telefonisch interview; (2) de mate waarin patiënten de pijnintensiteit van de afgelopen week kunnen herinneren; (3) de mate waarin pijnintensiteit fluctueert over tijd; en (4) het effect van het gebruik van pijndagboek. Gemiddeld was $86 \%$ van de pijndagboeken ingevuld. Dit hoge percentage is opvallend aangezien veel patiënten (pre-)terminaal waren. Hieruit blijkt dat zelfs erg zieke patiënten in staat zijn en bereid zijn het pijndagboek in te vullen. Het vergelijken van de pijnintensiteitscijfers uit het pijndagboek met pijncijfers zoals verzameld tijdens het telefonisch interview laat zien dat het registreren van "pijnintensiteit op dit moment" de voorkeur verdient boven "gemiddelde pijnintensiteit in de afgelopen week." De nauwkeurigheid van het herinneren van pijn wordt niet beïnvloed door de ervaren "pijn op dit moment", maar wel door de stabiliteit van de pijnintensiteit. Patiënten rapporteerden 's avonds significant meer pijn dan 's morgens. Omdat pijnintensiteit bij veel patiënten zowel gedurende de dag als over een bepaalde tijdsperiode fluctueert, is het bijhouden van het verloop van de pijnintensiteit zinvol. Van alle patiënten geeft $60 \%$ aan door het pijndagboek meer inzicht in de pijn te hebben gekregen.

Geconcludeerd kan worden dat het pijndagboek een goed hulpmiddel is om inzicht te krijgen in het verloop van de pijnklachten, zowel voor de arts, wijkverpleegkundige als de patiënt zelf. Het dagelijks invullen van het pijndagboek wordt niet als een grote belasting ervaren.

In Hoofdstuk 5 worden uitkomstmaten die de adequaatheid van de pijnbestrijding beschrijven en regelmatig in de literatuur worden gebruikt met elkaar vergeleken. Adequaatheid van de pijnbestrijding is onderzocht door middel van drie Pijnintensiteitsschalen, een Pijnverlichtingsschaal, een Tevredenheidsschaal en drie Pijn Management Indexen. Wanneer deze maten met elkaar worden vergeleken, blijkt het percentage inadequate pijnbestrijding sterk uiteen te lopen. Afhankelijk van de gebruikte uitkomstmaat varieert het percentage inadequate pijnbestrijding van $16-91 \%$. Op grond van deze resultaten kan worden geconcludeerd dat de keuze van het meetinstrument meer bepalend is voor de kwaliteit van de pijnbestrijding dan de pijnbestrijding zelf. Onderzoek naar het effect van de pijnbestrijding laat zien dat de resultaten met voorzichtigheid geïnterpreteerd dienen te worden.

In hoofdstuk 6 worden de psychometrische eigenschappen van de nieuw ontwikkelde maat om kwaliteit van de pijnbestrijding te meten, namelijk de Amsterdam Pijn Management Index, beoordeeld en vergeleken met acht andere uitkomstmaten. De Amsterdam Pijn Management Index is ontwikkeld om beperkingen van de bestaande meetinstrumenten te reduceren.

Uit dit onderzoek blijkt dat de mate van overeenstemming tussen de uitkomstmaten, met uitzondering van de Pijn Management Indexen van Cleeland, Zelman en Ward die afkomstig zijn van dezelfde groep onderzoekers en waarbij inhoudelijk een grote mate van overlap bestaat, zeer laag tot matig is. Op grond van onderzoek bij subgroepen die verondersteld worden van elkaar te verschillen of juist 
verondersteld worden gelijkwaardig te zijn, is de Amsterdam Pijn Management Index de meest valide maat om de kwaliteit van de pijnbestrijding te meten. De drie Pijnintensiteitsschalen en de Pijnverlichtingsschaal zijn beperkt in het kunnen onderscheiden van subgroepen, terwijl geen verschil tussen groepen patiënten kon worden aangetoond met de Tevredenheidsschaal. Ondanks het onderscheidend vermogen van Cleeland's, Ward's en Zelman's Pijn Management Index, zijn de gevonden verschillen niet in de verwachte richting. Veranderingen over tijd konden met alle uitkomstmaten worden vastgesteld. De effecten van de interventie konden alleen worden gemeten met de Amsterdam Pijn Management Index en de Pijnintensiteitsschaal gebaseerd op ergste pijnintensiteit.

In hoofdstuk 7 worden de effecten van het Pijn Instructie Programma voor de kwaliteit van de pijnbestrijding beschreven. Lange termijn effecten zijn beschreven door middel van Random Regressie Modellering. Deze statistische analysetechniek houdt rekening met incomplete data ten gevolge van vroegtijdige uitval.

Voor ontslag wordt $60 \%$ van de patiënten inadequaat behandeld. Door de interventie is het aantal patiënten dat inadequaat wordt behandeld in de interventiegroep significant kleiner dan in de controlegroep na twee weken ( $56 \%$ versus $41 \%$ ) en vier weken, ( $62 \%$ versus $42 \%)$, terwijl geen verschillen zijn gevonden na 8 weken (56\% versus $51 \%$ ). Het meewegen in de analyse van patiënten die tijdens het onderzoek zijn uitgevallen vermindert het verschil tussen de controle- en interventiegroepen. Terwijl het percentage inadequate pijnbestrijding in de groep patiënten zonder interventie stabiel blijft gedurende een periode van twee maanden, stijgt het aantal inadequaat behandelde patiënten in de interventiegroep.

Nagegaan is welke variabelen een belangrijke rol spelen bij het voorspellen van een stijging op de Amsterdam Pijn Management Index. Onderzoek wijst uit dat diverse factoren bepalend zijn voor een verbeterde pijnbestrijding. Naast de interventie en de kwaliteit van de pijnbestrijding voor ontslag, zijn opleiding, gezinsomstandigheid, tumorstatus, kankerdiagnose, fysiek functioneren, sociaal functioneren, medicatietrouw, pijnkennis en de hoeveelheid voorgeschreven analgetica bepalend voor de kwaliteit van de pijnbestrijding.

In hoofdstuk 8 wordt de mate van medicatietrouw onderzocht. Het doel is inzicht te krijgen in de mate van medicatietrouw bij kankerpatiënten met pijn en het effect van het Pijn Instructie Programma te evalueren. Drie fasen kunnen worden onderscheiden bij het beschrijven van het proces van medicatietrouw: (1) het medicatievoorschrift van de arts; (2) de mate waarin de patiënt op de hoogte is van het pijnmedicatievoorschrift; en (3) de mate waarin de patiënt de dosis, frequentie en het tijdstip waarop de medicatie gebruikt dient te worden volgens het voorschrift opvolgt. Data zijn verzameld door middel van zelfrapportage. Uit het onderzoek blijkt dat één op de vier patiënten in het ziekenhuis niet op de hoogte is van de pijnmedicatie die hem of haar is voorgeschreven. Van de patiënten met pijnmedicatie herinnerde minder dan $50 \%$ de voorgeschreven pijnmedicatie op juiste wijze. Na ontslag uit het ziekenhuis zei $49 \%$ van de patiënten zich niet te houden aan de pijnmedicatievoorschriften en slechts $51 \%$ zegt de pijnmedicatie volgens een vast schema te gebruiken.

$\mathrm{Na}$ invoering van het Pijn Instructie Programma zijn patiënten beter op de hoogte van de pijnmedicatievoorschriften. Patiënten uit de interventiegroepen zijn meer niet-opioïden voorgeschreven dan patiënten uit de controlegroepen. 
generaliseerbaar zijn naar andere kankerpatiënten met pijn. Echter, de resultaten zijn op onderdelen vergelijkbaar met andere gerapporteerde onderzoeksresultaten.

Het Pijn Instructie Programma bestaat uit meerdere aspecten. Wat het effect van de afzonderlijke aspecten op de pijnintensiteit is, is niet duidelijk. Bij toekomstig onderzoek zou het effect van de verschillende aspecten van de interventie afzonderlijk onderzocht kunnen worden, zoals het effect van aanvullende.informatie en instructie, het pijndagboek en de pijnbrochure.

In dit onderzoek is het Pijn Instructie Programma uitgevoerd door speciaal daartoe aangestelde en getrainde verpleegkundigen. In de verpleegkundige praktijk is het echter wenselijk dat het Pijn Instructie Programma door afdelingsverpleegkundigen wordt uitgevoerd. Het tot stand brengen van veranderingen in de verpleegkundige praktijk is veelal complex. Teneinde het Pijn Instructie Programma te implementeren in de verpleegkundige praktijk is het nodig om verpleegkundigen bij te scholen. Door middel van onderzoek kan vervolgens worden nagegaan of het effect van het Pijn Instructie Programma zoals uitgevoerd door speciaal getrainde verpleegkundigen vergelijkbaar is met afdelingsverpleegkundigen die het Pijn Instructie Programma integreren in het totale zorgaanbod.

Gezien de positieve resultaten van het Pijn Instructie Programma is reeds gestart met het implementeren van een aangepaste versie van het Pijn Instructie Programma in de verpleegkundige praktijk. Door invoering van het Pijn Instructie Programma vindt deskundigheidsbevordering van (wijk)verpleegkundigen plaats, waardoor de continuiteit in de pijnvoorlichting wordt bevorderd en integratie van pijnvoorlichting in het totale zorgaanbod plaatsvindt. 


\section{Dankwoord}

Jaren geleden dacht ik, in al mijn naïviteit, dat het schrijven van twee onderzoeksvoorstellen voldoende garantie zou bieden voor één onderzoeksbaan. Ik kon toen niet vermoeden dat dit uiteindelijk zou leiden tot twee grote pijnonderzoeken: het Pijn Instructie Programma (PIP) en het Pijn Registratie Project.

De patiënten en (wijk)verpleegkundigen die aan het PIP-onderzoek hebben meegewerkt ben ik zeer erkentelijk. Het betrof vaak zieke patiënten voor wie dit onderzoek soms een zware belasting was. Per patiënt werden meer dan duizend gegevens verzameld door een team van verpleegkundigen, onderzoeksassistenten en studenten. Zonder hun enorme inzet, deskundigheid en gezelligheid zou dit proefschrift nooit tot stand zijn gekomen.

Mijn bijzondere dank gaat uit naar mijn promotoren. Frits van Dam, in de loop van de jaren hebben we een "bijzondere" vorm van samenwerken ontwikkeld. Het brainstormen over onderzoeksideeën, het discussieren over de resultaten en het bedenken hoe de klinische en verpleegkundige praktijk hiermee gebaat kan zijn heb ik het meest gewaardeerd. Huda Huijer Abu-Saad, ondanks de afstand, heb je de verpleegkundige aspecten van dit onderzoek op een stimulerende wijze ter discussie gebracht.

Anneke van Buuren, Karin van der Heijden en Gerleen Leenhouts wil ik bedanken voor de enorme inzet bij de deskundigheidsbevordering van patiënten. De inbreng van Linda Zandbelt bij het schrijven van de pijnbrochure en de dataverzameling was groot. Simone Loonstra wil ik bedanken voor de bijdrage bij het moeilijk te meten begrip "kwaliteit van de pijnbestrijding", Marie-José Litjens voor het valideren van de Pijn Cognitie Lijst en Marianne Hanneman voor het evalueren van de pijndagboeken. Met Marlies de Rond, als projectleider op het Pijn Registratie Project, werden de pijnonderzoeken een onderzoekslijn en kon naar hartenlust gediscussieerd worden over de rol van verpleegkundigen bij pijnbestrijding.

Ans Vielvoye-Kerkmeer en Carlien Mattern, als pijnartsen hebben jullie veel nuttige adviezen gegeven.

De verpleegkundigen, artsen en secretaresses van het Antoni van Leeuwenhoek huis ben ik erkentelijk voor hun bereidwillige medewerking.

Martin Muller en Hugo Duivenvoorden hebben mij bijgestaan met statistische adviezen wanneer ik via SPSS en BMDP toch weer SAS bleek nodig te hebben om de longitudinale data te bedwingen. Larraine Visser en Marja van de Hoorn bedank ik voor de Engelstalige correcties, Hub. van Kan voor de inzet om er een mooi boekje van te maken en Marian Broertjes voor administratieve ondersteuning.

Op de afdeling Psychosociaal Onderzoek en Epidemiologie van het Antoni van Leeuwenhoek huis heb ik een leuke en leerzame tijd gehad. In Rotterdam ben er ik er achter gekomen dat het ook als niet-psycholoog mogelijk is om prettig te werken op de afdeling Medische Psychologie en Psychotherapie. De woelige tijd bij het Pijnbehandel- en Pijnkenniscentrum is boeiend, maar niet altijd makkelijk. Gelukkig hebben collegialiteit en gezelligheid het werken altijd erg veraangenaamd.

Dit proefschrift en ik hebben helaas ook een "dip" doorgemaakt. Mijn bijzondere dank gaat naar mijn ouders, familie en vrienden die er voor hebben gezorgd 
dat ik uiteindelijk de draad weer heb opgepakt. Ardine de Wit, jij bent daarbij heel belangrijk geweest. Met regelmaat trokken we ons een weekje terug om aan onze proefschriften te werken in een rustige omgeving: de caravan in Grathem, het huis(je) in Rugny of onze eigen huizen. De gouden formule bestond uit vroeg opstaan, hard werken, hardlopen, haperende computers en. wijn. We moeten hier beslist mee doorgaan. Ook paranimf Marieke Schuurmans wil ik bedanken voor de ondersteuning. Onze discussies over "de toestand in de wereld van de verplegingswetenschap" zijn ongeëvenaard.

Niet iedereen die een bijdrage aan dit onderzoek heeft geleverd wordt met naam genoemd, maar ieders bijdrage heb ik zeer op prijs gesteld.

Ook na mijn promotie zal het doen van onderzoek een belangrijk deel van mijn werk blijven uitmaken, want in de loop van de jaren ben ik er achter gekomen dat hoe meer je onderzoekt, hoe meer doordrongen je raakt van wat onbegrepen is. Maar na een periode van drie jaar op drie locaties werken wordt het tijd om van mijn reputatie als vlo, die overal en nergens is, af te komen. 


\section{Curriculum Vitae}

Adriana de Wit (Rianne) was born on June 23, 1964 in Geldrop. In 1983, after graduating high school (VWO) at the Philips van Horne Scholengemeenschap in Weert, she began studying Health Science at the Universiteit Maastricht. She graduated in 1987 with a master's degree in Nursing Science. Then, she continued her study with Health Policy and Administration courses. From 1988 to 1990, she participated in the development of a new hospital, and continued her work as an assistant manager at the St. Antonius Hospital in Sneek. From 1990 to 1992 she had a fellowship in Psychosocial Oncology, granted by the Dutch Cancer Society. Since 1992, she was employed as a scientific researcher at the department of Psychosocial Oncology and Epidemiology at the Antoni van Leeuwenhoek hospital/Netherlands Cancer Institute in Amsterdam. The study "The (district) nurse and the cancer patient in pain: a nursing intervention study," which forms the basis of this thesis, was mainly performed during that period. She also participated in the "Pain Registration Project," funded by the Dutch Ministry of Public Health, Welfare, and Sports, and the National Centre for Nursing and Care. Since 1996, she worked as health scientist and methodologist at the Pain Expertise Centre of the University Hospital Rotterdam, and the department of Medical Psychology and Psychiatry of the Erasmus University Rotterdam. She is currently employed as acting head at the Pain Expertise Centre of the University Hospital Rotterdam. 

